

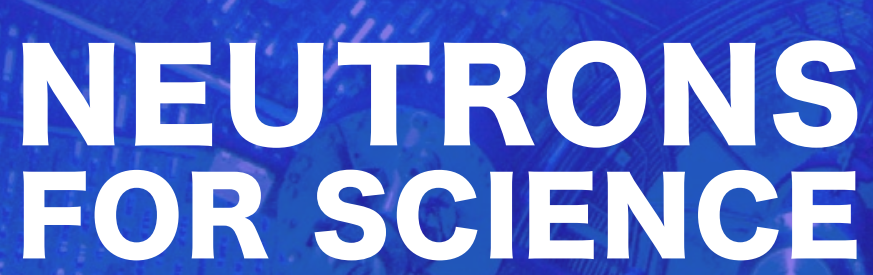

THE HISTORY OF THE INSTITUT LAUE-LANGEVIN. AN EXCEPTIONALLY SUCCESSFUL INTERNATIONAL COLLABORATION

\section{Bernard JACROT Translated by Ron Ghosh}

TN 1967, France and Germany agreed to cooperate on the construction and commissioning of a nuclear reactor dedicated to research in physics, chemistry and biology.

Thus was born the Institut Laue-Langevin, a project whose aim was to provide research scientists with an extremely intense source of neutron beams, a fundamental tool for probing the mysteries of matter.

Britain soon joined the project, followed gradually by other countries both from western and eastern Europe, making the Institut Laue-Langevin a particularly successful example of European cooperation. This success is a clear illustration of how, by joining forces and skills in this way, it was possible to provide scientists from "the old continent" with the means to tackle ambitious projects by giving them the best neutron source in the world.

Neutrons for Science tells the story of the beginnings of this project and shows how, with the right organisation, it was possible to optimise the use of the reactor. The book also paints the portraits of three eminent figures, Jules Horowitz, Heinz MaierLeibnitz and Louis Néel, who played a key role in this success.

In this English edition, a chapter has been added covering the period 2004-2018 in order to create a link with the modern era and highlight the dynamism that has marked the Institute since it was founded.

Bernard JACROT, a former student of the École Polytechnique (Paris), was the first French Associate Director of the Institut Laue-Langevin (1967-1973).

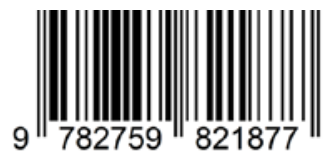

ISBN : 978-2-7598-2187-7

www.edpsciences.org

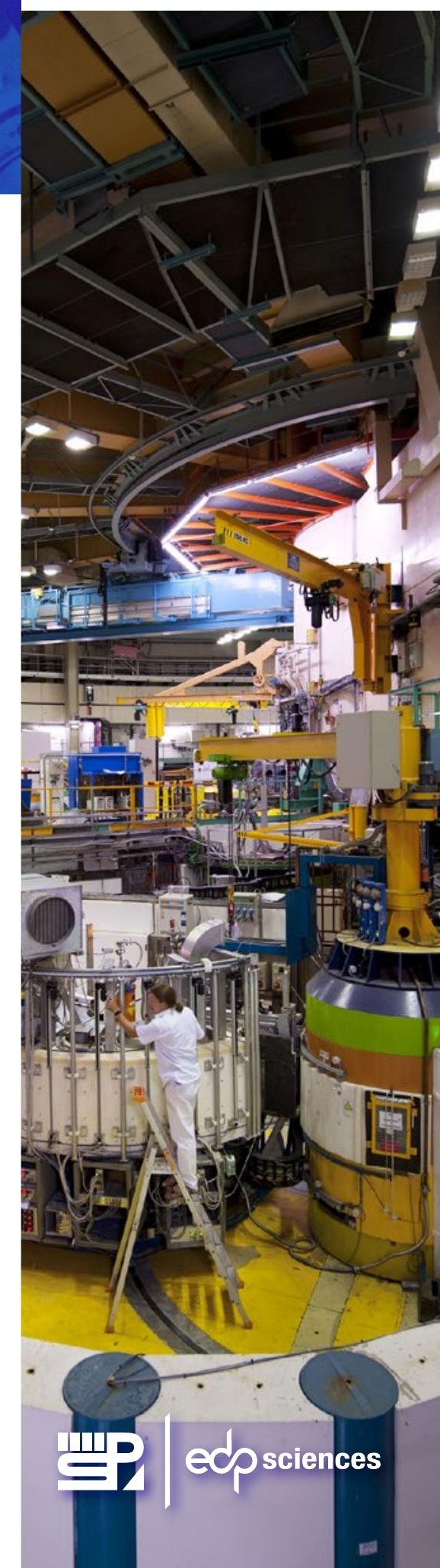




\title{
Neutrons for Science
}

\author{
The history of the \\ Institut Laue-Langevin, \\ an exceptionally successful \\ international collaboration
}

\author{
Bernard Jacrot \\ Translated by Ron Ghosh
}

edpsciences

17, avenue du Hoggar

Parc d'Activité de Courtabœuf, BP 112

91944 Les Ulis Cedex A, France 


\section{«Sciences E Histoire»}

The "Sciences \& History" series is intended for a curious science audience. As a narrative or biography, each volume provides an overview of the progress of a scientific field over a given time period. Sciences are set in a perspective, based on the history of theoretical and technical advances and the history of the people who initiated them.

Cover illustration: The swimming pool of the High Flux Reactor. The blue light is emitted by the uranium of the core (Cherenkov effect). (0) 1995 Institut Laue-Langevin, Jean-Luc Baudet.

Back cover: Inside the reactor hall with the neutron powder diffractometer D20 in the foreground. (02014 Institut Laue-Langevin and Marc Alexander.

Printed in France

ISBN (print): 978-2-7598-2187-7 - ISBN (ebook): 978-2-7598-2255-3

This work is subject to copyright. All rights are reserved, whether the whole or part of the material is concerned, specifically the rights of translation, reprinting, re-use of illustrations, recitation, broad-casting, reproduction on microfilms or in other ways, and storage in data bank. Duplication of this publication or parts thereof is only permitted under the provisions of the French Copyright law of March 11, 1957. Violations fall under the prosecution act of the French Copyright law. 
To all the young scientists, engineers and technicians

from Germany, the UK and France whose enthusiasm helped make the ILL a reality.

Translators Note:

Having known Bernard since 1974, I was disappointed that no English translation was available to the wider community. I was easily convinced by Alain Filhol to take on this task myself in 2013. I have included in my Note a few of my comments with an English view on the international nature of the ILL he created.

Translated from the original French (2006 - ISBN: 2-86833-878-2) by Ron Ghosh.

Some corrections and limited updates have been performed.

Edited by Alain Filhol assisted by Sylvie Crozel. 



\section{Table of contents}

Bernard Jacrot $\mathrm{V}$

Introduction. Why write a history of the ILL? vii

1. Pre-history 1

1.1. The situation in Europe 4

1.2. A new idea 11

2. Portraits of three founders of the ILL 17

2.1. Jules Horowitz (1921-1995) 17

2.2. Heinz Maier-Leibnitz (1911-2000) 21

2.3. Louis Néel (1904-2000) 28

3. Why invest so much money in a source of neutrons? 33

3.1. The interaction of neutrons with matter 34

3.2. Neutrons and condensed matter 36

3.3. Nuclear and fundamental physics 43

3.4. Neutrons are indeed indispensable! 44

4. The negotiations 45

4.1. The neutron source 46

4.2. The future users 51

4.3. The contract 52

5. The construction of the reactor and the scientific groups $\quad 59$

5.1. The first instruments 64

5.2. The construction of the reactor 72

5.3. The link between the ILL management and

Portfolio of some typical ILL instruments in $2018 \quad 96$

6. The start of research activities and the arrival of the British 103

6.1. The start of research activities 103

6.2. Further developments in neutron optics 107

6.3. The arrival of the British 108

7. Maturity 113

7.1. The EMBL 115

7.2. The ESRF 116

7.3. The problem of schools 119 
7.4. The evolution of the ILL and its problems

120

7.5. Modernisation of equipment

8. The dark years

8.1. The reconstruction of the reactor

8.2. The partial withdrawal of the British and the consequences

8.3. Supply of enriched uranium

9. Consolidation and the future

9.1. The millennium

9.2. The reorganisation of the ILL

9.3. Some figures

10. Conclusion: an appraisal

10.1. The Franco-German Cooperation

10.2. The scientific record

10.3. The future for the ILL

11. The ILL between 2005 and 2018

11.1. Introduction

11.2. Ambitious improvement plans

11.3. Complying with more demanding safety regulations

11.4. Funding the present and the future

11.5. Conclusions and future

Chronology of ILL events

Key people involved in the history of the ILL

Appendixes. Some historical documents

A1 - Franco-German intergovernmental agreement

A2 - Activity report by Maier-Leibnitz 1968

A3 - Visit of SRC 6-7 March 1970 - Conclusions (Jolliffe)

A4 - Letter from Flowers to Creyssel in January 1972

A5 - Fender: recommendation to build the synchrotron on the ILL site

A6 - Intervention of Dr. Newport at the Steering Committee of 28 November 1991

A7 - Ipoustéguy's interpretation of the work he made for the ILL

Acknowledgements. Past and present

Postscript. Translator's note 


\section{Bernard Jacrot}

Bernard Jacrot, who was the first French director of the Institut Laue-Langevin (ILL), also played an important role in the beginnings of neutron scattering in condensed matter physics in the nineteen fifties and of structural biology in the seventies and eighties. Bernard was always reluctant to speak about himself.

When I met him he had already switched to biology but I learnt a lot about his early career from his colleagues, who brought forward not only his scientific and technical achievements but also his profound humanism.

Jacrot entered the École Polytechnique in 1947. After graduation, he joined the CEA in Saclay, where a small reactor had just been built. He was among the few who initiated the application of inelastic neutron scattering to the then revolutionary science of condensed matter physics and is considered among the founding fathers of French neutron scattering. Jacrot was part of the group that first proposed the ILL at the Geneva conference in 1964.

German physicists and in particular Maier-Leibnitz, who became the first director of ILL, saw in the project a concrete political act, encouraged by Adenauer and de Gaulle. French and German neutron scatterers were fascinated by the achievements promised by the joint technical and scientific adventure.

Maier-Leibnitz and Jacrot recruited the young German and French scientists and engineers who designed and built a new generation of instruments and set up the policy that opened up the ILL to other than neutron specialists. After his term as associate director, Jacrot left Grenoble in 1973 to spend a year in Cambridge to 'learn' biology convinced that there were great discoveries to be made by applying the full breadth of physical methods to biological structure analysis.

He returned to ILL as senior scientist for biology determined to introduce the interdisciplinary physics/biology approach that also paved the way for neutron scattering in soft condensed matter. It was not an easy task but Jacrot patiently imposed structural biology on the site, first as ILL senior scientist then as director of the European Molecular Biology Laboratory outstation. He established a group in structural virology and published extensively in the field. He wrote a review of small angle scattering in biology that because of its clarity is still consulted today and visited labs to introduce neutrons to biologists in a language they could understand. He was appointed to the management team of the Life Sciences at CNRS where he contributed significantly to the development of structural biology in France. He wrote books about the relations between physics and biology and on the history of ILL. In 1980, he was awarded the Felix Robin prize of the French Physical Society for his lifetime achievement in physics.

Bernard Jacrot died peacefully in his ninetieth year on the $21^{\text {st }}$ of January 2016. 


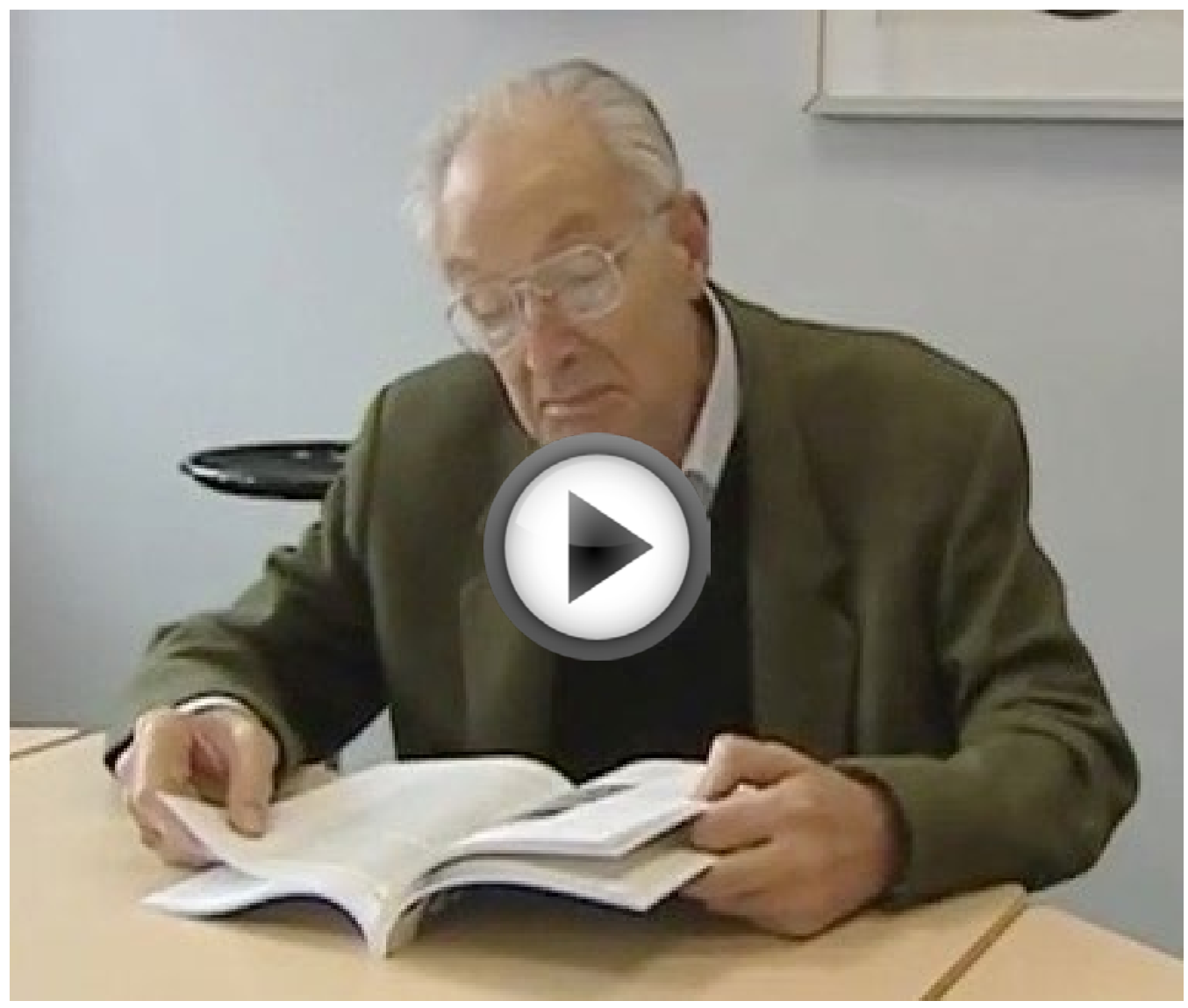

TV channel France 3 - September 2006 (in French) 


\section{Introduction Why write a history of the ILL?}

The Institut Laue-Langevin, or more formally the Institut Max von Laue - Paul Langevin (ILL), is one of the first examples of fully successful scientific collaboration between European countries. It was preceded only by CERN, the European Centre for Nuclear Research, and by EURATOM whose origins lie in the first years after World War II. The history of CERN, created in 1953, has been described in a massive work of 3 volumes ${ }^{1}$. EURATOM was established as part of the Treaty of Rome, in 1957. To my knowledge its history has not been published ${ }^{2}$. Perhaps this is a consequence of the somewhat mixed success of this organisation. In contrast to the creation of CERN, where the USA scientists played an important role, the ILL was a purely French and German initiative. Such a combined activity was far from evident between two countries which had battled, one against the other; furthermore the Institut was due to be placed in a region of France where the Resistance had its pinnacle position in the Vercors mountains. The name of the road to the ILL, the Avenue des Martyrs, bears witness to these events. How this all became possible is one of the themes which I will develop in this book. In current times where there is increased scepticism over the future of Europe, I feel it is of use to show how this collaboration has progressively become European-wide (there are now 10 countries involved and this number is increasing). The driving force has been the success achieved together being far better than any country could have obtained alone.

This book will attempt to show that the ILL has allowed Europe to surpass the USA in an important field of research thanks to a specific tool - a research reactor with a uniquely high continuous neutron flux which, even today, is unequalled in the world.

The prehistory of the ILL goes back more than 40 years [2018 addition: with this edition the period in question is now over 50 years]. Thus many contributors to this slow gestation which led to the construction of the Institut and its reactor are no longer alive. There remain those (notably the author) who, though all in retirement, can still harvest the evidence, though this needs to be done quickly to include in a complete history. However, this book is the work of a scientist who has no training as a historian, and who has learnt of the difficulties of this metier. The path of truth is as important in history as in physics, and calls for use of all available methods. One learns the need to recover the evidence, which is not always possible when the witnesses become sparse. The work was further complicated by the absence of archives at the ILL (and at the CENG, Centre d'Etudes Nucléaires de Grenoble). There isn't even a complete collection of ILL activity reports. Happily my own personal archives remained, some being rediscovered in

1 "History of CERN", by A. Hermann, J. Krige et al., 1987-96; North-Holland Physics Pub. and Elsevier.

22018 addition: In fact a history of EURATOM was published in 2002 "The origins and early history of Euratom, 1955-1968", Mervyn O'Driscoll, 2002, Ed. European Parliament, ISBN: 92-8231638-6. It was difficult to find when Bernard Jacrot wrote his book. 
a cupboard at the ILL. Hence, this history cannot be entirely objective. After the first version of this text was finished, a book was published by the Greek scholar and philosopher Jean-Pierre Vernant, La traversée des frontières [Paris, 2004]. He analysed the problems posed for those writing up recent events, and concluded that it is not possible to write a true history if we take into account the subjective nature of all the evidence, even if this is given with perfect honesty. I have tried to do my best.

I have had no responsibilities at the ILL for more than 30 years, and have been retired for more than 10 . Hence, I feel free to write the whole truth, even if, in a few rare cases, this is not politically correct. This is a test edition, because a time will come when true professionals will take up this work again, and will explore archives unknown to me. These will remain their only source; there will no longer be any remaining living witnesses to the creation of the ILL. I can add that it gave me great satisfaction to complete this book since it is always a pleasure to reflect on a successful enterprise to which one is proud to have contributed.

The creation of a scientific institution involves human interplay, with all that this entails, including conflicts between various members of the cast. Personality and charisma can play a fundamental role. For a scientific company, charisma necessarily involves an important component based on scientific credibility. I will try to highlight the human aspect in the history of the ILL. In particular I would like to try and paint a picture of three of the main actors in this story, three strong personalities, Jules Horowitz, Louis Néel and Heinz Maier-Leibnitz, alas all now deceased. This book should not look like a report of a scientific meeting which only gives the conclusions of the discussions, erasing all the discussions that led to arrive at these conclusions. Where they exist such minutes are essential since they provide the framework for adding the human elements from memories of surviving witnesses.

Since the ILL is a scientific establishment, this requires some explanation of the research studies which are undertaken. These studies impact a large number of scientific domains, from nuclear physics to biology; I will try and render the aim of this work, and the results, understandable to the non-specialist. 


\section{Chapter 1}

\section{Pre-history}

The neutron was discovered in 1932 by James Chadwick (Fig. 1.1 and Fig. 1.2). It is a neutral particle with a mass very close to that of the proton, both of which are constituents of atomic nuclei. The free neutron is produced in certain nuclear reactions. The first, which led to its discovery, was the collision between alpha particles and the nuclei of beryllium:

$$
{ }^{4} \mathrm{He}+{ }^{9} \mathrm{Be} \rightarrow{ }^{12} \mathrm{C}+\mathrm{n}
$$

During the early years, it was this reaction which was used in the construction of neutron sources. Such a source led to the discovery in 1939 by Hahn and Strassman that the nucleus of uranium ${ }^{3}$ would undergo fission, induced by capturing a neutron. It was shortly noted that this fission process, in addition to producing energy, was accompanied by the emission of neutrons (generally two or three); theoretically this could lead to a chain reaction. The origin of the energy evolved was the loss of mass occurring during the fission reaction. This mass $\mathrm{m}$ is transformed into energy E following Einstein's equation:

$$
\mathrm{E}=\mathrm{mc}^{2}
$$

where $c$ is the speed of light.

Such a reaction could lead to a new source of energy. The first practical realisation of the controlled chain reaction was achieved at the end of 1942 by Enrico Fermi in Chicago, USA. At that time the US was at war, and was working on the development of the atomic bomb, a more brutal way to implement this same chain reaction. All this work, including Fermi's was hidden with the greatest secrecy under the codename "Manhattan Project".

3 More precisely, the nucleus of ${ }^{235} \mathrm{U}(0.7 \%$ of natural uranium) is the only nuclide existing in any appreciable amount in nature that is fissile with thermal neutrons.

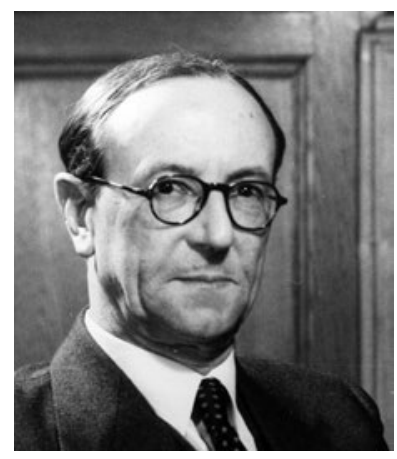

Fig. 1.1: James CHADWICK, Nobel prize winner for physics (1935)

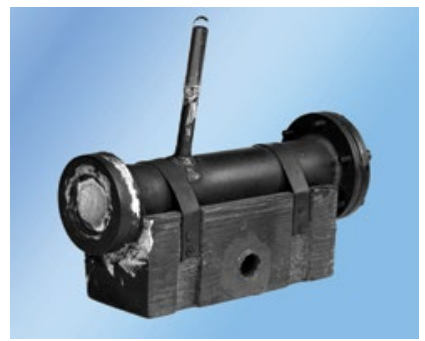

Fig. 1.2: The instrument of discovery used for the discovery of the neutron. In those days a very simple set-up could be enough to make a great discovery. The tube contained an alpha emitter, a beryllium target and an ionisation detector. 
The neutrons accompanying fission have energies of the order of 1 million electron volts $(\mathrm{MeV})$; it was quickly understood that when these particles hit nuclei of other atoms, notably those of small atomic mass, the neutron lost energy and slowed. After several collisions, the neutrons formed a sort of gas in thermal equilibrium with the medium in which they found themselves. These neutrons are known as thermal neutrons. The chain reaction is maintained by the fission being more favourably induced by these thermal neutrons. It follows that most nuclear reactors comprise a moderator of light material, with low neutron absorption (very pure graphite, light water, heavy water) arranged around and between bars of uranium. Fermi used graphite to construct the first reactor.

Neutrons have a wavelength as defined by the de Broglie equation relating to their velocity (hence energy):

$$
\lambda=\mathrm{h} / \mathrm{mv}
$$

Here $h$ is Planck's constant, $m$ is the mass of the neutron and $\mathrm{v}$ its velocity. Fast neutrons have shortest wavelengths of the order of the dimensions of the nucleus. By contrast, thermal neutrons have wavelengths of the order of Angstroms, i.e. comparable to inter-atomic distances. It is hence possible to observe diffraction effects with thermal neutrons in a similar way to X-rays. This was understood in 1936 and the theory was published by W.M. Elsasser". Later that year H. von Halban and P. Preiswerk showed the experimental proof ${ }^{5}$. This was immediately confirmed by D.P. Mitchell and P.N. Powers. These three articles are reproduced in George Bacon's book "Fifty Years of Neutron Diffraction" (1987) ${ }^{6}$. At the same time another discovery greatly increased interest in neutron diffraction. Felix Bloch, an American physicist, predicted ${ }^{7}$ that the neutron should possess a magnetic moment. This was rapidly confirmed experimentally by Hoffman et al. ${ }^{8}$ As a consequence, the neutron will interact with the magnetic

$4 \quad$ W.M. Elsasser, C.R. Acad. Sci., Paris (1936), 202, 1029.

5 H. von Halban and P. Preiswerk, J. Phys. Radium (1937), 8, 29-40, DOI 10.1051/jphysrad:019370080102900

6 "Fifty Years of Neutron Diffraction: The Advent of Neutron Scattering", G.E. Bacon, Adam Hilger, Bristol (1987), ISBN 0-85274-587-7, DOI 10.1002/crat.2170221020

7 Felix Bloch, Phys. Rev. (1936), 50, 259. DOI 10.1103/PhysRev.50.259

8 J.G. Hoffman, M. Stanley Livingston and H.A. Bethe, Phys. Rev. (1936), 51, 214-215, DOI 10.1103/PhysRev.51.214 
moment of atoms and can be used to study magnetic structures, a great advantage, where X-rays can contribute little ${ }^{9}$. In practice the flux of neutrons produced by the radium-beryllium source was much too feeble to perform these studies.

All changed in November 1943 with the start-up of the first experimental reactor at Oak Ridge in Tennessee, USA. Still called a "pile", the X-10 Graphite Reactor consisted of blocks of graphite into which were inserted bars of uranium, producing $3.5 \mathrm{MW}$ of heat, with a flux of neutrons in the centre of about $10^{12}$ neutrons $/ \mathrm{cm}^{2} / \mathrm{s}$. The primary role of this reactor was to produce plutonium required to build atomic weapons. During this wartime period, a spectrometer was installed adjacent to it specifically to use a neutron beam to measure the effective cross-sections of the neutron with various atomic nuclei which were to be used in the construction of the atomic bomb. After the war a two-axis diffractometer ${ }^{10}$ was built by Ernest Wollan which could record diffraction patterns.

In June 1946, Clifford Shull (Fig. 1.3) rejoined E. Wollan at Oak Ridge. In 1949 C.G. Shull and J.S. Smart demonstrated $^{11}$ that at the temperature of liquid nitrogen the magnetic moments on the manganese atoms in $\mathrm{MnO}$ are arranged in two sub-lattices with the moments oriented opposed. Such an arrangement had been predicted a few years earlier by Louis Néel. Cliff Shull was awarded the Nobel Prize for Physics for this work in 1994. This new type of magnetic order was baptised with the name "antiferromagnetic" by F. Bitter, and the temperature below which it appeared was called the Néel temperature by C.J. Gorter.

This all demonstrated the utility of neutrons for studying solid state physics, especially magnetic materials. There was an absolute need for higher neutron fluxes than those produced by the reactor at Oak Ridge. The first steps in finding a solution to this problem were made

92018 addition: This remained true until the 1980s. With the advent of synchrotron radiation sources producing extremely powerful X-ray beams, X-ray methods now contribute significantly to the study of magnetism.

10 A single-crystal was placed on the first axis and served to select a monochromatic beam of neutrons. These then impinge on the sample mounted on the second axis about which the detector rotates to measure the diffracted intensity.

11 C.G. Shull and J.S. Smart, Phys. Rev. (1949), 76, 1256-1257, DOI 10.1103/PhysRev.76.1256.2

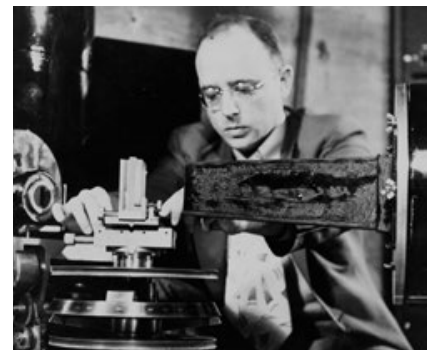

Fig. 1.3: Clifford SHULL working on two-axes diffractometer in the fifties. 
at Brookhaven under the leadership of Donald Hughes. This physicist was responsible for research at Brookhaven involving neutrons. In 1953, he published his book "Pile Neutron Research" which became a bible for young researchers who, like me, were entering the field. In 1954, he attracted the attention of the director of Brookhaven towards the need to give the Laboratory a reactor producing a higher flux than the graphite pile already available there. The steps that followed are very carefully described in Lawrence Passell contribution, "High Flux at Brookhaven", in George Bacon's book which was cited previously. The important feature of the reactor due to Jack Chernick was the concept of a core, under-moderated with heavy water ${ }^{12}$, surrounded by a heavy water reflector. This gives rise to a peak flux of thermal neutrons in this reflector, several centimetres outside the core itself. Looking at this zone, tangential beam tubes lead away the thermal neutrons. This minimises the background due to the fast and epithermal neutrons, and the gamma rays coming directly from the reactor core. This layout was of course re-used for the ILL's reactor. Herbert Kouts took responsibility for the detailed design of the Brookhaven reactor, which was completed in 1965 . This name will again figure in the ILL's reactor project.

\subsection{The situation in Europe}

Research using neutrons could only begin in Europe after the end of the war, gaining the USA several years' advantage. The UK, where numerous scientists had participated directly across the Atlantic, was the first to operate a reactor (GLEEP) from August 1947, followed a year later by $\mathrm{BEPO}$, a more powerful reactor where neutron diffraction experiments could be performed.

The situation in France and Germany, the two countries who founded the ILL is of prime importance here, but the other countries should not be forgotten. The Netherlands

122018 addition: In naturally occurring water, $\mathrm{H}_{2} \mathrm{O}$, one molecule in 41 million is made up of $\mathrm{D}_{2} \mathrm{O}$, where the hydrogen isotope deuterium, $\mathrm{D}$, is present. This has an additional neutron in the nucleus. The deuterium can be extracted and used to produce $\mathrm{D}_{2} \mathrm{O}$, heavy water, which has some very different properties from light water, $\mathrm{H}_{2} \mathrm{O}$, notably absorbing neutrons much less. 
and Norway jointly used a reactor at Kjeller in Norway from 1951, Denmark had its own in 1957 in Risø. In Poland a reactor was inaugurated in 1958. In Italy, researchers had a source in the Euratom Research Centre at Ispra in 1959 and then a national one in 1960 in Rome. Before this the USSR had several sources, and an international research centre regrouping Eastern Bloc countries was created at Dubna, about $100 \mathrm{~km}$ from Moscow in which were built pulsed reactors (from 1960). Sweden and India too each had a reactor at this time. There were frequent meetings between users of these various reactors, especially amongst those in Western Europe.

\subsubsection{In France}

France like UK entrusted a specific organisation to further nuclear research for civil and military purpose. The Commissariat à l'Énergie Atomique (CEA) was initially directed by Frédéric Joliot who, with co-workers Hans von Halban and Lew Kowarski (Fig. 1.4), had deposited several patents before the war on the use of nuclear fission for both civil and military purposes. France closely followed the UK with the launch of ZOE (1948), a very low power reactor like GLEEP, but employing heavy water as a moderator rather than graphite. This was a result of several considerations. The first was that before the war the only factory producing heavy water in Norway was built with French capital. The whole stock, amounting to 165 litres had been brought into France at the start of war, and then transferred across the Atlantic by Halban and Kowarski before the German invasion. Inevitably it was a French team (Frédéric Joliot, Lew Kowarski and Hans von Halban $^{13}$ ) which prioritised this substance in the studies and experiments on the possibility of creating a chain reaction. ZOE owes a lot to Lew Kowarski (1907-1987) who designed it then directed the construction. During the war he had the same responsibility for the first Canadian reactor, which also used heavy water

13 It is interesting to note that this French team included a Russian and an Austrian. Science is international. This essential point should not be forgotten, and it has contributed to the strength of American science. The atomic bomb could only be created by the USA because this country knew how to welcome European immigrants (Fermi, Szilárd, Einstein, etc).

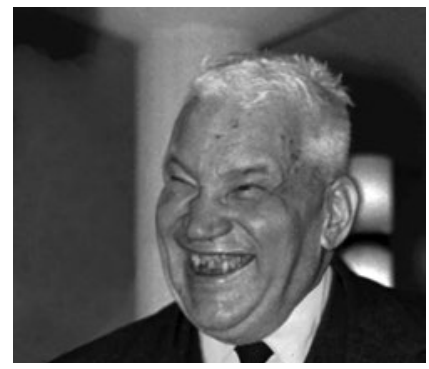

Fig. 1.4: Lew KOWARSKI in 1964. 


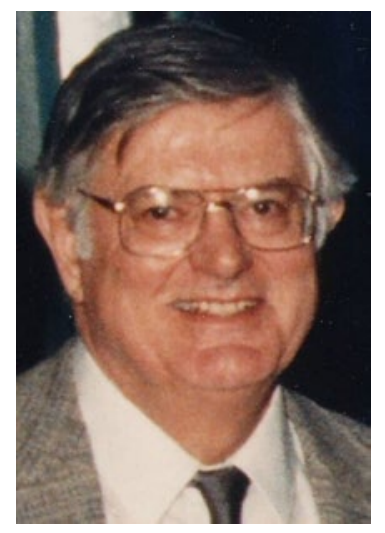

Fig. 1.5: Peter EGELSTAFF as a moderator. A final advantage was that a heavy water pile required about 10 times less uranium than a pile using graphite. At that date France had no metallic uranium and had to use uranium oxide. Thus, the CEA was forced to develop a ceramic fuel for the first time in the world. This reactor was built at Fontenay-aux-Roses, in the near suburbs of Paris.

In 1952, the CEA created a new site dedicated to civil research on the Saclay plateau near what later became the University of Orsay. On this site, French scientists had access to another heavy water reactor (EL2), more powerful generating a flux of $2.510^{12}$ neutrons $/ \mathrm{cm}^{2} / \mathrm{s}$. Again this reactor was built under the leadership of Kowarski. The flux was sufficient to perform nuclear physics experiments (measurement of cross-sections), but also diffraction, and spectrometry ${ }^{14}$ employing inelastic neutron scattering.

It was evident that the fluxes at BEPO and EL2 were still inadequate for a large number of experiments. Before envisaging the building of high flux reactors one idea was introduced and realised on BEPO by Peter Egelstaff ${ }^{15}$ (Fig. 1.5). For a number of experiments, especially spectrometry, it is preferable to use long wavelength (hence very low energy) neutrons, $4 \AA$ or more. Theoretically, it is easy to increase the flux of these neutrons. It is sufficient to introduce a quantity of liquid hydrogen at the end of the beam tube. In this medium neutrons are thermalised to a mean temperature of $20 \mathrm{~K}$, increasing their wavelength. The Saclay Group (Daniel Cribier and Bernard Jacrot) impressed by these results launched the construction of a cold source for a new reactor (EL3) being built at Saclay. This work entailed a close collaboration with the low temperature laboratory of Grenoble, directed by Louis Weil, and in particular with Albert Lacaze. The cold source, which operated from 1959, used a mixture of liquid hydrogen and deuterium, which allowed the source to have a greater volume. I should note that I often met Peter Egelstaff during the construction and benefited from his constant help, which was of great value. To gain time most of our meetings were often in the airports in London or Paris.

14 B. Jacrot, C.R. Acad. Sci. (1955), 240, 745-747.

15 I. Butterworth, P.A. Egelstaff, H. London, F.J. Webb, Phil. Mag. (1957), 2, 917, DOI 10.1080/14786435708242730 
Later cold sources were also installed in the German reactors in Karlsruhe and Jülich.

In 1956, a new CEA research site designated as the Centre d'Etudes Nucléaires de Grenoble (CENG) was created at Grenoble. Louis Néel was the originator of this laboratory, understanding the link of neutrons and of magnetic structures, and wishing to develop a nuclear engineering section within the Institut polytechnique de Grenoble (IPG). He became the first director of the CENG. In 1958, the first reactor, Mélusine, with initially $1 \mathrm{MW}$ power, entered operation. It was followed by Siloé in 1963. The 35 MW power could be used to study both atomic and magnetic structures. Felix Bertaut (Fig. 1.6), director of a crystallographic laboratory of the CNRS, was involved with these studies. This strong interlinking of the CENG and the laboratories of the CNRS and university was typical of the originality of the Grenoble site as distinct from Saclay. This intimate connection was enhanced by the fact that Louis Néel was at the same time director of the CNRS Magnetism laboratory (to which was attached Bertaut's laboratory), of the INPG, and of the CENG.

\subsubsection{In Germany}

An atomic weapons project was initiated during the war, however, the first attempts to construct a reactor failed ${ }^{16}$. The attempt was finally abandoned in favour of the development of the V1 and V2 rockets. After the war German researchers were barred from all activities involving nuclear energy. Physicists had to wait until 1955 for this restriction to be lifted and a wholly American-built reactor became operational at Garching, close to Munich in 1957. This reactor, with Professor Maier-Leibnitz as director was initially $1 \mathrm{MW}$ in power. It was attached to the Technical University in Munich, distinct from the reactors in the France and the UK which were installed on CEA (or the UK equivalent) sites, and which were isolated from the universities (with the exception of the CENG at Grenoble). The low power of this reactor limited the range of experiments and Maier-Leibnitz placed an

16 The graphite employed was not sufficiently pure and Germany had no heavy water.

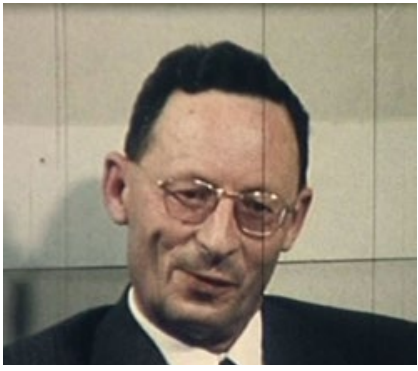

Fig. 1.6: Erwin Felix LEVYBERTAUT 
emphasis on developing techniques. Amongst these was the invention of neutron guides which has since been very widely used. These are the neutron analogues of optical fibres for light, and use total reflection to lead neutrons over distances up to tens of metres from the reactor with very small losses of intensity.

A few years later research institutes more similar to the CEA in France were created at Jülich and Karlsruhe with reactors more powerful than that at Garching. The reactor at Karlsruhe, the first designed and constructed by the Germans, went critical in March 1961, and reached a power of $12 \mathrm{MW}$ in December 1962. The reactor at Jülich which was similar to the British reactor DIDO, was operational in 1962. Initially with a power of $10 \mathrm{MW}$, this was increased to 15 then $23 \mathrm{MW}$ during the following ten years. There, directed by Tasso Springer, Hans Stiller and Werner Schmatz, all trained at Munich, numerous applications were developed using neutrons to study condensed matter.

\subsubsection{In America and UK}

This was the situation at the time when America initiated the construction of the High Flux Beam Reactor (HFBR) at Brookhaven. This was going to place European scientists at a marked disadvantage compared to their American colleagues. The first mention of a European high flux reactor I have found is in a report ${ }^{17}$ written in 1961 by Lew Kowarski entitled "New tendencies in atomic research and their international significance" (Fig. 1.7). In these times Lew Kowarski was already at CERN, but retained a great interest in nuclear reactors, a field to which he had greatly contributed. In addition he was scientific advisor of the European agency for nuclear energy.

In his report, he insisted on the need for European cooperation analogous to that of CERN to create a source comparable to that working, or about to operate in the USA. It was as the scientific advisor that he participated

17 This report and others cited a little later are in the archives of Lew Kowarski deposited in the Center for History of Physics of the American Institute of Physics, which I thank for having supplied me with copies. 


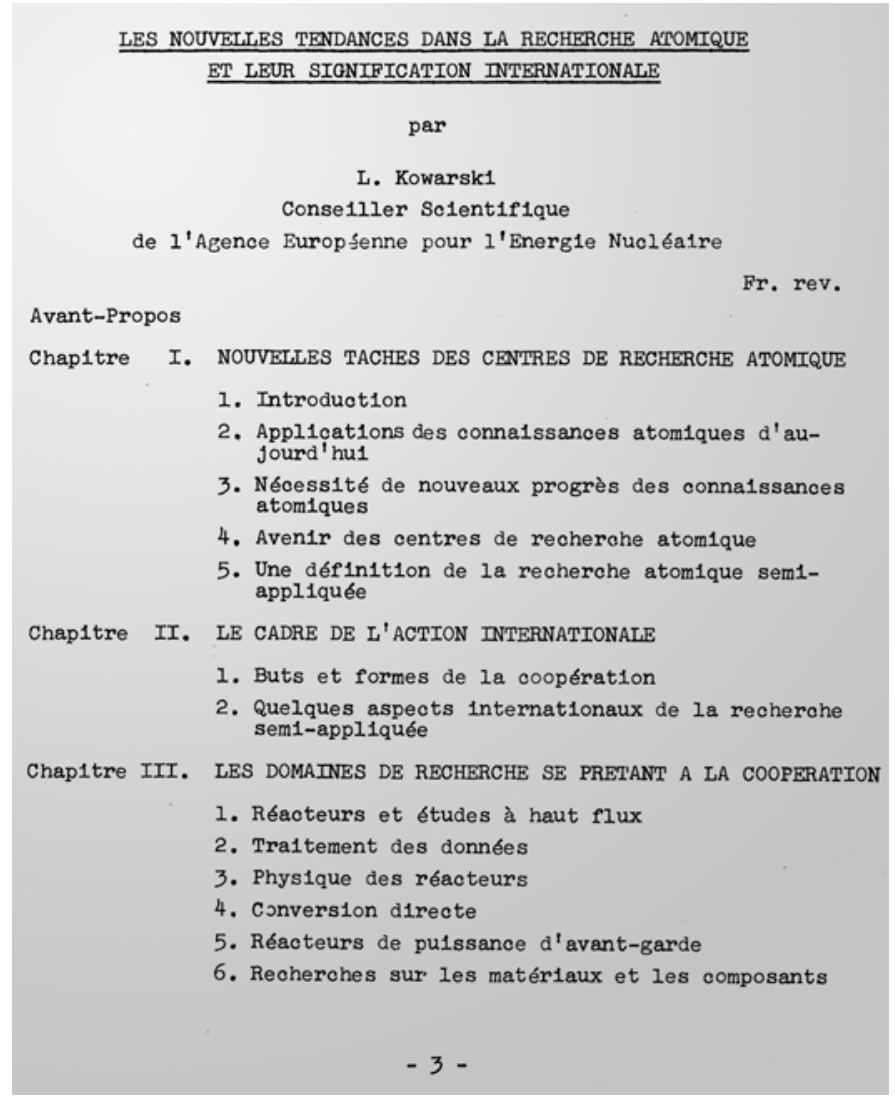

in a meeting organised by the Organisation for Economic Co-operation and Development, $\mathrm{OECD}^{18}$. The aim of this was to examine the proposals in Kowarski's report and deal with "cooperation in certain fields of nuclear research". The idea of a European high flux reactor was first discussed here. The British representative, Dr Vick ${ }^{19}$, mentioned that the studies were already under way in the UK for a heavy water reactor of $25 \mathrm{MW}$ intended primarily for research in solid state physics. This initiative was not a surprise; our British colleagues were certainly the most advanced, at least in Europe, in this domain of

18 This first European organisation was created in 1948 (with the name European Organisation for Economic Cooperation OEEC) to manage funds from the American Marshall Aid for the reconstruction of Europe.

19 I think this was Sir Arthur Vick (1911-1998) who worked at Harwell from 1959.
Fig. 1.7: First mention of a European high flux reactor in a report by L. Kowarski. See item 1 of "Chapitre III" which translates into English as:

Chapter III. Research areas suitable for cooperation 1. High flux reactors and studies 
applications of neutron scattering, thanks to scientists like Peter Egelstaff, Ray Lowde, John White, William (Bill) Mitchell, etc. As representatives of Germany, MaierLeibnitz and Joachim Pretsch, the German minister for research, participated in this meeting in which it was decided to appoint a committee of experts chosen from the future users of the envisaged high flux reactor.

Even in 1962, i.e. before operations of the Brookhaven reactor, a British study had produced a firm proposal for building an HFBR at Harwell ${ }^{20}$, an important laboratory of the UKAEA ${ }^{21}$ near Oxford. This document presented three options: the first was a pure and simple copy of the reactor in construction at Brookhaven. The second option was a small modification to this reactor to include a cold source and a hot source to maximise fluxes locally of long and short wavelength neutrons respectively. These depended on Brookhaven sending all its designs to Harwell. The third option which was the most developed in the report is for a British designed reactor for which further complementary studies would be necessary.

For this last choice the investment was priced at $£ 6.76 \mathrm{M}$ (equivalent to about $€ 161 \mathrm{M}$ in 2018) and 63 months would be needed for design and construction. A cold source and a hot source were planned. The cold source was to use liquid hydrogen (170 g) which limited its performance compared to a source using liquid deuterium as is used at the ILL. It appears that this choice was made deliberately to reduce the volume of the cold source which would minimise heating of the source by radiation from the reactor core. In the project it was even envisaged to reduce this volume further. Reading this document, authored by engineers, reveals a deep lack of dialogue between them and the future users.

The committee of experts met several times in 1962 to study several variants of high flux reactors. This panel was presided over by Kowarski, and comprised of scientific users of neutrons from member countries of the OECD. Amongst others it included the Briton Peter Egelstaff, Heinz Maier-Leibnitz, and myself. It was working with the idea of making a European project on the basis of the British project (although I only

20 V.S. Crocker, D.B. Halliday, B.O. Wade, E.M. Jackson, R. Forgan, High Flux Beam Reactor report (1962) AERE M 1123.

21 UKAEA: United Kingdom Atomic Energy Authority 
remember that a fat document of 160 pages and 60 illustrations describing this had been distributed amongst participants). The discussions of this working group (for which I could find no minutes) were certainly useful; for the first time the scientists from various countries, who knew a little of each other or had only met in congresses, would work together, or in any case, deliberate on a shared scientific aim. In fact these discussions between researchers went very well and showed that there was a considerable community which wished to use a high flux reactor. Unfortunately, budgetary problems (or perhaps political exigencies since the UK had been rejected from the Common Market) led to the UK withdrawing and the whole project was abandoned.

\subsection{A new idea}

From this failure the ILL was born as a Franco-German project. In fact the first reaction of Jules Horowitz was to say that it was necessary for the French to develop their own project and find partners willing to participate in the implementation. Horowitz was head of the department of mathematical physics at the CEA, which dealt primarily with the physics of nuclear reactors. He asked Robert Dautray (Fig. 1.8), then an engineer working for him, to develop such a project. In the book by A.L. Edingshaus ${ }^{22}$ and later in a discussion in July 1982 with Tasso Springer ${ }^{23}$, Maier-Leibnitz mentioned a conversation he had with M. Baissas about then. The latter was Chief of Staff to Francis Perrin, the High Commissioner of the CEA. During the conversation Baissas expressed his regrets over the demise of the European project, and suggested that it might be revived as a Franco-German construction, perhaps at Grenoble. At this time the powers of the High Commissioner were limited; the true head of the CEA was the General Administrator. I think Baissas thus spoke to Maier-Leibnitz of discussions which had taken place amongst the directors of the CEA.

22 Heinz Maier-Leibnitz, "Ein halbes Jahrhundert experimentelle Physik", memoirs collated by Anne-Lydia Edingshaus, Ed. Piper verlag, München and Munich (1986).

23 This discussion, recorded and transcribed, was given to me by Tasso Springer.

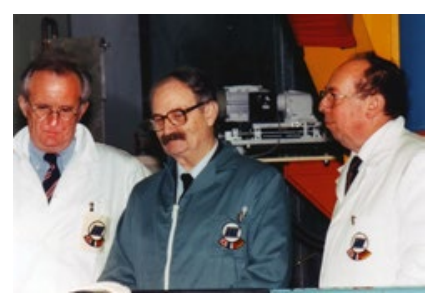

Fig. 1.8: From left to right: Jean CHARVOLIN, Robert DAUTRAY and JeanPaul MARTIN during the reconstruction of the ILL reactor (1994). 


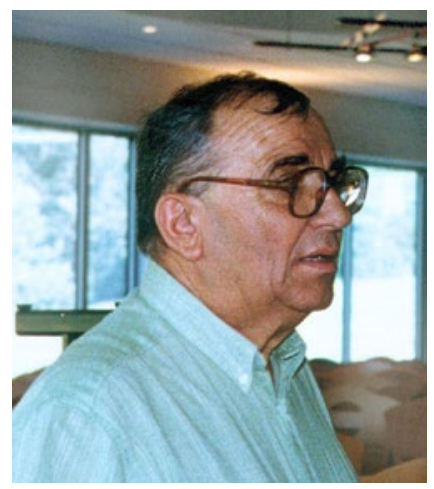

Fig. 1.9: Paul AGERON
For his part in his memoirs "A Century of Physics" Louis Néel makes no reference at all to the OECD meetings, which, if I remember correctly ${ }^{24}$, no scientists from Grenoble were present. He talks about his work with the leaders of the CEA and CNRS for a high flux reactor in Grenoble. It was also around this time that Maier-Leibnitz visited and met Louis Néel for the first time and spoke of his interest in high flux reactors. It seems to me that the essential tactic was that Horowitz asked Dautray to undertake the reactor study, passing the discussions from the stage of speculation through to a concrete project.

The neutron researchers and physicists in Grenoble expressed their own interest in such a project and for several reasons. The first being that the reactor should of necessity include a high performance cold source and that the know-how existed in Grenoble thanks to Louis Weil and Albert Lacaze, who had worked with us to design and build the cold source at Saclay. The second was that there was experience in Grenoble on the construction of a swimming pool reactor, which was an alternative to the Brookhaven model. Bertaut was, of course, interested in easy access to an intense neutron source for his diffraction studies. The last reason was a clearly formulated wish by the CENG, especially that of director Louis Néel, that such a reactor should be sited at Grenoble. This led to writing up the project entitled: "A high flux reactor and output beam tubes" which was presented at the 1964 Geneva Conference on the Peaceful Uses of Atomic Energy ${ }^{25}$. The main author was Paul Ageron (Fig. 1.9) with help from Deniélou, Dautray, Fornier, Jacrot, Perroud, Lacaze and Weil. This was a joint project bringing together physicists, reactor engineers, and low temperature specialists from Grenoble and Saclay. The reactor described summarily in this presentation was a swimming pool type. The only features retained from the Brookhaven design were the under-moderated core, and the use of highly enriched uranium.

Swimming-pool reactors are reactors where the core of enriched uranium ${ }^{26}$, is usually immersed in a light

24 Possible participants would have been Ageron and Bertaut, both now dead.

25 Proceedings: https://digitallibrary.un.org/record/848867.

26 In naturally occurring uranium there is only $0.7 \%$ uranium-235 which is the most common fissile isotope. In enriched 
water pool (demineralised ordinary water). The latter serves a triple role: it contributes to the neutron thermalisation and cooling of the core and in addition contributes as a protection against the radiation emitted. This type of reactor, developed in the USA since 1950 had been presented during a preceding Geneva Conference in $1955^{27}$. The SILOE reactor in Grenoble was of this type. The project presented in Geneva by Robert Dautray was similar, but incorporated a heavy water reflector. Jules Horowitz with Victor Raievski had filed a swimming pool reactor patent from where certain aspects were incorporated into the high flux reactor project (RHF).

Maier-Leibnitz was also present at the 1964 Geneva Conference, having been present at the OECD meetings in Paris. He was immediately captivated by the project and its possible realisation in Grenoble. He spoke of this to Joachim Pretsch, head of the division of nuclear research, and to Hans Lenz, the director of the German ministry of research, who were also attending the meeting. In his discussion with Springer, Maier-Leibnitz evoked the desire to please the French, who were at that time "somewhat obstructionistic in the community" ${ }^{28}$. Pretsch passed this on to the minister himself. The latter also had a conversation with Horowitz, to whom he gave Maier-Leibnitz's name as an intermediary. The first discussions between Horowitz and Maier-Leibnitz then ensued. Lenz had cordial relations with his French colleague Palewski. At this time the notion of French-German Cooperation initiated in April 1963 by de Gaulle and Adenauer lacked concrete achievements. The project of constructing a large scientific research instrument in the framework of a bilateral agreement was politically very well received. The two French and German ministers concerned thus made an agreement on the principle of constructing an intense source of neutrons at Grenoble within the Franco-German

uranium this percentage is increase by various physical methods (centrifugation, gaseous diffusion). It is said to be highly enriched when this percentage exceeds $90 \%$. This highly enriched uranium can be used for the fabrication of atomic bombs.

27 Proceedings: https://www.worldcat.org/title/proceedings-ofthe-international-conference-on-the-peaceful-uses-of-atomic-energy-1955/oclc/514057.

28 On 1 July of this year, 1965, de Gaulle challenged with the "Crisis of the empty chair" refusing to take part in Community activities. He considered Europe to be too federal. 


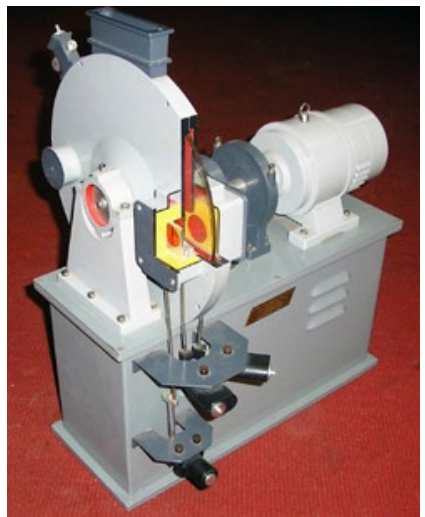

Fig. 1.10: A segment of fissile $\mathrm{U}-235$ on the rotating disk passes between two subcritical plutonium assemblies creating a pulse of fission reactions. cooperation framework. At that time I was attending a magnetism conference at Nottingham in England. It was there that the rumour concerning the accord passed at Geneva reached me.

It appears important to me to underline that while the political context favoured the decision to construct the RHF and the ILL, the motivation which drove the OECD then France, and finally the French-German combination to propose this construction were basically purely scientific. The cordial and often even friendly relations on one side between Maier-Leibnitz and his German colleagues and Néel, Horowitz, Dautray and me on the other side certainly facilitated the advancement of the project.

Horowitz, who had been at the Geneva Conference and had discussed the project with Maier-Leibnitz was satisfied to see that his ideas which had led to the presentation of this project now to be about to be realised, even if he would certainly have preferred construction to be sited at Saclay.

At the same time another group of scientists were studying the possibility of building a European pulsed pile. In a reactor, like those described above, fissile material and a moderator (light water, heavy water or graphite) are brought together to create a critical assembly ${ }^{29}$ where the chain reaction takes place. This reaction is controlled by the introduction of matter to absorb neutrons (cadmium, boron) to have a stable unit which produces a constant flux of neutrons. One can also envisage a sub-critical assembly which only goes critical momentarily by the introduction either of additional fissile material, or an additional reflector/moderator. This gives rise to the pulsed reactor. The first, IBR-1 (Fig. 1.10), was built in 1960 in the Joint Institute for Nuclear Research (JINR), USSR. The advantage of this technique is that with a modest average power one can obtain an intense flux of neutrons during the short time the reactor is critical. The European project I was describing, named SORA, was under development through Euratom by a team led by Walter Kley. With a nominal power of $1 \mathrm{MW}$ and a peak power of $300 \mathrm{MW}$ it would give rise to a maximum flux of $4 \times 10^{15}$ neutrons $/ \mathrm{cm}^{2} / \mathrm{s}$. We will see later how these peak

29 See section 4.1 for the definition of critical mass. 
fluxes are best used. There were hence appealing aspects in this project.

Euratom, created in 1957, had two main objectives: ensuring the non-proliferation of nuclear weapons, and to work on the creation of a civil nuclear industry in Europe. These themes were thus essentially technical and political. However, Euratom decided to create a joint research centre devoted, at least partially, to basic research. Ispra in northern Italy was chosen for this research centre. Within this framework, the SORA project, typical of fundamental research, proceeded. It was never constructed, but at the time it aroused great interest in the scientific community, and made it necessary to compare the merits of the high flux reactor and a pulsed reactor. The comparison was made difficult because there was no experience with pulsed reactors in western Europe. In November 1964 I went to Dubna for a visit of ten days. My conclusions were as follows:

"The range of applications of a pulsed pile like SORA is more limited than a reactor at constant high flux. For certain experiments the possibilities are much bigger; this is the case for nuclear physics. In inelastic scattering of cold neutrons, and for a fraction of diffraction experiments the pulsed pile will give better results than a static pile. Another important aspect is that a static reactor with a flux of $10^{15}$ is at the limits of technical possibility and no improvement can be expected. This is not the same with a pulsed pile, where important new advances can be expected. It seems that SORA is of considerable interest."

Maier-Leibnitz shared this view, and had great esteem for Walter Kley who was deeply involved in SORA. It was necessary to choose; Jules Horowitz's doubts on Euratom, and the absence both in France and Germany of expertise on pulsed reactors condemned the $\mathrm{SORA}^{30}$ project.

However, the value of pulsed reactors was demonstrated a little later by the start of operations in 1984 at Dubna of the pulsed reactor IBR-2. The concept and

30 In contradiction to what Néel writes on p 216 of his memoirs, "Un siècle de physique", Jacob, Paris, (1991), Horowitz never supported the SORA project. It is doubtful that he could have predicted a demise of plans for the Grenoble reactor because this project was being developed by Robert Dautray, one of his best employees. 
performance are close to that foreseen for SORA. Nonetheless the steady-state reactor of the ILL would amply prove the reliability and efficiency of this approach, whereas a pulsed reactor would be more fragile, less safe and more difficult to defend against the rising anti-nuclear sensitivity at the end of the 1970s. In other ways the technology of pulsed sources change direction towards more promising paths, like spallation ${ }^{31}$ sources or pulsed reactors coupled to an accelerator.

With hindsight, the choice of a constant high flux reactor optimised for the production of intense neutron beams was certainly the best at that time. In contrast, the next generation of neutron sources succeeding the ILL will certainly not be steady-state reactors. It will be very difficult, if not impossible, to improve the performance of these beyond the reactor of the ILL.

With this note, we have finished with the pre-history and it is time to look at how the verbal agreement at Geneva has materialised. Before this it is useful to look a little more closely at what can be done with neutron beams. The experiments of Shull and Wollan mentioned above were performed on a reactor which was not designed for this usage. The French-German project was for a reactor with a sole purpose to produce neutron beams, at a cost (in 2005 monetary terms) of $€ 300 \mathrm{M}$. Hence the justification for such expenditure needed a solid scientific case. This will be the theme of Chapter 3 which the non-scientist reader may skip.

31 These sources are not based on the nuclear reaction of fission as in a nuclear reactor but on the spallation process. In other words a powerful accelerator bombards a heavy metal target with high energy protons which emits a pulsed flux of fast neutrons. 


\section{Chapter 2}

\section{Portraits of three founders of the ILL}

The creation of an institute such as the ILL is the result of work and engagement of many contributors. Some of these are listed in chapter "Key people". As I have already written, three men had essential roles in the genesis of the ILL: Jules Horowitz, Heinz Maier-Leibnitz and Louis Néel. All three are now deceased. I will try and draw a brief profile of each of them. During their lives all three have played a role which far exceeds their involvement with the ILL. Horowitz was the originator of French nuclear developments, and the consequent national energy independence. Moreover, he contributed to making the CEA become a major force in French fundamental research. Louis Néel made Grenoble a national and international centre for basic and applied research. Maier-Leibnitz regenerated German physics as a major player, as it had been up to 1933. Thanks to their hard work and their intellect these key players imposed major policy options within their countries. They were undoubtedly men of power. They were fully aware of their intelligence, but were never arrogant. Arrogance is a sign of the weak and those who have no trust in others. Common to all three was their discipline, both intellectual and moral. This said, each had their own personality which I will try to show.

\subsection{Jules Horowitz (1921-1995)}

He had a major role in the founding of the ILL ${ }^{32}$. After the failure of the European project initiated by Kowarski, it was he who pressed the CEA to resume the venture as

32 This text is based on presentations made during the tributes to Horowitz in 1996, later published by the CEA in 1999 as "L'oeuvre de Jules Horowitz" by Lucile Arnaudet, Robert Deloche and Lucien Procope, and my personal memories.

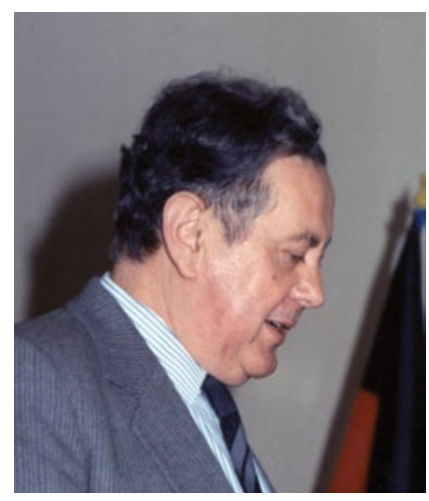

Fig. 2.1: Jules HOROWITZ at the ILL in 1995 
a purely French initiative. Initially, only Saclay engineers and physicists were involved, but these were quickly joined by teams from the CENG, leading to the preparation of the presentation in Geneva, and Ageron and coworkers' paper on the "high-flux reactor and output beams".

If Horowitz was not the principal author of this paper, he was the main motivator. In fact the whole design depended on a reactor aimed at producing neutron beams, and excluding use for irradiations. Horowitz had always been partisan to separating these two uses for neutrons, calling for different types of reactor. The ILL reactor followed this principle only having some irradiation facilities, which do not interfere with the production of neutron beams. This characteristic, on the other hand, posed a problem for the British during their discussions for joining the ILL; the British design attempted to take both functions into account on the same reactor.

Horowitz closely followed the work of preparation of pre-project, then the design, and the construction. He had innate confidence in those he had chosen to be in the field, namely Robert Dautray, then Jean Chatoux and myself. He wanted to be informed of what was happening on a daily basis, and became angry at any lapse. He was always respected and admired by all who had to work with him. He would always attend meetings of the Steering Committee up to 1987. Beyond the construction phase of the ILL his role was particularly important at the time of the negotiations with the British SRC. He always kept the atmosphere friendly but insisted very firmly on the point that he would not accept any use of the ILL by the SRC outside that of a partnership. He gained the appreciation of the British negotiators. Bill Mitchell, the chief proponent for the UK reactor, paid tribute as much for his intelligence and scientific brilliance as for his skill in negotiations. In 1979, Horowitz knew how to convince the partners to finance a Deuxième Souffle (Second Wind, or renewal) for the ILL to keep its vanguard position.

Born in Poland in 1921, Jules Horowitz, called Jules by everyone, emigrated with his family to Germany in 1926. There he acquired a good knowledge of the language and culture of the country. Anti-Semitism, the original reason for leaving Poland for Germany then led them to France in 1932. His father was a university scholar of the Old 
Testament. Young and brilliant, Jules was accepted by the Ecole Polytechnique in 1941, but was prohibited from attending by the racial laws. He was also given a place at the Ecole de Mines of Saint Etienne, and joined, but after the first term the Vichy authorities forced his dismissal. Horowitz left for Lyon where he undertook a Physics degree. There he had to borrow books from the library of the Lycee du Parc. A roundup there forced him to hide far from Lyon up to the Liberation ${ }^{33}$. Like his father he managed to escape the anti-Jewish raids, but his mother was arrested by the Vichy police and was deported to Auschwitz where she was murdered. He had to await the Liberation to continue his studies, firstly as a foreign student, until his naturalisation in November 1945, too late to enter the prestigious School of Mines to which he had already qualified.

After the war and leaving university in 1946 he was taken on by the CEA. His first job was to reconstruct the calculations for atomic piles (to help in the design of ZOE) from the notes brought back from America by Kowarski ${ }^{34}$. The following year he departed for Denmark to train in theoretical physics with Niels Bohr. On his return he was attached to the department of mathematical physics led by Jacques Yvon. The scientists in this group (Anatole Abragam, Michel Trocherie, then Albert Messiah, Claude Bloch, and others) shared their time between theoretical physics and reactor physics. The theoretical work of Horowitz focused on a variety of topics. In 1949, he wrote up an important clarification with Albert Messiah on the passage of neutrons through crystalline media ${ }^{35}$. I regret

\footnotetext{
33 The books disappeared during this flight. The Lycée du Parc lodged a complaint and Horowitz was convicted of theft by a court of the regime. After the Liberation he found himself with this criminal record which the new Justice Ministry refused to annul. I learnt these facts from Robert Dautray, and offer him my thanks. They demonstrate well the attitude of the French authorities at that time towards the Jews.

34 "Souvenirs de Jules Horowitz" published in a special edition of "Echos du CEA" after 20 years of ZOE.

35 See the book "L'oeuvre de Jules Horowitz" Tome 1, page 48. 2018 addition: Book edited by Lucile Arnaudet, Robert Deloche and Lucien Procope, Paris, CEA, 1999. The paper of 1949 is in a hard-to-find CEA report "Horowitz J. et Messiah A., Rapport SPM no 5". SPM stands for "Service de Physique Mathématique"
} 
I have not been able to find the actual text ${ }^{36}$, but the subject shows that at this time he was interested in what would be the main theme of research at the ILL.

In 1953 he was placed as in charge of the mathematical physics department. From then on, he concentrated full time on reactors. It was an era when the CEA was developing a civil energy programme based on gas-cooled reactors and using graphite as a moderator; the only solution which used resources available within France. National independence was very dear to Horowitz, and he fought to defend it throughout his life. When the Americans demonstrated in 1967 the economic advantage of watercooled reactors using enriched uranium this posed a dilemma that Horowitz resolved by advocating a continuation of the existing studies, but studying the American activities, and supporting the creation of a French plant for enriching uranium. This was at the time of the start-up of the ILL reactor, which had still held his interest. He was able to follow more closely when, in 1970, he became overall director of basic research at the CEA. As such in 1978 he unmasked the fraudsters who claimed to be able to detect oilfields using "sniffer planes"; the project had support of those in highest power of state, and hundreds of millions of dollars from the French petrol company ELF. He designed a simple but unequivocal test and proved the claims to be totally fraudulent.

After his death a memorial meeting 13 June 1996 was dedicated to him. If one neglects the inevitable elegiac nature of the contributions there are two essential features of the personality of Horowitz, which played a large role in his contribution to the ILL.

Firstly there was his distrust of multilateral agreements. When the scheme for a European reactor through the OECD failed Horowitz was quite satisfied because of this disdain (reinforced by his dislike of Kowarski). He then proposed taking it over in a purely French context, then as a bilateral enterprise which he liked a lot (becoming finally trilateral). When the European Science

36 I think I possess copies of all the articles used in this draft. They cover the effects of scattering and polarised neutrons. These copies have been heavily annotated. Comparisons with manuscripts from that time show these comments were written by Horowtiz. 
Foundation (ESF) proposed the creation of the ESRF ${ }^{37}$, Horowitz was initially reluctant and was only convinced when he was told that the ESRF, like the ILL, would have the status of a private company, under French Law ${ }^{38}$. In the field of fusion; however, the European project was already mature, but he preferred a world-wide project for the next stage ITER. In what followed he appears to have been right.

The second point on which all contributors were agreed was his extraordinary skill as a negotiator. I was able to appreciate this personally at the ILL, especially in discussions with the British. He was very firm, but managed finally to impose his point of view, firstly because he knew the facts much better than the others, that he spoke clearly and succinctly, and his firmness was accompanied by a great politeness that his opponents never had the impression of their submission. It is regrettable that he was not present during the final negotiations on ITER.

Horowitz was a man of the spoken rather than the written word; outside the scientific publications of his youth he left little written down.

\subsection{Heinz Maier-Leibnitz (1911-2000)}

Hermann Heinrich (Heinz) Maier-Leibnitz was born in 1911 in Esslingen on the Neckar, a pretty medium-sized town (90,000 inhabitants in 1995), just east of Stuttgart. Leibnitz was his mother's maiden name, a distant relation of the great scientist and philosopher Leibniz. It is common practice in Germany to attach a second name when the surname is as common as Maier, and this is what the father of M.L. had done. I remember that Maier-Leibnitz was very proud to bear this name. His father was a professor at the Technische Hochschule (Technical University) of Stuttgart. One of his uncles, Dr Reinhold Maier, a politician in the FDP, was the President of Baden-Wurttemberg. He, himself, did his graduate studies at Stuttgart at the Technical University where his father taught. The course included a 6-month industrial

37 The European Synchrotron Radiation Facility, a powerful source of X-rays, offering great complementarity to the ILL's powerful neutron source, see later.

38 This information was revealed in Paul Levaux's contribution to the commemorative meeting.

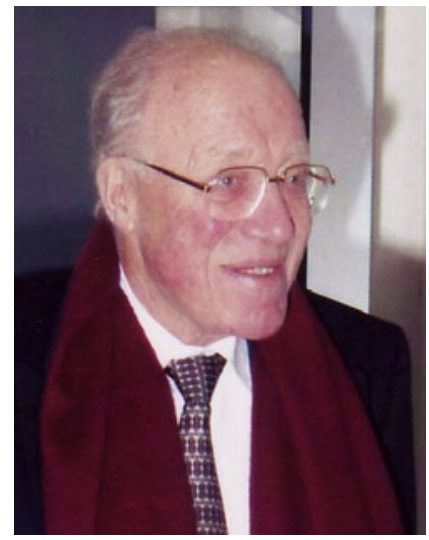

Fig. 2.2: Hermann Heinrich MAIER-LEIBNITZ 
internship in a foundry. After graduating he moved to Göttingen in 1931. This university was the Mecca of Natural Sciences (Naturwissenschaften), and the staff included, amongst others, Max Born, James Franck, Hermann Weyl, Ludwig Prandtl and Richard Courant. James Franck, Nobel Laureate in 1925 took him on as a thesis student.

Hitler came to power in January 1933, and on 13th April the decree was published dismissing all Jewish professors without compensation. Max Born, Richard Courant and other Jewish scientists had to leave Göttingen, and emigrate. Franck, deeply anti-Nazi, also left Germany in May 1933, with his family, to settle in the USA. Though profoundly affected, M.L. remained at the university in Göttingen, and in April 1935 managed to submit his thesis on a topic of atomic physics, the impact of electrons in the rare gases. This period greatly marked M.L. The personality and charisma of James Franck profoundly influenced him to the point that some observers said they could see in him these traits of Franck. In addition being in the laboratory where a great number of scientists had or would later have a Nobel Prize (Blackett, Maria Göppert, etc) made him think ${ }^{39}$ that every good physicist would be awarded this famous prize one day or another.

In July 1935 he joined Walter Bothe in Heidelberg as a collaborator at the Kaiser Wilhelm Institute for Medical Research (later renamed Max-Planck-Institute after the war). This institute was founded as a multidisciplinary centre with departments of pathology, physiology, chemistry and physics. The first director of the physics department was Karl W. Hausser, who had a great interest in the interplay of physics and medicine. He died in 1933, and Walter Bothe, who had been director of the physics department at the University of Heidelberg, succeeded him in 1934. Bothe, a nuclear physicist, with no particular interests in biology or medicine, was isolated from the other departments headed by leading researchers Richard Kuhn and Otto Mayerhof.

So, it was a lot less exciting than it had been for M.L. in Göttingen before Nazism. M.L. worked with Bothe on the development of using coincidence of signals in pairs and sets of detectors for which Bothe was awarded the

39 I report what he said to me. He was referring to the pre-war period and said that this was no longer the case with the great increase in the number of physicists. 
Nobel Prize in 1954. M.L. said to me that he considered it perfectly justified. There is nothing of special importance until in December 1938 Hahn and Strassmann discovered the fission of the uranium atom. A short while after the German ministry of defence created a group of scientists and the military to work on the application of this discovery to create new weapons. This team was known as the Uranverein (Uranium club). As a member of the group Bothe led major activities in the institute (tests to purify uranium-235 and calculations to build a reactor) related to the development of an atomic weapon. Two of his assistants were also involved: Fleischmann, who was appointed director of a new institute in occupied Strasbourg, and Wolfgang Gentner ${ }^{40}$, who was responsible for German research efforts in Paris. Bothe hated the Nazi regime but felt he had to remain loyal to his homeland. Maier-Leibnitz was detached at the beginning of the war to the Luftwaffe, working in France for the meteorological service. He returned to Heidelberg in 1942 when the government gave absolute priority to research, and sent scientists back to their laboratories. Having already served his country Bothe had a dispensation from the military program and was able to return to his basic research leading to the publication of two papers after the war. M.L. thus never participated in the Uranverein.

After an operation for appendicitis, he met Rita Lepper working as a nurse in the clinic. After an engagement of two months they were married on 25 August 1938. They had three children, Christine, Dorothée and Elisabeth. A son died as a baby. Madame Maier-Leibnitz was a very outgoing woman, very warm-hearted, without prejudices, and shared naturally excellent relationships with others. I remember her talking of the period of her life when she attended the fashion parades of the great Parisian couturiers and how she then reproduced from memory what she had seen. No mention of this aspect of his wife is given in the book of Anne-Lydia Edingshaus "Heinz Maier-Leibnitz, Ein halbes Jahrhundert experimentelle Physik" published in 1986, which includes many more memories of Maier-Leibnitz. He was a little surprised

40 In Paris Gentner was at the origin of courageous deeds. Amongst others he managed to obtain the freedom of Paul Langevin who had been taken hostage. He was one of the members of the first Steering Committee of the ILL. 
about this; he was always uncompromising over ethics but he did know the value of his wife's nature. I think a part of the success of M.L. in Grenoble was due to her.

I return to the scientific career of M.L. In 1942 he defended his habilitation (professorial thesis) and was appointed Dozent (lecturer) in Heidelberg. After the war he spent a year in the USA. He was appointed to a special professorship in Heidelberg in 1949, then, in 1952 he was given the post of Professor of Technical Physics. In 1956, on behalf of the state of Bavaria, he negotiated the purchase of a swimming-pool reactor from the USA. From this time onwards the field of neutron optics became his prime activity. With his collaborators (Tasso Springer, Anton Heidemann) he invented novel techniques ${ }^{41}$. These inventions were of great importance in the design of instruments at the ILL, and will be described here shortly. From then until his departure in 1972 the story of M.L.'s life is linked with the story of the ILL. In July 1971 his wife died from cancer. He was seen shaking with sobs in his office by his secretary, Silvia Brügelmann. In truth he was unable to suppress completely the great sorrow he suffered on the death of his wife. This did not prevent him fulfilling his duties as Director of the ILL to the end. A new era began for him after his departure in January 1972. It became difficult for him to return to live in Munich, so he accepted the Presidency of the Deutsche Forschungsgemeinschaft (DFG), which is somewhat like a German CNRS, but where the president has much greater powers. He was elected a foreign associate member of the French Academy of Sciences in 1978.

\subsubsection{The personality of M.L.}

M.L. certainly had a strong and complex personality. I think one gets a good idea of this from his replies to a questionnaire published by Paul Kienle on the occasion of his eightieth birthday which I include below ${ }^{42}$ :

- What is your biggest misfortune?

Not to be there for someone.

41 These are described in detail by these two colleagues in an article published in 2002 after his death in December 2000 in the journal: Neutron News (2002), 13(1), 32-36, DOI $10.1080 / 10448630208222873$

42 Following a French translation by Marie-Eve Meyer. 
- Where would you like to live?

Near people, close to a library.

- What is for you the greatest happiness on earth? To be able to be alone, not to be alone.

- What are the mistakes you forgive most easily? Those not made for personal gain or contempt of others.

- Your favourite fictional hero? I don't know.

- Who is your favourite historical figure? Socrates.

- Your favourite heroine in real life? I will not say.

- Your favourite heroine in poetry? I do not know.

- Your favourite artist? El Greco.

- Your favourite composer? Mozart.

- What qualities do you value most in a man? Openness, warmth, curiosity.

- What qualities do you value most in a woman? All.

- What are the virtues you value most? Absence of jealousy, fellowship with everyone.

- Your favourite occupation? Everything which can lead to something.

- Who or what would you have liked to be? A philosopher involved in social issues in 50 years' time.

- Your main character trait? A lack of self confidence.

- What do you value most in your friends? Affection and criticism.

- Your biggest weakness? Lack of courage (One doesn't know oneself).

- Your dream for happiness? Discover something.

- What would be your biggest misfortune? Lack of freedom.

- What would you like to be? A friend. 
- Your favourite colour?

Yellow.

- Your favourite flower?

Lilies of the field.

- Your favourite bird?

The nightingale.

- Your favourite author?

Shakespeare.

- The lyric poet you prefer?

Hilde Domin.

- Who are your heroes in real life?

Robert Schumann.

- Your heroines in history?

Marie Antoinette.

- Your favourite name?

Elisabeth.

- What do you hate most?

Cruelty.

- What historical figure do you most despise?

One should not despise (almost) anyone.

- What military achievements do you admire most? All that helped to avoid a major war since 1945.

- What reform do you admire the most? The reform of Baron vom Stein.

- What natural gift would you like to have? Intuition.

- How would you wish to die? Not before 43 a loved one.

- Your current mood? Curiosity, affection.

- Your motto?

He who is active longest lives longest.

Often the replies to this type of questionnaire lack sincerity, but that is absolutely not the case here. We see here Maier-Leibnitz's interest for science, and more generally knowledge. He liked to say "knowing is better than not knowing". This interest was coupled with that he had for human beings. In all recruitments I saw him

43 Perhaps a deliberate ambiguity. 
perform the human qualities counted as much as the scientific expertise. This definitely contributed to the good atmosphere, which characterised the institut. This said, it is clear that the strong personality of Maier-Leibnitz impressed many youngsters ${ }^{44}$, and that some were even a little afraid of him. As is often the case of strong personalities, he thought much of those who had the courage to counter him. This was the case for Andreas Freund, who admired him, but didn't think he was always right. Sylvia Brügelmann witnessed the confidence he had in his colleagues, and he appreciated their questions.

In a book "Flow" (1990) translated into French under the title "Vivre" in 2004 by the American psychologist Mihaly Csikszentmilhalyi, I found a reference to a small action that M.L. had invented to fill empty moments especially when he had to listen to boring lectures. He began by tapping his right thumb, then doing the same with his middle finger, index finger, ring finger and middle finger again and finally the little finger of the right hand. Then he did the same with the left hand. After this he reversed the sequence of the right and left hand. He found sufficient combinations to total 888 movements. This relieved the boredom, but was so automatic that his attention was aroused if something interesting was said. I have no recollection of this, nor has Andreas Freund, his student at the ILL. Silvia Brügelmann, then his secretary cannot recall it, though she could certainly imagine such a thing. Professor Csikszentmilhalyi told me in an e-mail that he knew Maier-Leibnitz and his second wife well, and had spent several weeks with him in the early 1990s, when Maier-Leibnitz had spoken of this. The fact I have no recollection of this may come from my lack of observational skills; perhaps he was not bored with Freund and me. I imagine he would have performed this activity very discreetly.

Despite his great height (about $1 \mathrm{~m} 90 \mathrm{~cm}, 6 \mathrm{ft} 3 \mathrm{in}$ ) he was shy and modest. He avoided showing his sensitivity in public. There was an area where his shyness faded; this was in the kitchen. He was undoubtedly an excellent chef and he knew it. He used this skill to establish informal links and friendships with those he liked. These meals, at least

44 A young theoretician starting at the ILL admitted voluntarily "Each time I speak with Maier-Leibnitz I have to spend weeks reflecting on what he said to me". 


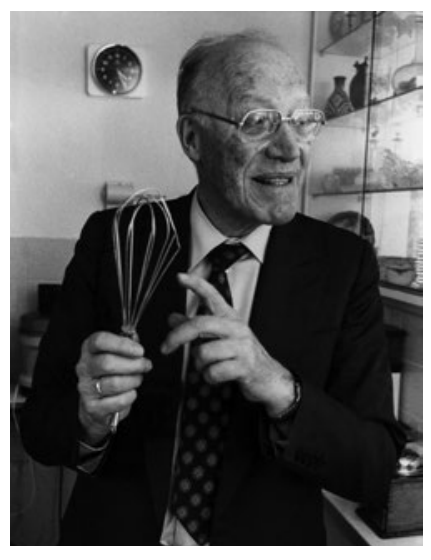

Fig. 2.3: Hermann Heinrich MAIER-LIEBNITZ in his kitchen showing a physicochemistry instrument which played an important role in the social life of the ILL in the early years.

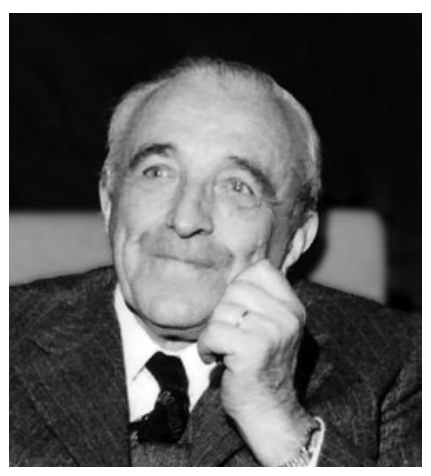

Fig. 2.4: Louis NÉEL at a reception in Grenoble in honour of his Nobel prize (1970) the ones I had the pleasure to join in, took place following a specific ritual: one dish, salad, and cheese (which he bought himself), and after the meal a good bottle of wine, most often a Burgundy. For many years we used the same supplier, a winemaker in Volnay. At that time I believed that wine served after the meal, as in Oxford and Cambridge colleges, was also usual in Germany; but nothing of the sort. I can testify that Maier-Leibnitz had a real interest in fine wine. During a journey in Bavaria he made us discover excellent German wines. His passion for cooking led him to write three cookery books. I cite his first book "Kochbuch für Füchse: Grosse Kiiche - schnell und gastlich" (The Crafty Cookbook Grande Cuisine - quick and homely) published by Piper in 1980. He intersperses his recipes with memories of meetings with world leaders.

This culinary skill of Maier-Leibnitz is one of the things which drew him to Louis Néel. I think the latter cooked a little for himself, but he had a special liking for good food. The guesthouse of the CENG, a little above Grenoble, was run by Monsieur Foiche, who presented an excellent Bressane cuisine (the best according to Néel in his memoirs) which Louis Néel liked to show off to his guests. Cooking full of taste. Such was also the case of meals prepared by M.L. After his Nobel Prize Néel was invited to a meal at Bocuse ${ }^{45}$, then the most famous chef in France (he was even filmed in the kitchens). I asked him afterwards what he thought; "it was disgraceful cooking", he replied, "because it didn't taste of the ingredients any more". After the first trip M.L. made to East Germany I asked him for his impressions. He told me there was much to criticise, but he found apples there with the same taste as those he had eaten before the war.

\subsection{Louis Néel (1904-2000)}

The role of Louis Néel in the creation of the ILL was quite different from Maier-Leibnitz and Horowitz, but was vital. Without him I do not know if the ILL would exist, but it certainly would never have been created at Grenoble, and would have been very different from what it is.

45 Editor's note: This is probably a typo in the original text and one should read instead "After his Nobel Prize Néel invited M.L. to a meal at Bocuse." 
Louis Néel was born in 1904 in Lyon. At the age of seven he suffered from polio, which left him with a limp throughout his life. In 1924 he entered the Ecole Normale Supérieure in Paris, and in 1928 became assistant to Pierre Weiss in Strasbourg. The latter was the foremost French specialist in magnetism. Néel submitted his thesis in 1937, and was appointed professor when Weiss retired.

It was at this time he imagined the existence of compounds called antiferromagnets, composed of two equivalent lattices but magnetised in opposite directions. Most theoreticians, with the exception of Van Vleck, couldn't believe in the existence of such compounds. Néel mistrusted the theoreticians, and had great respect for Van Vleck. There was no experimental proof for the existence of these compounds, but soon it was found that manganese oxide, $\mathrm{MnO}$ had a magnetic susceptibility which varied with temperature following that predicted by Néel for antiferromagnetism. It was necessary to wait until 1949 for Shull to demonstrate the accuracy of Néel's predictions with the help of neutron diffraction. This was sufficent to induce in Néel a great interest in neutrons, and hence for the reactors which produce them.

During the war he worked on magnetic mines at the research centre of the French navy. He had the idea to demagnetise boats. This was a very demanding operation which required capabilities from Néel well beyond those of a researcher. From this period on he would always keep a high regard for sailors, and a taste for industrial work.

When the University of Strasbourg withdrew to Clermont-Ferrand, he chose to settle in Grenoble following the suggestion of Félix Esclangon, director of the Institut polytechnique de Grenoble (IPG). There is the following description of Grenoble before the war in an interview given by Jean Wyart ${ }^{46}$ :

"Grenoble where the university was brand new, but where nothing was done. Very expensive apparatus was left in corridors for two years without even being unpacked".

Such was the state of research in Grenoble before the arrival of Néel. He created and named his own Ferromagnetism Laboratory, which became the Laboratory of Electrostatics and Physics of Metals (LEPM). This was the first laboratory belonging to the CNRS outside Paris,

46 Cahiers pour l'histoire du CNRS (1989), 2, 13-34. 
and was located in the Joseph Fourier Institute, which it shared with mathematicians, and which at that time was partially empty. In 1943 Félix Bertaut joined the laboratory to create a group for X-ray crystallography. Later, in 1956, the CEA created the Centre d'Etudes Nucléaires (CENG) in Grenoble for Néel. Two reasons motivated him; the first was his desire to create a nuclear engineering section at the "Institut Polytechnique" he directed. The second was the need to provide a source of neutrons for Bertaut. The former polygon artillery range, two kilometres from the centre of Grenoble, had long been abandoned. After lengthy negotiations the army agreed to sell 80 hectares (about 200 acres). This terrain was much larger than needed by the CEA, but much later could be proposed as a site for the construction of the ILL, and later still for the ESRF. The idea of creating a nuclear engineering faculty in an engineering school was new and shows Néel's interests were still in nuclear reactors and the energy they could produce.

The regular contacts $^{47}$ between Néel and MaierLeibnitz within the office of the International Union of Pure and Applied Physics (IUPAP) were important in the creation of the ILL. Once the ILL was created, the CENG offered a maximum of aid to the newcomer.

Louis Néel was a kind of enlightened scientific monarch, director of all, or nearly all the scientific laboratories in the town. His deeds definitely led to the spectacular development of Grenoble. He strove to establish links between the CEA, the CNRS and the university laboratories. He also fostered relations between industry and the university. His legacies were the high quality laboratories he left. The current development of Grenoble is the evident result of innovative industries being attracted by the presence of the laboratories linked to the CNRS or the CEA. But like all monarchs he was often difficult at first. In the annals of the Fondation Louis de Broglie, published in 2000, Georges Lochak, president of the Foundation, wrote:

"Néel was a leader with all that implies: decisiveness, ability to choose, sometimes a little abrupt in nature".

47 I was unable to find either where or when the two met for the first time. Evidence from their memoirs is contradictory. 
He always thought he was right, and most often this was true. Pierre Averbuch, one of his former employees, says Néel was not authoritarian, but no one would have imagined countering his wishes. For him the priority was the scientific and industrial development of Grenoble. He worked to reverse the flow of good scientists from the provinces towards Paris, hence his desire to site the ILL in Grenoble. He tried to attract top-level Parisians (de Gennes, Noziéres). Despite the rebuff he wanted them. Finally Noziéres came, attracted by the ILL; this improved their relationship. I think that the CNRS joined the ILL as a partner is due to him, though I have no proof of it.

Néel worked a lot through direct contact rather than by correspondence. What I said above about Horowitz also applies to Louis Néel; there is little written remaining outside of his publications before the war and the immediate post war period. They were nearly all in French $^{48}$. In almost all of these publications, most often an interpretation of experimental results collected by others, he is the sole author. He never put his name on an article to which he hadn't contributed, usually by offering his analysis of measurements. Before the war he performed experiments devised by himself together with theory; after the war he himself no longer performed the experiments he thought up. He shared his ethics on publication with Maier-Leibnitz. Today, unfortunately, many laboratory directors have an impressive list of publications because they insist that all publications from the laboratory bear their signature even if they have not participated in the work. (His memoirs too were only published some twenty years after he had retired) The comparison between Maier-Leibnitz and Néel can be expanded. I mentioned their common interest in good food. If many colleagues of Maier-Leibnitz have enjoyed his cooking, I have never met anyone who has eaten Néel's. The latter, in fact, never mixed his personal with his professional life. He always entertained colleagues at the CEA guesthouse. Both of them had a major influence on the work of their collaborators and knew how to transfer their knowledge. According to

48 I could only find one in English, published in 1953, in the American "Review of Modern Physics" et "Advances in Physics". 2018 addition: There is also a paper in English in "Advances in Physics" published in 1955. 
several witnesses, it seems that both were fairly mediocre teachers at university.

Néel's attitude towards theoretical physics is complex. He himself belonged to the endangered race of scientists who were both practical experimenters and theorists. His theoretical contributions not only made use of classical physics, but he knew enough quantum mechanics to teach up to degree level. He strongly supported the creation of the Physics School at Les Houches at a site belonging to the Académie de Grenoble. Here, for the first time in France, twentieth century physics was to be taught at the highest levels. He himself criticised the University for having neglected to provide this training pre-war. He had great respect for Louis de Broglie, a lone pioneer ignored by the university, especially because of his solitary nature.

The area where the CENG, the ILL and ESRF and various institutes of the CNRS are sited together has been named the "Polygone Scientifique Louis Néel". It is a just tribute to someone who acquired the land and who established or facilitated the establishment of all these research laboratories. It is difficult to understand that the town of Grenoble hasn't named a main road after him. The town owes him so much for having transformed a nondescript provincial town into a metropolis known worldwide. 


\section{Chapter 3}

\section{Why invest so much money in a source of neutrons?}

With the previous two chapters we have finished with prehistory and it is time to look at how the verbal agreement of Geneva materialized. Before this, it seems useful to look more closely at what can be done with neutron beams. Shull and Wollan's experiment mentioned above was carried out using a neutron beam from a reactor which had not been designed for this purpose. The Franco-German project was for a reactor dedicated to producing these beams at a cost (in 2005 values) of about $€ 300 \mathrm{M}$. It was necessary that justification for such expenditure was based on a sound scientific basis. This will be the theme of this chapter, which the non-scientific reader might prefer to skip.

Neutron sources accessible to scientists are somewhat rare because they require an infrastructure almost as costly as a particle accelerator or a big telescope. However, their goal is not to discover new particles and new galaxies ${ }^{49}$, but simply to allow us to see where atoms are, and how they move, by using a particularly suitable probe. There are hence a great number of applications in the field of condensed matter studies, even if there are also applications in nuclear physics, as well as fundamental physics (quantum physics). For condensed matter studies many techniques are used (X-rays, NMR, Raman spectroscopy, etc.) and one can ask why is it necessary to add neutrons to these; quite simply because neutrons see aspects which cannot be detected by these other methods. A user community has evolved who employ other techniques in their home laboratories, but who then call on neutrons to complete and clarify their vision of the samples under study. In 1997 this community of potential users numbered more than 4000 in Europe of whom more than 1000

49 I have re-used the comparison presented by D. Clery and G. Vogel, Science (2003), 300, 1226-1227, DOI 10.1126/ science.300.5623.1226 
2018 addition:

This overload factor has remained quite stable up to the present date. come year after year to use neutrons at the reactor of the ILL. The users are required to submit a proposal for their experiment. These proposals are reviewed twice a year by committees of scientists from outside the ILL. Due to an overload of demand for the instruments only one out of every two can be accepted. I will review the various areas of uses of neutrons. Some of the examples here are taken from recent experiments, much later than those prompting the decision to construct the source.

\subsection{The interaction of neutrons with matter}

All samples comprise of atoms, and it is with the nuclei of these atoms that the neutron interacts. There are two possible results: either the neutrons are absorbed (captured) or they are scattered. The probabilities of these two events are expressed by what is called their cross-section. Following this convenient notation the probability of an interaction with a neutron is No/A where $\sigma$ is the cross-section, $\mathrm{N}$ the number of nuclei in a surface area A. The cross-section is expressed in units of the barn, an area of $10^{-24} \mathrm{~cm}^{2}$. Often capture cross-sections are proportional to the neutron wavelength, and vary considerably from one atom (more specifically one nucleus or isotope) to another. The value is close to zero for helium- 4 , but very large for helium-3. Boron-10, cadmium, gadolinium and lithium- 6 have all very large capture cross-sections. This enables them to be used to create neutron detectors, or be used to in devices to control a reactor. In contrast deuterium, beryllium, carbon, oxygen and magnesium capture very few neutrons. Aluminium absorbs a little, but not too much. This makes these elements the materials of choice with which to construct a reactor, in particular heavy water and graphite as a reflector.

With such contrasting behaviour of the two isotopes of helium it is worth adding that firstly helium-3 is only present as 1 in $10^{4}$ in natural helium, which can thus be used in the neutron beam path (rather than a vacuum). Secondly, helium-3 is a by-product of the nuclear industry, and is very interesting for scientists. It is the only simple substance which absorbs neutrons and is a gas, hence usable to create a detector (see paragraphs later on detectors). This 
is of such importance that the ILL purifies this rare isotope routinely. In addition it was shown by Larry Passell ${ }^{50}$ in 1966 that the absorption of neutrons was dependent on the relative orientations of the spin of the neutron and that of the helium-3 nucleus. Only neutrons with spins anti-parallel to that of the helium-3 are absorbed. Hence if we fill a container of polarised helium-3 the container will be transparent to neutrons in one of the spin states, but would strongly absorb the other. It would therefore be a device for producing polarised neutrons. The advantage in this method, as distinct from others, is that it acts on neutrons with a wide range of energies. To achieve a working device requires preparing polarised helium-3 then concentrating it. This challenge has met with success by Francis Tasset in collaboration with several laboratories, principally the University of Mainz (E.W. Otten et al). This is not the place to describe the very complex technique required for a functioning system. The project to implement this on instruments at the ILL was financed by the SERC.

Having described absorption of neutrons and practical applications, I will now consider the second type of interaction, neutron scattering. In this case a description in wave terms ${ }^{51}$ is most appropriate. When the incident neutron wave encounters a nucleus, the wave is emitted where the amplitude varies from one nucleus to another, and can even be negative. If there are several adjacent nuclei these emerging waves can interfere. If the nuclei are atoms in a regular crystalline lattice this interference will give rise to a diffraction pattern, as in the case of X-rays. In the case of neutrons there is an added complication due to the interaction being with the nucleus. Most atoms have several isotopes having the same number of electrons, but different nuclei, hence the scattering amplitudes for scattered neutrons are different. Isotopes have no effect on diffraction of X-rays (where scattering is a result of the interaction with the electrons). In contrast there is a major effect with scattered and diffracted neutrons. Isotopes are randomly distributed in the crystal lattice, which blurs the results a little. Scattering includes two parts, one that corresponds to the diffraction pattern, called coherent scattering, and a part

50 L. Passell and R.I. Schermer, Phys. Rev. (1966), 150, 146-151, DOI 10.1103/PhysRev.150.146

51 All elementary particles as mentioned earlier are associated with a wave-like property. 
which does not contribute called incoherent scattering. There is also a second source of incoherent scattering: the dependence of the cross-section as a function of the relative spins of the neutron and the scattering nucleus. The combination of unpolarised neutrons and an unpolarised target produces a disorder scattering equivalent to that arising from a mixture of isotopes.

If the atoms of the sample are in a gaseous form, the interaction of the neutron is accompanied by recoil of the atom, and a loss of energy from the scattered neutrons. When the atoms are part of a crystal, and hence bound to their neighbours the motions are also connected. These collective movements are described by means of phonon waves propagating in the crystal with energy $\mathrm{E}$ and a wave vector $Q$. If a neutron is scattered from one of these atoms the scattering has two components: an elastic part as described above, and one called inelastic. In this second case the neutron can absorb energy, annihilating the phonon, or can create a phonon (if it possesses sufficient energy). Energy and momentum are necessarily conserved. Hence, scans changing neutron energy transfer or momentum transfer will show peaks in intensity of scattered neutrons which correspond exactly to these values for the created (or emitted) phonons.

\subsection{Neutrons and condensed matter}

The vast majority of applications of neutrons lie in this area. They make use of the following properties. From quantum mechanics we know that all elementary particles have at the same time both wave like and particle properties. Thermal neutrons have wavelengths of the order of 1 Ångström ${ }^{52}$. Cold neutrons have wavelengths of the order of $5 \AA$. These neutrons have energies comparable to phonon energies E. These two characteristics together of neutrons make them especially well-adapted to study simultaneously structure and internal motions of these structures. There are two fields where this is applied: diffraction, which employs the wave-like nature of neutrons, to determine average atomic positions (structure), and inelastic scattering, which depends essentially on the corpuscular nature of neutrons, to study dynamics.

52 One centimetre is equal to 100 million $\AA$ Angström ( $)$. 


\subsubsection{Diffraction}

Neutrons can fulfil the same role as X-rays, however, they have two benefits in certain applications which largely compensate for the low intensity of available beams. I have already mentioned the neutron's magnetic moment which makes them unique for determining magnetic structures. This was the first field of success for neutrons, worth the Nobel Prize received by Clifford Shull in 1994.

The other advantage arising from impact of neutrons with an atom is that they interact with the nucleus, whereas $X$-rays are scattered by the electrons orbiting the nucleus. As a consequence X-rays have an interaction 92 times greater with a uranium atom than with a hydrogen atom. The latter will contribute very little to a diffraction image from X-rays. On the contrary, with neutrons the contribution to this image from an atom of hydrogen and a much heavier atom are of the same order of magnitude. It is thus easier to see hydrogen atoms with neutrons than X-rays. There have been numerous applications of this. Very early, in 1969 Benno Schoenborn ${ }^{53}$ using the Brookhaven HFBR studied the protein myoglobin, completing the X-ray results of John Kendrew for which the latter was awarded a Nobel Prize in 1962. An additional advantage arises from the fact that hydrogen has a negative scattering amplitude while deuterium has positive amplitude. The applications in biology, which make use of this difference, have been described by Heinrich Stuhrmann ${ }^{54}$. While facilitating the location of hydrogen atoms the use of neutrons in life sciences has not had the development which might have been expected. This is mainly due to the outstanding quality of data that can be collected with X-rays thanks to powerful modern sources such as synchrotron radiation, which can locate hydrogen in simple molecules. There are, though, cases where hydrogen plays an important role in catalytic processes induced by proteins where neutron diffraction provides more detailed information (see, for example, work on endothiopepsin ${ }^{55}$ ).

\footnotetext{
53 B.P. Schoenborn, Nature (1969), 224, 143-146, DOI $10.1038 / 224143 \mathrm{a} 0$

54 H.B. Stuhrmann, Rep. Prog. Phys. (2004), 67, 1073-1115, DOI 10.1088/0034-4885/67/7/R02

55 L. Coates, P.T. Erskine, S.P. Wood, D.A.A. Myles, J.B. Cooper, Biochemistry (2001), 40, 13149-13157, DOI 10.1021/bi010626h
} 


\subsubsection{Small angle scattering}

These studies have expanded considerably. With this technique, one does not attempt to determine structure at an atomic scale, but rather shapes and sizes of a microscopic object. There are many applications in both pure and applied research for studying polymers, colloids, alloys (grain structure), superconductors, and viruses. Here too the main assets are the neutron sensitivity to hydrogen and magnetism as well as their ability to penetrate thick samples.

\subsubsection{Inelastic scattering}

The change of neutron energy is measured after impact with atoms in motion. As just mentioned, when the sample is a crystal these movements are quantised and are described in terms of phonons. The wave motion modes have characteristic energies $E$ as a function of wave vector $\mathbf{Q}$, which need to be analysed in each direction in the sample crystal. Measuring the neutron energy change after interaction with phonons can explore these dependences. There are numerous ways of performing these measurements which I will briefly describe a little further on. When the sample is a liquid the internal motions are described by a probability distribution $G(r, t)$ which gives the probability of finding an atom at time $t$ at a distance $r$ from its position at time zero. In 1954, Léon Van Hove showed ${ }^{56}$ that the angular distribution and energy of neutrons scattered by a liquid is related simply to $G(r, t)$. This theoretical work had a major impact on the use of neutrons for studying what is now known as condensed matter.

The simplest way to measure inelastic neutron scattering, in principle, is to use a monochromator crystal to select a neutron beam of a given energy. Neutrons of a specific energy are reflected in a direction defined by Bragg's Law:

$$
\lambda=2 \mathrm{~d} \cdot \sin \theta
$$

where $\mathrm{d}$ is the distance between the selected lattice planes and $\lambda$ a certain wavelength (hence specific energy). After

56 Leon Van Hove, Phys. Rev. (1954), 95, 249-262, DOI 10.1103/ PhysRev.95.249 
scattering by the atoms of the sample under study (also usually in the form of a single crystal) the final neutron energy is selected by a last reflection from an analyser single crystal. This method, known as triple axis spectrometry (Fig. 3.1 and Fig. 3.2) was developed by Bert Brockhouse $^{57}$. He showed that it was possible to measure the neutron intensity scattered as a function of the energy transfer $E$ associated with each wave-vector $\mathbf{Q}$. The intensity peaks when the $\mathrm{E}$ and $\mathbf{Q}$ changes match the creation or annihilation of a phonon. For this he was awarded the Nobel Prize in 1994. The principle of the method is shown graphically in Fig. 3.2.

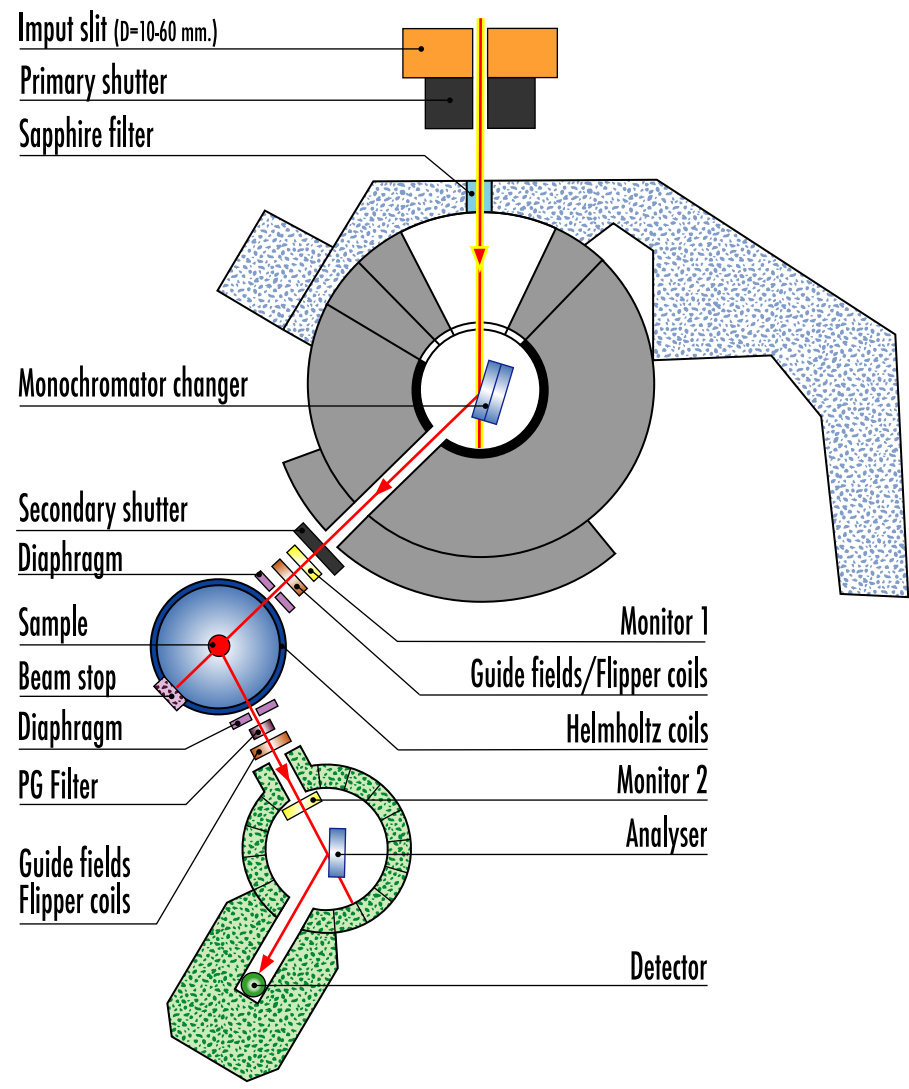

Fig. 3.1: Diagram of the IN20 triple axis spectrometer with polarised neutron options (guidefields, flipper coils, etc.) (updated layout).

57 B.N. Brockhouse, Phys. Rev. (1955), 98, 1171, M7, DOI 10.1103/PhysRev.98.1144. This very short note gives what is probably the very first description of a three-axis-spectrometer. 
Fig. 3.2: This diagram illustrates one of the uses of a triple-axis spectrometer which measures scattered intensity scanning energy associated with a fixed specific momentum transfer $Q$. Here the final energy (wave-vector $\mathbf{k}_{\mathrm{f}}$ ) is kept constant and the incident energy (wave-vector $\mathbf{k}_{\mathbf{i}}$ ) and the angles between the arms of the spectrometer are varied to satisfy the geometry represented in the figure.

Fig. 3.3: Layout of the inelastic scattering instrument IN5, a typical time-of-flight spectrometer (updated layout)

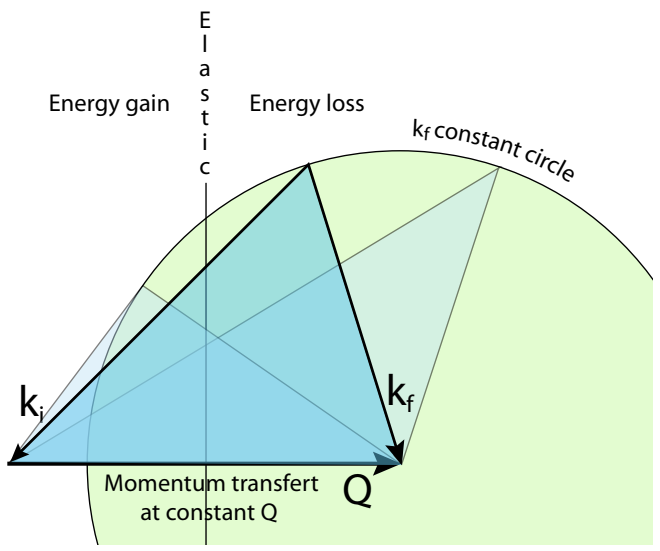

This method has been much used, and further developed at the ILL. Use of back-scattering at the monochromator and analyser developed at Munich and Jülich enables very small changes in neutron energy to be measured (see $\S 6.1$ ).

Another type of apparatus to measure inelastic scattering uses a measure of the time the neutron takes to pass from the sample to the detector to determine any change in energy, hence the name time-of-flight spectrometry. Monochromatic neutrons are selected by a rotating crystal monochromator; the timing can then be related to when this crystal passes through the Bragg reflection angle. A monochromatic beam may also be produced by a set of rotating disks with slits, which only allow neutrons with a certain speed to pass through.

Let us take the ILL instrument IN5 as a prototype of a time-of-flight spectrometer (Fig. 3.3).

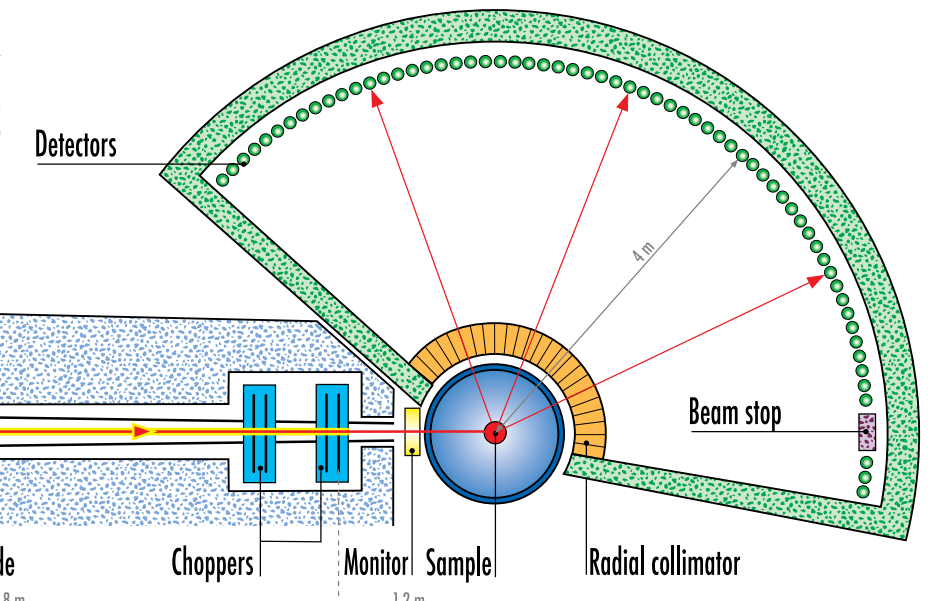


The incident polychromatic neutron beam comes from a $20 \mathrm{~cm}$ high cold neutron guide (peak flux between 4 and $5 \AA$ A). It impinges three pairs of contra-rotating discs (choppers) coated with neutron absorbing material, except for two opposite windows to allow the neutrons to pass. The choppers can rotate at up to $12000 \mathrm{rpm}$ with phasing accuracy within 0.5 milliradians. This assembly "chops" the beam into short quasi-monochromatic pulses as follows:

The beam is pulsed by the first pair of choppers. The pulses are funnelled down to a $5 \mathrm{~cm}$ high beam using supermirrors to the final monochromating chopper pair. Only neutrons of a specific speed (hence energy) can pass through these. Those with half or multiples of the speed are eliminated by the intermediate pair of choppers. The monochromatic neutrons are then scattered by the sample, and are sorted by arrival time and position at the detectors, giving the change in energy and momentum in the sample.

Since neutrons slowed by the sample can arrive during the time frame of the next pulse, this overlap can be reduced by rotating the $3 \mathrm{rd}$ and 4 th discs more slowly (in Fig. 3.3 the later are shown as two pairs of counterrotating disk choppers), suppressing an integer fraction of pulses and increasing the time between pulses, but with an inevitable loss of intensity.

\subsubsection{Polarised neutrons}

In many experiments, elastic and inelastic, it is necessary to use polarised neutrons, that is neutrons which mostly occupy one of the two possible states of spin $1 / 2$ (in the presence of a magnetic field the magnetic moment of the neutron may be either parallel or anti-parallel to the field). There are several ways of producing such beams where the mean magnetisation points in one direction. All methods depend on the differences occurring between the two spin states of the neutron when it encounters polarised material. This was suggested by Felix Bloch in 1936 (in a publication $^{58}$ of less than a page length) where he hypothesises the existence of the neutron's magnetic moment. In 1937 Hoffmann, Livingstone and Bethe ${ }^{59}$ produced a

58 F. Bloch, Phys. Rev. (1936), 50, 259-260, DOI 10.1103/ PhysRev.50.259

59 J.G. Hoffman, M. Stanley Livingston and H.A. Bethe, Phys. Rev. (1937), 51, 214-215, DOI 10.1103/PhysRev.51.214 
Fig. 3.4: Layout of the neutron spin echo spectrometer IN15 (updated layout) small number of the first polarised neutrons using the transmission of neutrons through iron magnetised with a magnetic field, a method proposed by Bloch in his article.

We now know how to polarise neutron beams efficiently. I presented above the use of helium-3, where the nuclear spins can be polarised by optical pumping. More often a crystalline ferromagnetic monochromator or a polarised mirror (or super-mirror) is used. To detect the polarisation after scattering a similar device is used. Using a specific magnetic field configuration (a spin flipper) it is possible to invert the polarisation direction of the neutron.

\subsubsection{Neutron spin-echo}

This technique was invented in 1972 by Ferenc Mezei ${ }^{60}$ and allows very small changes of neutron energy to be measured. The principle is shown in Fig. 3.4. It is totally different from other inelastic scattering instruments, and is worth a brief description. A velocity selector (a rotating drum with helical slots) roughly monochromatises the beam of neutrons. The neutrons are first polarised parallel to the direction of the beam using a super-mirror. They then pass through a flipper where the polarisation direction is turned through 90 degrees. Then they pass along the axis of a solenoid with the field along the propagation direction of the neutrons. In this field the spin direction of the neutrons rotates about this axis (the phenomenon known as Larmor precession). The angle depends on the speed of the neutron. After the solenoid the neutrons pass

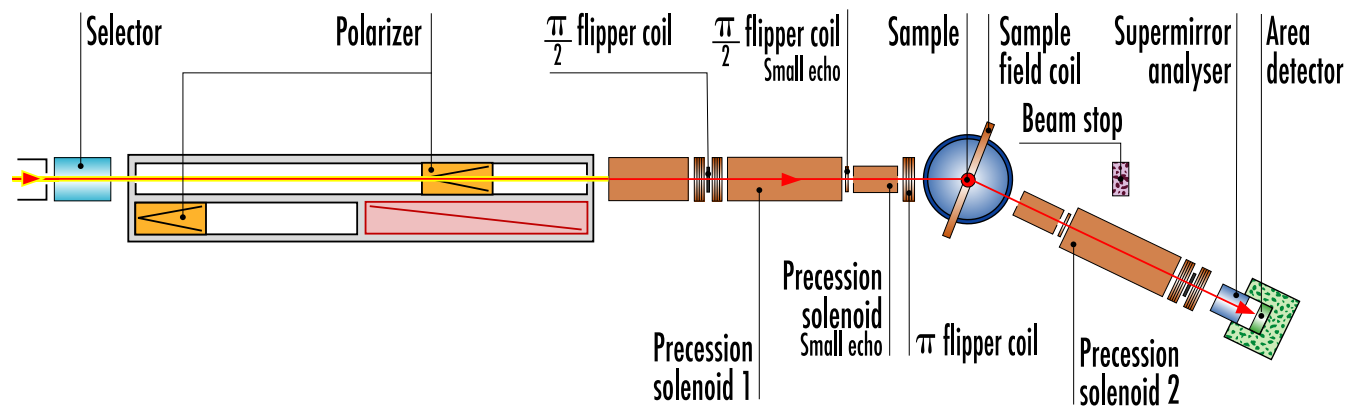

60 F. Mezei, Z. Physik (1972), 255, 146, DOI 10.1007/BF01394523 
through another flipper which turns all spins by 180 degrees, after which the second part of the apparatus is identical to the first. In the second solenoid the neutrons are re-polarised. After another rotation by 90 degrees the final polarisation is measured.

In the absence of a sample the final polarisation is identical to the initial polarisation. The presence of a sample between the two solenoids can change the velocity of the scattered neutrons, modifying the precession in the second solenoid; the polarisation will hence be different from the initial polarisation. Mezei showed that measuring this change of polarisation allows a very precise determination of the velocity change. The name of the method spin-echo comes from the muchused nuclear magnetic resonance technique. The resolution attained in the first version of these instruments was about a factor of 10 better than that available with back-scattering techniques. More recent versions using longer wavelength neutrons have improved this by another factor of 10 .

Neutron spin-echo is an ultra-sensitive method which, alone, allows measurement of very slow motions like the reptation of macromolecules. This wriggling motion was proposed by Pierre-Gilles de Gennes to explain the behaviour of polymers, and the first definitive experimental confirmation came from neutron spin-echo measurements ${ }^{61}$.

In practice scientists rarely use a single method to observe the dynamics of matter, and they try and cover the largest possible energy range (speed of motion) by combining inelastic scattering measurements from triple axis spectrometers, backscattering spectrometers, and spin-echo, but also inelastic scattering of X-rays.

\subsection{Nuclear and fundamental physics}

The nuclear physics experiments based around a reactor relate partly to the study of fission. Fission products are analysed to determine their mass and charge. Other experiments study the radiation emitted by a nucleus when a neutron is captured. This may consist of $\gamma$-rays

\section{8 addition:}

Why is this important? The triple axis and timeof-flight spectrometers are able to observe atomic and molecular vibrations but other movements in matter being much less energetic, many efforts were made to improve the energy resolution of instruments. The backscattering technique (see the end of § 6.1) gives an improvement of 100 to 1000 . Spin-echo goes even further and thus was the first technique able to observe the very slow motion of macromolecules.

61 D. Richter et al., Phys. Rev. Lett. (1990), 64, 1389-1392, DOI 10.1103/PhysRevLett.64.1389. 
2018 addition:

the proportion of experiments is now $40 \%$ for magnetic structures and $15 \%$ for biology and biochemistry. or electrons, called conversion electrons, ejected from the nucleus. Instruments have been constructed at the ILL to study both types of radiation.

The neutron is itself an elementary particle, and it is important to study its properties. We will see later in the review of the ILL that neutrons have made fundamental contributions as much in quantum mechanics as the Standard Model of elementary particles and its possible limits.

\subsection{Neutrons are indeed indispensable!}

I have cited these examples of applications of neutrons to demonstrate even the most basic of physics can be studied with these particles. However, most of the 700 or so experiments performed each year at the ILL relate to the determination of magnetic structures, the precise location of hydrogen atoms in organic molecules, including proteins, and the study of motion in solids and liquids, all performed with this particle, now becoming familiar to many scientists. These measurements would be mostly impossible with any other technique.

This presentation shows the great variety of areas where neutrons are useful. This huge range justifies the large investment required to construct a high flux reactor.

I will give further examples in the last chapter which will review the operations of the Institut Laue-Langevin. As will be seen, with hindsight, this relatively heavy investment has been justified. 


\section{Chapter 4}

\section{The negotiations}

This was a long process since the act officially creating the ILL was not signed until 17 January 1967. It has to be understood that the Geneva Agreement of 1964 was concluded on the basis of a very immature project, and that if there was a desire to build a Franco-German neutron source in Grenoble ${ }^{62}$ the nature of the source and detailed planning and precise financial costing remained to be clarified. At the time of the Geneva Conference it was not known if such a source would cost FF $50 \mathrm{M}$ or $500 \mathrm{M}$. Ministers declared ${ }^{63}$ that negotiations should not dwell on this point, and this would be examined later. It was also necessary to define the legal basis for the construction of such a joint source.

Several groups therefore set to work:

1. a group developing a draft design of the source

2. groups to identify the needs of the physicists and other scientists

3. a group developing the legal framework and the contract defining the articles of incorporation of the new institute

There was inevitably overlap between these activities and some coordination between groups was necessary. Firstly, the two countries had to designate those who would be in overall charge of setting up the new groups.

I think everything was launched at a meeting held on February 22nd or 23rd, 1965, in Grenoble. On the German side, accompanying Maier-Leibnitz, were Heinz Beckurts from Karlsruhe, Tasso Springer and Peter Armbruster from Jülich, and Fiebiger from Frankfurt. I was unable to find a document naming the participants on the French

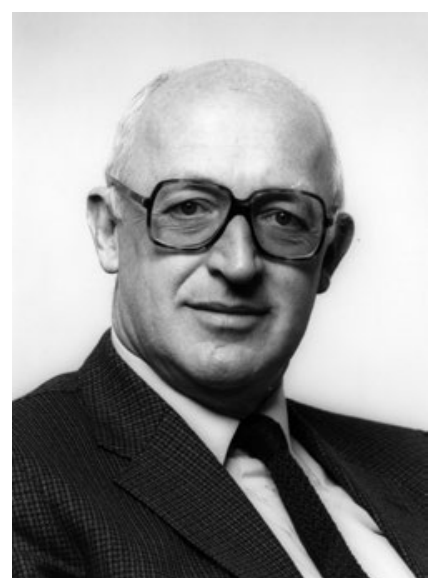

Fig. 4.1: Heinz BECKURTS

\footnotetext{
62 A site in Germany was proposed by certain Germans, but was finally dropped and never arose in the Franco-German discussions.

63 This is mentioned in the Maier-Leibnitz - Springer discussions, and is undoubtedly true; one could not invent this kind of thing.
} 
side. Besides Néel, and myself, there was, without any doubt Dautray, and most likely Ageron and Deniélou. During this meeting Dautray presented a draft he had drawn up following a request from Horowitz (personal communication from Dautray). Maier-Leibnitz endorsed this draft and designated Beckurts ${ }^{64}$ as the German representative for the creation of the detailed reactor design.

\subsection{The neutron source}

Dautray and Beckurts immediately set to work on the reactor project. Both had existing groups to help. Kouts who had built the HFBR at Brookhaven spent much of 1966 at Saclay bringing all his experience with no reservations. The Soviet knowledge was also very valuable. In June 1966 a group led by Pierre Balligand (Néel's assistant at the CENG) and comprising nearly all the French who participated on the design team, visited the USSR to see what was being done on research reactors, and to discuss the fuel element.

The idea of a pulsed reactor was quickly abandoned for the reasons I have already mentioned above. However, Maier-Leibnitz always regretted dropping the Ispra group which continued their own activities towards a pulsed reactor project. In Dautray's notes and his questions where I have written records there is never any questioning of a static source. There remained many other choices to be made. The year 1966 was filled with meetings to make decisions on various aspects of the design.

\subsubsection{Choice between light and heavy water}

The most important decision concerned the choice of using ordinary water or heavy water as coolant for the reactor core. The source presented at Geneva used ordinary water. This was the logical consequence of choosing a swimming pool option. Heavy water offers some distinct advantages. These result mainly from the better neutron properties of deuterium compared to hydrogen. It has a capture cross-section about one thousand

64 Heinz Beckurts later worked for Siemens and was murdered in July 1986 by the Red Army Faction. 
times smaller. The notion of reactivity helps explain this advantage. During a fission event about two neutrons are emitted from each nucleus of uranium-235. In order for the chain reaction to continue at least one of these neutrons must induce a new fission process. Neutrons are lost because they are absorbed by the other matter in the reactor, or by escaping from the confines of the reactor. This leads to the idea of a critical mass or size which must be attained to reduce these losses and allow the chain reaction. This critical mass can be reduced by placing a reflector around the core which scatters back a fraction of the neutrons which would otherwise be lost. When the chain reaction is being established the reactivity excess is greater than 1 for neutrons inducing a new fission. In continuous operation this reactivity excess is zero and the reactor is controlled by introducing or withdrawing neutron absorbing material.

Replacing light water by heavy water for cooling the core obviously gives a greater safety factor in operation. When restarting after an interruption there is a xenon ${ }^{65}$ build-up. With light water about 36 hours must elapse for this xenon poisoning to decay, or have negligible effect on the reactivity. In a reactor cooled by heavy water the greater reactivity margin allows a restart at any time. This is of some importance in the case of unplanned stoppages (for example an electricity supply failure) As fewer neutrons are captured by the cooling water, for a given power there are more neutrons in the reflector where the experiment beam tubes end, hence more neutrons for the instruments, which is quite a powerful argument. In addition the maximum in the flux of thermal neutrons is a little further from the core, which allows space for a greater number of experimental beam tubes to see this zone. Evidence gathered in current times suggests that the idea of a massive throughput of water at high pressure through a fuel element immersed in a reflector tank of heavy water was rather risky (what would assure the absolute seal between the two media?); this was the prime motivation for the choice of heavy water as coolant.

While the solution with heavy water coolant was thus better, it led to an increase in the cost of the reactor,

65 Amongst fission products is xenon-135 which absorbs neutrons very strongly and has a half life of 9.2 hours. 
principally due to the greater volume of heavy water needed, estimated at the time as FF $20 \mathrm{M}^{66}$ (about $10 \%$ of the total cost).

The budget for the Institut was estimated (meeting January 12, 1967) at FF 228M divided as follows:

\begin{tabular}{ll}
\hline Reactor with light water cooling & FF 102M \\
Site development & 17.5 \\
Reactor Building & 10 \\
Equipment & 48.5 \\
CEA provisions & 20 \\
Personnel (40 staff during 4 years) & 10 \\
Contingencies & 20 \\
Additional costs for heavy water coolant & 20 \\
\hline
\end{tabular}

Technically, it is easier to use light water as coolant in a swimming pool reactor. For this reason, and based on experience with the SILOE reactor, the CENG tried to impose the choice of light water cooling. Beckurts was in favour of the heavy water option, supported by Kouts and Dautray. The difficulty for implementing the latter was further complicated by the wish of the future users to have demountable beam tubes so that the reactor configuration and experiments were not fixed for all time. This required designing joints with seals to provide the necessary water tightness, though both water circuits were at atmospheric pressure. Our Brookhaven friends thought that this disassembly would be unachievable.

A conference was held 19-23 September 1966 at Santa Fe (New Mexico, USA) by the American Atomic Energy Commission $^{67}$. Various possibilities for intense neutron sources were compared there, including continuous reactors, pulsed reactors and sources not employing fission. In an introductory review Robert Dautray presented all high flux reactors then in operation (Brookhaven HFBR), under construction or consideration (Oak Ridge HFIR irradiation reactor, the British

66 Then the Franc was roughly worth that of the Euro today. 2018 addition: by January 2018, the ratio was roughly $€ 1.3$ for FF 1 . 67 "Intense Neutron Sources: Proceedings of a United States Atomic Energy Commission/European Nuclear Energy Agency Seminar", Santa Fe, New Mexico, 19-23 September 1966; CONF-660925. Physics TID-4500. 
project, and the Franco-German project at Grenoble) and the experiment of operating one of the reactors at Savannah River temporarily at high flux. This comparison showed up the limitations of continuous reactors; each of these was then presented in detail. The future ILL project was presented by Robert Dautray and Karl Beckurts; the two water options had been compared. In their conclusions they noted:

Our study has revealed that the design objectives can be met by both the $\mathrm{H}_{2} \mathrm{O}$ and the $\mathrm{D}_{2} \mathrm{O}$ cooled version. There are many features common to both versions. There are, however, characteristic differences: the $\mathrm{H}_{2} \mathrm{O}$ version has a simpler cooling circuit, offers simpler fuel handling and is less expensive; it will also be somewhat simpler to operate. The $\mathrm{D}_{2} \mathrm{O}$ version has a larger high-flux volume available for experiments and somewhat lower backgrounds. The fuel is at a lower temperature level, making a later increase of flux and power possible, and the problem of the core shroud ${ }^{68}$ is less severe. The fuel cycle costs will be slightly lower, partly due to lower power, partly due to the longer duration of the fuel cycle. On the basis of the results of this study, the steering committee of the project will make a decision on the coolant medium within the very near future. After this, the preliminary design can be rapidly completed and it is hoped to pass some design contracts to industry in the not too distant future. Scheduled completion date for the reactor is late 1971.

There are no definitive conclusions but Dautray and Beckurts, supported by Kouts, the father of the Brookhaven reactor, favoured the heavy water option that is best for the users. This choice led to severe criticism from the CENG towards Dautray, but was afterwards supported by Horowitz.

This was not yet the final choice, and at its first meeting, the steering committee on 19 January 1967 again had a debate on the subject. The Germans insisted on the aim of realising the best possible reactor, which was with heavy water cooling. The final decision was taken at the following meeting of the steering committee on 16 March 1967. Achieving 35 years of operation [ 49 years in 2019] without any incidents linked to the coexistence of heavy water

68 This is the barrier which separates the light water coolant at 12 bars from the reflector of heavy water at about atmospheric pressure. 
More than 10 years after this sentence was written the ILL still uses aluminium. Thanks to the experience gained, the lifetime of all the heavily irradiated aluminium parts is now well known and thanks

to some improvements to the already excellent design (see Chapter 8), they can all be replaced during scheduled maintenance operations. As a result, it has been possible to extend the lifetime of the reactor considerably while remaining in full compliance with the safety rules.

:2018 addition with ordinary water showed this was a wise decision. The ability to remove beam tubes, as requested by the users has proved very useful as it was found that, under the influence of radiation for a decade, the aluminium alloy used to fabricate beam tubes became embrittled. It was then necessary to replace them, an operation foreseen in the original design. This embrittlement had been taken into account in the project. Dautray had actually asked for an analysis of the vessel of the Pegasus reactor operating at Caderache, and an extrapolation to predict the lifetime in the RHF. The alloy used for the RHF was aluminium-magnesium AG3Net. The studies showed the necessity for a replacement of the core assembly ${ }^{69}$ every five years, and this was incorporated into the reactor design. This fragility of heavily irradiated aluminium is well-explained in the report at the Santa Fe conference. At present the ILL is studying the possible use of Zircaloy for this assembly.

\subsubsection{The reactor building}

The coolant choice was of primary importance since this influenced the whole reactor design. Choices concerning the building were less demanding, though MaierLeibnitz thought it was of great importance. The building enclosing the reactor at Munich was and is very elegant in the form of the nose of a rocket (Germans speak of it as an egg). Maier-Leibnitz hoped that the ILL would be as beautiful. He also wanted to be able to mount cumbersome instruments within the building. As other experiments might use less space he insisted that the reactor was placed off-centre in the building. In fact in the draft presented at Santa Fe the reactor is quite off-centre. This would have led to great problems in providing adequate handling means (overhead cranes, etc). There were bitter and sterile discussions on this subject which lasted up to April 1967. Finally, it was decided to construct a very large building, about $60 \mathrm{~m}$ in diameter which would leave about $25 \mathrm{~m}$, as demanded by Maier-Leibnitz, between the central reactor and the walls; it is indubitably a world

69 This assembly comprises the fuel element, the reflector tank containing heavy water, the beam tube nose-pieces close to the fuel element, and the integrated sources (cold source and hot source). 
record. Aesthetics were sacrificed to technological imperatives. The new reactor at Garching too lacks the beauty of its predecessor. I see in my notes that during a meeting with Chatoux, 1 February 1968, that Maier-Leibnitz again insisted on the need to study a self-supporting building, as had been constructed at Garching.

Another problem for the building was that it had to have a sealed atmosphere. This was discussed at length at a meeting in Munich on 6 June 1966, where Kouts was present. It would be necessary to take into account a possible meltdown of the fuel element (which has never occurred). It was essential that the building was fully air tight and could withstand an over-pressure of $1 / 7$ atmospheric pressure. Kouts insisted on this need in Grenoble due to the proximity of households. Dautray was in complete agreement. This air-tightness is achieved with a double containment: an inner volume with $40 \mathrm{~cm}$ thick walls of reinforced concrete, and an exterior shell in $11 \mathrm{~mm}$ steel resting on a sunken base again in concrete. This type of double containment is now proposed for electricity producing reactors.

\subsubsection{Various problems}

It should be appreciated that the Grenoble RHF is the result of a series of technical innovations. The average specific power is $1.15 \mathrm{MW} /$ litre rising to hotspots up to $3.3 \mathrm{MW} /$ litre, values far higher than in reactors for electricity production. The design of the core was of prime importance. The concept of the core of the Oak Ridge HFIR has been re-used. In this American reactor, which was aimed as an irradiation facility with the highest flux possible, the core is cylindrical with radial vanes and a central cylindrical cavity for the irradiations. In the Grenoble case this cavity serves to accommodate the control rod (as in the patent for a swimming-pool reactor of Horowitz and Raievski in 1960). The technical specification of the reactor will be given later when I write about its construction.

\subsection{The future users}

Maier-Leibnitz and myself were responsible for discussions with other users. In particular for this activity there 
was always close consultation with Louis Néel, whom Maier-Leibnitz visited at the start of 1965 . The idea MaierLeibnitz had for the Institut, and with which I was in total agreement, was quite novel for that era. The aim was to create a pile and the beam instruments to be used primarily by visiting scientists coming from different laboratories in France and Germany. Often these visitors would not have previous experience of the use of neutrons. It was essential that the Institut had a team of researchers firstly to build instruments and then help visitors as a collaborator or "local contact". Correspondingly, it was necessary to involve the scientific community in the choice of instruments to build.

Instrument construction would begin at the same time as the reactor to ensure these would be ready at the start of operations. The community had to be consulted at the same time that the reactor design was being finalised. According to my records the first such meeting was held on 3 and 4 May 1965, well before the formal establishment of the ILL, at Spitzingsee, a mountain resort about $65 \mathrm{~km}$ from Munich. Bertaut and Springer were present as researchers having experience in the use of neutrons, but in addition there were others new to the field of great scientific renown. I remember that on the French side were Jacques Friedel and André Guinier who had created the Solid State Physics laboratory at Orsay. In short, it was a forerunner for what would later become the scientific council of the ILL. The wide variety of neutron applications led to the creation of more specialised working groups to define instruments for diffraction, inelastic scattering and nuclear physics. I'll continue with this later.

\subsection{The contract}

The construction of a reactor at an estimated expenditure of 200 million francs and the cost of a Franco-German Institute with a number of staff to one day reach the figure of several hundred, required a clear legal framework. This legal framework was defined by two texts, an agreement signed between the two governments saying:

The Government of the French Republic and the Government of the Federal Republic of Germany are eager to continue the implementation of the Franco-German Treaty of 22 January 
1963, in particular the development of scientific collaboration between the two countries. Taking into account the interest of research that has already been done in France and Federal Republic of Germany in the field of nuclear physics and solid state physics,

- noting that in Europe the new facilities are necessary for the development of such research,

- wishing that other European countries can participate in the actions they propose to undertake in common,

- have agreed to promote for peaceful purposes the construction and operation a reactor with very high neutron flux and are therefore agreed to the following arrangements.

The two Governments undertake to make available to the members:

- one, a sum of 163 million French francs (132 million DM) to cover the cost of construction of the reactor.

- secondly, up to 43 million French francs (35 million DM) as an annual subsidy to cover operating expenses.

The original full text of this convention is given in Appendix 1.

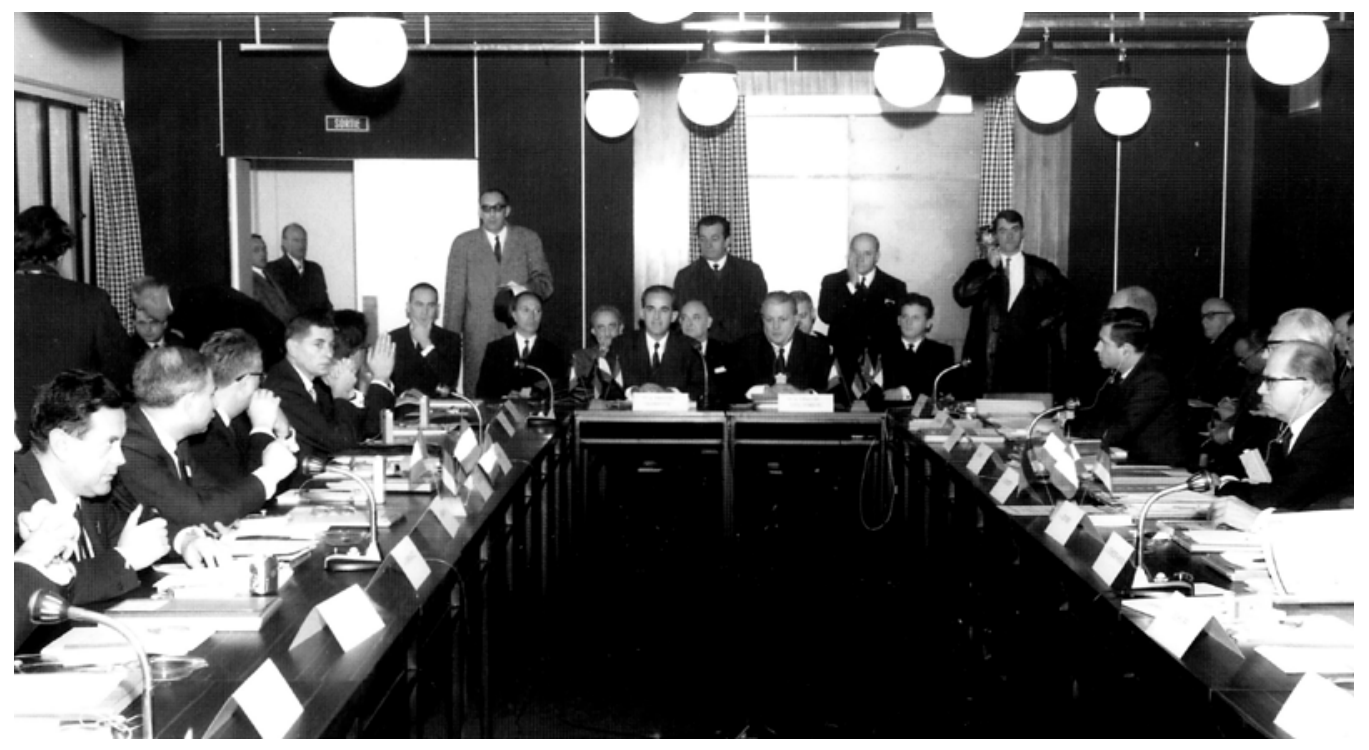

Fig. 4.2: Signing the agreement creating the Institut Max von Laue - Paul Langevin. The two ministers (Monsieur Peyrefitte and Monsieur Stoltenberg) are seated directly ahead. Others present include Francis Perrin (High Commissioner CEA), Horowitz, Abragam, Eiserman (Head of Project), etc. 
These provisions specify that the operation of the reactor, object of the Convention, is entrusted to a Private Company whose shareholders are the Commission for Atomic Energy (CEA), the National Centre for Scientific Research (CNRS) and the Nuclear Research Centre, Karlsruhe (GfK). This company is to be known by the name "Institut Max von Laue - Paul Langevin". It clearly states that the activities are for peaceful purposes, and that the Director must be a renowned scientist proposed by the German partner. This agreement was signed on 19 January 1967 in Grenoble by the two ministers responsible, namely Monsieur Stoltenberg and Monsieur Peyrefitte.

Some comments on the text may be helpful. The first is that the French party is an association of the CEA and the CNRS. I think the inclusion of the latter is due to Néel's initiative, because it is consistent with his policy of always associating the two in Grenoble. In his memoirs Néel writes of contacts (unspecified) he had in 1966 with the leadership of the CNRS. The Director-General Professor Jacquinot was certainly in favour. If certain other officials (I am thinking of Hubert Curien, then Director of Physics) agreed too, the body of scientists was obliged to join the enterprise. Antagonism from some of the physicists, who were somewhat shocked by the cost of the ILL, quickly led to the renaming of the project "Réacteur à Haut Flux" to "Réacteur superflu" (superfluous reactor). The concerns of part of the scientific community were included in a very biased article published by the weekly L'Express, 26 September 1971, entitled "An experiment for nothing". This hostility was quickly dispelled when the scientists realised that the new facility would be different from the reactors at Saclay and not just serve a limited group of specialists but could be useful for all of them. The balance sheet for the CNRS and the ILL seems positive overall. Most of the French users come from laboratories of the CNRS.

My second comment concerns the name of the Institut. Originally Maier-Leibnitz had proposed to name it "Institut Langevin ${ }^{70}-$ Laue $^{71 "}$ ", then "Institut Laue-Langevin". The latter title was rejected by the French because of the

70 Paul Langevin (1872-1946) French physicist: inventor of Sonar, worked on relativity and magnetism.

71 Max von Laue (1879-1960) German physicist: discovered the diffraction of X-rays by crystals for which he was awarded the Nobel Prize in 1914. 

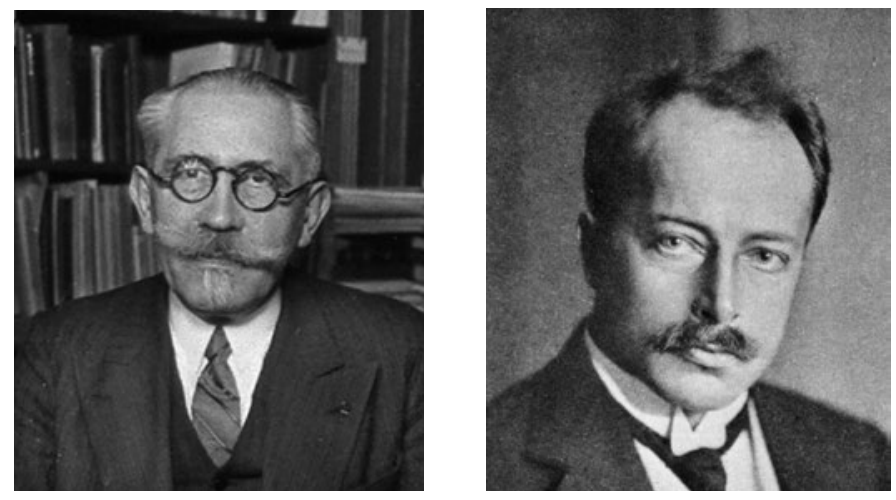

Fig. 4.3: Paul LANGEVIN and Max von LAUE

name Langevin being associated with the communist past of Langevin; it was only considered acceptable, if it was accompanied by his first name ${ }^{72}$. Hence the current official name. Remarkably, however, in both the texts signed by the ministers on 19 June 1967, the institute they created is named "Institut Max von Laue - Paul Langevin", but in the statutes, signed by the associates it is entitled "Institut Paul Langevin - Max von Laue". The anomaly was remedied in the amendment to the articles signed on 19 July 1974, when the third partner, the British SRC joined. In practice, despite wranglings over the uses of the forenames, these are usually dropped and the institute is simply known by all as the ILL or "Institut Laue-Langevin".

Another comment concerns the sane restriction to limit the activities to purely peaceful aims. This clause was included at the request of the Germans (meeting on 28 June 1966). The ILL has a detritiation plant for the heavy water, and thus produces relatively large amounts of tritium. Civil uses of tritium have almost completely disappeared, so this isotope is difficult to sell. On the contrary it has a very high value for military use (in the hydrogen bomb). Such usage is prohibited through this clause in the agreement. With the project ITER aimed at testing the use of nuclear fusion to produce energy this tritium may find a useful outlet in the civil domain.

A last important point is that the ILL is a private company under French law, and that the labour laws of France apply, notably requiring a works committee and

72 This remains a personal memory; I have no documents on this problem of forenames. 
personnel representatives ${ }^{73}$. In addition it requires the personnel to pay French taxes. This is a major difference from CERN or the EMBL, which have statutes of international organisations where the staff does not pay tax. There is no doubt that this status as a private company with salaries analogous to those at the neighbouring CEA greatly helped the relationships between the scientists of the ILL and those of the CENG.

The increase in expenses resulting from monetary inflation made it necessary to add an amendment to this agreement. This amendment signed on 6 July 1971, shortly before the start of the reactor, states that "a sum of 335 million francs is available for construction of the reactor, the instruments and the operating costs of the institute during the study and building phase". This amendment takes into account Maier-Leibnitz's wishes that the instruments should be constructed at the same time as the reactor. It also refers to "an annual subsidy to cover operating costs capped at 53 million French francs for the first year of normal operations which will be in 1972 at the earliest". I'll return later to the various modifications which were made to the agreement during the life of the ILL.

The second is the text of the Articles of Incorporation of the company "Institut Paul Langevin - Max von Laue", which was also signed on 19 January 1967 by the representatives of the three partners the GfK, the CNRS and the CEA. These statutes define the structure of the company, the Steering Committee (coming from the partners), the Director, and the Accounting Control Board. They also create a Scientific Council. The functions of each are specified here. For the Germans the Director has full powers. It was essential for the Germans that the Council had a purely consultative role. A compromise was found removing the casting vote of the Director, and the veto of the Council. In reality throughout the life of the ILL there has never been, to my knowledge, any conflict between successive directors and the Scientific Council. Originally, the Council was chaired by the Director. Since the 90s the chairman has been appointed from one of its members named by the directors of the ILL; William (Bill) Stirling was the first president named.

732018 addition: These are now replaced by the "Comité Social et Economique" (CSE). 
The first meeting of the Steering committee was held from 6 January 1967 in Bad Godesberg, that is even before the Institut was officially established. The following were appointed at this meeting: the president (Dr Pretsch), the vice-president (Néel), the first secretary (Balligand), the second secretary (Hasenclever), the Director (MaierLeibnitz), the Deputy Director (Jacrot), the project manager (Dautray) and deputy project manager (Eisermann). The team which would build the reactor and the ILL was formally announced. The members of the Scientific Council were also named: for France Bertaut, Cribier, Dautreppe, Dreyfus, Herpin, Guinier, Moussa, and Niefenecker; for Germany Armbruster, Beckurts, Dachs, Fiebinger, Fulde, Springer and Wiedemann. The first proposals were made for the choice of industrial architect, and finally the need for a budget for the management of the institute and the project manager was discussed.

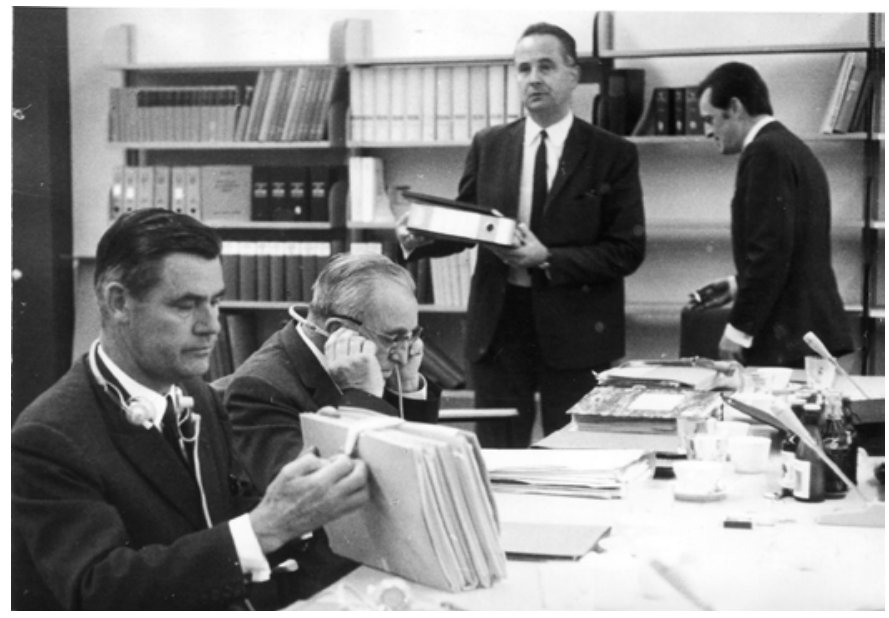

Setting the budget was one of the tasks of the committee during the second and third meetings, on 16, 17 March and 3, 4 July in Paris. For 1967 this was set at 47.2 million francs broken down as follows:

\begin{tabular}{ll}
\hline Operating expenses & FF 7M of which FF 4.8M for the project team \\
Site and infrastructure & FF 5.2M \\
Building & FF $9.8 \mathrm{M}$ \\
Reactor & FF $22.3 \mathrm{M}$ \\
Instruments & FF $1.8 \mathrm{M}$ \\
Contingencies & FF $1.1 \mathrm{M}$ \\
\hline
\end{tabular}

Fig. 4.4: Taken during one of the first meetings of the Steering committee shows W. Hasenclever (standing) with Néel and Balligand in front of him. 


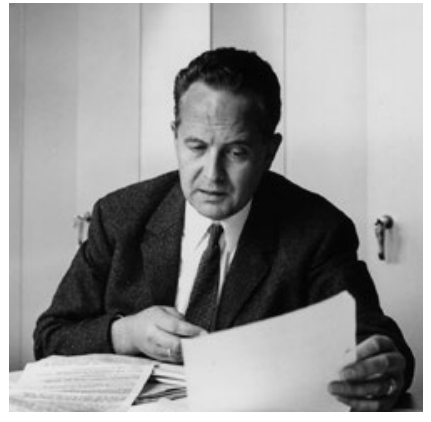

Fig. 4.5: Wolfgang HASENCLEVER
The budget for the project team is for 43 people in the basic team plus about 30 other contract workers. The Building item covered all buildings. During the committee's March meeting FF $11.1 \mathrm{M}$ had been authorised. It was also then that Wolfgang Hasenclever was nominated as chief administrative officer of the ILL. The latter, aged 35 came from Jülich. He was full time in Grenoble from July 1967. Results showed that this was a good choice by Maier-Leibnitz, and the success of the ILL owes much to Hasenclever; while being firm, he was always considerate to the staff.

The budget presented by the Institut was approved at the meeting in July 1967, where the committee also endorsed the replacement of Dautray (called to other CEA activities) by Jean Chatoux as project manager. I remember my reservations over this change; Dautray had been excellent, and, at that time, I knew little of his replacement. Dautray then told me that he thought Chatoux would be better than himself for the construction phase. I do not know what might have happened with Dautray, but Chatoux was certainly excellent.

It would be tedious to go through the various meetings of the Steering Committee and the Scientific Council which took place during the project period and construction leading up to the initial criticality of the reactor on 31 August 1971, and to full power in December the same year. They took place at least twice a year, and for the Steering Committee even 4 times a year during the construction phase. 


\section{Chapter 5}

\section{The construction of the reactor and the scientific groups}

The life of the Institut began in 1967 in a few rooms loaned to us in the CENG. The report by the Director of the Institut for 1967 stated that at the end of the year there were 10 staff ( 7 scientists including 2 postgraduate students $^{74}$ ) working in Grenoble (two partially at Saclay), and 6 at Munich. Maier-Leibnitz was very insistent on creating a temporary group of theoreticians located in Munich, awaiting development of this activity in Grenoble. The year 1968 was particularly interesting. There was a significant increase in staff, which by 1 March had risen to 48 people in Grenoble. I have already mentioned engaging Hasenclever who was able to organise the start of the administration of the ILL. He was also able to contribute to the relations between the Management of the ILL and the Steering Committee. Michel Jacquemain was recruited in September 1967 as responsible for all technical services. Yves Droulers was made the future head of the reactor in April 1968. Both had come from the Reactor Department at the CENG. They played an important role in the relations with the project group (see below). Later, in reports drafted by the SRC representatives, they attribute a large part of the success of the Institut to the very early recruitment of suitable leaders.

At the end of that year Maier-Leibnitz wrote a text for the Steering Committee entitled "The role of the high flux reactor in solid state and liquid research"75. It began with a review of how this work was conducted at Oak Ridge and

742018 addition: The $1^{\text {st }}$ thesis student was the theoretical physicist Konrad Matho (1967-1972). Since the theory group of Peter Fulde (Munich) never moved to Grenoble, Konrad mainly worked at the CNRS/CRTBT, then at Orsay. He was the first student representative at the first steering committee.

75 The full text is given in Appendix 2. 
Brookhaven and made the following criticism of use of both reactors:

1. Except at Brookhaven these reactors are not dedicated to the output from the neutron beam tubes, and hence are not optimised for this type of research.

2. Experiments are performed by specialists in neutron physics rather than by solid state physicists.

3. There is weakness in theoretical physics at the reactors.

4. There are insufficient physicists at the reactors.

5. There is no organisation of facilities for visiting scientists.

6. The instruments are very conservative and sub-optimal.

This analysis is followed by a list of the benefits of the facilities of the ILL, and proposals to avoid the ILL from suffering faults seen elsewhere. These proposals are important since they define what the ILL should be. In practice the essentials in these proposals were actually realised.

The specific advantages expected from the reactor of the ILL were:

1. It was a reactor designed to provide neutron beams as a prime function.

2. With a diameter of $60 \mathrm{~m}$ the scientists would have more space for their instruments. The level of the instruments is the same as the surrounding ground which allows the neutron beams to pass outside the building, and by employing neutron guides allow instruments to be sited at a large distance from the core of the reactor hence in a region where the background is minimal.

3. Quoting Maier-Leibnitz: "The reactor, with its protective shield, the neutron guides, the cold source, the hot source have all been developed in collaboration with the experimenters, the future users of the reactor. We hope to install an optimum number of instruments (perhaps 40) around the reactor".

Maier-Leibnitz then described in detail the organisation of the scientific work which he considered necessary to make best use of these inherent advantages of the design of the Grenoble reactor:

1. about 200 scientists comprising $50 \%-70 \%$ visitors,

2. an annual budget, excluding reactor, of FF $25 \mathrm{M}$, 
3. a drawing office and workshop, working in conjunction with the CENG and the CNRS laboratories in Grenoble,

4. hosting facilities to ensure all necessary aid for visitors,

5. a group of theorists.

All this has been achieved and has contributed to the success of the ILL. One point in the scientific organisation which is not mentioned in this text of Maier-Leibnitz, but which played a part in this success was the absence of a rigid hierarchical structure. There has never been a nuclear physics department with a head and allocated room space. From the beginning there was a nuclear physics college involving physicists who worked on the instruments in this field. The term college appears in the annual report for 1971 to describe the scientific activity of the nascent Institut. The colleges served to construct and run the instruments decided on by the various subcommittees of the Scientific Council. There were 10 colleges:

\begin{tabular}{ll}
\hline College 1 & Theory, at Garching (Munich) \\
College 2 & Theory, at Grenoble \\
College 3 & Nuclear Physics \\
College 4 & Properties of pure crystals \\
College 5 & Crystallographic and magnetic structures \\
College 6 & Liquids, gases, and amorphous solids \\
College 7 & Imperfections in crystals \\
College $8 / 9$ & Biology, polymers, chemistry \\
College 10 & New projects. \\
\hline
\end{tabular}

Maier-Leibnitz established this structure of colleges to encourage discussions between scientists engaged in the construction of instruments designed to answer the scientific questions in the appropriate college. They evolved naturally leading to a scientific life within the Institut and the collaborations with visiting researchers. It is interesting to note that the list and numbering of the colleges has remained little changed to the present day, except for college 1, which disappeared with the Munich group. Due to this, the list of colleges started with college 2. More recently a college 1 has been re-created for instrumental techniques and the college 10 "New projects" has been replaced by "Structure and dynamics of soft-condensed 
matter", a topic that really emerged after the beginning of the ILL (the term "soft-matter" was invented is 1970). The titles of the colleges have changed a little to account for the current themes of study. From early on it was necessary that a scientist took on some organisational work for the college. A secretary for the college was co-opted by its members. Later this appointment was replaced by formal election. The secretary received a small bonus (initially 200 francs per month) to perform this function, and was given a small budget which enabled speakers to be invited to give seminars, and to make small purchases.

This lack of rigid hierarchy, and the youthful age of most of these scientists produced an atmosphere that was both studious and relaxed. The hard work was compensated by more or less improvised parties. Fasching, the German carnival, was celebrated regularly, with the very active presence of Maier-Leibnitz and his wife. There were also moments of relaxation entirely improvised, for example, between midday and two o' clock when a group would leave to ski in the Vercors. There were no traffic jams in those times, and the snow reached down to low altitudes. The atmosphere was described as "very young student-like" by one of these early scientists.

Maier-Leibnitz started implementing his programme in 1968. Guy Gobert, who had worked with me at Saclay, came to run the design office. Reinhard Scherm and Bernd Maier, two experienced German scientists came the same year. The choice of the first instruments to be built was made with help from the Scientific Council and its sub-committees. It was only in 1969 that the construction was able to commence; the objective was to have about half the devices ready when the reactor became operational.

The ILL had its first building (aptly named ILL1) available on 1 March 1969, with an area of 1200 square metres. One of the first facilities there was the library that seemed to us to be essential for scientific life. Christine Castets was recruited to take charge of this.

We also thought it indispensable to provide the first scientists with laboratory equipment while waiting for neutron beams. There was a laser which could be used for Brillouin scattering, yielding complementary information to that from inelastic neutron scattering. Reinhard Scherm set up and looked after the system with a student, Anne Hamelin. Later, in 1970, a four circle X-ray 
diffractometer was installed, with the collaboration of Janine Lajzerovitz from Grenoble University. This, with Michel Thomas in charge, helped familiarise the physicists with crystallographic techniques. The arrival of Jacques Villain from Saclay in September 1969 started off the theoretical physics group at Grenoble. His arrival was also important because it compensated for the difficulty and even impossibility to attract the Saclay experimental physicists. This inability I associate with Parisianism; these colleagues had a tendency to think that there was nothing good outside the region of Paris. This contrasted strongly with the attraction the ILL held for German scientists from the start. Another sign of the scientific life of the ILL was the organisation of a Summer School on the use of neutrons from 20 September to 10 October 1969. This was held at Saint Maximin, in the monastery attached to the superb church in the little Provencal town. Among others the teaching group included de Gennes, Sjölander and Brenig.

During 1970 the number of staff rose from 106 in 1969 to 216 , distributed as follows

\begin{tabular}{lcccc}
\hline & Total & French & German & Others \\
\hline $\begin{array}{l}\text { Scientists, engineers, } \\
\text { executives:(cadre) }\end{array}$ & 81 & 36 & 35 & 10 \\
Thesis students & 24 & 15 & 6 & 3 \\
Invited researchers & 11 & 3 & 2 & 6 \\
Others & 100 & 87 & 11 & 2 \\
\hline
\end{tabular}

This table highlights a problem that the ILL has encountered since its inception, and which has not yet been completely solved. The annual report for 1970 contains the following analysis:

The ILL continues to have difficulties in recruiting German staff below university level. The reason is that general workers, laboratory workers, programmers, technicians, and engineers without a degree have little knowledge of a foreign language and consequently greater difficulty to adapting to French life. The main obstacle however lies with this category of personnel, paid on the ILL salary scale, cannot receive salaries as high as those in the Federal Republic of Germany. The rules concerning the additional indemnities for foreigners adopted by the 8th Steering Committee on 14 April 1970, 
are insufficient and need improvement. The problem posed by this inadequate expatriation allowance has been the subject of numerous discussions of the Steering Committee.

I noted earlier that there was a similar problem in recruiting scientists, but for different reasons. It was impossible to attract physicists from Saclay to Grenoble. The only French expertise in using neutrons was at Saclay and the CENG; it was hence difficult to recruit French scientists during this construction phase. It was a real headache. Finally, several French coming from different backgrounds, with no experience of neutrons were tempted by the adventure of the ILL. I am thinking of Roland Currat, who had a PhD from MIT (USA), José Dianoux, a physical chemist, who already had a permanent post at the CNRS, which he dropped to come to the ILL with a five-year contract, and also Ferdinand Volino and Michel Roth, who all performed excellent work. There was no difficulty in recruiting French engineers. In the French system, notably in the CEA, there is no clear distinction between researchers and engineers. In the CEA they are all called ingénieur. Engineers enjoy a prestige at least as high as that of scientists. This is certainly due to the Grandes Ecoles which produce the engineers, and are often considered to provide the best advanced education. The situation in Germany was different again; there was a sort of hierarchy among researchers and engineers. In the CNRS too this hierarchy also exists. It is clear that this hierarchy did not exist for Maier-Leibnitz; he was too interested in instrument development for this.

\subsection{The first instruments}

The scientists at Jülich had made very advanced study of what instruments could be associated ${ }^{76}$ with the reactor. The results of this were presented at the conference in Santa Fe mentioned earlier. The study largely influenced the choice of instruments to build. Three instruments for nuclear physics, five spectrometers for inelastic

76 P. Armbruster, G. Maier, R. Scherm, W. Schmatz and T. Springer, "Design studies for the experimental equipment at a very high flux reactor" in the report "Seminar on intense neutron sources", USAEC/ENEA, Santa Fe, p701 (1966). 
scattering and ten for diffraction and small angle scattering were the first projects started and represent about half the forty instruments foreseen.

\subsubsection{Nuclear physics}

Three instruments were built which were extensions of those in operation at Munich, Jülich and Risø (the Danish reactor centre had a collaboration with Jülich). Experts from these reactors helped in the construction work at the ILL.

1. "Lohengrin" a mass spectrometer for fission fragments

This instrument separates fission products as a function of their mass, energy and charge. It was designed and constructed by industry under the supervision of Eberhard Moll (arrived at the ILL in 1968, coming from Maier-Leibnitz's laboratory in Garching). The very large instrument was the origin of Maier-Leibnitz's wish to have the core offset in the reactor building. There were no problems in implementation in a building of $60 \mathrm{~m}$ diameter.

2. Conversion electron spectrometer

This spectrometer is used to measure the conversion electrons following the capture of thermal neutrons. It is installed on the single vertical beam tube, thus at the upper level of the swimming pool. Conceived by von Egidy, then developed at the ILL with Bernd Maier as the responsible scientist, it was partly built at the CENG, and part in industry.

3. Spectrometers for measuring gamma rays emitted after neutron capture

These were designed by Otto Schull and are installed on the two ends of the beam tube that traverses the reactor. The source holder was built by Neyrpic in Grenoble. Part of the spectrometer from Risø in their collaboration with the Munich physicists was re-used. At the beginning Rüdiger Koch also had responsibility for this instrument.

\subsubsection{Inelastic scattering}

Five instruments were selected to be the first built:

- IN1 a triple-axis spectrometer on the hot source

- IN2 a triple-axis spectrometer for thermal neutrons

\section{8 addition:}

a portfolio has been added at the end of the chapter that shows some of the ILL's instruments. 
- IN3 a high resolution triple-axis spectrometer on a thermal guide

- IN4 a time-of-flight spectrometer with a rotating crystal monochromator

- IN5 a multi-chopper time-of-flight spectrometer on a guide from the cold source

The first of these instruments, IN1, was built at Saclay by Bernard Hennion et al. The first ILL responsible was Defendente Tochetti assisted by Alain Castets.

IN2 was constructed at Jülich by Bruno Dorner and Georg Duesing, who both came to the ILL, Duesing in 1970, and Dorner in 1972.

IN4 was the responsibility of Winfried Drexel at Kahrlsruhe. He joined the ILL in 1971.

The other two instruments were more complicated, and were designed at the ILL. The idea of IN5 came from Scherm while still at Jülich in 1965. It was a much improved version of a Saclay instrument. The monochromatic beam is produced by a set of four disks with slits (or choppers) which spin at high speed about a horizontal axis. These disks absorb neutrons except at the windows. By synchronising these rotors only neutrons of a chosen velocity pass through the four choppers. The use of four rather than two serves to eliminate harmonics. Guy Gobert and Francis Douchin led the project; the mechanical construction was entrusted to the Bertin Company while the electronics came from Ispra where the specialised know-how already existed. The triple axis spectrometers IN2 and IN3 were different from the classic IN1 design by incorporating the possibility to vary the distance between the sample and monochromator and analyser crystals. This enables focussing to be optimised. This is actually achieved by mounting the tables bearing the crystals on air cushions, which enables them to be easily moved. The name "Tanzboden" (dance floor) used for this technique comes from the components of the instruments sliding on air cushions, as waltzers on a dance floor. At the time this was quite new, and was perfected by Guy Gobert who made a demonstration by placing Maier-Leibnitz on such an air cushion platform and gliding it about (Fig. 5.1). It was used for other triple axis spectrometers but after greatly reducing the distances between tables, which were far too long in the first instrument leading to a large and unacceptable loss of measured intensity. 


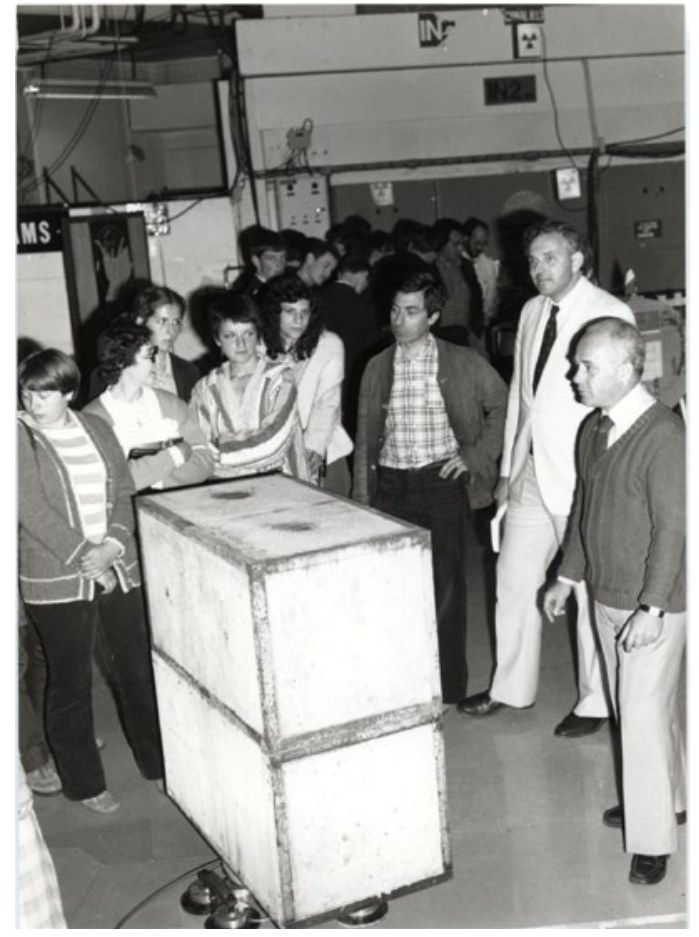

\subsubsection{Elastic scattering}

The instruments proposed and built for these studies can be classified in three categories.

\section{Diffractometers for powder samples}

- A combination of two diffractometers, D1A and D1B, to be installed on a thermal neutron guide and using the beams of neutrons diffracted by different planes of the same monochromator crystal. One, D1A was designed for high resolution work, the other, D1B used a multi-detector for fast data acquisition. These instruments were installed by Paul Burlet $^{77}$, coming from the CENG, and recruited by the ILL in October 1970.

- An instrument for measuring magnetic structures, D2, constructed by the CENG to be placed on the H11 beam tube also by Paul Burlet.

2018 addition: it is fair to say that Edouard Roudaut (CEACENG) and then his thesis student Pierre Convert did a large part of the design and installation work, especially for D1B and its multi-detector.
Fig. 5.1: Guy Gobert (on right) demonstrating his "Tanzboden" air cushion during an open day. MaierLiebnitz perched on the 1st ILL air cushion (1971), this photo is probably lost but, in place of the concrete blocks, you can imagine a tall man hovering on a marble floor. 


\section{Diffractometers for single crystal measurements}

- The D8 diffractometer, also placed on the H11 beam tube was a conventional 4-circle instrument installed by Alain Filhol coming from the crystallography laboratory of Robert Gay in Bordeaux and Michel Thomas.

- The D6 diffractometer, christened "Igel" (hedgehog) which allowed the simultaneous measurement of multiple reflections from the sample crystal (Fig. 5.2). This was achieved using 100 moveable detectors mounted on a spherical shell about the sample. This instrument, conceived at the ILL to study the structure of proteins was built by Bertram Klar for his thesis. It never worked completely satisfactorily partly because its mechanics and electronics were too complex for its time. Today multi-detectors are placed completely around the sample to perform these simultaneous measurements.

- The diffractometer D5 for polarised neutrons was installed on the $\mathrm{H} 4$ beam tube which led from the hot source. The polarised neutrons are produced by an Fe-Co monochromator, and an analyser table allowed measurement of the polarisation of the diffracted neutrons. The instrument was designed in Bertaut's laboratory and was constructed by Jacques Schweizer coming from this group.

- The diffractometer D10 could function as a classic 4-circle instrument or a 2-circle instrument and was designed and built at the ILL by Armin Tippe and installed on a thermal guide. The Eulerian cradle (4-circle) was equipped with a cryostat allowing data collection from the sample crystal down to $20 \mathrm{~K}$, a record temperature for this type of instrument. Later on, it became very versatile when equipped with an optional second monochromator (C. Zeyen and A. Filhol), an innovative zero-gravity dilution cryostat and a spin echo option (C. Zeyen), a "banana" multi-detector (B. Ouladdiaf), etc.

Apart from instrument building it seemed necessary to train researchers on protein crystallography which appeared to be a very important research field for a highflux reactor, and for which D6 had been constructed. The 
first idea for this training was to invite David Blow, an eminent English crystallographer and one time student of Max Perutz, to come to Grenoble with a permanent post. This was late in 1970, or January 1971. David Blow in his reply of 15 January 1971 declined the offer, while expressing his interest in neutron diffraction and proposing collaboration. Hartmut Fuess, one of the first scientists at the Institut was sent for a year to work with Dorothy Hodgkin who had solved the structure of vitamin B12, and had completed the X-ray work with a neutron study. Then in September 1972 Ulrich Arndt, coming also from Max Perutz's group, was recruited, staying until August 1973. The D6 diffractometer (Fig. 5.2) was shown to be ill-adapted, and the field of protein crystallography was dropped, before being re-adopted on conventional diffractometers.
However the Laue technique pioneered by D6 resurfaced 20 years later with the innovative Laue diffractometers $\mathrm{LADI}^{78}$ making use of a large image plate detector, and then VIVALDI and LADI III based on similar technologies). CYCLOPS, the most recent one, is equipped with CCD neutron detectors.

:2018 addition

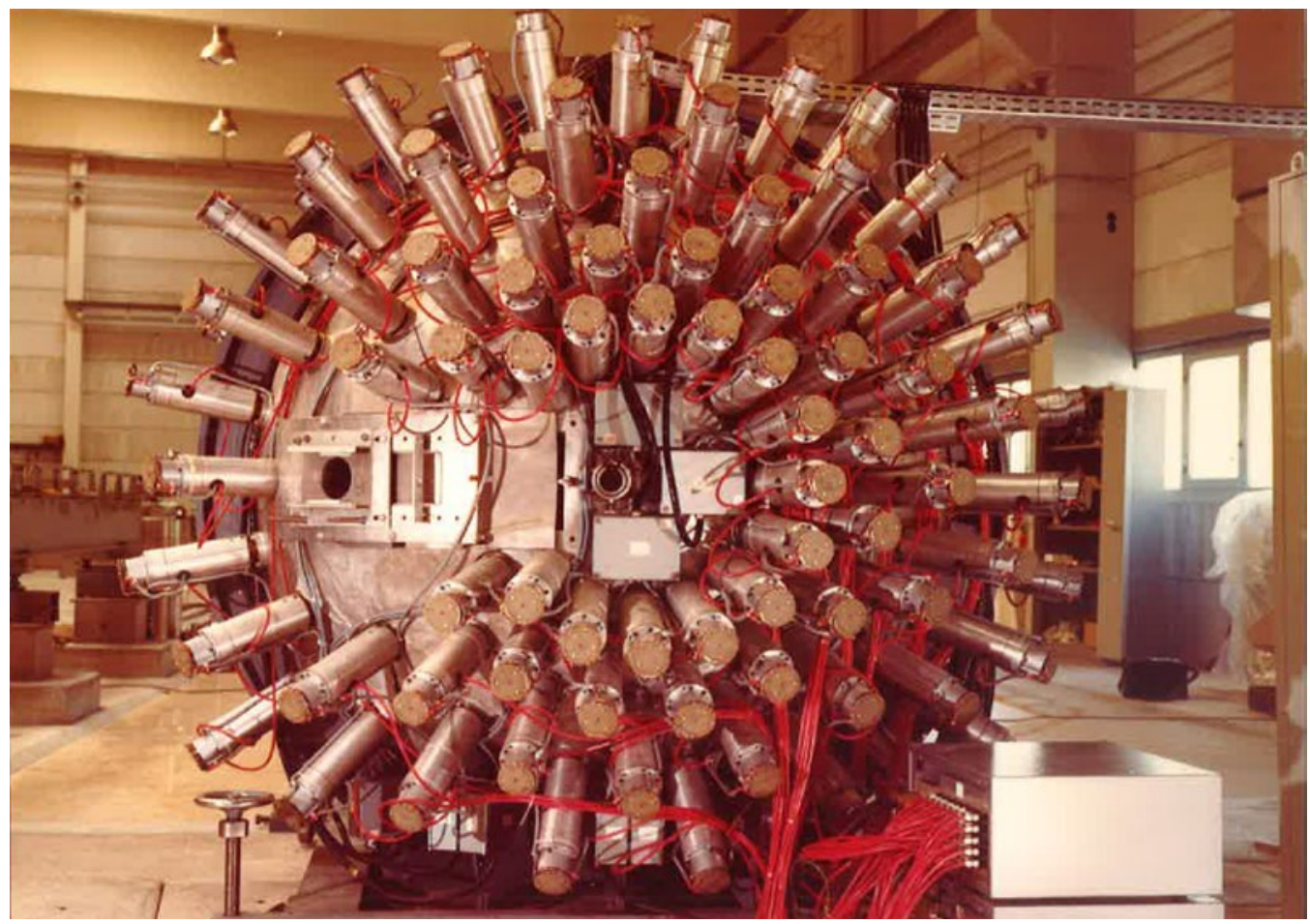

Fig. 5.2: The Hedgehog diffractometer, D6 (1971).

78 F. Cipriani, J.C. Castagna, M.S. Lehmann, C. Wilkinson, Physica B (1995), 213-214, 975-977, DOI 10.1016/0921-4526(95)00340-F 


\section{Devices for diffuse scattering}

Two instruments were designed for these studies

- The first, D11, was to measure small-angle scattering to study large structures (e.g. viruses), or large inhomogeneities. The apparatus was designed at Jülich, and installed on one of the cold-source guides by Konrad Ibel, who arrived from Jülich at the beginning of 1970. A rotating drum velocity selector acts as monochromator. The distances between the monochromator and the sample, and between the sample and detector could be as much as $40 \mathrm{~m}$. These distances could be reduced by inserting movable guides (before the sample) or moving the detector (after the sample). These huge distances had been proposed initially by Tasso Springer, and were supported by Maier-Leibnitz, since they allowed gains in intensity at the same resolution. I was, wrongly, of the opposite opinion. The detector was a two-dimensional multidetector with side dimensions of $64 \mathrm{~cm}$ created in collaboration with the detector group of the CENG. The instrument can also be used for diffraction by systems with a periodicity with a large lattice. This is essential, for example, to study vortex lines in type II superconductors in a magnetic field.

- The second, D7, also on a cold-source guide, was conceived for studying scattering from point defects. The design was refined at Jülich by Günter Bauer and later by Otto Schärpf. It was built by Wilhelm Just who came to the ILL after completing his postdoc at MIT (Boston). A monocrystal selects a monochromatic beam, and the scattered neutrons are measured in a set of detector. A spinning disk (chopper) just before the sample pulses the beam and allows analysis of the energy of scattered neutrons. The instrument can also use polarised neutrons.

Such were the first instruments foreseen and put into manufacture at the ILL or in European laboratories with existing reactors (Saclay, Munich, Jülich, Karlsruhe, Grenoble and Risø). 


\subsubsection{Neutron optics}

One aim for all instruments using crystal monochromators, whether for inelastic scattering or diffraction, was to make a large effort to optimise these components. Once again it was one of Maier-Leibnitz's ideas to use focussing crystals. This involved the establishment of an infrastructure: furnaces to grow the crystals, and the means to study their mosaicity. A number of ILL physicists was involved in this research; Andreas Freund was foremost in the field. He joined the ILL at the end of 1967 to prepare his thesis on this theme with Maier-Leibnitz. He constructed the first X-ray backscattering diffractometer using bremsstrahlung radiation (i.e. white beam), while Jochen Schneider constructed the very first gamma-ray diffractometer ${ }^{79}$, also in the framework of a thesis. Then Freund gradually became the coordinator of the Monochromator Group in charge of supplying monochromator crystals for the ILL instruments. Three gamma-ray diffractometers were in use even before the reactor was operational, to monitor crystal growth and the evolution of their mosaïcity spread under pressure, etc.

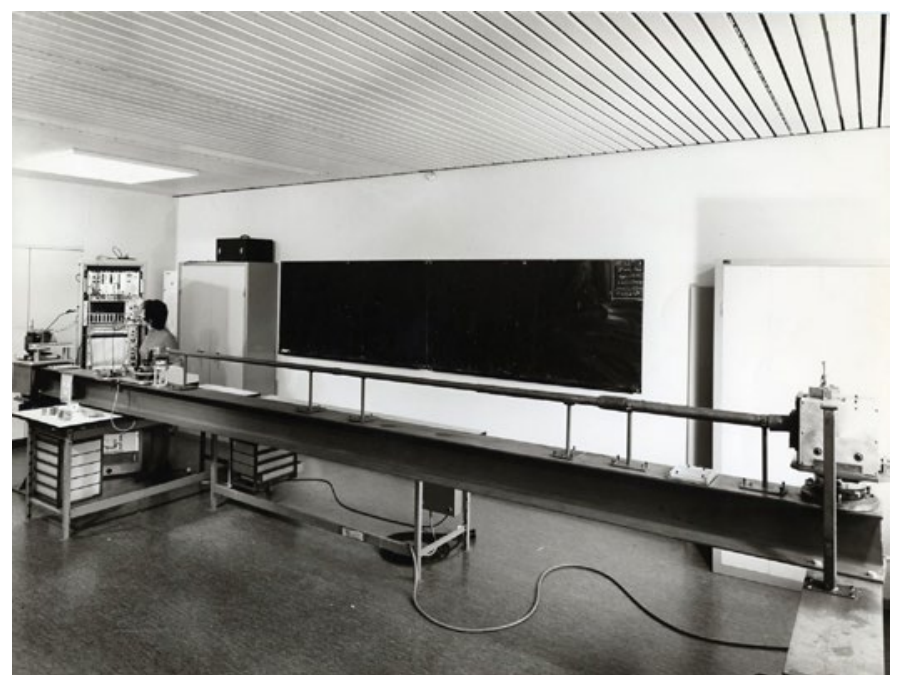

Fig. 5.3: The gamma-ray diffractometer proposed by Heinz Maier-Leibnitz and built by Jochen Schneider in 1970.

A gold foil irradiated at the CENG reactor Siloé emitted radiation with a very short wavelength $(0.03 \AA)$. It was the first instrument of this type in the world. When Siloé was shutdown (1988), it was replaced by a hard X-ray diffractometer.

79 A. Freund and J. Schneider, J. Cryst. Growth (1972), 13/14, 247-251, DOI 10.1016/0022-0248(72)90163-7 
The ILL had to rely upon itself to fabricate these single crystals: in general, industry was very reluctant to get involved in a field where the prospects were so limited.

Monochromators is not all about neutron optics but multilayers for neutrons came later and other groups were in charge of choppers, neutron guides, etc.

\subsection{The construction of the reactor}

At this stage of the reactor construction the work consisted of refining and terminating the design studies. Placing orders then followed. To do this work the team of about 25 (15 French, 10 German engineers and 2-3 translators) stayed in the Paris area in unused buildings belonging to the CEA. This offered it some breathing space from the reactor division which the Germans found to be a little overwhelming. At this stage there was no need to be located in Grenoble. An industrial architect was chosen by strong mutual agreement to act as the project coordinator and construction manager. This was actually a consortium of Interatom on the German side (an associate of AEG and Siemens), and GAAA ${ }^{80}$ and GERI ${ }^{81}$ for the French. For the ILL an additional task of the architect was

Fig. 5.4: Visit to the construction site in 1971 with Néel in the foreground, on his right Chatoux, and Droulers on the right edge of the picture.

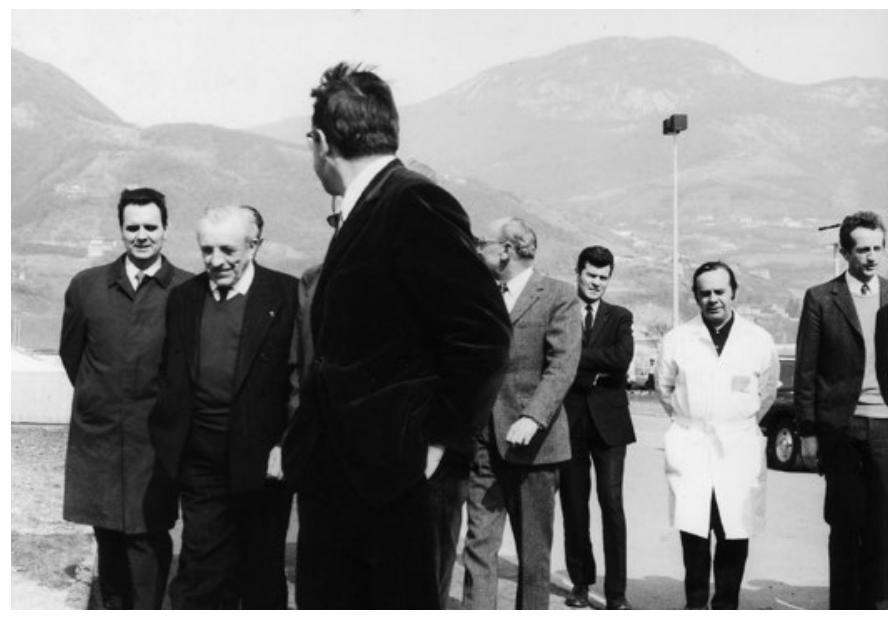

80 Groupement Atomique Alsacien Atlantique later known as Novatome.

81 Gestion Etude Réalisation Ingénierie Sarl, a group specialising in civil engineering. 
sharing the orders equally between the two countries. A small part of the team only moved to Grenoble at the end of 1968 when the heavy construction work started; the others shuttled back and forth from Paris.

The works in Grenoble began well. Sadly, 1970, a crucial year in the development of the Institut, was marked by a terrible accident on the reactor building site.

\subsubsection{The accident}

On 13 February 1970 at 15:30 the roof of the reactor building under construction collapsed bringing down with it seven assembly workers who were linking it together. The death toll was five people with two severely injured. To understand this accident you should know that the roof was made of concrete petals each weighing seven tonnes cast in a factory and then assembled on the site. For this a tubular scaffold had been erected starting from the level which is now the experimental floor. The slabs were placed on the top of the scaffold to be finally coated with a layer of concrete. This house of cards collapsed when about a quarter of the petals had been laid. The dead workers were connecting the slabs and fell with them. The five dead were Albert Botta (29), Abder Khader Benfatem (22), Rabah Ben Mohamed Dahmani (28), Abdel Khader Bachir-Elezaar (30) and Belkhacem Khadraoui (22). These men, who died so that the scientists would have the best neutron source in the world, deserve the right to be named in this book. An hour or two after the accident five coffins were delivered. There were four of the most simple and least expensive model, and one more plush, with copper handles. The reader can guess for whom the last one was intended. All who saw this were deeply shocked.

The accident was recalled at the Steering Committee meeting on 14 April 1970. After a minute's silence proceedings took place normally and Chatoux gave a report on the accident, which would lead to a two-month delay. The personnel would hold a collection for the victims, and Hasenclever asked the Steering Committee to authorise an additional grant of FF 7000 (about $€ 7300$ in 2018) to add to this. The proposal was accepted "provided that the collection was seen to be an anonymous gesture, to avoid that the Institut would be held responsible, even indirectly, for the accident." 
Two companies were involved in this part of construction: Campenon-Bernard who assembled the roof and Mills who built the scaffolding. It should be noted that this employed a technique never before used on a building of this size. The scaffolding was very lightweight, and unattached to the walls, hence very unstable. I remember well that I avoided entering the site while the roof was under construction. Both companies were charged with being responsible for the accident. Finally two leaders from Mills were brought to justice and convicted. It is remarkable that the ILL has no archive recording the accident. In particular I have not been able to find any photos, and can only show here a photo (Fig. 5.5), which appeared in the local press (Dauphiné Libéré) from my own archives. In 1992 a stand in the Furiani Stadium in Bastia collapsed bringing down spectators and causing many deaths. Again the stand was sitting on a tubular scaffolding assembly.

This accident led Chatoux to reorganize the project team. He noted a lack on the part of the industrial architect to monitor the works satisfactorily and he entrusted Reutler and Martin with special duties. Reutler was in charge of all aspects involving safety, with rights delegated directly from the project manager. Martin (Fig. 1.8) was given the task of coordination with the industrial architect, again with full rights delegated from the head of the project. These engineers then worked full time on the construction site. After this there were no further problems. It is important to say that the roles of Reutler and Martin were essential to the success of the reactor construction.

\subsubsection{Reactor characteristics}

The reactor was completed in the summer of 1971, and went critical for the first time on 31 August that year, only 3 years after the start of work on the site. Full power operation was reached on 21 December 1971, less than 5 years after the creation of the ILL. 

ipole (en construction) du réacteur de l'Institul iire franco-allemand de Grenoble s'effondre: Cinq ouvriers tués, deux blessés

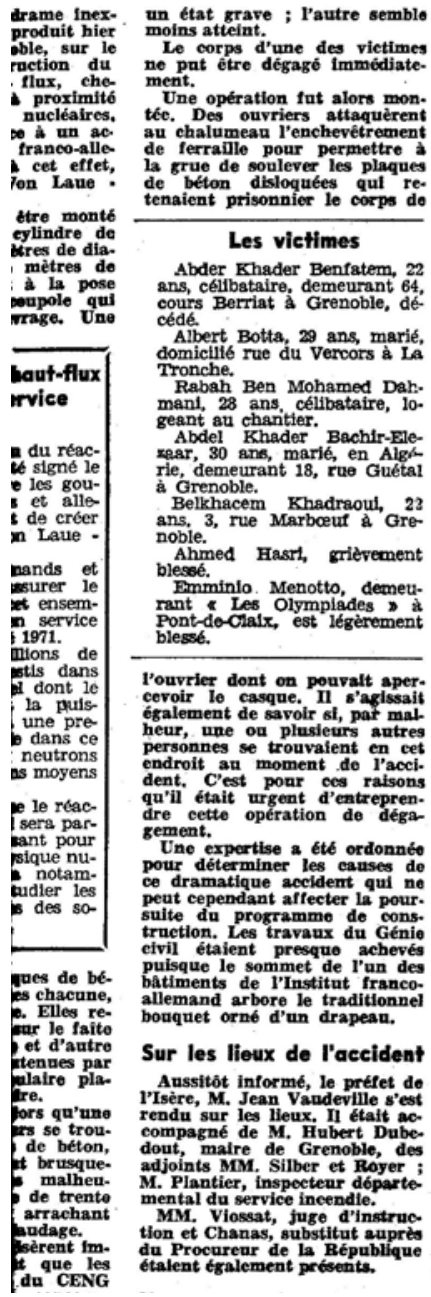

ment déclarer : "Une commis sion denquête se réunira dès ce soir, mais on peut dire des a present, que les causes exactes seront encore miner.

Le proó́dé employé pour la construction du toit de cet edifice n'a rien de révolution
il est couramment utilisé.

" Pour l'instant, nous ne nous expliquons pas les raisons de ce drame. $:$

En haut du cliché, sur le pourtour du mur circulaire de béton, on distingue une partie des plaques de béton devant constituer le dôme abrl du réacteur. $A$ gauche. l'échafaudage $t u b$ ulaire dont une partie fut arrachée et broyée par la chute des 210 t. de béton. Ce sont ces plaques qu'il tallut enlover pour dégager le corps de l'une des victimes de la tragédie.
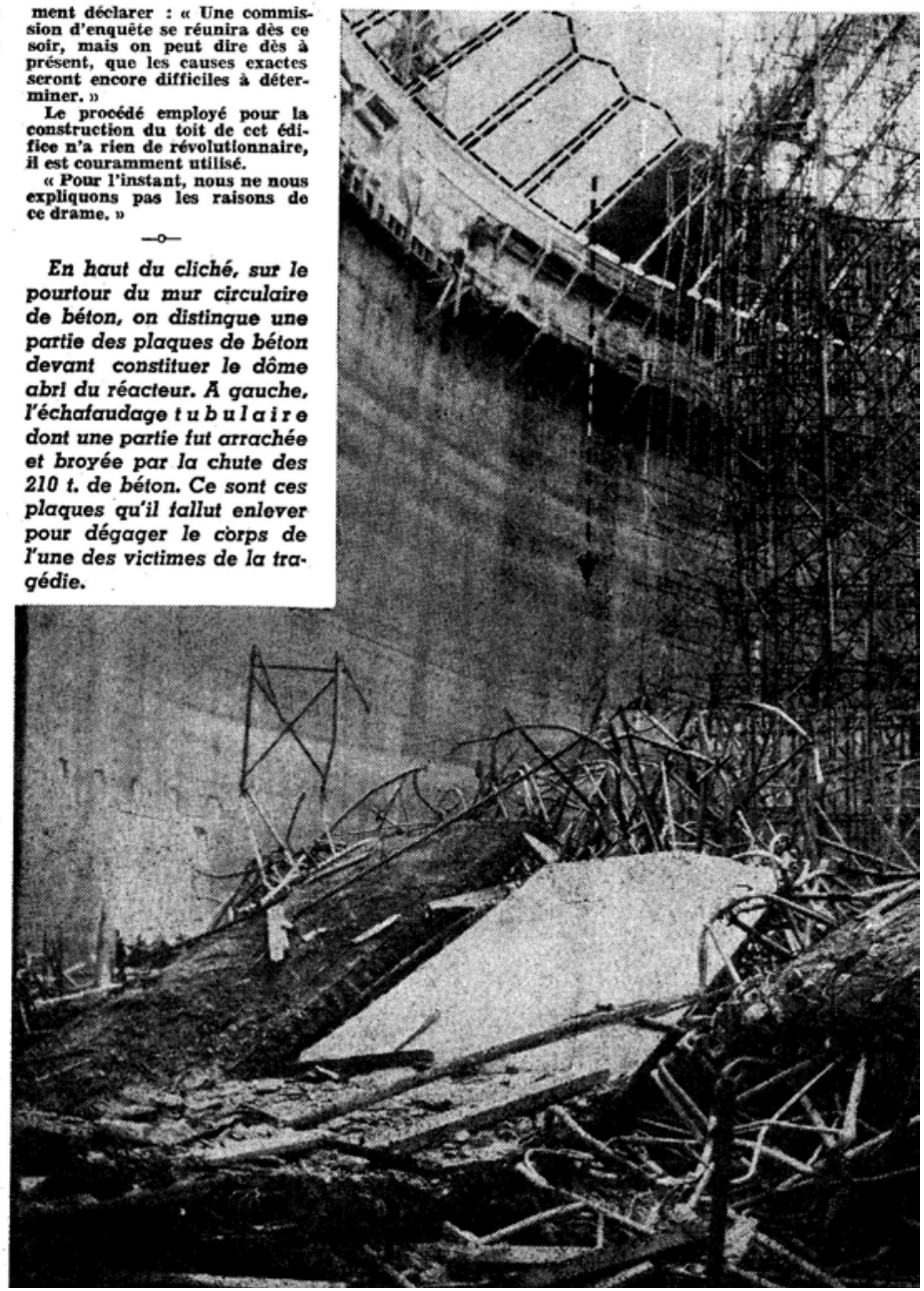

Fig. 5.5: Photograph of the future reactor hall after the collapse of a part of the roof under construction published 14 February 1970 in the regional newspaper Le Dauphiné Libéré. 


\section{Characteristics of the ILL reactor}

Characteristics

Nominal Power

$57 \mathrm{MW}$

Coolant

Heavy water

Reflector

Heavy water

Flux of thermal neutrons unperturbed in the reflector at $57 \mathrm{MW}$

$1.5 \times 10^{15} \mathrm{n} / \mathrm{cm}^{2} / \mathrm{s}$

Perturbed Flux at the end of a tangential beam tube

$10^{15} \mathrm{n} / \mathrm{cm}^{2} / \mathrm{s}$

Flux in the fuel element

$2.2 \times 10^{14} \mathrm{n} / \mathrm{cm}^{2} / \mathrm{s}$

Mean Flux in the heavy water

$1.8 \times 10^{14} \mathrm{n} / \mathrm{cm}^{2} / \mathrm{s}$

Fast neutron flux $(0.8 \mathrm{MeV})$ at the fuel rod

$3.5 \times 10^{14} \mathrm{n} / \mathrm{cm}^{2} / \mathrm{s}$

Fast neutron flux $(0.8 \mathrm{MeV})$ on the control rod

$2.7 \times 10^{14} \mathrm{n} / \mathrm{cm}^{2} / \mathrm{s}$

Fast neutron flux $(0.8 \mathrm{MeV})$ at the end of the beam tubes

$1.5 \times 10^{12} \mathrm{n} / \mathrm{cm}^{2} / \mathrm{s}$

\section{Reactivity}

Uranium consumption $10.5 \%$

Poisoning by xenon and samarium $5 \%$

Unconsumed Boron at the end of a cycle

$0.5 \%$

Beam tubes $5 \%$

Effect of temperature $0.6 \%$

Reserve at the end of cycle

Safety rods withdrawn

Control rod $15.5 \%$

Initial poison consumable

$5.1 \%$

Fuel Assembly (annular shape with curved plates)

Active Zone

$\begin{array}{ll}\text { Internal radius } & 14.0 \mathrm{~cm} \\ \text { External radius } & 19.5 \mathrm{~cm} \\ \text { Height } & 80.0 \mathrm{~cm} \\ \text { Thermal exchange surface } & 30.17 \mathrm{~m}^{2} \\ \text { Volume } & 46.3 \mathrm{dm}^{3}\end{array}$


Fuel Assembly (annular shape with curved plates)

\begin{tabular}{lll}
\hline Plates & & \\
\hline & Total thickness & $1.27 \mathrm{~mm}$ \\
& Cladding & $0.38 \mathrm{~mm}$ \\
& Thickness of uranium ${ }^{235} \mathrm{U}$ & $0.51 \mathrm{~mm}$ \\
& Width of cooling channel & $1.8 \mathrm{~mm}$ \\
& Number of plates & 280 \\
\hline Uranium & & \\
\hline & enrichment ${ }^{235} \mathrm{U}$ & $93 \%$ \\
& Total mass ${ }^{235} \mathrm{U}$ & $8.57 \mathrm{~kg}$ \\
& Consumable poison $\left({ }^{10} \mathrm{~B}\right)$ at the & $14.8 \%$ \\
plate-ends & $36 \%$ \\
\hline
\end{tabular}

Cooling

Power

Power density Maximum

Power density Average

Heat flow Maximum

Heat flow Average

Flow rate of coolant within the fuel rod during operations

Flow rate of coolant within the fuel rod while shutdown

In the control rod during operation

In the control rod while shutdown

Velocity of coolant between plates

Pressure of coolant entering the fuel rod

Pressure of coolant leaving the fuel rod

Pressure in the reflector tank

Maximum temperature at the surface of fuel plates
$57 \mathrm{MW}$

$3.3 \mathrm{MW} / \mathrm{dm}^{3}$

$1.15 \mathrm{MW} / \mathrm{dm}^{3}$

$500 \mathrm{~W} / \mathrm{cm}^{2}$

$174 \mathrm{~W} / \mathrm{cm}^{2}$

$2158 \mathrm{~m}^{3} / \mathrm{h}$

$150 \mathrm{~m}^{3} / \mathrm{h}$

$75 \mathrm{~m}^{3} / \mathrm{h}$

$60 \mathrm{~m}^{3} / \mathrm{h}$

$15.5 \mathrm{~m} / \mathrm{s}$

14 bar

3.2 bar

4 bar

$147^{\circ} \mathrm{C}$ 
Fig. 5.6: The fuel element. The control rod occupies the central space. The uranium is in the fins between which circulates the heavy water coolant. The heavy water is an essential component of the reactor; some 42 cubic metres are needed for reactor operation. The majority $\left(40 \mathrm{~m}^{3}\right)$ was supplied by the factory of Mazingarbe

(France). The final two cubic metres were of American origin.
The above table (taken from a booklet prepared by Franco Franzetti for the twentieth anniversary of the ILL) gives all the features of the reactor and shows that the exceptional amount of power to be removed from the core requires a very special design. This core, derived from that of the Oak Ridge High Flux Isotope Reactor (HFIR), was conceived and calculations were made by Louis Brégeon. It is in the form of a cylinder and consists of an assembly of long $(80 \mathrm{~cm})$ and thin $(1.27 \mathrm{~mm})$ curved plates between which the coolant circulates (see Fig. 5.6). The fuel element is highly enriched ${ }^{235} \mathrm{U}$. The central hole, which in the Oak Ridge reactor is used to place material for irradiation, is used here to house the control rod yielding the best conditions for neutron beam production.
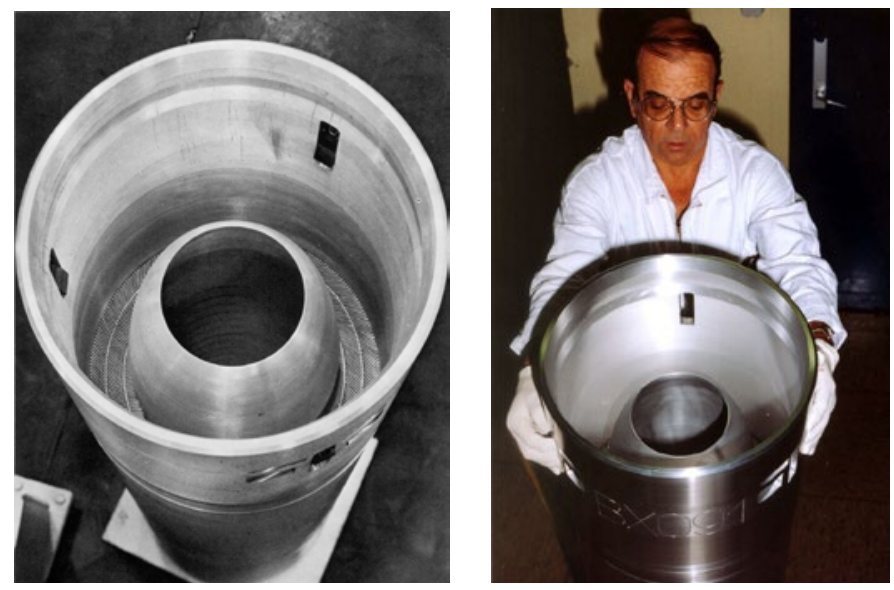

This raised the problem of the supply of enriched uranium. Germany, of course, had no enrichment plant. France had one at Pierrelatte built for military use, but the cost of this uranium was prohibitive. It was necessary to seek provision from the USA. At that time the USA did not have very strict export regulations for highly enriched uranium (usable for making a bomb). An agreement was made with the USA for the purchase of the fuel, and the ILL reactor could be started up without any problems. We shall see later that the later introduction of a more rigorous regulatory regime has posed serious problems for the ILL.

It should be noted that the characteristics of this reactor are much more stringent than those of reactors for producing electricity. The power density in the core is at 
least an order of magnitude larger than pressurised water reactors and three orders greater than gas cooled graphite reactors.

The deuterium in heavy water has a capture cross-section about 1000 times smaller than that of hydrogen, but it cannot be ignored. Capture leads to the formation of the radioactive isotope of hydrogen, tritium, which has a half-life of 12 years. If not removed the heavy water of the reactor would reach equilibrium with a radioactivity of 80 curies per litre. In these conditions even a modest leakage of heavy water could have very serious consequences for the environment, and would also make maintenance interventions on the heavy water circuits more difficult. The institute included a detritiation facility (Fig. 5.7). For a long time this prototype installation has remained unique in the world. It comprises a stage with catalysed exchange between the heavy water vapour and deuterium gas, followed by liquefaction of the deuterium gas and fractional distillation which separates out hydrogen and tritium from the deuterium. This also removes all

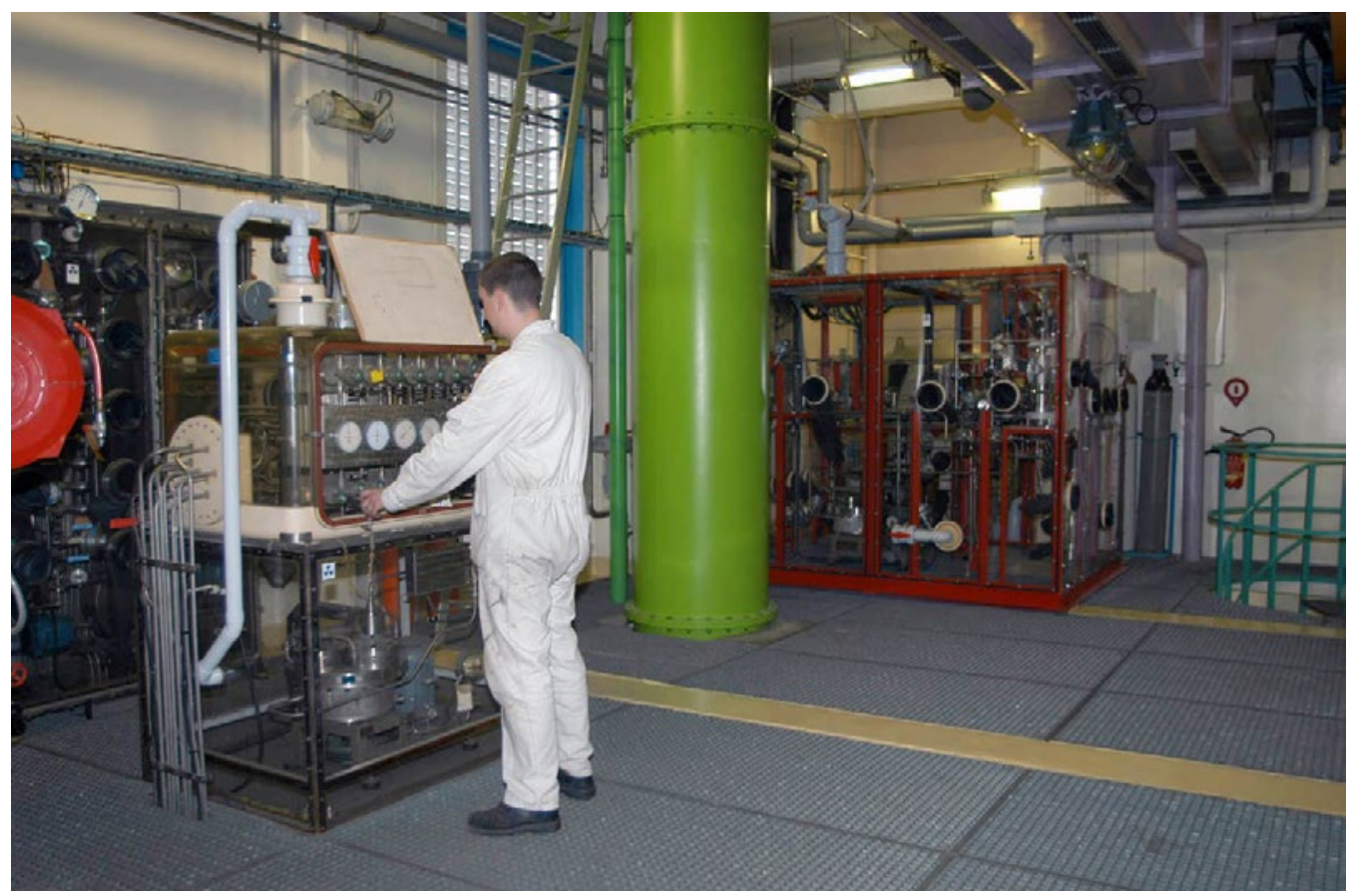

Fig. 5.7: The detritiation facility in 2004. On the left the monitor circuit and in the background the exhaust circuit for the tritium gas. 
contamination of the heavy water by light water. All this is housed in a specially designed building where every precaution is taken to avoid any explosion of hydrogen gas. I mentioned the difficulties of finding a buyer for the tritium. Such a plant was unique. In particular the Brookhaven HFBR had none. It would be unfair to attribute closure in 1999 to this absence, but the shutdown followed a very light contamination by tritium in the basement of the reactor building. This tritium came from a storage pool containing used fuel elements which received a little tritiated water with each transfer from the core to storage.

\subsection{The link between the ILL management and the project group}

There were frequent discussions between Maier-Leibnitz and myself with Dautray and then with Chatoux and Eiserman. This was not enough to ensure a fully efficient cooperation. Two people played an essential role in this coordination. The first was Yves Droulers, already mentioned, who would have the responsibility for daily reactor operations once complete. For him it was clearly necessary to know it in every detail. He quickly formed the reactor service (there was always a policy towards early recruitment) which at the end of 1970 already comprised 37 staff, who were tightly integrated with the teams of the project group and the industrial architect; it was certainly the best way to learn about the reactor. The second person was Paul Ageron (Fig. 5.8). We have already come across him in the first chapter since he was the author of the communication in Geneva in 1964 which led to the creation of the ILL. He was soon a key player in the project group, then was recruited by the ILL on 1 January 1970. In these two posts he dealt primarily with the cold source and the neutron guides (which have an in-pile component, and sections outside). These two novel and key features enabled the reactor to outperform all others. To realise this it was essential to have a close collaboration between the future users and the project group. With his expertise Paul Ageron was liked and respected by all. 


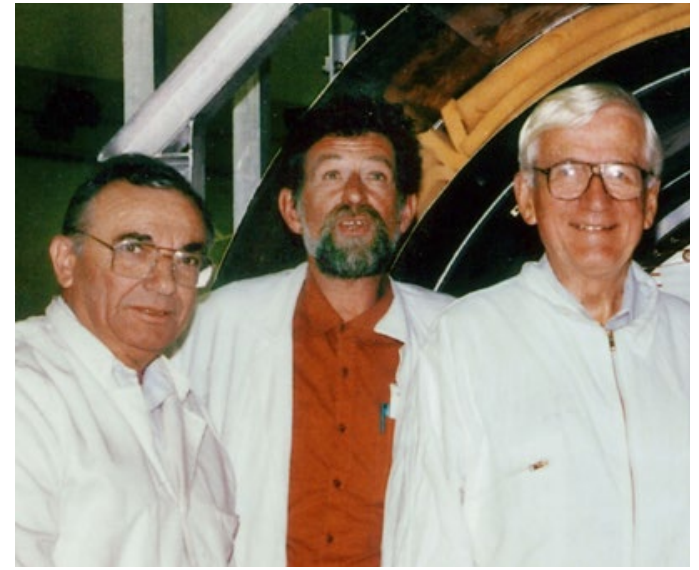

Ageron relied on the low temperature group of the CENG to construct the cold source ${ }^{82}$. Jean-Marie Astruc, an engineer, was recruited in 1970 to direct the project in the reactor service. Liquid deuterium was chosen because it enabled a large volume (25 litres), sufficient to provide beams for five neutron guides $202 \times 33 \mathrm{~mm}^{2}$. In addition the deuterium disrupted the neutron flux much less than liquid hydrogen. The power to be dissipated from the liquid deuterium was about $6 \mathrm{~kW}$, which needed a refrigeration power close to that required for operating the biggest liquid hydrogen bubble-chamber detectors used with large accelerators.

Liquifier offers came from the German firm, Linde, and the French firm Air Liquide. The latter was innovative using a turbine mounted on gas bearings. This was finally chosen; the device has proved to be very reliable and still works after 30 years of service. The cold chamber is inserted vertically into the reflector tank from the upper level. It is located $50 \mathrm{~cm}$ from the surface of the core (see diagram, Fig. 5.9). The safety issues have been studied; everything is done to ensure that no oxygen can come in contact with the hydrogen, avoiding formation of a potentially explosive mixture. However, if such a mixture is formed the walls will resist a pressure of
Fig. 5.8: On the left is Paul Ageron(1931-1998), on his right Walter Mampe (19391992) and Norman Ramsey (Nobel prize for Physics 1989) who visited regularly after his retirement and performed many experiments at the ILL with Mampe.

82 Described in the publication "La source de neutrons froids pour le réacteur à haut flux franco-allemand de Grenoble" by Ageron P., Verdier J., Ewald R. and H. D. Harig, Energie Nucléaire (Paris), (1971), 13, p15-21. 
19 bars, which is the pressure of a detonation wave. The presentation of the ILL reactor at the Santa Fe conference included the cold source with deuterium liquid already foreseen. It was this component of the reactor which was then the subject of the largest number of questions which demonstrated certain scepticism among some participants. It was a radically different choice from the British project which sought to minimise the volume of liquid hydrogen in the interior of the reactor. The results showed that there was no basis for this scepticism.

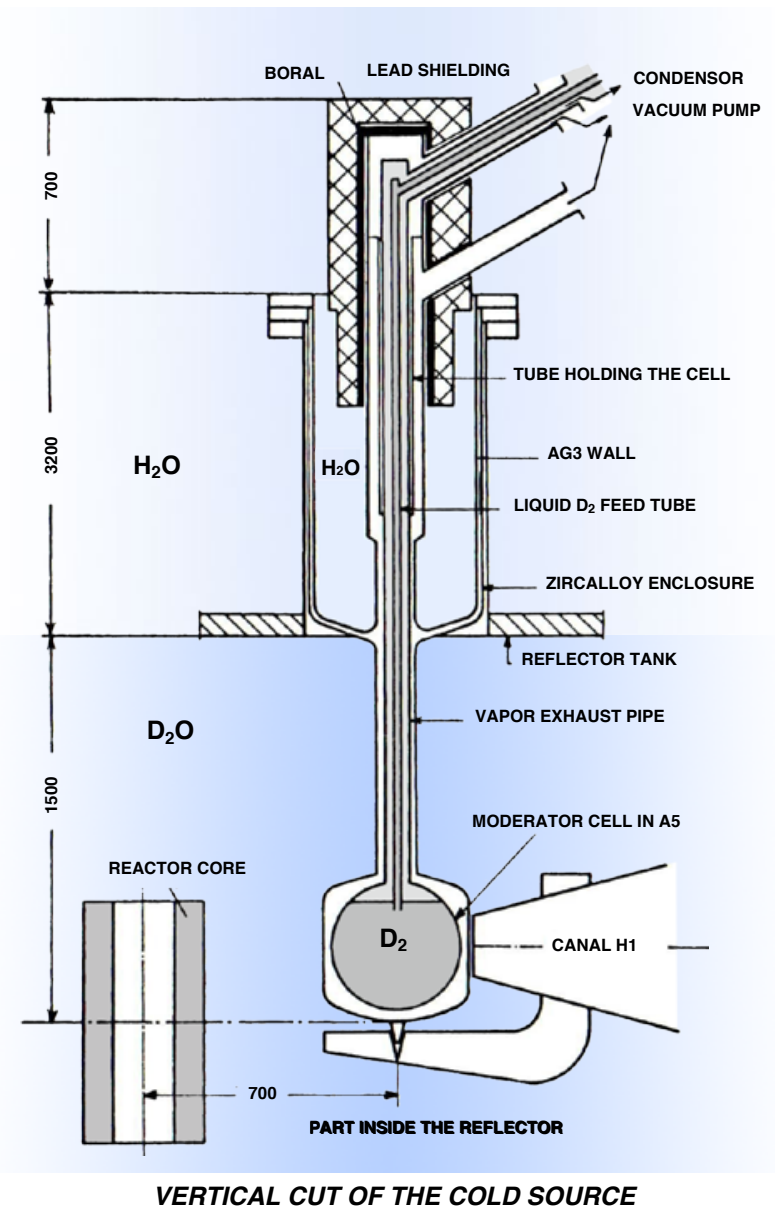

\section{Chamber}

Aluminium sphere diameter $380 \mathrm{~mm}$, thickness $1.5 \mathrm{~mm}$ in zircaloy vacuum vessel

\section{Volume}

$\mathrm{D}_{2}$ liquid $\sim 25 \mathrm{l}$

$\mathrm{D}_{2}$ gas $50 \mathrm{~m}^{3}$ at NTP

\section{Pressure}

$\mathrm{D}_{2}$ ambient temperature 3 bars

$\mathrm{D}_{2}$ cold 1.5 bars

\section{Specific Energy}

$0.8 \mathrm{~W} / \mathrm{g}$ for $\mathrm{D}_{2}$ liquid

$1.5 \mathrm{~W} / \mathrm{g}$ for Aluminium

Total nuclear heating $5.8 \mathrm{~kW}\left(3.1\right.$ in $\left.\mathrm{D}_{2}\right)$

\section{Heat losses}

$1.2 \mathrm{~kW}$

\section{Refrigeration power}

$10 \mathrm{~kW}$ at $25 \mathrm{~K}$ requiring

2 helium compressors, each $400 \mathrm{~kW}$

Average thermal neutron flux at the cold source

$$
5 \times 10^{14} \mathrm{n} / \mathrm{cm}^{2} / \mathrm{s}
$$

\section{Function}

Deuterium liquid vaporises in the sphere, rises to the condenser which is cooled by helium returning the liquid to the sphere.

Fig. 5.9: Diagram of the first version of the cold source. When it was necessary to replace it, an improved version (Fig. 7.4) offered increased intensity and added a vertical beam tube. 
The reactor also included a hot source which amplifies the flux of neutrons with energies between 0.15 and $1 \mathrm{eV}$. Paul Ageron was not directly involved in its construction. The study was carried out by the GfK at Karlsruhe in collaboration with the project group, and the manufacture was entrusted to Heraeus. It consists of a graphite cylinder $20 \mathrm{~cm}$ in diameter and $30 \mathrm{~cm}$ high which is heated to $2000 \mathrm{~K}$ (about $1730{ }^{\circ} \mathrm{C}$ ) by radiation; three horizontal and one inclined beam tube are pointed at the source. The utility of the hot and cold sources to change the neutron spectrum is shown in Fig. 5.10. The location of these devices in the reflector tank is shown in Fig. 5.11.

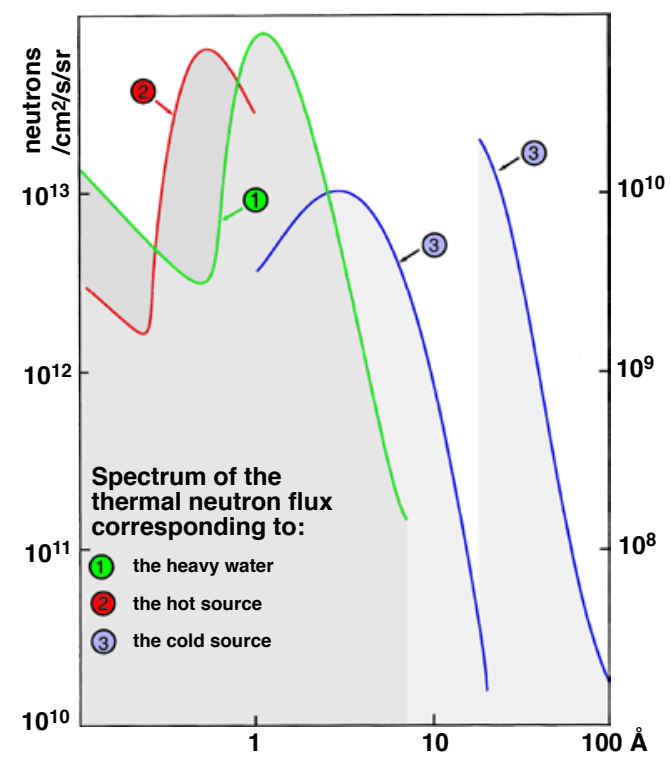

Neutron guides are of fundamental importance at the ILL, and have been in use from the start of the reactor providing $40 \%$ of the possible locations for instruments. Since the installation of the second cold source this fraction has further increased. The principle was discovered more or less by accident ${ }^{83}$ in 1961 by Peter Höhne and

83 During an experiment at Munich a neutron beam was left unprotected over several metres. To avoid people crossing the beam a brass tube was placed around the beam. This led to a
Fig. 5.10: Neutron flux from a normal tangential tube (curve 1), the hot source (curve 2), and the cold source (curve 3) as a function of wavelength. The appreciable gains in flux at short wavelengths are seen for the hot source, and the converse for the cold source. 
Fig. 5.11: The arrangement of all the experiment beam tubes and the cold and hot sources in the reflector tank. The hot and cold sources operated from 1972, and were located in the vertical tubes V1 and V2.

The horizontal cold source was added in 1987.

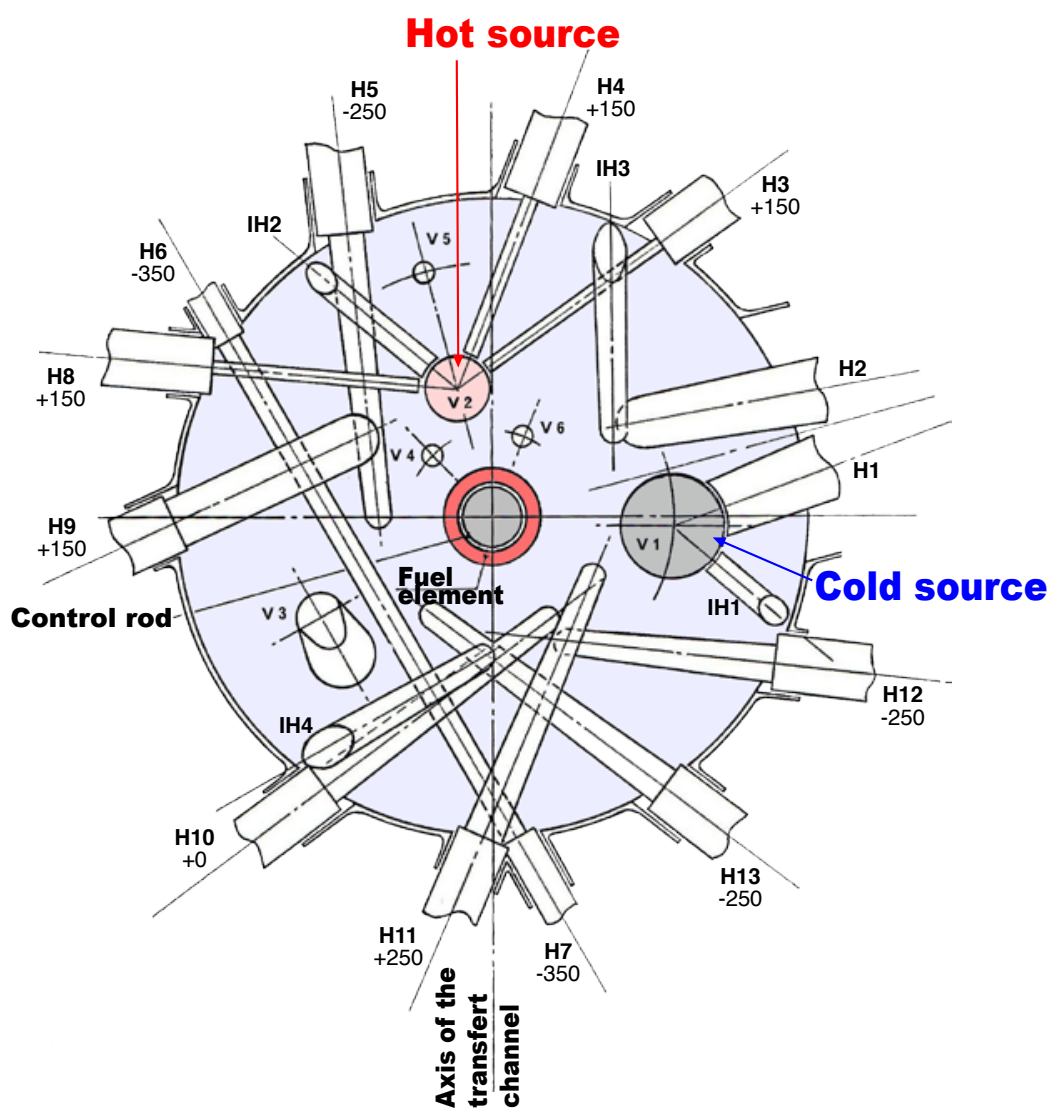

Tasso Springer in Munich, and then developed by MaierLeibnitz and Tasso Springer. Total internal reflection of neutrons occurs with neutrons, as with light. When there is an interface between a vacuum and a medium which has a refractive index $\mathrm{n}$ less than unity there is total reflection of neutrons when the grazing angle of incidence is

great increase in neutron intensity at the far end of the tube. This greatly surprised the scientists, with the exception of Peter Höhne, who was preparing his thesis with Tasso Springer, and had deliberately chosen a brass tube. I learnt this from Peter Armbruster who was also a thesis student (see "Maier-Leibnitz and Neutron Optics", T. Springer and A. Heidemann, Neutron News (2002), 13, 1, DOI 10.1080/10448630208222873). The exploitation of this phenomenon is due to Tasso Springer and Maier-Leibnitz. 
less than the critical angle $\gamma^{84}$ defined by the relation $\cos (\gamma)=\mathrm{n}$. This index is linked to the coherent scattering length a of the medium and the wavelength $\lambda$

$$
\mathrm{n}=1-\left(\mathrm{N} \cdot \mathrm{a} \cdot \lambda^{2}\right) / 2 \pi
$$

where $\mathrm{N}$ is the number of nuclei with scattering length a per unit volume.

The material most often used at that time was a glass plate (which could be made industrially with a perfectly flat surface) covered with a layer of nickel to increase the scattering length, and hence the critical angle. The total internal reflection allowed the beam of neutrons to be led away over several tens of metres into zones where the background was much smaller than adjacent to the reactor. The guides could also be gently curved which stopped fast neutrons reaching the sample, and allowed more space and a greater number of instruments. The guides, of course, had to be within an evacuated tube to minimise neutron loss. This method of eliminating the fast neutrons obviated use of neutron filters which had been necessary up to then. The filters were made of a material which did not absorb neutrons, and had a very small incoherent cross-section. Only neutrons with a wavelength longer than the inter-planar distances were transmitted; shorter wavelengths were diffracted out of the beam. Beryllium was a preferred substance. The British project of 1962 foresaw placing these filters in the beam tubes inside the reactor. In the ILL beam tubes there is no solid material (which would lead to a reduction in flux) along the flight path from the interior of the reactor.

At the ILL 10 guides were installed at the start, 5 viewing the cold source (H1) and 5 in the reflector tank (H2) delivering thermal neutrons. They exit from a single combined nose-port in the reactor vessel $(\mathrm{H} 1 / \mathrm{H} 2)$. Eight $(4+4)$ of these guides terminate outside the reactor building in an adjacent building known as the Guide Hall, which is $90 \mathrm{~m}$ long and $35 \mathrm{~m}$ wide (Fig. 5.12, Fig. 5.13).

84 The $\gamma$ used here is the complement of the angle of incidence used in conventional optics text books relative to the normal to the surface plane; here this is a small angle otherwise all angles would be close to 90 degrees. This changes the equation from sine to cosine. 


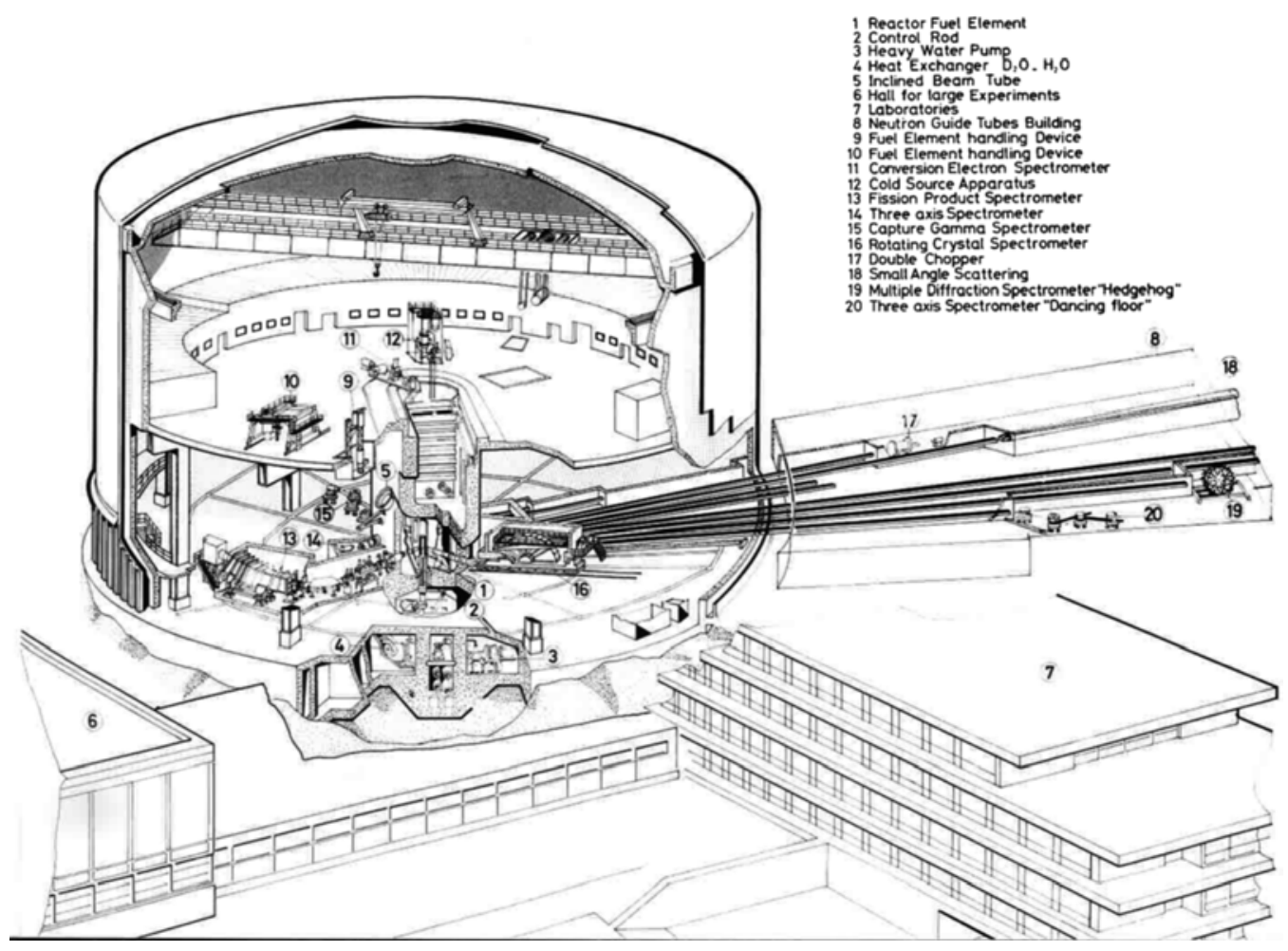

Fig. 5.12: Sketch representing the reactor in its building with the neutron guides exiting into a separate building. Some instruments are shown. Again this is from the early days. Since then a new cold source has been added which feeds guides entering a new hall situated behind the reactor as shown here.

They are slightly curved to reduce the background with the radii varying from $25 \mathrm{~m}$ to $27 \mathrm{~km}$. The whole installation comprises $473 \mathrm{~m}$ of main guides with another $120 \mathrm{~m}$ of channels from the ends of these which distribute the neutron beams to the different instruments. The main guides are $20 \mathrm{~cm}$ high leading to three instruments on each guide. Paul Ageron and Paul Blum took charge of the construction and installation of these guides: the optics were supplied by Jobin-Yvon - Jouan-Quetin, and the mechanical supports and vacuum chambers by Neyrpic and M.A.N. One can appreciate the important role of Paul Ageron's work on the beam-lines to bring the Institut into reality. Now some nickel-coated guides are being replaced by supermirrors guides (described in Section 6.2). 


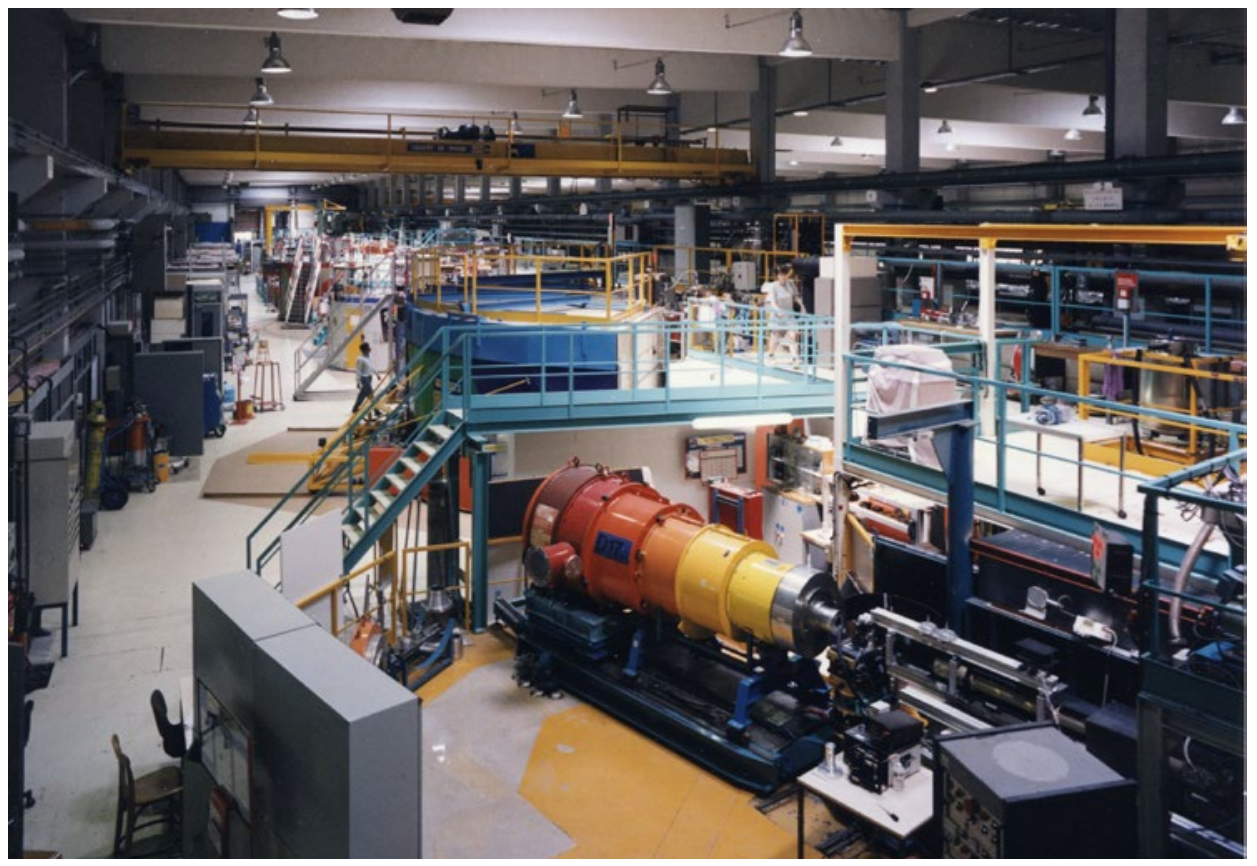

Fig. 5.13: A view of a part of the guide hall with some of the instruments installed on the cold guides. In the centre is the shielding for the detectors of the time-of-flight spectrometer described above (Fig. 3.3) The instruments are painted in vivid colours and this was started in 1972 to create a more cheerful atmosphere for the visitors.

\subsubsection{Computing at the ILL ${ }^{85}$}

The ILL was built at a time when computing was beginning slowly to take the importance which it now has adopted. In the work I did at Saclay when I was measuring the neutron time of flight from selectors I only had ten channels, which had to be read manually. I remember my amazement visiting the Brookhaven reactor and seeing each experiment coupled to a mini-computer (using PDP8s I think), which piloted the instrument and collected the data. The progress of colleagues at Brookhaven was a consequence of there being an industry capable of implementing such systems. Michael Taeschner was recruited in 1969 to deal with computerisation of the experiments. At that time the policy both

85 I thank Alain Filhol and Ron Ghosh for their help in editing this section. 
in Germany and France was to support and use national industry. We had to take this into account.

Instrument control was based on two systems. The first, called CARINE, used two T2000 computers manufactured by the French company Télémécanique. The systems were used on 12 instruments with demanding control requirements, but simple data collection (diffractometers, triple-axis spectrometers.) The realization was entrusted to the electronics and computing laboratory (LETI) of the CENG were Mathurin Le Sourne (recruited 1 January 1971) wrote a realtime FORTRAN for the instrument control. Once delivered it was supported by Walter Kaiser (recruited 1 July 1970) assisted by Gérard Pastor and Jean-Pierre Delacroix. The second system called NICOLE, was based on two Telefunken TR86 computers. This managed 6 instruments which had to treat a very large amount of data (e.g. small angle scattering, time of flight, mass spectrometer). The GfK, Karlsruhe, provided the expertise for the realization. At the ILL, Michel Grevaz (1970) took charge assisted by Helga Schwab, Jean-Jacques Tschofen and Günter Anderlohr. Two of the nuclear physics experiments each benefited from using a PDP11 mini-computer under the responsibility of Philippe Ledebt assisted by Philippe Blanchard.

This support of national industry soon proved to be a handicap. Using time-sharing on slow systems like CARINE and NICOLE led to evident absurdities. For example, on CARINE each command sent was followed by a wait often exceeding 5 seconds. While not too debilitating for a slow instrument like a triple-axis this was catastrophic for others performing rapid scans, and also greatly limited graphical applications. For example for the four-circle diffractometer D8 this resulted in a loss of efficiency of more than 50\% (50\% measuring time, 50\% awaiting the computers response); it amounted to losing more than half the neutron flux available. This untenable situation had to await the arrival of Mössbauer to abandon these national preferences and install one computer per instrument (PDP11 or SEMS Solar ${ }^{86}$ ) which resulted in a substantial gain in efficiency for most experiments.

86 These French computers were the last bought to satisfy the national preferences. While fast they lacked software. They had to be replaced fairly quickly (though not fast enough for the users) by PDP11 systems. 
It was, of course, also necessary to have access to more powerful means to treat the data. At the start, until 1973, this was possible using a remote job-entry terminal (RJE, terminal lourd) connected to an IBM-360 computer at the computer centre (IMAG) of the university. Yvon Siret came from this centre on 1 January 1971 to take charge of scientific computing at the ILL.

\subsubsection{Computer sharing at the ILL}

Computing at the start of the ILL was an excellent example of the spirit of freedom and power being made available to the users. Then, well before the advent of the personal computer, a central computer was a huge machine, very costly, and locked in a room with access strictly controlled and managed by a small group of experts with the users at a safe distance.

To the great surprise of new arrivals there were no such barriers at the ILL. The RJE terminal connected to the IBM 360/50 of the IMAG was quickly replaced by a more modern DEC PDP-KI10 (also known as DECsystem10 or DEC10) computer offering time-sharing and much better adapted for scientific use. The incredible open door computer policy was made by Y. Siret on the arrival of this machine. In other words, after minimal instruction, in the absence of the operators, any scientist could start the machine at night or weekends, mount or dismount tapes, mount or dismount the removable hard disks, replenish printer paper, etc. Y. Siret, supported by the Directors, correctly gambled this would work due to the intelligence and serious work ethic of the scientists. Rightly so: in more than ten years of operation of the DEC-system10 there was no significant problem. This daring choice for the era would have numerous benefits. Firstly, the high cost of the computer equipment was offset by the young scientists able to work at night and weekends. In addition the scientists very quickly acquired excellent computer skills, including at the system level, allowing them to discuss these matters with the professionals on equal footing. The choices made reflected the users rather than the informatics specialists who usually directed laboratory mainframe systems at this time. 


\subsubsection{Electronics and detectors}

This was the domain of Anton Axmann who arrived at the ILL on 1 July 1969. He had experience with both electronics and physics, and had worked in industry, but also with Tasso Springer at Jülich. This background made him an ideal candidate to take charge of electronics at the ILL.

Detectors comprised a considerable part of the electronics. Neutrons being electrically neutral particles cannot be detected directly. First they must undergo a nuclear reaction which produces charged particles which are then detected. The reactions most often used are those following neutron absorption by boron-10 (usually in gaseous form as $\mathrm{BF}_{3}$ ), helium-3, lithium-6 or gadolinium. This is not the place to explain all the variants of detector construction. I will simply say that, in many experiments, there are great advantages in simultaneous collection of neutrons scattered at different angles ${ }^{87}$. A specific case is small angle scattering. In most cases this is achieved using two dimensional detectors where the electrode arrangement is used to locate the points of impact of the neutrons with a resolution of the order of $1 \mathrm{~cm}$ for gas detectors, and about a millimetre for detectors using a solid absorber.

Help from CENG/LETI, and in particular Robert Allemand from Roger Gariod's group, was vital for this development of these multi-detectors.

\subsubsection{Sample environment}

A large fraction of experiments require the sample to be at high or low temperatures, possibly under pressure, or placed in a magnetic field. An advantage of neutrons over $\mathrm{X}$-rays is the fact that they penetrate metal enclosures

\footnotetext{
2018 addition: The main actors involved in this field included Jean Jacobé (1967, engineer), André Rambaud (1969, technician), Pierre Convert (1970, scientist) and Dominique Feltin (joined the team in 1982). The group did an excellent job and played a key role in the advent and popularisation of neutron multi-detectors (also called Position Sensitive Detectors), which can be either one dimensional and curved (so-called "banana" detectors) or two dimensional. With the development of ever bigger and more efficient multi-detectors over the years, these components rapidly became a standard feature of the majority of neutron spectrometers both at the ILL and around the world. The original patent dates back to 1968 (see FR148589A or US3614437A).
} 
much more easily; this facilitates creating a suitable environment when required by the experiment.

The first devices were made for low temperatures. Grenoble could offer excellent support in this field. I have already mentioned the CNRS low-temperature laboratory (CRTBT) directed by Louis Weil until his death in 1968. They had helped build the cold source at Saclay. Weil also led a low temperature group at the CENG. In addition Air Liquide had an outstation at Fontaine, in the outskirts of Grenoble. Louis Weil and Albert Lacaze had created a company named TBT (Très Basses Températures) to exploit their expertise. This company had been taken over by Air Liquide. One of the very first recruits to the ILL was Gabriel Prati, a technician from TBT, in 1969, followed in 1971 by Serge Pujol, also from TBT. Initially, cryostats were ordered from French and German companies. It was quickly apparent that these commercial devices were not well adapted to the needs. They were much too slow for the rapid cycle of experiments at the RHF and not easily usable by novices to cryogenics. An engineer, Dominique Brochier, was recruited from the CNRS/CRTBT. With Pujol, he launched the construction of cryostats at the ILL, likely to be used by non-specialists (often total beginners) and which could be mounted on one instrument or another according to needs. These were remarkably successful. Originally, we had nothing prepared to recover the helium $^{88}$ that spewed out of each cryostat. To reduce these costs we were obliged to install a gas recovery system, which though expensive, was quickly amortised ${ }^{89}$.

For high temperatures it was necessary to await the arrival in 1974 of Pierre Aldebert, coming from the Odeillo solar furnace, a CNRS laboratory, to prepare a thesis on refractory oxides at high temperature.

High pressures were introduced in 1971 by Christian Vettier (French deputy director, 1991-2007), who at that time worked on a thesis on samples under pressure, directed by Daniel Bloch from the laboratory of Louis Néel.

The importance of high magnetic fields was recognised later. In this field the key proponent was another student, Francis Tasset, who was preparing a thesis supervised by Jacques Schweitzer from the crystallography laboratory of the CEA-CNRS.

88 Helium is a rare gas, hence expensive. 
In 10 years, the above distribution has not changed much since the sample environment service is working to the maximum of its capacity in both manpower and equipment. It is therefore supply, not demand, which sets the percentages. The main novelties of recent years are the gradual introduction of new categories of sample environment and the increased automation of devices.
Some figures will show the importance of providing suitable sample environments. In 2005 the percentage of experiments ${ }^{90}$ needing at least one controlled parameter were:

\begin{tabular}{ll}
\hline Low temperatures & $48 \%$ \\
High temperature & $10 \%$ \\
High pressure & $4 \%$ \\
Magnetic field & $11 \%$ \\
Several environment controls & $9 \%$ \\
\hline
\end{tabular}

A major effort has been invested into providing the equipment for users to study their samples in the right conditions. This was certainly a success which has contributed much to the performance of the ILL. While thesis work by students was certainly a motivation, none of this would have been possible without very strong technical support and the necessary resources such as workshops.

\subsubsection{Mechanical Workshops}

These were evidently essential when instrument construction was the main activity. Guy Gobert took care of the drawing office and workshops. Jean Claude Faudou, who came on 1 January 1970, specialised in apparatus for nuclear physics, and Jean Courteau who looked after maintenance. They all reported to Michel Jacquemain. At that time there was a large workshop with several skilled workers. The availability of the workshop and a test hall helped with novel developments, for example the air-cushion technology mentioned above. This did not preclude the use of industry, especially local companies, when necessary. This had the merit of encouraging these enterprises to develop precision engineering competence which would be useful later when they were to tender for work at the ESRF. Now the ILL no longer has its own workshop staff. All projects are contracted to outside companies, but there is still a need to construct new, and improve existing instruments.

90 My thanks to Alain Filhol for sending me these figures. 


\subsubsection{Buildings}

At the end of 1970 all the skills and staff were present at the ILL to implement the operational programme that Maier-Leibnitz considered necessary for the success of the enterprise.

Fortunately, a large building for physicists was constructed at the same time as that for the reactor. A German architect, Professor Erich Schelling, was in charge. He was definitely a good architect, and very attached to the outward appearance of the building. We very nearly had a centralised control of all the external sunblinds. Finally, we had a high quality functional building. Blackboards were installed at our request on each landing to encourage discussions. The directors' offices were moved to (and still remain on) the first floor, together with the library (which, alas, has since been moved to the Common building of the ILL-ESRF, somewhat out of the way ${ }^{91}$ ). A cafeteria was installed on the top floor; again a place for discussions, for which there were, of course, blackboards. Everyone could meet the directors there. This has now been replaced with offices. The building was delivered at the end of 1970 which helped in welcoming new staff, which had doubled during the course of the year.

Maier-Leibnitz knew about the French 1951 law requiring new academic buildings to invest $1 \%$ of the construction costs in original works of art, to be integrated into the architecture. A similar law exists too in Germany. The ILL is not an academic building, hence the French law does not apply in this case. Maier-Leibnitz nonetheless proposed to the steering committee to implement ${ }^{92}$ it. This was greeted with a varied response, but such was the prestige of MaierLeibnitz to the committee, it was finally accepted. There only remained finding artists. We were helped in this by Monsieur Alfred Bauer from the Karlsruhe Centre. The first idea was to ask Calder to create a stabile, as he had made the one placed in front of the station for the city of Grenoble. The price was exorbitant, far exceeding 1\%. For the same reason we dismissed the idea of works by Picasso or Ernst.

912018 addition: in 2014 the library was moved again, this time to the Science Building (even more out of the way). In particular, it was made smaller at the expense of some archives and book collections, since most literature search are now online.

92 In this it was a precursor, since 2002 its application was extended to all State administered buildings and public administrative institutions. 


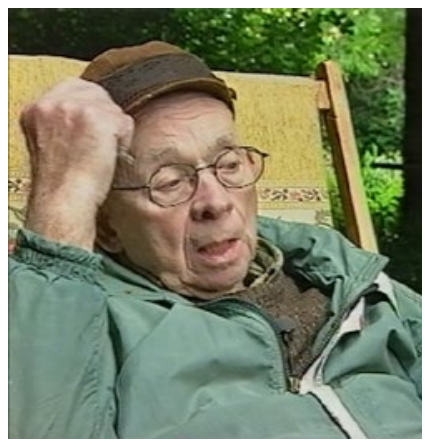

Fig. 5.14: Ipoustéguy in 2003.
Yves Droulers who was a city councillor put us in contact with the Maison de la Culture. It was there that the name of Ipoustéguy (born in Lorraine in 1920) was proposed for the first time. Very little was known of him in France then. Contacted in 1970 the artist made a drawing of his proposal the same year, which he called "L'accomplissement de l'homme vers son unité" (the fulfilment of man walking towards unity). The interpretation by the artist of his work is given in Appendix 7 . We were won over. Our own opinions were not sufficient, and Alfred Bauer submitted the project to various experts, including Dr Fuchs, Director of the Kunsthalle, Mannheim, and an expert in contemporary art, of which the museum had an exemplary collection. At the same time, to ensure the binational character of the ILL a second project to be placed in the lecture theatre was also submitted. Produced by the German artist Wilhelm Loth, born in the same year as Ipoustéguy, it was called "Anthropomorphic Signal". I recall the following from the expert's opinion:

"The concept proposed by Ipoustéguy promises an original composition, of great artistic value. The placement at the proposed site will guarantee enhancing the special character of the sculpture. Finally, Ipoustéguy - and also Loth - show here that he feels at one with the tradition of Rodin's art".

Dr Fuchs also endorsed the project of Loth. For his part, Dr Beye, Director of the Museum of Stuttgart said:

"the mood of the work by Ipoustéguy is especially appropriate",

adding:

"Ipoustéguy is considered to be the most important French sculptor of our epoch."

Faced with such a chorus of praise the steering committee gave its approval. The set of sculptures from Ipoustéguy was completed in May 1972 and installed the following month. Its cost was DM 200,000 (about $€ 600,000$ in 2018); the work of Loth was about DM 18,000. The total was much less than $1 \%$ of the price of a construction costing 30 million DM. The purchase of a work by Schlemmer, an artist from the Bauhaus in the early 20th century was considered, but never finalised. 


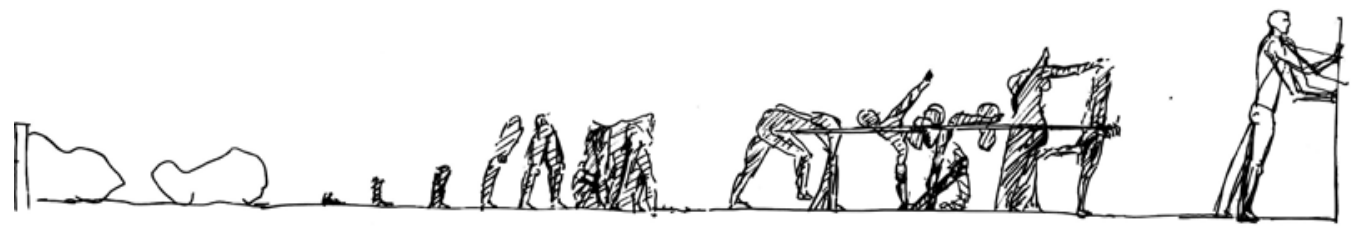

Fig. 5.15: Preparatory drawing for the sculptural assembly proposed by Ipoustéguy.

The whole sculpture has the various components distributed along a concrete slab $20 \mathrm{~m}$ in length. This was installed by the artist in 1972 beside the path leading to the entrance of the main building (see Fig. 5.16). Shortly afterwards representatives of the municipality visited to celebrate the acquisition of a new major work of art in Grenoble. At that time the site was open and everyone could see the Ipoustéguy work. Sadly, this is no longer the case. The presence of a reactor requires very strict control of entry to the site as part of security measures necessitated by the Vigipirate counter terrorism strategy.

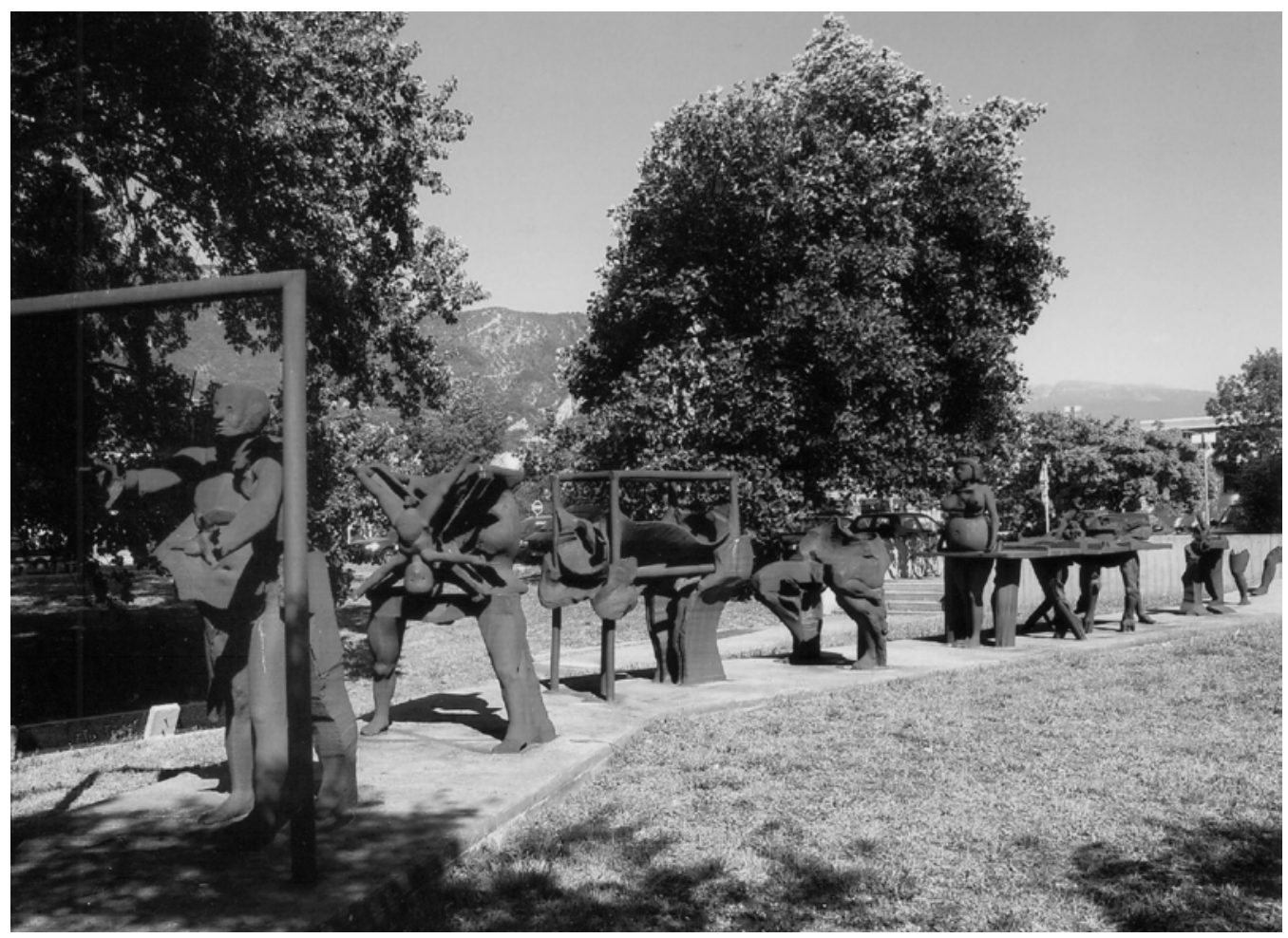

Fig. 5.16: The assembly completed by Ipoustéguy in front of the ILL main building. 
Portfolio 1: D20, a neutron powder diffractometer (2014).

Portfolio 3: LADI III, a neutron Laue diffractometer (2015).

Portfolio 4: SALSA, a neutron strain imager (2016).

\section{Portfolio of some typical ILL instruments in 2018}

The ILL operates about 50 spectrometers. The choice below is somewhat arbitrary; details about more instruments can be found at https://ill.eu/instruments/.

\section{D20, a neutron powder diffractometer}

This is a workhorse instrument for conducting crystal and magnetic structural studies of powder and ceramic samples as a function of intense conditions (e.g. temperature, pressure and magnetic field). Its extremely high neutron flux and versatility opens up new possibilities for real-time experiments on very small samples. The instrument is equipped with a large microstrip detector, which is unique in the world.

\section{D9, a single-crystal neutron diffractometer}

This instrument makes it possible to accurately measure the structure of single crystals, a prerequisite to many scientific studies. It is also used to measure magnetic structures, e.g. those of absorbing elements. Its sturdy Eulerian cradle can accommodate sample environment devices, such as a furnace (as shown here) or a cryocooler.

\section{LADI III, a neutron Laue diffractometer}

Neutron protein crystallographic projects typically aim to address questions concerning enzyme mechanisms and drug or ligand-binding interactions. However, measuring the crystal structure of large molecules involves measuring tens of thousands of Bragg reflections. An instrument like LADI III speeds up the process substantially and the use of neutrons instead of X-rays makes it possible to observe about twice as many atoms.

\section{SALSA, a neutron strain imager}

Mapping residual stresses in actual engineering components is very important for industry. Using neutrons it is possible to study non-destructively metal and composite parts from just a few millimetres to over a metre in size. 


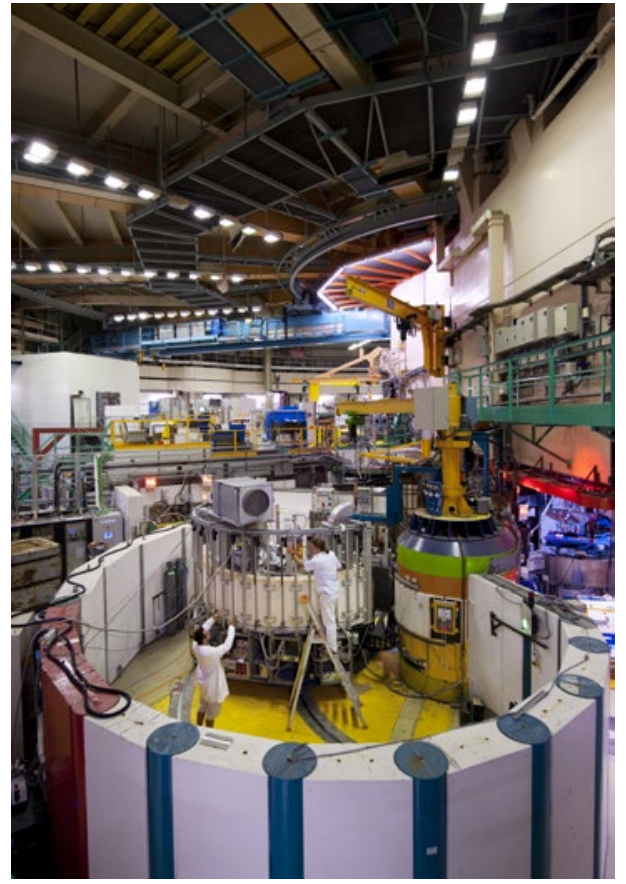

Portfolio 1: D20, a neutron powder diffractometer (2014).

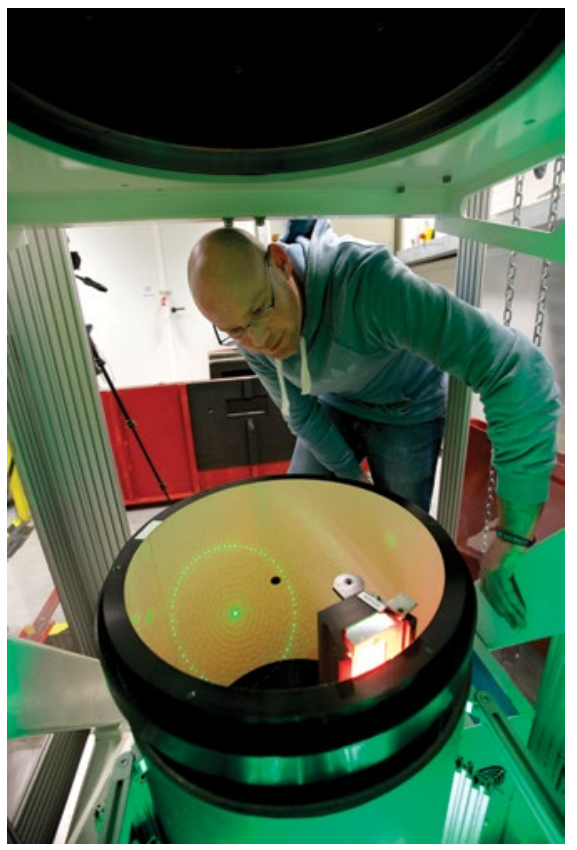

Portfolio 3: LADI III, a neutron Laue diffractometer (2015).

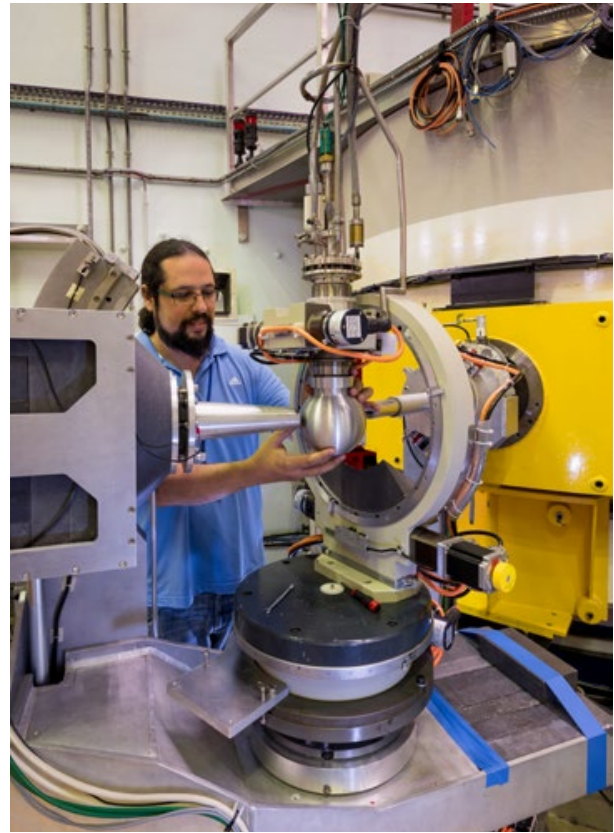

Portfolio 2: D9, a single-crystal neutron diffractometer (2016).

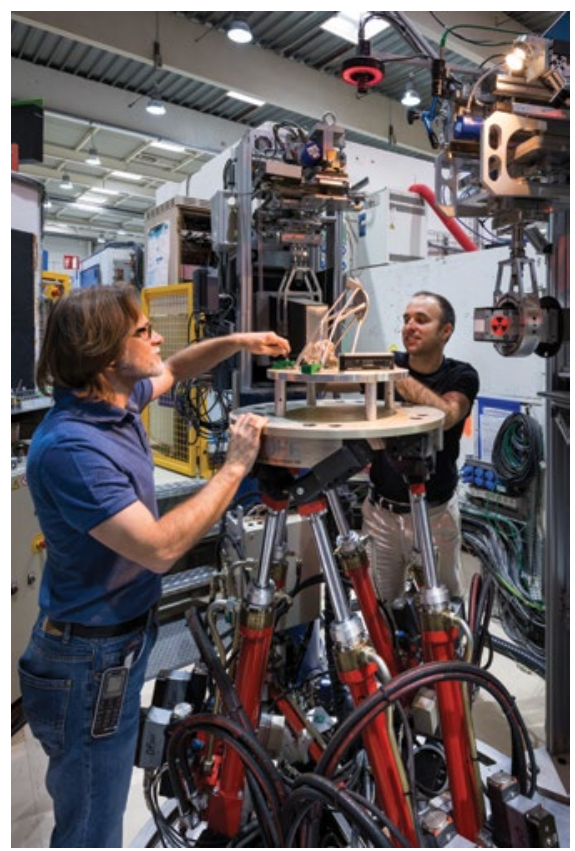

Portfolio 4: SALSA, a neutron strain imager (2016). 
Portfolio 5: D11, a SmallAngle Neutron Scattering instrument (SANS) (2009).

Portfolio 6: IN5, a neutron time-of-flight spectrometer (TOF) (2012).

Portfolio 7: ThALES, a threeaxis neutron spectrometer (TAS) (2016).

Portfolio 8: IN15, a spin echo spectrometer (2017).

\section{D11, a Small-Angle Neutron Scattering instrument (SANS)}

This $80 \mathrm{~m}$-long pinhole-geometry instrument for small-angle neutron scattering (the longest in the world) is designed for the study of large-scale structures in soft matter systems, chemistry, biology, solid state physics and materials science. The sample is placed in the beam in the bottom right-hand corner of the photo. The two-dimensional detector is in the yellow vacuum tube and can be moved from close to the sample up to the far end, allowing measurement of distances in samples from 1 to $100 \mathrm{~nm}$.

\section{IN5, a neutron time-of-flight spectrometer (TOF)}

Atomic, molecular and spin movements inside matter are responsible for energy gain or loss when the neutron passes through the sample. An efficient way of measuring this effect is to measure the time that the neutrons take to cross the distance between the sample and the detector. The resulting motions - diffusive, localised, propagative, rotational, oscillating, etc. - can be studied in a variety of materials ranging from biological compounds to technological and/or magnetic materials.

\section{ThALES, a three-axis neutron spectrometer (TAS)}

Phonons and magnons are atomic and magnetic waves that travel through crystals and drive many of their physical properties. TAS spectrometers are today the most accurate way to measure these phenomena. Typical related scientific problems are in the field of quantum magnetism and the physics of highly correlated electron systems.

\section{IN15, a spin echo spectrometer}

The complex assembly of magnetic coils in this instrument makes it possible to manipulate the spins of the neutrons in such a way that they can be used as a precise internal stopwatch. It is therefore possible to time the diffusion and slow movements of atoms, molecules and polymers. 


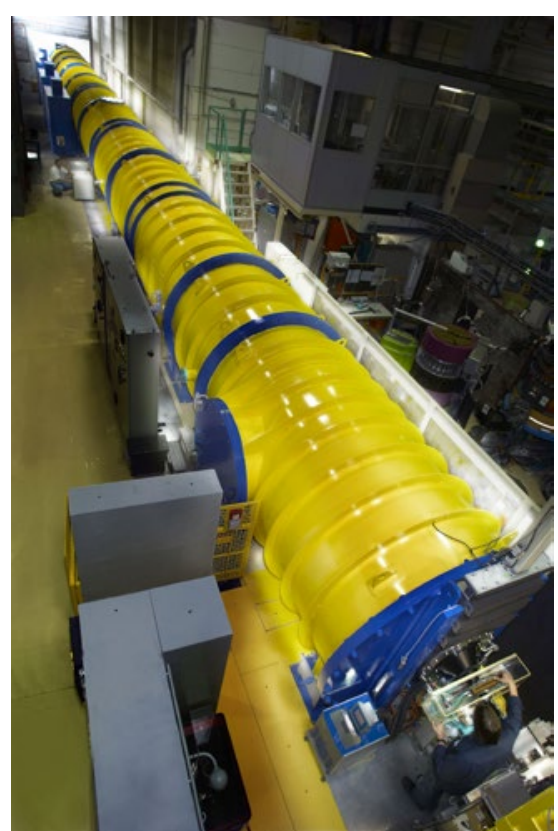

Portfolio 5: D11, a Small-Angle

Neutron Scattering instrument (SANS) (2009).

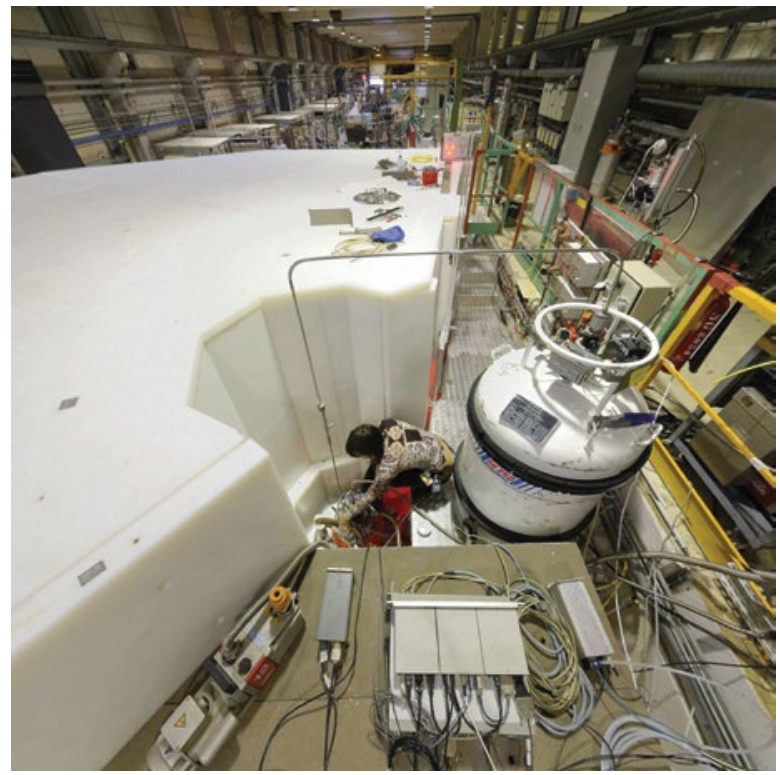

Portfolio 6: IN5, a neutron time-of-flight spectrometer (TOF) (2012).

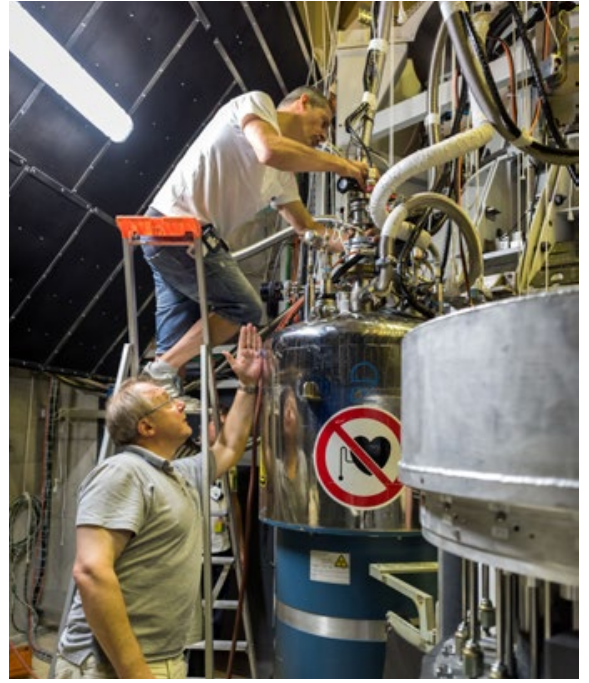

Portfolio 7: ThALES, a three-axis neutron spectrometer (TAS) (2016).

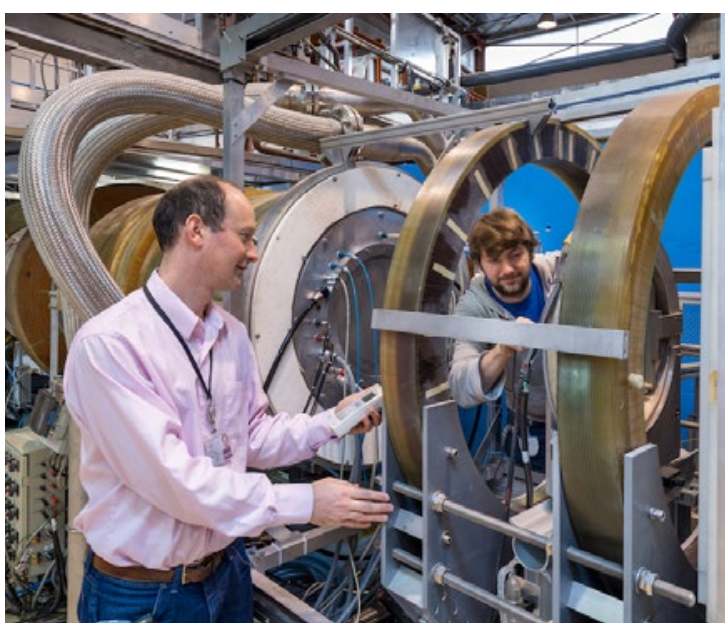

Portfolio 8: IN15, a spin echo spectrometer (2017). 
Portfolio 9: FIGARO, a neutron reflectometer (2003).

Portfolio 10: GRANIT, a gravitational neutron spectrometer (2009).

Portfolio 11: S18, a neutron interferometer (2016).

Portfolio 12: PN1, a nuclear physics spectrometer (2015).

\section{FIGARO, a neutron reflectometer}

Neutron reflectometry investigates the nanoscale structure of surfaces and thin films at the interface between materials. These interfaces can be air-water, buried solid-liquid or liquid-liquid interfaces, and some of the key application areas are soft condensed matter and biomacromolecules.

\section{GRANIT, a gravitational neutron spectrometer}

This instrument was the first to observe quantum states of ultra-cold neutrons in a gravitational field. It now uses these quantum states, and the resonant transitions between them, as probes for measuring physical phenomena with ultra-high energy resolution. The photo illustrates the fact that the quantum states of the neutron hover above the mirror of the instrument.

\section{S18, a neutron interferometer}

The heart of S18 is a perfect silicon crystal, which constitutes an interferometer for thermal neutrons. The instrument is used to perform advanced experiments in neutron optics, making it possible to study fundamental phenomena in quantum physics. Another important application is the precise measurement of neutron scattering lengths.

\section{PN1, a nuclear physics spectrometer}

The fission fragment separator PN1 (also called LOHENGRIN) separates atomic nuclei produced in nuclear fission according to their mass, charge and kinetic energy. This serves for an improved understanding of the nuclear fission process and to provide accurate nuclear data for applications (e.g. calculations of reactor decay heat). Nuclear fission produces also short-lived exotic nuclei that play an important role in nucleosynthesis, i.e. the creation of heavy elements in the universe. Decay spectroscopy of nuclei enables, e.g., to infer their shape (spherical or deformed) and excitations (vibrations and rotations) which in turn may influence the nucleosynthesis process.

The photo shows a model of a deformed nucleus (inflated in size by 13 orders of magnitude) inside the Ge detector array installed at the focal plane of LOHENGRIN. 


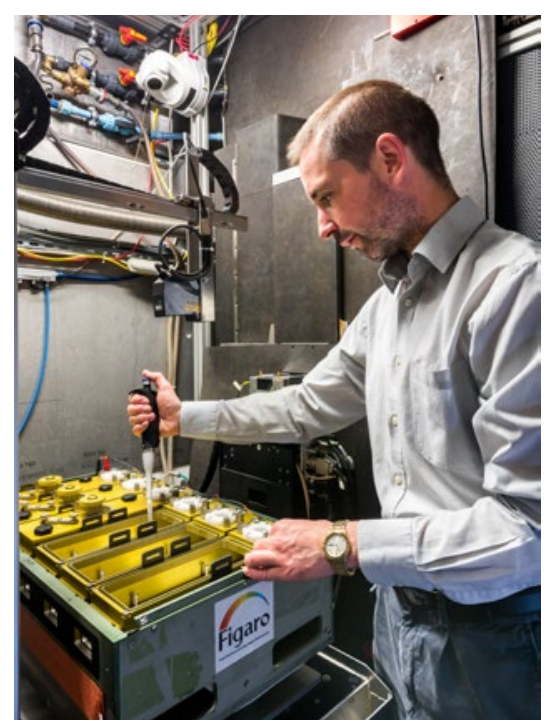

Portfolio 9: FIGARO, a neutron reflectometer (2003).

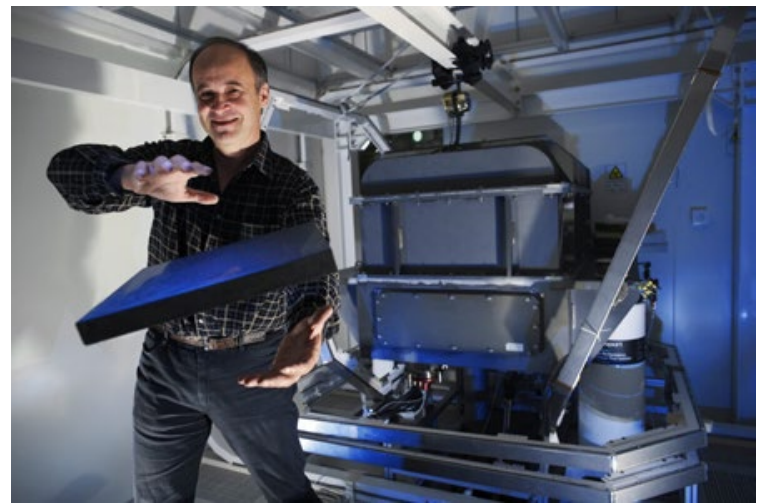

Portfolio 10: GRANIT, a gravitational neutron spectrometer (2009).
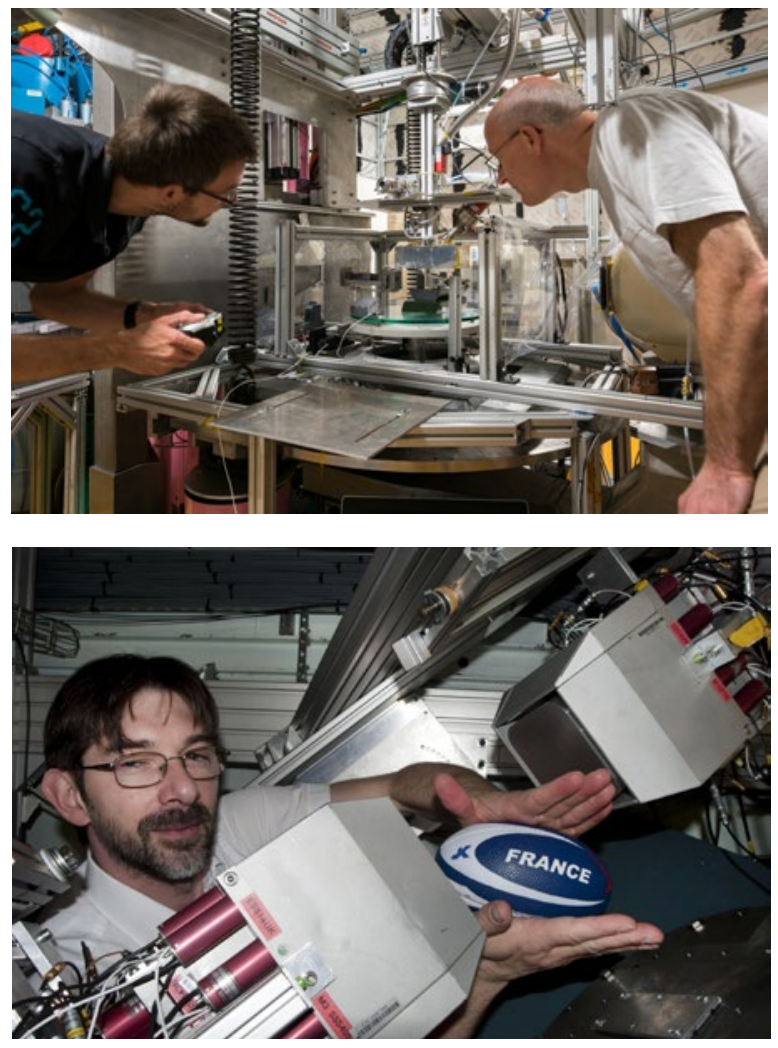

Portfolio 11: S18, a neutron interferometer (2016).

Portfolio 12: PN1, a nuclear physics spectrometer (2015). 



\section{Chapter 6}

\section{The start of research activities and the arrival of the British}

\subsection{The start of research activities}

The year 1972 marks the transition of the ILL from adolescence to adulthood. The reactor operated at full power from December 1971. In May 1972 the hot and cold sources were in operation.

We can say that the construction phase of the reactor was over. Henceforth, operation was entrusted to the head of the reactor department. This was an important responsibility, and was a vital role for the well-functioning of the institute. For the first years Yves Droulers fulfilled the post, then from 1979 to 1989 Franco Franzetti; both had come from the CENG. They were followed by a German, Ekkehardt Bauer from Franzetti's team. We will see later that he had a particularly important task when it became necessary to rebuild the reactor. In 2002, he was replaced by Hervé Guyon who came from Saclay.

The change in status of the reactor was accompanied by the replacement of the director. Maier-Leibnitz left at the end of January 1972. He had presided over the construction and commissioning of a great research tool equipped with instruments necessary for optimal operation. It was the realisation of a work for which he had longed, when the Institut obtained the first scientific results. The organisation he wanted was in place and would stay in place without major modifications until the present day.

He was replaced on March $1^{\text {st }}$ by Rudolf Mössbauer (Fig. 6.1), a recent Nobel Laureate for the discovery of the effect named after him. The choice of Mössbauer as director was a little surprising; he had no connections with neutrons, but he was a former student of Maier-Leibnitz. It is also difficult to imagine two more different personalities.

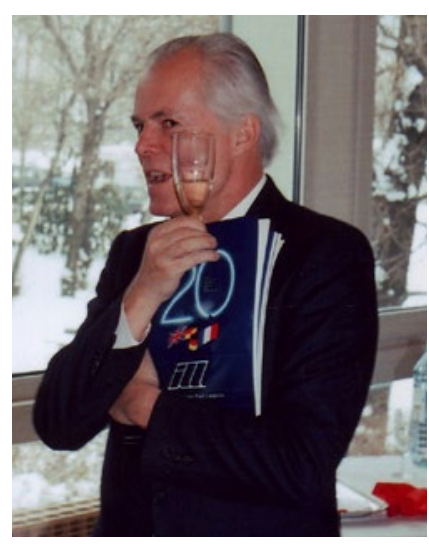

Fig. 6.1: Rudolf MÖSSBAUER 
Maier-Leibnitz made no boundaries between professional and private life. He invited many to his house, and this was a deliberate way of making contacts with others. His wife was very active in the social life of the Institut. For Mössbauer this boundary was totally insurmountable. This said, he was an excellent director. My relations with him during the two years that I spent with him at his request were very good. The roles of these two successive directors were very different. Maier-Leibnitz had to create an institute; Mössbauer had to make it work. The annual reports reflect well the two styles of leadership. The major policy decisions disappeared to be replaced by an ordered review of events occurring during the year. Several important decisions were taken during the first year, though there was no conflict with the structure established by Maier-Leibnitz. In particular I'll mention:

1. The creation of a scientific secretariat whose function was to coordinate the aid which the ILL had to provide for external users (the majority of users). Bernd Maier, assisted by an excellent secretary, Christel Kazimierczak, was entrusted with this important task to implement Maier-Leibnitz's scientific policy. The aid offered included the appointment of a local contact for each experiment to help the users and if necessary arrange technical support. The aid included a refund of travel expenses for visitors who had proposals accepted by the subcommittees and the Scientific Council.

2. The theoretical physics group based in Munich was abandoned to bring all scientists together in Grenoble. Philippe Nozières was recruited in October 1972 which enhanced the group's status internationally.

3. The subcommittees of the Scientific Council were formalised. They had been meeting since 1966; their future role was to take responsibility twice a year for selecting experiment proposals for beam time. These subcommittees treated (and continue to treat):

- Nuclear physics

- Motion in crystals (phonons)

- Crystallographic and magnetic structures

- Liquids, gases and amorphous solids

- Defects in solids.

- Chemistry

- Biology 
Each subcommittee thus matches one of the colleges of the Institut. This system was very effective and persists today.

4. The initial rental and subsequent purchase (as second-hand) of the DEC PDP-KI10 central computer. The computer system was in service from 1973 to 1982 and usefully replaced the link to the computer centre of the university.

The change of director had been quickly followed (though unlinked) by a change of the administrator. Wolfgang Hasenclever was replaced from November 1973 by Adalbert Plattenteich (01/11/73 to 31/12/77), who had represented the German Ministry of Research on the steering committee. All administrators were German, as all heads of the reactor department were French. The administrators were then Wolfgang Grillo (1/1/78 to 30/4/83), Cristoph Eitner (1/5/83 to 30/4/88), Hans-Martin Spilker (1/6/88 to $31 / 7 / 94)$, Sigurd Lettow (1/8/94 to 31/7/01), Norbert König (17/09/01 to 16/09/06) [2018 addition: Amin Saidoun (17/09/06 to 31/08/11), Martin Walter (interim: $1 / 09 / 11$ to 31/02/12), Manuel Rodriguez Castellano $(01 / 04 / 12$ to $30 / 09 / 16)$ and Alexandre Durand (01/10/16)].

I have already briefly described the first instruments under construction. Table 6.1 below, taken from the activity report for 1972 shows the degree of progress made on their installation. The last column shows the date on which the instrument entered (or was intended to enter) routine operation. We see that very few instruments were completely ready when the reactor was fully operational with the cold and hot sources in May 1972. Most were installed in position around the reactor but in a test phase.

Table 6.1 Operational instruments in the activity report of 1972

\begin{tabular}{lllll}
\hline IN1 & Triple-axis & Hot source & Routine operations & February 73 \\
IN2 & Triple-axis & Thermal beam tube & Routine operations & October 72 \\
IN3 & Triple-axis & Thermal guide & Construction finished - on test & April 73 \\
IN4 & Rotating crystal & Thermal beam tube & Construction finished - on test & April 73 \\
IN5 & Multi-chopper & Cold guide & $\begin{array}{l}\text { Installation nearly finished - on } \\
\text { test }\end{array}$ & April 73 \\
IN6 & Triple-axis & Hot source & Installation foreseen in May 1973 & April 74 \\
IN7 & Statistical chopper & Thermal guide & Installation finished; on test & April 73 \\
IN8 & Triple-axis & Thermal guide & Awaiting parts & April 73 \\
IN9 & Polarised proton target & Cold guide & On test & Autumn 73 \\
\hline
\end{tabular}




\begin{tabular}{|c|c|c|c|c|}
\hline IN10 & Backscattering & Cold guide & In progress & Begining 73 \\
\hline D1A & 2-axis diffractometer & Thermal guide & Installation finished & May 73 \\
\hline D1B & 2-axis diffractometer & Thermal guide & Installation finished & May 73 \\
\hline D2 & 2-axis diffractometer & $\begin{array}{l}\text { Thermal } \\
\text { beam tube }\end{array}$ & Routine operations & August 72 \\
\hline D4 & 2-axis diffractometer & Hot source & Routine operations & February 73 \\
\hline D5 & $\begin{array}{l}\text { Diffractometer with } \\
\text { polarisation analysis }\end{array}$ & Hot source & Installation finished; tuning & April 73 \\
\hline D6 & Hedgehog diffractometer & Thermal guide & $\begin{array}{l}\text { Installation finished; } \\
\text { background problems }\end{array}$ & $?$ \\
\hline D7 & Diffuse scattering & Cold guide & Routine operations & March 73 \\
\hline D8 & 4 circle diffractometer & Thermal beam tube & Installation nearly finished & May 73 \\
\hline D9 & 4 circle diffractometer & Thermal beam tube & Under manufacture & March 74 \\
\hline D10 & 4 circle diffractometer & Thermal guide & & End 73 \\
\hline D11 & Small angle scattering & Cold guide & Routine operations & July 72 \\
\hline D12 & $\begin{array}{l}\text { Modified Laue } \\
\text { diffractometer }\end{array}$ & Thermal guide & Installation under way & End 73 \\
\hline PN1 & $\begin{array}{l}\text { Lohengrin, fission } \\
\text { fragment spectrometer }\end{array}$ & Thermal beam tube & Installation unfinished & August 73 \\
\hline PN2 & $\begin{array}{l}\text { Conversion } \\
\text { Electrons }\end{array}$ & Thermal beam tube & Installation unfinished & August 73 \\
\hline PN3 & Gamma ray spectrometer & Transverse beam tube & Routine operations & March 73 \\
\hline
\end{tabular}

There are some instruments that were not in the above list from 1969. One of them is IN10, a back-scattering spectrometer. The principle was proposed in 1966 by MaierLeibnitz, and tested in 1969 in Munich by Bert Alefeld and Anton Heidemann ${ }^{93}$. The idea was to use crystals for monochromatisation and analysis of neutrons scattered by the sample which used Bragg angles very close to 90 degrees. Under these conditions the angular divergence of the beam only affects the resolution in energy to second order. A fairly large beam divergence can be used while having good energy resolution, which can attain $0.62 \mu \mathrm{eV}^{94}$. The scanning is performed by the oscillating

93 The principle had been used earlier in 1954, in the context of a neutron filter by P.A. Egelstaff and R.S. Pease, J. of Scientific. Instruments (1954), 31, 207-212, DOI 10.1088/0950-7671/31/6/305

942018 addition: This is about 100 to 1000 times less than the energy of molecular vibrations. With such a small energy resolution it became possible to observe atomic quantum tunneling effects in matter, as well as the coupling between electronic and nuclear spins. These may seem exotic topics but we should not 
motion of the monochromator along the beam direction, shifting the energy by the Doppler effect. The construction of this instrument launched by Maier-Lebnitz was almost stopped because, in 1972, a Hungarian physicist, Ferenc Mezei joined the ILL bringing with him a technique he had invented, neutron spin echo, described earlier, which offered even better energy resolution. Finally, it was decided to build both. The two instruments have different applications. The spin echo spectrometer is well adapted to study systems where there are several relaxation times, but it could not easily distinguish sets of spectral lines. Over the following years the success of these two techniques has led to the construction of several versions of these two instruments.

The table includes reference to the first problems encountered with the "Igel" (hedgehog) diffractometer D6. These led to the project finally being abandoned. The high resolution diffractometer D1A could attain the desired resolution, but the measured intensities were so low as to be unusable. After the arrival of the British, Alan Hewat modified the collimators using the expertise of the SRC-Rutherford Laboratory, and together with additional detectors it became fully operational and was heavily used.

When the instruments were ready experiments were immediately started. On IN2 Steiner and Dorner measured spin waves in a one-dimensional ferromagnet $\mathrm{CsNiF}_{3}$ which was then published in $1973^{95}$. The first small angle scattering tests were performed by Konrad Ibel and Henrich Stuhrmann on myoglobin ${ }^{96}$, and Renouprez measured $\mathrm{SiO}_{2}$.

\subsection{Further developments in neutron optics}

Developments in neutron optics did not cease with the departure of Maier-Leibnitz. On the contrary, it was expanded by the arrival of a new activity, the development

forget that, for example, atomic clocks which are so important for satellites and, in particular, the GPS technology are based on the latter phenomenon.

95 M. Steiner and B. Dorner, Solid State Communications (1973), 12, 537-540, DOI 10.1016/0038-1098(73)90652-2

96 K. Ibel and H.B. Stuhrmann (1975) JMB B, 255-265.

DOI 10.1016/0022-2836(75)90131-X 
of supermirrors. These were invented by Ferenc Mezei ${ }^{97}$. The starting point was work done at Brookhaven by Benno Schoenborn et al. ${ }^{98}$. They demonstrated that by evaporating alternating sequence of layers of different metals on a flat support they could create a one-dimensional crystal which could serve as a monochromator. The principle of a supermirror is to produce a sequence of broad Bragg peaks just beyond the critical angle of reflection. This is achieved by progressively varying the thickness of an alternating sequence of deposited layers. Then one obtains a mirror which acts like a slightly less efficient conventional mirror (70\%), but which will continue to reflect at up to four times the critical angle, hence the name supermirror. If only twice the critical angle of nickel is taken as the acceptable limit then the efficiency rises to $92 \%$. This has led to a programme of gradual replacement of the nickel mirrors in the neutron guides by supermirrors. All this implied a huge task of research and development, especially to improve the quality of the deposited films. By using a magnetic material for one of the layers the supermirrors can be used to produce polarised neutrons. Otto Schärpf led even more research work to find the best materials and techniques ${ }^{99}$.

However the most important event for the ILL with Mössbauer as director was the arrival of the British as an equal third partner. This was the result of lengthy negotiations which had started in the time of Maier-Leibnitz.

\subsection{The arrival of the British}

Negotiating ${ }^{100}$ with the British for their accession to the ILL was totally different in nature from that which led to the establishment of the Institut. Negotiation between French and Germans was intended to build a reactor that had yet to be precisely defined. I have indicated above the many decisions which had to be taken. Negotiation

\footnotetext{
97 F. Mezei, Communications on physics (London), (1976), 1, p81-85. F. Mezei and P.A. Dagleish, Communications on physics (London), (1976), 2, p41-43. Papers available here.

98 B.P. Schoenborn, D.L. Caspar and O.F. Kammerer, J. Appl. Cryst. (1974), 7, 508-510, DOI 10.1107/S0021889874010302

99 O. Schärpf, I.S. Anderson, Physica B (1994), 198, 203-212, DOI 10.1016/0921-4526(94)90161-9

${ }^{100}$ I wrote this chapter using copies of the original documents (letters, minutes of meetings, memoranda) which I possess.
} 
with the British took even more time despite the fact that there were only a few technical points to discuss since the reactor was already operational, with instruments ready, or nearly ready, to be used. The slowness of talks was a consequence of British procrastination which hovered between two positions: fight for a purely British high flux reactor, or join the ILL. The 1962 British project was improved and the use of guides was envisaged. When I speak of the British I think of the Science Research Council (SRC) who had been our negotiating partner during these years of discussions. The British Associate, SRC (or under its newer name, Science and Engineering Research Council, SERC), the German Associate (GfK, then FZ-Jülich) and the French Associates are now partners in the private company which manages the ILL.

Openings were initiated while Maier-Leibnitz was still director, and continued when Mossbauer suceeded him. The first practical action was the visit of a small delegation from the SRC to the ILL on 6 and 7 March 1970. The group comprised Bill Mitchell (Fig. 6.2), who was the chairman of the Neutron Beam Research Committee, Dr Valentine, Mrs Wade, Mr Wood, and Mr Jolliffe. At that time the construction of the ILL reactor was well under way, and the pre-studies for the British project were quite advanced.

The report written by Jolliffe for the SRC about the visit is interesting to read (the conclusion is included here as Appendix 3). One senses some scepticism for the ILL maintaining the announced schedule ("We are doubtful of this being achieved") and it is striking that an emphasis is placed on the so called difficulties in the Franco-German collaboration. As I have stated elsewhere, in fact these difficulties have never existed. A collaboration between the ILL and the SRC was raised, which would be useful for the British during the following five years, i.e., until the completion of the reactor in the UK. There was never any mention that the SRC would join the ILL as a partner.

The second British visit was by a delegation of the "Council for Scientific Policy", a body composed of top level scientists who advise the government on science policy. The delegation included Professor Dainton, Sir John Kendrew, Dr Merrison, Feilden and Embling, under secretary of state for science and education. The first day was spent at the Délégation Générale à la Recherche Scientifique et Technique (DGRST), a part of the Prime Minister's Office, in Paris with Pierre Aigrain who presided over the

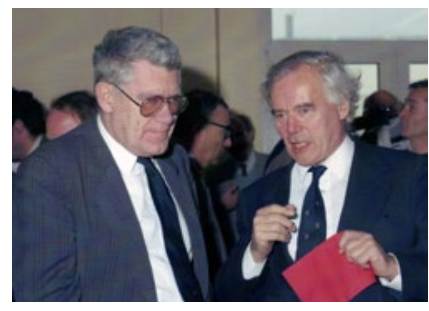

Fig. 6.2: Bill Mitchell (right) in conversation with Tasso Springer 
committee of "The Sages", whose role for the French was analogous to the British visitors. The whole of the following day, 6 November 1970 was spent in Grenoble. During the morning at the CENG, Louis Néel included a visit to the ILL, where I met them all. The possible participation of the SRC in the ILL had not really been discussed, however I think that the visitors gained a good impression of Grenoble, and the ILL in particular. This visit had a definite importance when the British government made its decision two years later. The visit also had consequences for the EMBL, as will be evident when I write more of the creation of the EMBL outstation at the ILL.

A new visit of the SRC representatives took place on 2 December 1970. The discussions focused mainly on the scientific programmes, with contributions from Mitchell (British programmes), Allen (polymers), and White (dynamics of liquids). It was an opportunity for us to appreciate the progress made by the British in certain fields, notably for studying polymers. Another visit took place on 25 and 26 February 1971. For the first time the subject of a collaborative contract was addressed seriously, and Maier-Leibnitz gave a presentation on the matter at the following meeting of the Steering Committee. His impression was that the SRC no longer expected a positive decision on the construction of a British reactor, and was consequently interested in a long-term participation in the ILL. However, the Council of the SRC met on 21 April 1971 and recommended to the Minister to build a reactor in the UK; the request was the subject of an article in the Financial Times on 1 June. They asked at the same time to be able to use $10 \%$ of the reactor resources of the ILL.

On 19 June 1971 Mitchell wrote a document listing the experiments that SRC scientists wished to perform at the ILL, and the relevant instruments. For all these it was proposed to buy $10 \%$ of the operating time of the reactor. To clarify the discussions the Steering Committee appointed a sub-group of Greifeld, Loosch, Creyssel and Horowitz, to be responsible for conducting the negotiations with the SRC, whose delegation was led by Sir Brian Flowers. Three meetings were held in 1971 (12 July, 28 October and 14 December).

On 25 October the French Ministry for Industrial and Scientific Development expressed in writing its veto on British participation at $10 \%$. The reason given was that this percentage would not be sufficient for the needs of the British, given the scientific activity in the UK and 
especially in the field of research using neutron beams. Note that the Financial Times had published an article on 30 September 1971 that a decision by the government on financing the reactor was imminent. The year 1971 thus ended in a state of total confusion with the ILL (or more precisely the Associates) insisting on fully shared membership with the SRC (and working towards easing and improving the financial conditions for this), and the SRC continuing to fight for its own reactor. This situation is described in a telex (included here in Appendix 4) from Flowers to Creyssel, then president of the Steering Committee, on 23 or 24 January 1972.

There was nothing new in the negotiations during the first half of 1972. There was a meeting between the ILL and SRC on 27 June in Grenoble, where again nothing was recorded, but Horowitz did note that the meeting had taken place in an excellent atmosphere, which certainly had not always been the case in the past. Two explanations for this change may be given. The first is that, at the start of the meeting, Mössbauer, now Director of the ILL, announced the successful start-up of the hot and cold sources. This demonstrated the successful construction of a reactor now fully operational. The second is that Flowers was probably aware of the decision of the government to authorise opening negotiations with the ILL for the SRC to become a partner of the ILL. The decision had been communicated to Creyssel on 23 August, and made official on 31 August 1972. It was immediately criticised by Mitchell ${ }^{101}$, chairman of the SRC Neutron Beam Research Committee. He said the wrong decision had been made, but he was happy that it had finally been made, and he would do his best to complete the negotiations.

The official negotiations began on 29 September 1972. It was convenient to make the fewest possible changes to the statutes of the ILL, and simply make adjustments made necessary by the presence of an additional partner (working language, membership of committees, etc). It only remained to agree on how the SRC would contribute to the construction costs for the reactor and instruments already expended by the current partners. An agreement was needed on new instruments now necessary with a new partner. Everything was settled in time for British

101 "Reactors: Collaboration at Grenoble", Nature (1972), 239, p60-61, DOI 10.1038/239060b0 
membership to become effective from 1 January 1973. Changes to the intergovernmental agreement made necessary by the involvement of a third government were signed on 19 July 1974. Apart from changes made necessary by the arrival of a third partner the only significant change relates to Article 2. Instead of the governments making a fixed amounts of money available to the associates this sum would have to be agreed upon unanimously ${ }^{102}$ each year by the Steering Committee. Also of note in Article 7 is the extension to two years for any notice of termination. The new text remains unchanged to this day. Successive amendments of 1981 and 1993 only relate to the extension of the life of the company. An obsolete reference to the Land of Berlin was removed.

It is important to note that Mitchell, who had been the chief proponent of the British reactor was always flawless in his dealings with the ILL, and only for domestic reasons could he not accept nomination to be the first British Director. In fact, he took responsibility in the early months between January and May 1973 awaiting the arrival of Lomer. Mitchell helped decide on the first scientists recruited coming from Britain (in particular Sax Mason, Julia Higgins, Jo Zaccai, Stephen Lovesey, Alan Hewat, Bill Stirling etc, who arrived in Grenoble between June and November 1973). These decisions were taken in meetings with him and Mössbauer, one of which took place in a brasserie in the Latin Quarter in Paris (Le Balzar). This was a reminder of the tradition of the first meetings of the Scientific Council in the time of Maier-Leibnitz where at least one took place at the station in Geneva. It is certain that the arrival of the British who had a dominant position in the use of neutrons in various fields of research, was a considerable asset to the scientific life of the ILL; they introduced and developed the use of neutrons in chemistry and the study of polymers. The arrival of the British researchers was warmly accepted by the staff of the ILL.

It could have been hoped that the protracted negotiations would have led to a stable state which would never be challenged. This was the case for nearly 20 years. We shall see later that, unfortunately, this was not always to be.

$\overline{102}$ In practice this rule proved to pose problems and could lead to the budget being defined by the financial constraints of the country with the most budgetary problems. 


\section{Chapter 7}

\section{Maturity}

Maturity is a period of life during which one achieves maximum efficiency, but also when the first serious illnesses occur. For the ILL I would place this time between 1984 and 2005 as having these positive and negative signs of maturity. The number of users had grown greatly and hundreds of scientific publications resulted each year, but there was a progressive ageing of the irradiated reactor infrastructure to be accounted for one day. This would lead to long interruptions to the scientific measurements.

One of the positive aspects of this maturity is that the success of the ILL with an increasingly international character, has made Grenoble attractive to other multi-national organisations. The quality of the Université Joseph Fourier de Grenoble, the CNRS laboratories therein, and the CENG reinforce this attraction. A modern industrial base (Hewlett Packard, etc.) has evolved too, all contributing to the appeal of the city. The land ceded by the CENG for the ILL is sufficiently large to accommodate other international laboratories. Hence, the arrival first of an outstation of the European Molecular Biology Laboratory (EMBL) then the European Synchrotron Research Facility (ESRF). I will now describe briefly the evolution of these two institutes and what led to their being built on the ILL site. These establishments have transformed a space once completely empty before the advent of the ILL (Fig. 7.1) into a busy multi-laboratory site (Fig. 7.2). 
Fig. 7.1: View of the site where the ILL will be built.
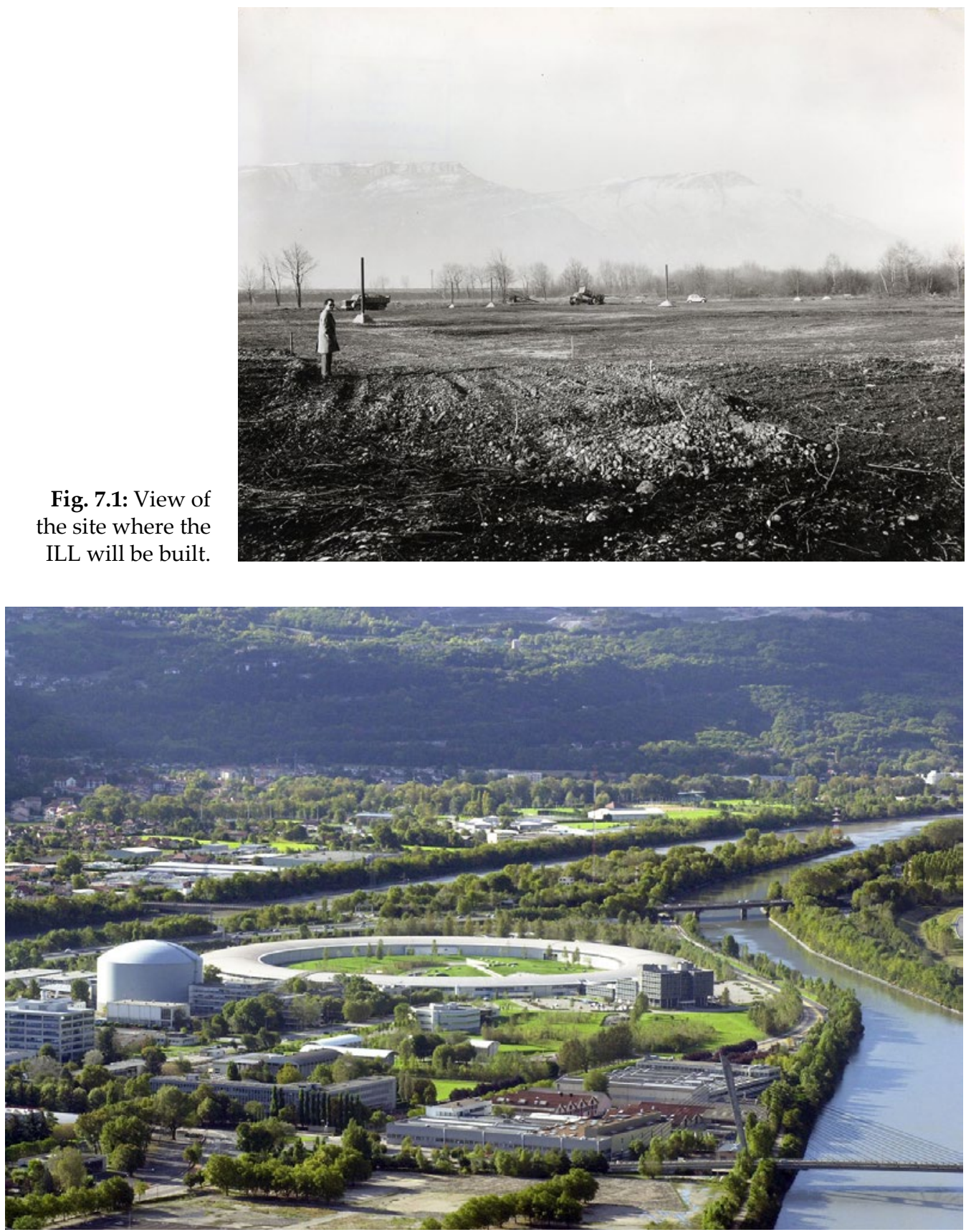

Fig. 7.2: The view in 2005 of the confluence of the Isère and the Drac. The large circular building is the ring of the European Synchrotron Radiation Facility (ESRF). In front and to the left is the reactor building with the ILL main building adjacent. The EMBL laboratories are sited between these two institutes. 


\subsection{The EMBL}

To understand what led the EMBO create a laboratory in Grenoble at the ILL, we must go back to November 6, 1970. At that time the "Scientific advisory commitee" of the British government during a two-day visit to Grenoble, came to the ILL. I have already mentioned this visit in describing the events that led to the British becoming partners in the ILL. I return to this now because the committee had among its members Sir John Kendrew (19171997), an eminent structural biologist who received the 1962 Nobel Prize for his determination of the structure of myoglobin, using X-ray crystallography, Sir John was motivated by a strong desire to develop cooperation between biologists of various European countries, which was shared by most of his colleagues.

At the time the European Centre for Nuclear Research (CERN) located in Geneva, was the only example of European scientific cooperation. In 1962 Vicktor Weisskopf was director of CERN. With Leo Szilárd, one of his friends from the Manhattan Project ${ }^{103}$, both saw that European biologists would benefit by joining forces to keep Europe competitive as the nuclear physicists had done. They invited Jim Watson and John Kendrew to come and discuss this on their return from receiving their Nobel prizes in Stockholm. From this was born the idea of a European molecular biology laboratory, which would naturally find its place next to CERN, the two forming the first steps towards a European scientific university. A private company, EMBO, the European Molecular Biology Organisation was established.

In 1964 Szilárd died, and Kendrew found himself alone on the project. The departure of Weisskopf from CERN left the Geneva site less attractive, since his successor did not share his interests. Kendrew attached great importance to the proximity of physicists. In 1970 a site was proposed at Heidelberg by Germany. Wolfgang Gentner was in Heidelberg, a nuclear physicist who had worked with Maier-Leibnitz when the laboratory was led by Bothe. Gentner's acts during the war had been remarkable (he had managed to obtain the release of Paul Langevin, who had been taken hostage). The site at Heidelberg was good but not comparable with a location adjacent to CERN.

103 This was the code name for all scientific activities leading to the creation of the atomic bomb by the USA. After the war Szilárd left physics and became a biologist. 
2018 addition:

The Carl-Ivar Brändén

Building, inaugurated in 2006, now hosts the

Partnership for Structural Biology and the Deuteration laboratory. This building also hosted the Partnership for Structural Biology (the UVHCI), from 2007 to 2015.
Such was the situation when Kendrew came with his committee to visit Grenoble and the ILL. Kendrew was struck by the strength of physics, notably solid state, in Grenoble. Now the physics of solids is fundamentally of greater interest to biologists than nuclear physics. At the end of the visit he explained to me that the site at CERN was no longer a possibility, and he didn't have great enthusiasm for the location at Heidelberg. He found the Grenoble site perfect (France had proposed Nice), and he asked me to go immediately and see François Jacob and speak to him. Though very nervous, for he had a reputation of being very cold, I did this straightaway. There, in front of me François Jacob telephoned the minister for foreign affairs (Maurice Schumann), who told him that France had just promised Germany to support the Heidelberg site. Kendrew told me he would do everything so that there would at least be an outstation in Grenoble to promote the use of neutrons in biology. The early work in structural biology using neutron diffraction had been performed in Brookhaven by one of his former students, Benno Schoenborn. This work clarified the structure determined by Kendrew, who was convinced of the usefulness of neutrons in biology. He held his promise, and in 1976 the Grenoble outstation was in operation led by Andrew Miller, a biophysicist from Oxford, and the collaboration between the laboratory and the ILL has proved very successful. Since its inception the area of laboratory space has doubled, and there is a project with the ILL and ESRF to further enlarge this outstation whose usefulness has further increased since the start of production of the intense X-rays of the ESRF.

\subsection{The ESRF}

During the creation of the European Science Foundation (ESF) in 1975, Maier-Leibnitz had the idea of satisfying the desires of the scientific community by making the construction of a European machine producing intense beams of X-rays the subject for study by the recently born ESF. After many delays the idea was extensively developed, giving rise to the Black and the Blue Books ${ }^{104}$.

104 The Black Book: "Synchrotron Radiation, a Perspective View for Europe" (1975) Ed. The European Science Foundation, Strasbourg; The Blue Book "European Synchrotron Radiation Facility: The Feasibility Study" (1979), Ed. The European Science Foundation, Strasbourg, ISBN 2-903148-01-5. 
It would only materialise in February 1984 when Brian Fender, then Director of the ILL, formulated the proposal to locate the European synchrotron radiation source on the ILL site. Previous arguments, in 1979 and 1982, for the construction of the source had been developed and well received. In a report of 21 February 1984 (in Appendix 5) Fender presented the scientific and economic arguments for an installation beside the reactor of the ILL. Finally this reasoning was accepted and the European Synchrotron Radiation Facility (ESRF) was created on the site of the ILL and the EMBL.

Construction began in 1988, and the first users had access to the machine in 1994 . The point made by Fender that the ESRF should not be a mere appendage of the ILL has been fully taken into account, and the partners who fund the ESRF are not exactly the same as those of the ILL. France $(27.5 \%)$ and Germany $(25.5 \%)$ are included again; Italy $(15 \%)$ has a share almost the same as that for the U.K. $(14 \%)$, Switzerland (4\%), the Nordic countries, etc ${ }^{105}$.

There is a natural synergy between the two institutes, each retaining its independence. For example, Andreas Freund, who had developed monochromator crystals at the ILL, moved to perform the same type of work at the ESRF. A building was constructed in 1992 for joint activities; it includes a cafeteria, library, and the group of theorists. It certainly helps save money. For the ILL the disappearance of the library and cafeteria from the main building is a big loss for the scientific life and human relations. More recently a new guesthouse for use of visiting researchers has opened and offers direct contacts between the scientists from the two institutes.

A growing number of projects require the use of the two sources, neutrons and X-rays. One area in which the complementarity between these two sources is important is structural biology. High intensity X-ray sources, achievable with synchrotrons, have enabled considerable progress by facilitating measurements of increasingly large entities in smaller and smaller crystals.

However in the case of complex objects composed of several proteins $X$-rays come up against the difficulty of knowing which of these proteins belongs to any element

105 Addition 2018: Current shares are France 27.5\%, Germany 24\%, Italy $13.2 \%$, UK $10.5 \%$, Russia $6 \%$, Belgium and The Netherlands $5.8 \%$, Nordic countries $5 \%$, Spain $4 \%$, Switzerland $4 \%$. 
2018 addition:

The Partnership for Structural Biology was launched in 2002, it is still active and hosted in the Carl-Ivar Brandén Building. determined by X-ray diffraction. This happens in the case of ribosomes. This enormous structure (on the scale of a cell) is the factory where the cell synthesises proteins. It is composed of two sub-units, one comprising 21 proteins and one chain of RNA, the second 34 proteins and two fragments of RNA. Single crystals have been obtained of each of the sub-units, and even the complete ribosome. These single crystals can be used to obtain an electron density map at high resolution. In order to best interpret these maps it is necessary to use knowledge of the topology of the sub-units. This topology is a structure at low resolution wherein each of the proteins is localised. This result was obtained with the help of neutrons (principally at Brookhaven). We know how to reconstruct these ribosomes in a test-tube from the components. If two proteins are replaced by their deuterated analogues, it is possible to determine the distance separating them due to the large difference in scattering powers of deuterium and normal hydrogen. Progressive replacement of different pairs of proteins allows triangulation of the proteins in the ribosome. This is a good example of the complementarity between $\mathrm{X}$-rays and neutrons.

With such needs for deuterated proteins, produced by growing bacteria in heavy water, the ILL in collaboration with the EMBL has established a deuteration unit. These collaborations between three partners, (ILL, EMBL, ESRF) have led to the construction of a joint laboratory, under construction as this is being written (2005). The Institute de Biologie Structurale (IBS) in Grenoble, a joint enterprise between the CNRS and CEA, is associated with this operation, as is the virology laboratory of the University Joseph Fourier of Grenoble.

Structural biology is not the only area where there is complementarity between intense X-ray and neutron sources. A review of these fields has been published by W.G. Stirling ${ }^{106}$. A good example ${ }^{107}$ is the determination of the complex magnetic structure of the compound UPtGe. Both X-rays and neutrons were needed to resolve this

106 W.G. Stirling "Complementarity between neutron and synchrotron X-ray scattering" in Proceedings of the Sixth Summer School of Neutron Scattering, Zuoz, Switzerland, 8-14 August 1998, (edited by A. Furrer), ISBN 978-981-02-3558-1, DOI 10.1142/3870 107 D. Mannix et al., Phys. Rev. B (2000), 62, 3801-3810, DOI 10.1103/PhysRevB.62.3801 
structural problem. An unexpected field of complementarity is the study of phonons, hitherto reserved to neutrons. The high intensity X-ray beams can be obtained with energy resolution comparable to neutrons, and the field of phonon studies broadens to include substances where the velocity of sound is very high. Conversely, it is remarkable that neutrons continue to be useful despite the very feeble intensity of these sources. Assuming the neutron is equivalent to one photon, the brightness of the ILL neutron source is like a candle, while the brightness of the ESRF $\mathrm{X}$-ray source is like hundreds of millions of suns ${ }^{108}$.

\subsection{The problem of schools}

The accession of Britain, then later the creation of the ESRF, had made it even more important to provide children of employees of German and British and other nationalities the opportunity to access an education that did not handicap their return to their own country. We were aware from the creation of the ILL of the importance of finding a solution. It is likely that the absence of such education played a role in the difficulty, mentioned above, to recruit German (and later British) technicians.

A first meeting with the Rector of the Academy of Grenoble was held in July 1967. It was obvious from the beginning that only the creation of an international school could meet the needs of non-French families whilst offering French families an option that would allow them to give their children an education opening towards Europe. At this time the Ministry of Education was not really open to the idea of an international school.

Towards 1972 the Houille Blanche school was chosen for primary education; English and German teachers paid by their countries allowed the children to keep contact with their language and culture of origin. It was necessary to wait twenty years for a solution to secondary education to be established. The Stendhal Lycée was chosen from 1987 to introduce international classes where several hours tuition was given in the children's mother tongue. The teachers in charge of these supplementary courses, like those of the Houille Blanche were initially paid by the ministries of their original countries (for the Germans,

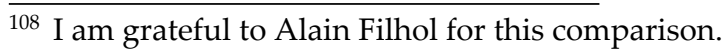


2018 addition:

Today six languages are taught in "international sections" located in six different primary schools.

The CSI (Cité Scolaire Internationale) senior school now has more than 1000 pupils with 40 different nationalities. It provides free schooling in six different

languages. Another senior school in Grenoble has a Chinese section (2014) and an American section (2015).
Italians and Spanish), or by the institutes and the town of Grenoble (for the English teachers); then from 1990 the English and German teachers were paid by the Rectorat.

The success of this formula, the support of the mayor, and the increasing demand partly due to the start of the ESRF, but also the arrival of non-French engineers in the new booming technological industries, lead to the construction of a brand-new international school. This has status of an "établissement public local d'enseignement" (EPL) dependant on the Ministry of Education. This establishment houses together a secondary college (565 pupils in 2004) and a lycée (470 pupils). As in every EPL schooling is free. About $30-35 \%$ of the pupils are foreign. For everyone there is a choice based on knowledge of a foreign language. Language teaching is a priority involving 60 out of 150 teachers, of whom 30 are French. The students therefore have eight hours of course work per week more than a traditional lycée. Teachers coming from Britain or Germany are paid by the French national education system. Those from other countries are paid by their country. This all requires a lot of work-time organisation (each student has his own timetable), which was managed by the headmaster Mr Ben Lahcen.

The Houille Blanche school for primary education continues to offer the functions originally introduced by the ILL.

\subsection{The evolution of the ILL and its problems}

It was nice to have built an institute with its reactor which very quickly took a prominent place in the world, and which by its success could attract others. It is necessary to be able to maintain this position as world leader. A continuous effort is needed to improve instruments and create new ones if necessary. It was also necessary to keep the underlying organisation established by MaierLeibnitz which had proved to be so effective. This second point was not easy to achieve. Since the departure of Maier-Leibnitz 12 directors [16 in 2018] have succeeded him (alternately German or British, with one exception ${ }^{109}$

109 The exception was made at the request of the French because of the reconstruction of the reactor during this period. 
between 1991 and 1994 during which, Jean Charvolin, who was French took over). There have been 20 deputy directors (some of which became directors). Since the arrival of the British there have been two deputy directors simultaneously. The table 7.1 shows the list of these successive leaders (see also Fig. 7.3). Often a new director calls into question work of a predecessor. This is not what happened in general at the ILL. What made the ILL novel has been kept: the five-year contracts for scientists (in 2004 $45 \%$ of scientists had such contracts), the balance between a service role and ILL scientific life, and the organisation of this life through the colleges. My impression is that the staff is very attached to these novel aspects.

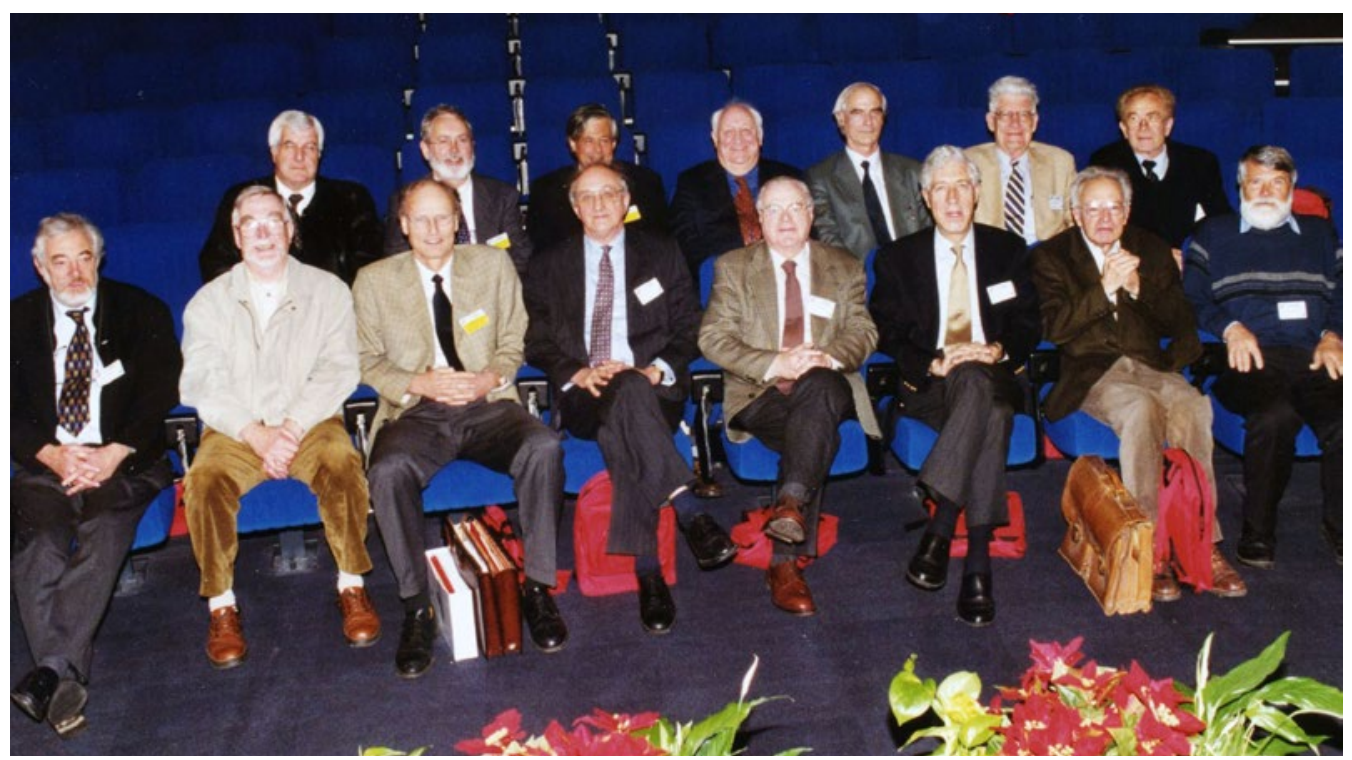

Fig. 7.3: Group photograph taken in September 2001 with past directors and deputy directors. First row (left to right) Scherm, Leadbetter, Dubbers, Enderby, Schofield, Day, Jacrot, Armbruster, Second row: Haensel, Carlile, Vettier, Fender, Joffrin, Springer, Gläser.

There was one small exception; on his arrival in 1973 the first British deputy director, Mick Lomer, was surprised, and even a little shocked by the absence of a hierarchy in the scientific life, and thought up a new structure. Without touching the colleges, he introduced groups corresponding to various types of instruments, for example the triple-axis spectrometers, analogous to more obvious technical groups such as computing. This was a logical rationalisation, helping coordinate the practical aspects of the instruments and their associated equipment. 
Problems arose because the management of the institute chose these leaders, named group coordinators. This was badly received and those named didn't come to the first meeting. Finally, calm was restored. The colleges remained a privileged place for the actual scientific life of the ILL. In the annual reports more than half the pages is devoted to their works.

Table 7.1 Directors and Assistant Directors of the ILL

Proposed by: F the French Partner - D the German Partner - GB the UK Partner

\begin{tabular}{|c|c|c|c|}
\hline Name & Country & Function & Tenure \\
\hline Heinz Maier-Leibnitz & DEU & Director & $01 / 02 / 67-31 / 01 / 72$ \\
\hline Bernard Jacrot & FRA & Assistant Director & $01 / 02 / 67-30 / 09 / 73$ \\
\hline Rudolf Mössbauer & DEU & Director & $01 / 03 / 72-28 / 02 / 77$ \\
\hline Mick Lomer & GBR & Assistant Director & 01/05/73-31/10/74 \\
\hline Bernard Dreyfus & FRA & Assistant Director & $01 / 10 / 73-31 / 03 / 76$ \\
\hline John White & GBR & Assistant Director & $01 / 04 / 75-28 / 02 / 77$ \\
\hline " & & Director & 01/03/77-31/03/80 \\
\hline Jacques Joffrin & FRA & Assistant Director & $01 / 10 / 76-30 / 06 / 81$ \\
\hline Tasso Springer & DEU & Assistant Director & $01 / 03 / 77-31 / 03 / 80$ \\
\hline “ & & Director & 01/04/80-30/09/82 \\
\hline Brian Fender & GBR & Assistant Director & $01 / 04 / 80-30 / 09 / 82$ \\
\hline " & GBR & Director & $01 / 10 / 82-31 / 03 / 85$ \\
\hline Jacques Winter & FRA & Assistant Director & $01 / 07 / 81-31 / 12 / 83$ \\
\hline Henner Ruppersberg & DEU & Assistant Director & $01 / 10 / 82-31 / 03 / 85$ \\
\hline André Michaudon & FRA & Assistant Director & 01/01/84-30/06/89 \\
\hline Ruprecht Haensel & DEU & Director & $01 / 04 / 85-31 / 05 / 86$ \\
\hline John Enderby & GBR & Assistant Director & 01/08/85-31/08/88 \\
\hline$"$ & & Director & $01 / 06 / 86-31 / 07 / 86$ \\
\hline Wolfgang Gläser & DEU & Director & 01/08/86-30/09/89 \\
\hline Peter Day & GBR & Assistant Director & 01/10/88-30/09/89 \\
\hline “ & & Director & 01/10/89-30/09/91 \\
\hline Jean Charvolin & FRA & Assistant Director & 01/07/89-30/09/91 \\
\hline “ & & Director & 01/10/91-30/10/94 \\
\hline Peter Armbruster & DEU & Assistant Director & 01/10/89-30/10/92 \\
\hline Peter Schofield & GBR & Assistant Director & 01/10/91-30/04/94 \\
\hline Reinhard Scherm & DEU & Assistant Director & 01/12/92-30/10/94 \\
\hline “ & & Director & 01/11/94-31/12/97 \\
\hline Alan Leadbetter & GBR & Assistant Director & 01/05/94-31/07/99 \\
\hline
\end{tabular}




\begin{tabular}{llll}
\hline Name & Country & Function & Tenure \\
\hline Philippe Leconte & FRA & Assistant Director & $01 / 11 / 94-31 / 08 / 99$ \\
Dirk Dubbers & DEU & Director & $01 / 01 / 98-30 / 09 / 01$ \\
Colin Carlile & GBR & Assistant Director & $18 / 08 / 99-30 / 09 / 01$ \\
Christian Vettier & & Director & $01 / 10 / 01-30 / 09 / 06$ \\
Werner Press & FRA & Assistant Director & $20 / 09 / 99-30 / 09 / 07$ \\
\hline 2019 addition: & DEU & Assistant Director & $01 / 01 / 02-01 / 03 / 06$ \\
Andrew Harrison & & & \\
“ & GBR & Assistant Director & $01 / 10 / 06-30 / 09 / 11$ \\
Richard Wagner & & Director & $01 / 10 / 11-31 / 12 / 13$ \\
“ & DEU & Assistant Director & $01 / 03 / 06-01 / 10 / 06$ \\
José Luis Martínez Peña & & Director & $01 / 10 / 06-30 / 09 / 11$ \\
Charles Simon & ESP & Assistant Director & $01 / 10 / 07-30 / 09 / 12$ \\
William Stirling & FRA & Assistant Director & $01 / 10 / 12-30 / 09 / 17$ \\
Helmut Schober & GBR & Director & $01 / 01 / 14-30 / 09 / 16$ \\
“ & DEU & Assistant Director & $01 / 10 / 11-30 / 09 / 16$ \\
Mark Johnson & & Director & $01 / 10 / 16-$ \\
Jérôme Estrade & GBR & Assistant Director & $01 / 10 / 16-$ \\
\hline
\end{tabular}

\subsection{Modernisation of equipment}

This had two components. First there was constant updating of instruments in service. For example, the triple-axis spectrometer IN3, for which there was little demand due to the low flux, was transformed into a more conventional spectrometer. The shared CARINE computer control system was progressively replaced by individual PDP11 or Solar computers. It would be tedious to list the continuous improvements made using the normal operating budget.

The second part of the updates was the start of a modernisation programme decided by the partners, and funded outside the annual budget of the ILL. The first programme of this type initiated in 1977, and granted in 1978 had a planned budget of FF 82M, which was finally adjusted for inflation to FF 104M for the period 1979-1985. The "Deuxième Souffle" (Second Wind) programme was launched by Jules Horowitz who knew how to convince the other partners to finance it. The arrival of the British had greatly increased demand on various instruments. It 
was hence necessary to build new instruments and further optimise the existing ones. The choices were made in consultation with the Scientific Council, which finalised its recommendation in the meeting of 18 March 1978. The new infrastructure included a new Central Computer (DEC1091, after a protracted 18 month multi-national tender operation), and total replacement of the CARINE system by individual mini-computers for each instrument.

More important was the replacement of the cold source with a new design ${ }^{110}$ which has led to an increase in flux by a factor of about 1.6 (Fig. 7.4). It was also possible

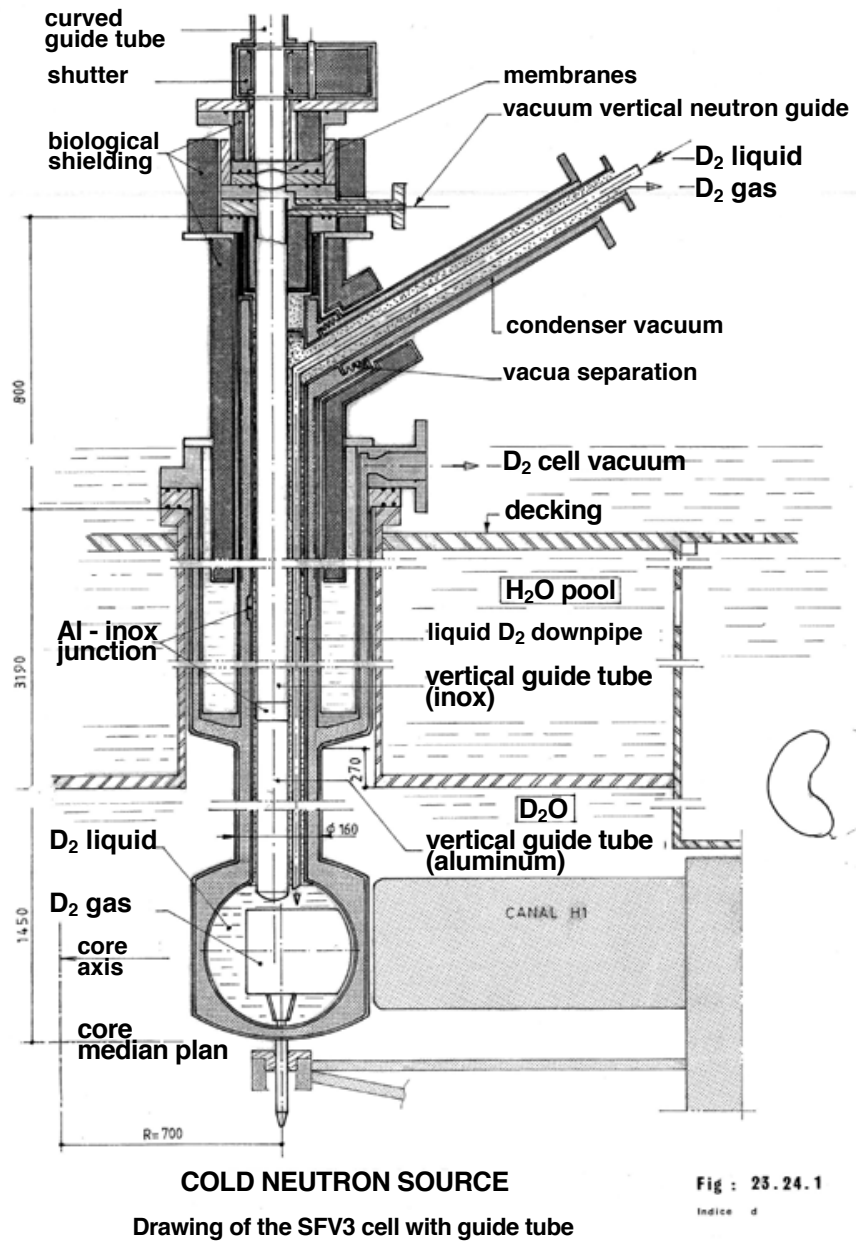

${ }^{110}$ Paul Ageron conceived the new design which consisted of introducing a cavity filled with deuterium gas into the sphere containing the liquid deuterium. This conserved the dimensions of

Fig. 7.4: The replacement cold source (1980). Comparison with Fig. 5.9 shows the new vertical beam tube, which selects very cold neutrons which the turbine converts into ultra-cold neutrons. 
to add a vertical beam tube exiting at the control-room level of the reactor, creating a new experimental zone. This vertical beam tube served to increase greatly the source of ultra-cold neutrons. Then, in December 1981, the Steering Committee approved the construction of a second cold source. This was installed in a horizontal beam tube, and was foreseen to have three neutron guide tubes which would terminate in a second hall adjacent to the reactor building. The new source was operational in 1987 with a new beam tube constructed using zircaloy to have a longer life under irradiation.

This "Second Wind" led to the construction of four new instruments chosen in collaboration with the Scientific Council. As an example the triple axis spectrometer IN2 was replaced by the IN20 triple axis with much enhanced performance and allowing use of polarised neutrons.

Capital was available for new buildings; a new hall for the new computer, large enough to accommodate the biggest new system tendered, and the Biology group of the ILL joined that of the EMBL in a new laboratory building.

In April 1981 the first beam-tube nose replacement took place. This was performed on one of the hot source beams. The exchange was necessary because a small crack had been detected. To avoid possible consequences of future cracks the beam-tubes, originally evacuated, were filled with helium under pressure which reduced the strains to which the nose was subjected. The operation took place very smoothly and it was possible to envisage generalising these exchange operations which could be achieved during a normal shutdown (about 10 days between reactor cycles). Study of the original nose-piece after removal has enabled assessment of how the strength of the aluminium has been affected by the irradiation conditions in the reactor. Other beam-tube exchanges followed, taking place during normal shutdowns (one in 1982, and four in 1983).

A much longer shutdown of eleven months had to be planned between October 1984 and August 1985 to gather together more complex maintenance activities, including replacing the $\mathrm{H} 1 / \mathrm{H} 2$ beam-tubes. These cold and thermal guides shared a combined nose assembly which was ageing. This time the aluminium structure would be

the source feeding the guides. Calculations predicted an increase in the flux of cold neutrons which was confirmed in practice. 
replaced by zircaloy which would have a longer lifetime. Already at this time samples taken from different nosepieces taken from the reactor had enabled the dynamic evolution of the alloys under high flux to be studied. The changes in the aluminium would lead to planning a replacement of the reactor vessel. This possibility had been foreseen in the original design of the project. A note on this subject was written by Franzetti, the head of the reactor department. The new replacement vertical cold source mentioned above was installed during this long shutdown.

In early 1990 it was discovered that the actual reactor power had been nearly $10 \%$ greater than $57 \mathrm{MW}$ from the beginning of operations. This was indicated by the lifetime of the fuel element being somewhat shorter than that calculated. The error was due to using cooling flow rates based on light water, without further adjustment for the heavy water used. In addition pressure differences were measured using a mercury column, without taking into account the difference in density between light and heavy water. To re-establish the power that had been announced to the safety authorities the reactor power (and hence the neutron flux) had to be reduced. As a consequence the cycles could be extended from 44 to 50 days. The discovery of the over-running of the reactor explained a troubling fact. During the first years the used fuel had been sent back to the USA for reprocessing. The Americans reported that the remaining quantity of uranium-235 unconsumed was $10 \%$ smaller than expected; this was confirmed when reprocessing was later performed in France $^{111}$.

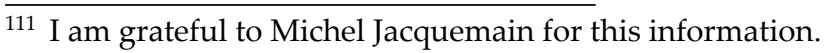




\section{Chapter 8}

\section{The dark years}

\subsection{The reconstruction of the reactor}

During routine inspection of the reactor vessel in April 1991 a crack was observed which would require its replacement. This operation needed a very long shutdown of the reactor which would only restart on 6 January 1995. Here is a description of the events of 1991 written by Jean Charvolin in the Annual Report for 1991.

"On 30th March, during a reactor shutdown after a normal operating cycle, a routine inspection revealed unusual marks on an anti-turbulence grid in the heavy water in the reactor vessel; on 5th April, after a detailed analysis, it was found that these marks were transverse cracks in the grid, which must therefore be replaced. Such an operation implies major intervention work in the reactor vessel, preceded by long preparation. At that time the ILL hoped to be able to strengthen the grid to permit temporary operation during the preparation period but, as the continued investigations gave a better understanding of the origin of the damage, this idea was given up in view of the amount of strengthening work required. It was decided on 10 th July to keep the reactor shut down and to initiate immediately studies for the major intervention work. The possible technical options, with a first evaluation of their cost and duration, were submitted at the end of September to the Associates, who then requested the ILL to prepare a detailed analysis of the option involving complete replacement of the reflector tank and its internal parts by the end of January 1992, to give them all the elements necessary for a decision. During the summer the cost and duration of this option were estimated at FF 150M and 28 months, respectively, and the work in progress should give these estimates a firm basis of industrial commitments.

Since 30th March 1991 the Reactor Division teams have been involved in analysis and proposal work of great precision and efficiency, and $l$ should like to thank them on behalf of the whole of the ILL." 


\section{Financing the reconstruction of the reactor}

As stated above, the refurbishment is to be financed out of a reserve set up in the budgets for the years 1991 (FF 313M), 1992 and 1993 (FF 310M). In 1991, because of the late date of the final decision to keep the reactor shut down, it was not possible to make any major contribution to this reserve, and the majority of the savings must be effected in 1992-93. Part of this amount has obviously been found in the immediate consequences of the reactor shutdown: fuel elements, electricity, cryogenic fluids for experiments, expenditure on visitors, and suspension of recruitment of scientists. But this was not sufficient, and it was necessary to reconsider the timetable for the ILL's development plan, to encourage personnel close to retirement to leave, to favour secondment to other laboratories and to impose a freeze on recruitment to posts becoming vacant. Application of these measures with effect from the end of 1991 makes it possible to envisage building up half of the reserve in 1992. Similar work must be continued in 1992 to provide the necessary additional amount in 1993. Finally, if the more precise evaluation of the cost due at the end of January 1992 should lead to a downward revision, that part of the reserve not used by the reactor could be returned to the instrument programme, with the Associates' agreement.

[...]

The reactor, the heart of the ILL, has been shut down since 30th March 1991 and will not resume operation before 1994. This event has not only interrupted certain aspects of the ILL's scientific activity, but also necessitates reconsideration of its medium term plans: development of instruments, distribution of staff, relations with the scientific user communities and the other research centres. Whereas the ILL's function has been to develop a range of instruments and a scientific life designed to provide the most efficient possible reception for the users, it now has to ensure that its reactor is refurbished as quickly as possible, which means the setting up and smooth implementation of a large and expensive nuclear engineering project, while conserving its scientific and instrumental potential. This sudden change in orientation also has to take place in a relatively difficult context due to budgetary constraints and the envisaged renegotiation of the intergovernmental convention covering the ILL." 
It really was a total reconstruction of the reactor. For this a small project group was established under the responsibility, at Dautray's initiative, of Jean-Paul Martin ${ }^{112}$, who brought in four CEA engineers he knew well. As I mentioned earlier this excellent engineer had a very important role in building the reactor, which he probably knew more about than anyone. Moreover in recent years at the reprocessing plant at La Hague he had gained extensive experience in cutting up radioactive materials. This would constitute the most difficult part of renewing the reactor.

Jean-Paul Martin proposed a solution to achieve it. An engineering consultant (Technicatome) had been appointed but it was the ILL who was responsible for the work which was delegated to Ekkehardt Bauer, then head of the reactor division. Most of the actual work was done by the ILL engineers and technicians. The whole team was involved, but in addition others were detached from the scientific sector. 24 members of staff were thus temporarily added to the reactor division. It was they who took out the original heavy water tank and cut it up to be stored as active material before replacing it with a new vessel constructed by the German company Zeppelin (Fig. 8.1).

1122018 addition: In 2014, he wrote in French a detailed story of the reconstruction of the reactor. See http://www.arill.fr/ documents/2014-remplacement-du-bidon-reacteur/ 
Fig. 8.1: The new reactor vessel built by Zeppelin is installed in the swimming pool.

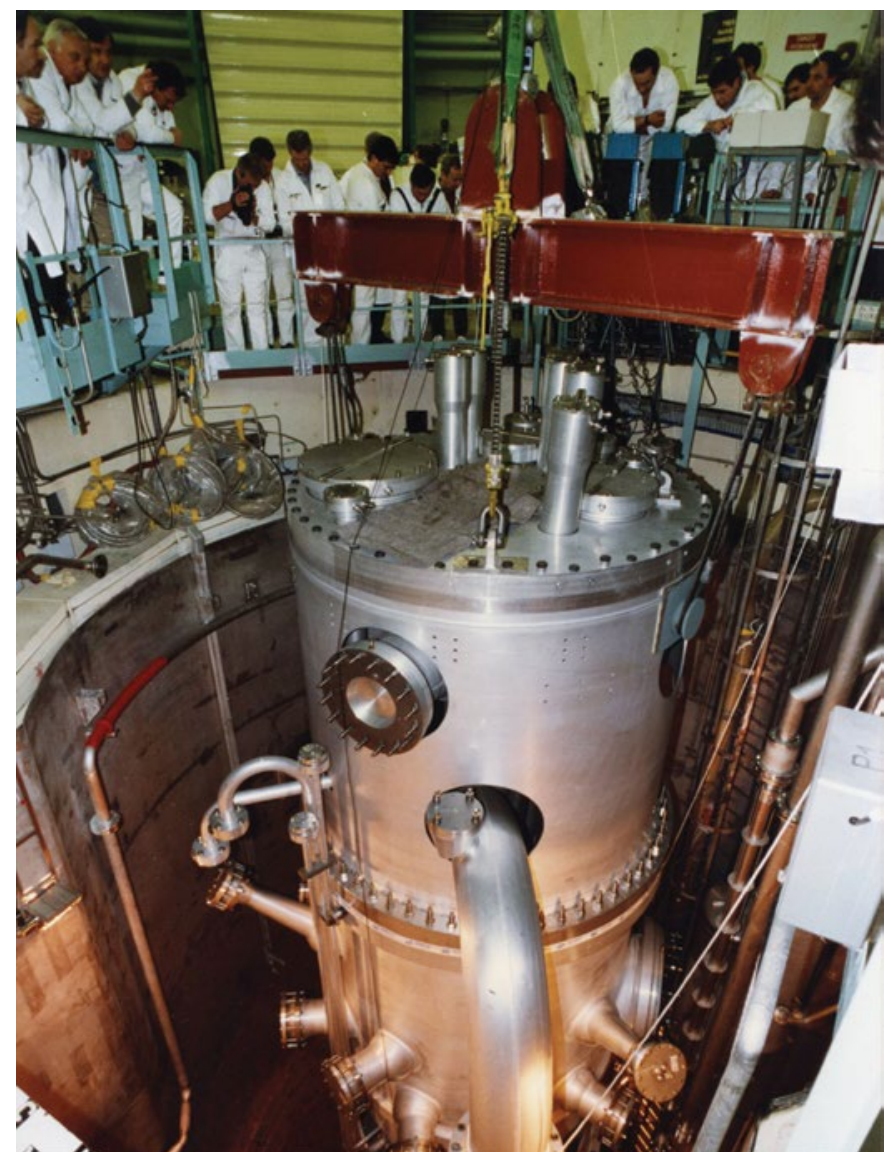

The reactor could only be restarted on 6 January 1995. A number of minor changes were made, such as removing the beta beam-tube, as well as important changes, such as the introduction of a replaceable anti-turbulence grid. Apart from the considerable loss of reactor time the whole operation was very costly. The ILL had been obliged to spend $€ 23 \mathrm{M}$ on outsourcing and orders (for an interim budget of $€ 26.3 \mathrm{M}$ (FF 173.1M). The contribution of the Institut staff, without which the costs would have been much higher, is estimated as $€ 18 \mathrm{M}$. Supporting the reconstruction of the reactor on the normal budget of the institute required a rigorous savings plan with a reduction of secretaries, and loss of the ILL's cars and drivers. To amass the funding from only the budgets of 1992 and 1993 the plan had to be even more stringent than that needed when the British announced a reduction in their participation (see later). 
A significant reduction in staff costs was essential. Staff numbers fell from 483 in 1991 to 469 in 1992, 420 in 1993 to finish at 377 in 1994 . To achieve this restructuring, early retirement at the age of 55 years was offered under the auspices of the FNE, the National Employment Fund. This happened at a time when it was the policy of the French Government to encourage early departures. These measures were discussed with staff representatives and were imposed on all those who met the age criteria. The conditions were good and were mostly well accepted by those concerned. Some scientists suffered badly on being laid off work that was their main reason for living. Fortunately, the management made one or two exceptions where there were special needs and there was the pressure from the scientists wanting to keep a colleague $^{113}$. More new recruits were to enter the ILL (13 in 1992 and 7 in 1993). This brought younger people to the ILL (who were both cheaper and had new ideas). Other measures such as part-time working, and detachment to other institutes were also encouraged (saving about FF 7.8M in 1993). Some technical skills, notably in electronics were lost and were slow to be relearnt. Inevitably the budget restrictions prevented desirable modifications being made to the instruments. The restart of the scientific operations was difficult due to the lack of personnel. The main object had been achieved; the renewal of the reactor was a success and had been completed strictly within the budget foreseen.

With hindsight one can pose questions on the length of the shutdown of the reactor. The cracks were observed in April 1991. It was not until November 1991 that the Steering Committee asked for a comparative study of the various options to resolve the problem. The replacement of the reactor vessel was decided in February 1992. By July 1994 the reassembly was finished and the reactor declared technically ready. A public inquiry necessary for the restart had begun during May, but the decree was only signed on 6 December. On 25 November 1993 the Steering Committee mentioned the slowness of administrative procedures, and expressed concern about subsequent delays for the restart. This has led to certain

113 Jane Brown, an eminent British crystallographer, was one such case who was able to remain; after retirement she later stayed on at the ILL as a UK visiting scientist until 2011. 
scientists thinking that the shutdown could have been reduced by a year. (I am aware of such criticisms from some ILL scientists.)

In reality things are not so simple. Even the idea of reconstruction was not obvious to the partners. The reactor shutdown had a destabilising effect when the partners were involved in developing the ESRF. Outside support for the ILL was severely affected. In Great Britain some (but not all) hoped to see the ILL closed, with the consequence of making ISIS, the spallation source in Britain, the only high flux source in Europe. The Germans had been stung by budget overruns of reactor work done at Jülich and Berlin. The means of the French partners were limited and they hesitated a while before supporting the renewal work demanded so urgently by the management. Finally, the request was only accepted by all the partners when the ILL management agreed to perform the renovation within the annual budget, and only asking that the budgets should continue as foreseen, and which was achieved. A sub-committee was created by the Steering Committee to follow the reconstruction very closely. We can then see that these considerations and critical technical studies needed a lot of time. Regarding the restart it is necessary to remember how things had changed since 1971, when the nuclear industry enjoyed total public support in France. Since then there had been the tragic accident at Chernobyl which greatly influenced people's minds. In the 90s there was environmental pressure and some public opinion was becoming reticent towards nuclear power. The safety regulators had insisted on having a French director during this period of reconstruction. They insisted that the decree authorising the restart should be very well-founded, which again necessarily took time. Safety took precedence before satisfying the scientists eager to resume their work.

\subsection{The partial withdrawal of the British and the consequences}

This major failure of the reactor had a serious consequence. In 1991 Great Britain asked for a renegotiation of the intergovernmental agreement with a view towards reducing its financial share. It had always been hoped 
that the spirit and letter of this convention would always be honoured for better or for worse. Margaret Thatcher's general policy of cuts for public spending reduced the budget of the SRC. Faced with a difficult situation which persisted after her departure in 1990, the officials of the SRC (now SERC) studied their expenditure and came to the conclusion that Britain was spending too much money on neutrons. The majority of this sum of $£ 22 \mathrm{M}$ was divided more or less equally between participation in the ILL and the developments at the UK's ISIS spallation source. Mick Lomer chaired a committee which was responsible for making cuts of about $£ 5 \mathrm{M}$ in these costs. They came to the following conclusions: to reduce finance for ISIS would lead to the death of the project so they proposed to reduce the participation in the ILL from 33 to $25 \%$. This proposal was first announced at a press conference then presented to a meeting of the Steering Committee on 28 November 1991 in Grenoble. The announcement of the partial withdrawal of the British was not well received by the staff and management of the ILL. It came at a very bad time when the reactor was shut down and the partners were asking whether it was necessary to carry out a reconstruction of the reactor. In the press conference as well as in his statement ${ }^{114}$ to the Steering Committee the SERC representative, Ron Newport, made much of the fact that this decision was not connected to the reactor problems, though this was a little hard to believe. This did not prevent good relations being established between Newport and the ILL management.

The practical consequence was that the British contribution dropped from FF $100 \mathrm{M}$ in 1993 to FF 66M in 1994. This significant fall in budget was only slightly offset by a small increase of the contributions from the scientific associate countries (this was for scientific activities, rather than the functional budget. In 2001 this corresponded to about $14.2 \%$ of the annual budget). Hence it was necessary to make economies. Firstly, the staffing restrictions which were introduced to raise money for the rebuild were continued. The second way of making economies was to create "Collaborative Research Groups" (CRG). These would manage instruments constructed jointly between the ILL and external laboratories with shared costs. The principle had been suggested at the

114 The original text is in appendix 6. 
start of the ILL, but had never been followed up. There were three levels of CRG:

1. CRG type A

These were constructed by the ILL and remained its property; $50 \%$ of time was reserved for the ILL.

2. CRG type B

These are instruments of general interest, built and paid for by an external group; $30 \%$ of beam time is reserved for the ILL. This included some existing ILL instruments bought by these groups. This was the case, for example, of the IN12 triple-axis spectrometer acquired by the Jülich research centre.

3. CRG type C

These were experiments rather than beam instruments. A single external group offers both construction and operational costs. There is little interaction with the ILL, except for the field of safety. One example is the interferometer constructed by the Technical University of Vienna, which performed some of the experiments I describe in the chapter assessing the ILL.

Introducing this system reduced the number of purely ILL instruments to 25. There were 11 CRG instruments established, 9 of which included some time for ILL experiments. The first contracts of this type were made with the Paul Scherrer Institut (Switzerland) in 1994 for partial use of the D1A diffractometer and a triple axis spectrometer. Implementation of the CRGs has, in addition to the financial gains, allowed the ILL to function with the lower number of staff remaining after all the early retirements.

I have already mentioned the very negative reception of the partial withdrawal of the British. This placed the British deputy director in a difficult position. There was no British director between the departure of Peter Day in 1991 and the appointment of Colin Carlile in 2001 (after a period when he was deputy director). The return to having a British Director was made possible by a progressive increase in the British contribution (27\% in 2000, 29\% in 2001 and $32 \%$ in 2002) to 33\% in 2003. This return was welcomed by everyone at the ILL. 


\subsection{Supply of enriched uranium}

Another problem for the reactor ${ }^{115}$ arose at the same time. In 1992 the conditions for the export from USA of highly enriched uranium were modified by the Schumer Amendment. This stipulated that highly enriched uranium (which we recall can be used directly to make an atomic bomb) could only be exported for use in a research reactor if uranium with $20 \%$ enrichment would not allow the reactor to function at all. The buyer should ensure his reactor was adapted to use the lower enrichment as soon as possible. In the case of the ILL the use of such medium enriched uranium would be very difficult, if not impossible. In addition the ILL management did not want to be constrained by the yoke of the USA, and turned towards the Russian market, accessible after the collapse of the USSR.

At this point the leaders of the CEA, who had to guarantee the supply of fuel for the Orphée research reactor at Saclay, took over the negotiations. A contract written in 93-94 was finally signed on 19 April 1996. It foresaw three successive deliveries of $165 \mathrm{~kg}$ at three yearly intervals covering the needs of the ILL for 9 years. The delivery was repeatedly delayed and at the end of 1997 the officials turned again to the USA. This implied complying with the Schumer amendment, i.e. engaging a commitment to change the reactor if it proves possible to achieve the same performance with low-enriched uranium. A memorandum was thus signed at the end of 1998 between the USA State Department and the ILL with, of course, the agreement of the governments of the three partners. Then the Russians, with whom contacts had been maintained, delivered $227 \mathrm{~kg}$ of uranium (of which $165 \mathrm{~kg}$ was for the ILL) two months after signing the memorandum with the USA. The following deliveries foreseen in the contract took place normally. To understand the prevarications it is useful to remember that Russia and the USA were in negotiation to refine concrete measures to limit the spread of nuclear weapons ${ }^{116}$.

115 I am grateful to Philippe Leconte for the information in this section.

116 The negotiations are analysed in the book "De Tchernobyl en tchernobyls" by G. Charpak, R.L. Garwin and V. Journé, 2nd edition, Paris: Odile Jacob (2005) ISBN 978-2-7381-1374-0. 



\section{Chapter 9}

\section{Consolidation and the future}

\subsection{The millennium}

There was little or no modernisation of the instruments in the period 1991-1994. Fortunately, after this very difficult time for the ILL, in 2000, Dubbers, the Director, launched a programme of reinvestment. On $1^{\text {st }}$ January 2000 an annual budget of $€ 3 \mathrm{M}$ was earmarked for the update and renewal of instruments in the Millennium Plan. The budget came partly from the ILL (from economies), part from the partners, and also from external finance in particular from Europe. The British part was directed towards specific instruments. In the plan 9 instruments were rebuilt or new. For example the choppers on IN5 have been completely replaced; apart from being new and implementing contre-rotation, important for high-performance rotating machinery, they allow a bigger beam to be used.

Reactor safety is obviously of prime importance. Earthquake tremor standards are more rigorous than when the buildings were constructed. The reactor also had to be protected against attack. To take account of these there had to be some building works, in particular modifying the attachment of the reactor building with those adjacent (main building, and guide halls). The cost of this was estimated at $€ 20 \mathrm{M}$ towards which the partners contributed an extra contribution of $€ 9 M$. The remainder was from the normal operating budget of the ILL. This required making the additional economies, reducing the annual number of cycles to 3 (150 days) instead of 4 to 5 .

Becoming mature there were some changes made to the statutes of the ILL. One change is that several countries have joined the three partners as scientific members which guarantees access to the instruments. These include Spain (1987, 4\% participation), Switzerland (1988, 3\%), Russia (1996-2005, 2.2\%) and a central Europe consortium 
2018 addition:

The list of scientific members has been extended since 2005 with Sweden (2005), Belgium (2006), Hungary (2006-2016),

Poland (2006), Denmark (2009), Slovakia (2009) and India (2011-2014). In 2015, the 10 scientific members contributed $21 \%$ of the operating budget.
(1990, Austria and 1999, the Czech Republic) for $2 \%$, and Italy $(1997,4 \%)$ : in total about $15 \%$ of the operating budget in 2004. These countries each have a representative on the Steering Committee as well as the Scientific Council.

In January 1996 the Forschungszentrum Jülich replaced GfK Karlsruhe as the German partner at ILL, as it was already at the ESRF. The main reason was that neutron scattering activities were more developed in Jülich, while diminishing at Karlsruhe. Again there was an advantage in having the same German partner at the neighbouring ESRF and ILL institutes.

\subsection{The reorganisation of the ILL}

The Steering Committee asked the ILL management to put in place the following organisation.

Two divisions were to be created, a scientific division and a division for projects and techniques. Each division would be under the responsibility of one of the deputy directors, and they complement the two existing divisions, the reactor, and administration. The new structure was put in place from July 1993. The new structure had the great advantage of clearly defining the role of the deputy directors. There was a tendency to consider themselves as representatives of the scientific community in their countries. This was absent in the original Franco-German institute, but developed when there were three countries. The new organisation has the merit to kill this trend by giving each deputy director supranational responsibility. However, it seems that there is a great danger in creating a hierarchical structure in science. This may undermine the college organisation which, as I said above, was and remains a novel but scientifically fertile feature of the ILL. The people who have so far exercised these responsibilities have kept this original structure, but the risk remains that of authoritarian deputy directors.

\subsection{Some figures}

The number of staff grew during the construction phase (see Fig. 9.1) but has remained remarkably stable over the long term with 422 in 1980 and 427 in 2003. 
Between 1981 and 1983 there was a sudden change resulting from the ILL following a new law requiring companies to recruit contract staff who worked full-time. This included security and cleaning teams, amongst others. 35 people were thus recruited in 1982 and another 23 in 1983, bringing the total workforce to 502 employees, including 105 researchers, and 223 technicians. This recruitment was at a significant cost. In the 1982 budget engagement of 30 staff was FF $1.95 \mathrm{M}$, partially offset by reduction of expenditure on external services, leaving about FF $0.6 \mathrm{M}$ to be taken from the investment budget of the ILL, that is to say from instrument developments.

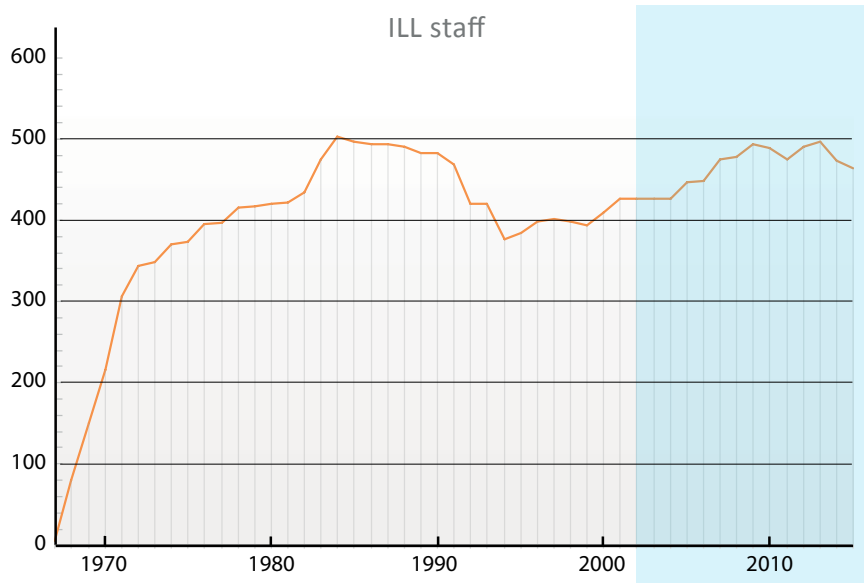

As I mentioned above the problems posed by the reconstruction of the reactor and the partial withdrawal of the British imposed a reduction of total staff back to the numbers of 1981, about 420-427. The number of scientists (excluding thesis students) dropped from 72 in 1981 to 56 in 2003.

To achieve the work of the "Deuxième Souffle" (Second Wind) the partners offered 12 people on detachment. The constant workforce level over 20 years seems remarkable. It led naturally to relative stability in the budget (excluding the period of the British reductions), and this increased little more than inflation. In 1980 the budget (excluding the Second Wind) was FF 137.6M; in 2002 it was 60 million euros, which corresponds to about FF 174M in 1980 (according to the INSEE inflation figures). This shows that the budget only grew on average by $1 \%$ per year in constant money terms.
Fig. 9.1: Change in staff numbers at the ILL since its creation in 1967 (updated up to 2015) 
A further extension up to 2023 was approved in 2013. With the Endurance programme, the target is now a more distant horizon, that of 2030. :2018 addition
The original intergovernmental agreement (1967) creating the ILL was set for a life of 13 years, and it was expected to be extended from year to year by tacit agreement. In fact it has been extended several times, the last time being in 2002 until the end of 2013, i.e. 45 years after creation. 


\section{Chapter 10}

\section{Conclusion: an appraisal}

This assessment must take into account two aspects which were highlighted during the creation of the ILL, and justified creating a Franco-German scientific collaboration to reinforce the Adenauer-de Gaulle agreements.

\subsection{The Franco-German Cooperation}

As I mentioned in the introduction, this collaboration was not obvious. In 1965 the war was not far away. There was still a distrust of Germany amongst the ordinary French. We [the French] continued to use the pejorative term "Boche" when speaking of the Germans. This was particularly true in Grenoble where the memories of the resistance in the Vercors, and its tragic end, were very alive. German researchers came at a late date to use neutron beams, and their contributions were often ignored by their more experienced French colleagues. The collaboration was not always well viewed in France. It is extraordinary that amongst the main players in the creation of the ILL, two Frenchmen, Jules Horowitz and Robert Dautray, both of Jewish origin had both suffered from the Nazis. The father of Dautray, and mother of Horowitz had both been murdered at Auschwitz. They themselves only just avoided deportation. They knew and they appreciated the culture of Germany and refused to associate Nazism with Germany. Both worked after the war on Franco-German cooperation. This attitude contrasted with what prevailed after the wars of 1870 and 1914-18 when ideas of revenge and penance were dominant. De Gaulle too knew that German culture was incompatible with Nazism; he sealed the reconciliation between France and Germany with Konrad Adenauer. This has certainly been instrumental in the solidarity and even friendship now existing between the two countries. French public opinion, and that of scientists, often remained suspicious. 
At the ILL the role of Maier-Leibnitz and his wife was crucial in dispelling this unease. His charisma helped here. I remember a meeting at the beginning of the ILL which was held in Saint Nizier in a hotel which had been completely razed during the elimination of the Vercors maquis by the German army. The owner was basically reluctant to welcome us. After seeing Maier-Leibnitz his reluctance dissolved and we had many meetings in this hotel (which served an excellent gratin dauphinois). The relations between Maier-Leibnitz and Dautray were really friendly, as were mine.

I hardly ever had conversations with Maier-Leibnitz on the war and the preceding period. It was as if his scientific life had started in Munich. I have learned the facts about these difficult times reading his biography "Ein halbes Jahrhundert experimentelle Physik". However in a book of three hundred pages less than sixty pages are used to describe his pre-Munich period (1929-1952). I think that this discretion demonstrates his modesty.

The first German researchers who arrived at the Institut all belonged to a generation who had never known these dark times personally. I am thinking especially of Reinhard Scherm and Andreas Freund. The latter arrived in 1967 to work on a thesis with Maier-Leibnitz. The work of these two scientists was typical of the excellence of our German colleagues. They proved too, by their behaviour that the period of Nazism was certainly not representative of what was truly German. Bertaud's attitude was very significant. Born Lewy in Germany (1913) to a Jewish family he emigrated in 1933. His parents did not wish to follow (not wishing to be subjects to former enemies) and both perished in concentration camps. He was naturally wary at first, speaking French to M.L. He was happy to find his compatriot was quite free from Nazism, and later had no hesitation in conversing in German.

The experiment of the ILL as that of the EMBL and CERN shows that nothing is better than working together to dispel prejudices.

An important component in this success was the youth of staff who made up the ILL in its early days. Looking at a film shot in 1973 by German television ${ }^{117}$ I am struck by

117 German TV channel ZDF (1973) Part of the series "Die stillen Stars" (The silent stars) https://wwwarchive.ill.fr/about/ what-is-the-ill/history/ill-in-1973-movie/ 
the young scientists and engineers who had large responsibilities. For all, the war belonged to a past that they had only known about as children.

There was always a friendly atmosphere at the ILL thanks no doubt to this wise recruitment of German physicists. A recent survey amongst the older members of staff has confirmed that there was a total absence of conflicts, even minor ones, between French and Germans. At the ILL the non-French personnel received a salary supplement known as the "prime de dépaysement" to compensate for living abroad ${ }^{118}$. This never posed any serious problems, though the same was not the case at the ESRF undoubtedly because the atmosphere there was never so relaxed.

The career evolution for the scientists could pose some problems due to differences in the two countries. The CEA career structure (which served as a basis) only had permanent posts which could be offered to young scientists. At the CNRS again there are only permanent posts but these are obtainable only after submitting a thesis. In Germany, until 1975, only full professors had permanent posts. After a period when this practice was abolished it has now returned. There were also some permanent posts in government research centres like Jülich, and the Max Planck Institutes. Before reaching this status the scientists passed from one fixed term contract (assistant) to another similar contract. At the ILL it was decided that physicists recruited would be offered 5 year contracts which could only be transformed into permanent posts on expiry in exceptional cases justified by special responsibilities. This situation was outside normal employment law but was legalised by a law passed by Parliament on 22 December 1998, and by the Senate on 23 November 1999, published in the "Journal Officiel" on 2 December 1999.

It was a joint team that designed and built the reactor; there again could have been problems. The French had a much greater experience in building reactors, having started earlier, and having military activities. This point was well recognised, and the design of the reactor vessel and choice of aluminium were completely left to the French in the group. On the contrary the responsibility for safety was entrusted to the German engineer Reutler who did a superb job. All this happened with an excellent

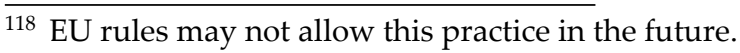


ambience. It is remarkable that more than 30 years after links were established between the French and German engineers during the construction phase that some continue to meet regularly.

Communal life at the ILL has allowed us to see to what degree the French and Germans have common cultures. Close, but not identical, as the following anecdote illustrates:

In the summer of 1973, John White, future director of the ILL, was a scientific visitor, and performed one of the first experiments on a biological sample, collagen, and he noted that it diffracted neutrons rather well. We had the following conversation:

B.J.: - Yes, collagen diffracts neutrons well; did you make any calculations before the experiment?

J.W.: (surprised) - Uh, no.

B.J.: - It is always like that with the Anglo-Saxons; they never make preliminary calculations. The Germans, they make such beautiful calculations they have hardly any need to make measurements.

J.W.: - And the French?

B.J.: - We believe it is necessary to do the calculations, but we rarely do it.

John White who reminded me of this dialogue concluded that research needs to be multinational as at the ILL. I completely agree with this conclusion.

The British were not used to the management of the ILL. Apparently, there are no works committees in the UK as are foreseen by the law in Germany (Betriebsrat) and in France (Comité d'entreprise). In the case of the ILL it was taken very seriously. From 1973 the principal of staff representation on the Steering Committee had been discussed, and finally accepted in December the same year. This was applied from the meeting in May 1974. At the time of the reconstruction of the reactor and the consequent reductions in staff the presence of the staff representatives enabled a consensual decision to be made. This has always amazed the British partners. In Great Britain the unions have many members, but they do not play a large or other role in the life of a company. This was the cause of misunderstandings. The unilateral decision to reduce the financial contribution did not help. There remained the notion of unreliability of British institutions. 
None of this affected the relations between colleagues in the Institut; these always remained good regardless of political storms. Many publications have been co-authored by contributors from the three founding countries, and others.

Common to all international collaborations where people of different nationalities work together the ILL staff too work in relaxed and friendly atmosphere irrespective of their country of origin. These international institutions receive their budget from the different contributing countries hence there is competition for funding with national facilities. In the case of the ILL there is competition with local reactor and other neutron sources in member countries, and this has impact on the budget of the ILL. I mentioned earlier the problems with Britain arising from competition between the ILL and the ISIS spallation source. I think now there are problems on the German side which is struggling to provide for both the budget of the ILL and the new reactor in Munich. While it may be justified that Europe has more than one neutron source it is unfortunate that these have been built separately, country by country (first France with Orphée, then Great Britain with ISIS, and Germany with the Munich reactor), instead of being in collaboration between the three countries.

This appears to be a European weakness. In the USA the construction of research reactors has been done systematically and without costly duplication. Inevitably there has been competition between the various research centres as to where new facilities would be sited. A federal authority finally took the decision. Now a spallation source called SNS ${ }^{119}$ is under construction at the Oak Ridge laboratory. This source will cost 1400 million dollars, and will operate in 2006 . It should produce pulsed beams with peak neutron intensities 100 greater than the ILL reactor but much weaker average neutron flux.

The construction is a joint enterprise proposed by the five most important national laboratories working in the nuclear field (Oak Ridge, Argonne, Brookhaven, Los Alamos and Lawrence Berkeley). Thanks to cooperation the Europeans have been ahead in the field. Unless these international collaborations have a priority compared to national projects this leadership will be lost. It is perhaps

\section{8 addition:}

As expected SNS is operating since 2006 reaching full power in 2014.

$\overline{119}$ SNS website: https://neutrons.ornl.gov/sns 
useful to recall that Airbus Industrie, whose technical and commercial successes are known to all was created as a Franco-German cooperation in May 1969, two years after the ILL. The Franco-German pairing clearly works well.

\subsection{The scientific record}

In this text I have tried to tell the story of an institute whose beginnings date back more than forty years (more than 50 years in 2018). This is not an unusually long time for a normal scientific institution - the Institut Pasteur is over a hundred years old. However, the existence of the ILL is based on a single facility, and if this facility were to be closed down it would have no future whatsoever. This explains the care, effort and budget needed to maintain it. These investments are only justified, if the scientific rewards are satisfactory. I will try and make this assessment with certain examples since I do not feel competent to comment in all areas of research using neutron beams.

Study of the neutron as a fundamental particle has been especially fruitful. A recent experiment conducted at the ILL shows well what can be done with neutrons. The aim was to demonstrate for the first time the quantum states of matter in a gravitational field. The weakness of this field compared to a magnetic field makes observation difficult. As an uncharged but heavy particle the neutron is the best contender to show these states. V.V. Nesvizhevsky and coworkers ${ }^{120}$ used ultra-cold neutrons with a velocity $5-10 \mathrm{~ms}^{-1}$ produced by a device developed by Steyer ${ }^{121}$. In this apparatus neutrons from the vertical beam from the cold source are scattered from the surface of the blades of a turbine which is moving in the same direction as the incident neutrons and thus are strongly slowed down as a ball in a tennis drop shot. The idea was developed in 1966, with a first realisation at the Munich reactor in 1975, then the turbine was installed at the ILL in 1985. The experiment of Nesvizhevsky et al. made these very slow neutron bounce on the surface of a mirror and measured their jump heights. Macroscopic

${ }_{120}$ V.V. Nesvizhevsky et al., Nature (2002), 415, 297-299, DOI $10.1038 / 415297 a$

${ }^{121}$ A. Steyerl and S.S. Malik Nucl. Instrum. Methods Phys. Res. A (1989), 284, 200-207, DOI 10.1016/0168-9002(89)90282-9 
quantified jump heights were observed thus demonstrating the existence of neutron quantum states with discrete energies in a gravitational field. This was the founding experiment of a new gravitational spectroscopy capable of measuring extremely low energies.

The experiment above which tests the generality of quantum physics is not the only one in the field of fundamental physics which has been carried out with the help of neutron beams. We know that at the beginning of the twentieth century Einstein and Bohr were in opposition debating whether quantum physics was a complete theory, or whether there were hidden parameters waiting to be found. Einstein was for the former. Experimental tests were proposed and performed using photons which disproved the existence of these parameters. Hasegawa ${ }^{122}$ and his collaborators have used neutrons for these tests. Using a neutron interferometer they confirmed the results obtained with photons so demonstrating that the correlations between different degrees of freedom as a result of quantum entanglement were not only a feature of photons but existed also for neutrons.

Physicists have expended enormous effort to develop a theory which accounts for the four types of forces existing in nature: electromagnetic, weak interactions, strong interactions and gravity. The Standard Model has been painstakingly developed. The use of capitals in the name shows the importance given to this theory. The neutron spontaneously dissociates into a proton, an electron, with the emission of a antineutrino. The lifetime of the neutron is 885.7 seconds ${ }^{123}$. This process is controlled by the weak force, and is the simplest known case of $\beta$-decay (beta-decay). From the theoretical works of T.-D. Lee and C.-N. Yang, and experimental work of C.S. Wu and co-workers it has been shown that parity is not conserved during this process. That is to say there is a difference between the disintegration of the neutron, and what one

122 Y. Hasegawa et al., Nature (2003), 425, 45-48, DOI 10.1038/ nature01881. T. Denkmayr et al., Nature Comm. (2014), 5, 4492, DOI 10.1038/ncomm5492.

${ }^{123} 2018$ addition: This was an average over all measurements when B. Jacrot wrote his book (C. Amsler et al., Phys. Lett. B (2008), 667, 1-6, DOI 10.1016/j.physletb.2008.07.018). A discussion on more recent measurements can be found here: Greene G.L. and Geltenbort P., Scientific American (2016), 314(4), 36-41, DOI 10.1038/scientificamerican0416-36. 
2018 addition:

About 21,000 scientific publications in 50 years. would observe in a mirror image. This results in the electrons being preferentially emitted in a direction opposite to the neutron spin. Measurement of this asymmetry by $\mathrm{H}$. Abele and co-workers, associated with the lifetime of the neutron defines a quantity which should be equal to one, according to the Standard Model. This is not what is found ${ }^{124}$, and suggests we should advance beyond this model. This is a domain where a reactor provides information having the same impact as that from a big accelerator such as those at CERN. I can also cite the work on the measurement of the electric dipole moment of the neutron which is linked to space-time invariance.

Despite my lack of competence in this area I have cited these experiments to demonstrate that the most fundamental physics can be studied using these particles. However most of the 700 or more experiments performed each year at the ILL relate to the determination of magnetic structures, the precise location of hydrogen atoms in organic molecules, including proteins, and the study of motion in solids and liquids.

A very good example is the study of polymer melts. De Gennes proposed a model to account for the reptation of the long polymer molecules. The model was in competition with other mechanisms, and there was no experiment to show which was the best model. Experiments using a neutron spin-echo spectrometer ruled in favour of the de Gennes model ${ }^{125}$.

Overall, since the creation of the ILL, the work done there has resulted in at least 10,000 scientific publications in peer reviewed journals. Elegant experiments have been performed on magnetic substances, which is a field where neutrons are absolutely irreplaceable. About $28 \%$ of publications treat different aspects in this field of research.

Neutrons are even more useful if one uses polarised beams, that is to say where all their magnetic spins are parallel. There are many methods to produce such beams. I have presented some of them briefly in Chapter 3 which explains the use of neutrons. When they are polarised it is possible to reverse the direction of polarisation. By

${ }^{124}$ The value found is 0.9924 with a possible error of 0.0028 , hence significantly different from 1 . One can see the precision which can be achieved in some experiments.

${ }^{125}$ D. Richter et al., Phys. Rev. Lett. (1990), 64, 1389-1392. DOI 10.1103/PhysRevLett.64.1389. 
measuring the scattering of polarised neutrons in these two opposite senses the distribution of magnetisation in the sample can be studied. It is hence possible to determine what are the origins of magnetism in organic matter which contains no metals. It is also possible to understand the giant magnetocaloric effect in certain substances where the temperature falls by more than $5 \mathrm{C}$ when they are demagnetised.

There are other aspects of magnetism which are important for technology. We know that computer memories make use of magnetisation and demagnetisation of small domains. The smaller these domains are, the higher is the storage capacity. Here too, neutrons can provide useful information.

Magnetism is not the only area where the work done at the ILL contributes to technology. One example: we know that hydrogen is under consideration as a substitute for petrol. Firstly, there are many problems to resolve. One of these is the storage of this gas. A Swiss group led by Professor Yvon at Geneva has studied the use of metal alloys which can absorb great quantities of hydrogen. The ideal material has not yet been found. The diffraction of neutrons is perfect for studying these substances full of hydrogen.

In biology the record of the ILL is very favourable. The principal tool is so-called contrast variation. This method uses the vast difference in scattering powers of hydrogen and deuterium, and therefore between ordinary and heavy water. Small-angle neutron scattering which is only sensitive to the shape of the object can use a solvent mixture of light and heavy water and render invisible a molecule or part of molecule with the same scattering power. In a compound consisting of a nucleic acid and a protein (which have different average scattering densities) one or other of the two components can be measured depending on the solvent mixture used. This has found many applications in enzymology and virology. Another area in which inelastic neutron scattering has provided useful information is in protein dynamics. An excellent review ${ }^{126}$ on this subject was published by G. Zaccai.

${ }^{126}$ Giuseppe Zaccai, "How soft is a protein? A Protein Dynamics Force Constant Measured by Neutron Scattering", Science (2000), 288, 1604-1607, DOI 10.1126/science.288.5471.1604

\section{8 addition:}

This effect had its first practical application in 2015 for the production of refrigerators with energy savings of up to $50 \%$ and using no polluting gas. 
Most of these measurements would be impossible with other techniques, and difficult if not impossible to perform with beams from a medium flux reactor. Some of these applications arise in unexpected fields. For example Artioli ${ }^{127}$ and his colleagues have used neutrons to understand how an axe was forged in the Bronze Age. They studied the texture of the bronze axe using neutron diffraction, which has the advantage of being a non-destructive method for testing within a thick sample. The results found no texture, which showed that these ancestors were alternating cold working and prolonged annealing which removed the stresses induced by the cold working. This is an example of applying a technique widely used by engineers to a problem of interest to historians of technology.

To facilitate access to neutron beams and X-rays to study stresses a laboratory called Fame38, funded by the EPSRC, the UK's Engineering and Physical Sciences Council - successor to SERC, was created jointly between the ILL and the ESRF. It is expected (with some optimism) that through this laboratory the use of neutron (or X-ray) scanning to study stress will be as widespread as scanners in medicine.

2018 addition:

The ILL has been extended until 2023 and an extension to 2030 is expected. Technically speaking, the reactor could be operated well beyond indeed

because of its very specific design which makes it highly repairable.

\subsection{The future for the ILL ${ }^{128}$}

The present management of the ILL considers that the reactor will be operational at least until 2020, and it is essential that it remains competitive until then. To ensure this it proposes to strengthen the aspects where the domination of the ILL is strongest. A third cold source is under study, and it is necessary that each instrument should not only be improved, but should be the best possible with the technology available.

Whatever the quality of improvements and care is taken to maintain it one day or another a reactor must cease activities. It is necessary to think of that. We must take into account the commissioning in the USA of the SNS spallation source in June 2006. An equivalent source

127 Artioli et al., ILL Annual Report 2003, page 50.

128 What follows is my personal view which I have at no time discussed with the current management of the ILL, and hence they cannot be held to any future engagement. 
is foreseen in Japan for 2007. These machines are designed to produce peak fluxes of $10^{17}$ neutrons per centimetre squared per second. The solution that comes to mind is to plan now to replace the ILL reactor by a neutron source more modern and more powerful. The nature of this source is known: a spallation source as in the USA and Japan, which produce neutrons by the impact of high energy protons on a heavy metal target. There is even a pre-project for a European Spallation Source (ESS). The project is estimated to cost $€ 1500 \mathrm{M}$.

Like the SNS it will offer pulses of neutrons about 100 times as intense (at the peak of the pulse) as the flux from the reactor of the ILL. To make optimal use of this intensity requires use of time of flight techniques. In 2003 the project seemed buried by the withdrawal from the project of Germany and Great Britain. A recent letter appeared in Nature in July 2004 which offers new hope ${ }^{130}$. It is clear that the choice of potential site for this machine will not be made without difficulty. The arguments already put forward by Fender for the implementation of the ESRF on the site of the ILL seem to apply also to the ESS. This would also assure a long term future for the ILL which has shown its capabilities and deserves to last beyond the lifetime of the current reactor.

\section{8 addition:}

The J-PARC facility ${ }^{129}$ has been built and reached the full design power of $1 \mathrm{MW}$ in 2015.

\section{8 addition:}

This hope has materialized but not for Grenoble since ESS is being built at Lund in Sweden ${ }^{131}$ for a cost of $€ 1843 \mathrm{M}$ based on 2013 estimations. Its first neutrons are expected in the early $2020 \mathrm{~s}$.
${ }_{129}$ J-PARC website: https://www.j-parc.jp/MatLife/en/index.html

130 Schiermeier, Q., Nature 430, 493 (2004). DOI 10.1038/430493b.

131 ESS website: https://europeanspallationsource.se 



\title{
Chapter 11
}

\section{The ILL between 2005 and 2018}

\author{
W.G. Stirling ${ }^{132}$ and C. Vettier ${ }^{133}$
}

\subsection{Introduction}

The period from 2005 until 2018 involved the ILL in some of the most challenging chapters of its existence. The ILL management and staff were faced with two extremely demanding reconstruction/strengthening projects, the ILL Refit and the Stress Test Response (STR) programme (REX Fukushima); these resource intensive programmes, required by the French safety authorities (the latter in response to the Fukushima nuclear disaster), carried the potential of threatening the very existence of the ILL.

In parallel with these programmes that were extremely demanding both financially and in terms of human effort, the ILL maintained a scientific programme of the highest quality while also upgrading significantly the facilities and capabilities of the institute (the ILL2020/Millennium programme and the subsequent Endurance programme).

This period was also one of expansion in terms of Scientific Members. Whereas in 2004 there were 6 Scientific Members, this had grown to 11 by 2010. It is undeniable that this expansion led to an enrichment of ILL's scientific life by introducing new communities across Europe. However, the increase to around $20 \%$ in the Scientific Members' contribution to the budget introduced a number of complications in the determination of financial and scientific policies that were no longer defined uniquely by the three Associate countries.

The European neutron landscape was also undergoing major changes. Not only were some major national sources entering their final phase of operation (ORPHEE at Saclay,

\footnotetext{
132 ILL Director: 2014 - 2016; ILL scientist: 1973 - 1987.

133 Assistant Director: 1999 - 2007; ILL scientist: 1978 - 1990; ILL PhD Student: 1970 - 1974.
} 
BER-II in Berlin) but the formidable European Spallation Source (ESS) project moved from the planning to the construction phase. The ESS, planned as the (international) successor to the ILL, was viewed with mixed feelings by ILL staff and ILL users. However, it is clear that without the future promise of the ESS, the ILL risked losing a number of national communities; in the longer term, the ESS would provide unparalleled possibilities for European scientists.

\subsection{Ambitious improvement plans}

Since its inception the ILL and its three Associate countries have cooperated in a policy of more or less continuous maintenance and enhancement of the reactor, instrument suite, and associated infrastructure. During the period from 2005 this policy was materialised in two major programmes, the Millennium and Endurance Programmes.

\subsubsection{The Millennium Programme}

In 2000 the ILL Millennium Programme was launched, with the goal of maintaining the ILL in its leading position in world neutron science. The programme was set out in the Roadmap document for the decade 2000-2010, published in 2001. The first mission of the Millennium Programme was the completion of five instruments which should have been upgraded during the previous decade. In 2006, the full scope of the Millennium Programme was laid out in another strategic document, Future Perspectives and Opportunities for the Institut Laue-Langevin ${ }^{134}$. This report documented a coherent plan for the next decades, with three major goals: the provision of new infrastructure for instrumentation (neutron sources and neutron transport, instruments and techniques), the foundation of partnerships on the common site shared by ILL, ESRF and EMBL, and the renewal of key reactor component (Fig. 11.1).

An important aspect of instrumental development was the use of large area detectors, especially for timeof-flight instruments (Fig. 11.2). This has proved to be an essential step in matching the performances of pulsed neutron source instruments; such detectors were pioneered in particular by the ISIS spallation source.

${ }^{134}$ https://wwwarchive.ill.fr/instruments-support/modernisationprogrammes/perspectives-opportunities-2006/ 

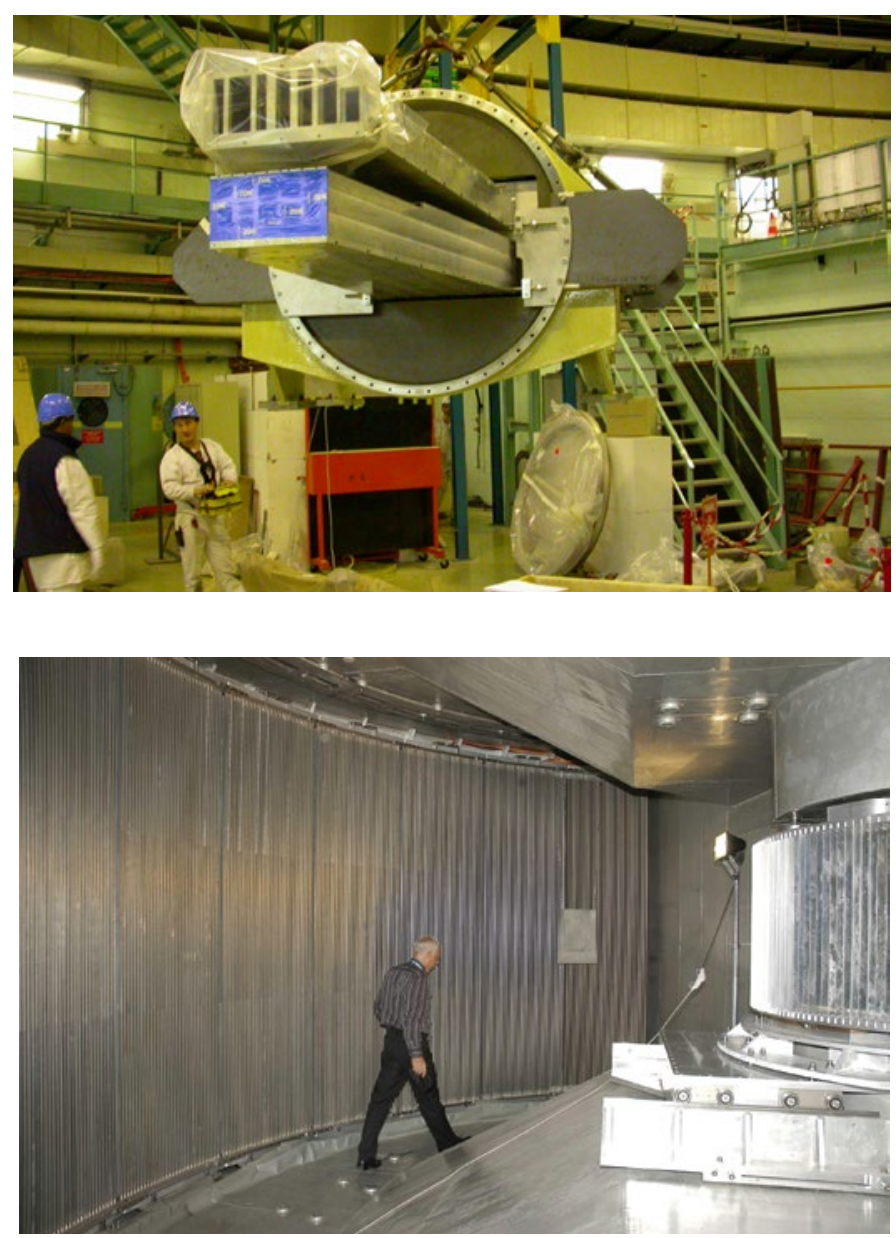

The final instrument to be completed at the ILL was a high-performance wide-angle neutron spin-echo spectrometer (WASP); this world-leading inelastic instrument, shown in Fig. 11.3, will extend spin-echo spectrometry to time domains hitherto inaccessible, opening up new scientific fields.

In parallel with these instrument developments, the ILL established services to offer users more than simply neutron beams (for example, deuteration facilities to grow deuterated biological crystals, the C-Lab to perform computer simulations before or during the actual experiments, the Partnership for Structural Biology with the neighbouring institutes ESRF and IBS). Building on this experience, the ILL proposed a Partnership for Soft
Fig. 11.1: The exchange of beam-tubes such as the $\mathrm{H} 1-\mathrm{H} 2$ shown here is part of the continuous upgrade of key reactor components.

Fig. 11.2: The new IN5 detector bank (on the left) covers $147^{\circ}$ in scattering angle; its ${ }^{3} \mathrm{He}$ detectors are $3 \mathrm{~m}$ high with a total surface of $30 \mathrm{~m}^{2}$. 
Fig. 11.3: A view of WASP

(Wide-Angle-SPin-echo spectrometer) a couple of weeks after it received its first neutrons.

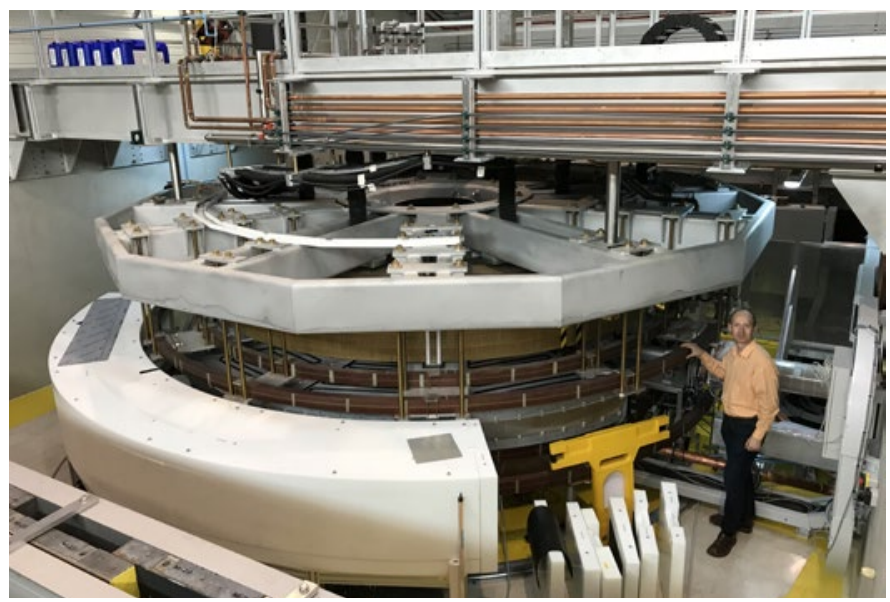

Matter with the ESRF which was established in 2013 in order to promote the integrated exploitation of neutron and synchrotron methods in combination with the most advanced laboratory techniques in the field of soft matter.

The Millennium instrumentation programme aimed at the production and delivery of optimally tailored neutron beams to upgraded or newly designed instruments. For example, refurbishing the neutron guides provided a gain of $\sim 10$ in the neutron flux at instruments. The overall gain factor, allowing for all relevant factors (principally improved neutron transport and detection), lies between 20 and 25 averaged over the entire instrument suite, an excellent result for the total investment $€ 77 \mathrm{M}$ (Fig. 11.4).

Fig. 11.4: Gain in detection efficiency at ILL obtained through Millennium upgrade programmes (blue bars).

Associated integrated investment (green points and curve).

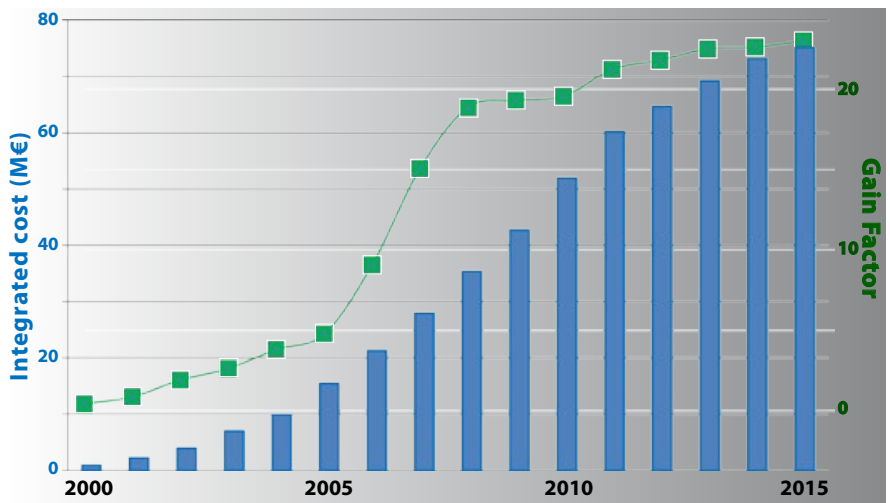




\subsubsection{The Endurance Programme}

The Millennium Programme was followed by the most recent set of upgrade and maintenance projects, Endurance. This programme is set to run for the period 2016 to 2023 and includes new and modified instruments, underpinned by further investment in sample environment, data reduction and analysis software, and improvements to thermal neutron guide tubes.

It is instructive to consider briefly the details of Endurance since the scope of the programme demonstrates that after some 50 years of forefront neutron research, the ILL continues to equip itself for cutting-edge research. During the first phase (2016-2019) a major renewal of one of ILL's principal thermal guide tubes is planned, along with an upgrade of the associated instruments, plus a new powder and single-crystal diffractometer for extreme conditions science, and a "work-horse" diffractometer. Extra new or upgraded instruments include a Collaborating Research Group (CRG) backscattering spectrometer, a new thermal neutron time-of-flight instrument for inelastic studies, and a white beam reflectometer, while the important field of nuclear physics is represented by a new fission fragment spectrometer (Fig. 11.5) and a new ultra-cold neutron source. These significant improvements to ILL's instrument suite are to be accompanied by ambitious projects to extend and improve data treatment packages and sample environment capabilities.

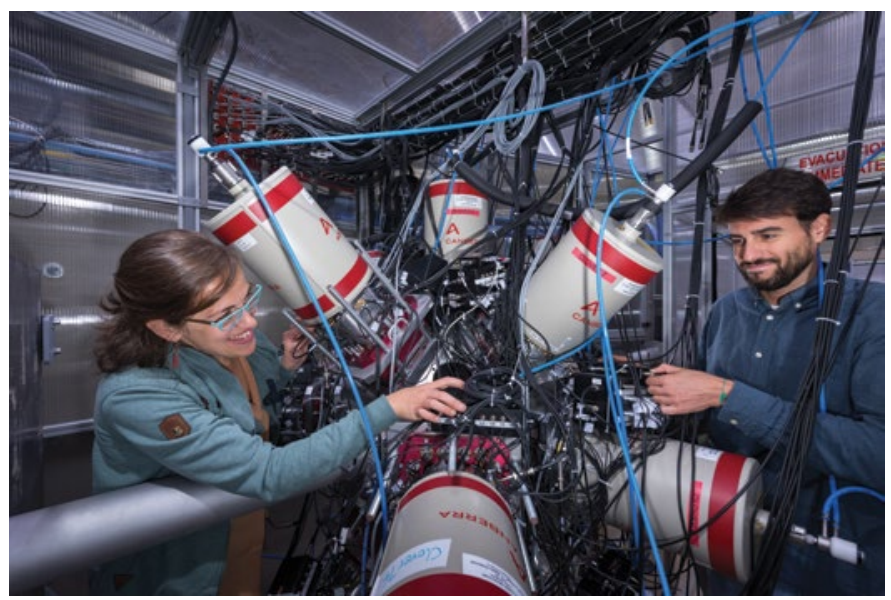

Fig. 11.5: FIPPS (FIssion

Product Prompt gamma-ray Spectrometer) with its array of high efficiency germanium clover detectors. 
This first phase of Endurance will be followed by further instrument and infrastructure upgrades during phase 2 which will provide the ILL among other things with a world-leading imaging instrument, further enhanced performance on the time-of-flight and three-axis spectrometers (including state-of-the-art multiplexing), a real boost to its diffuse polarized scattering instrument, a range of new detectors for diffraction and small-angle instruments, further advances on the fundamental and nuclear physics side as well as several additional CRG instruments.

Looking back from 2019, the Millennium and (current) Endurance programmes can be seen to be successful and cost-effective investments, maintaining ILL's leading position among neutron scattering centres world-wide.

\subsection{Complying with more demanding safety regulations}

In the more than 50 years since the ILL was established, attitudes to nuclear research and nuclear power have changed significantly. For the ILL one manifestation of this evolution has been a continual tightening of the security regulations applied by the French authorities, particularly during the period after the Fukushima disaster in 2011. Up until the time of writing the ILL has responded to satisfy these demanding requirements without sacrificing the basic precepts by which the ILL has operated (relatively open academic campus atmosphere, access to instruments on the basis of peer review, effective personnel safety regulations). That this has been possible is due to the remarkable original design of the ILL reactor, a flexible design which has permitted extensive modification. It is noteworthy that the reactor was designed at a time when the methods to evaluate performance and risks were much more limited than nowadays.

\subsubsection{The Refit}

As part of a regular safety review of the ILL reactor that took place in 2002, the ILL engaged in a vast programme of actions to reinforce and renew the whole of 
the nuclear installations in compliance with currently applicable seismic regulations, while maintaining active research activities and keeping the momentum of the Millennium Programme. The programme of work, the Refit programme, comprised many tasks ranging from the reinforcement of buildings against seismic hazards to new control systems, including all aspects related to the storage, manufacture and reprocessing of fuel elements.

The first objective of the Refit programme was to ensure that three main structures of the reactor building remain stable in case of an earthquake (at level 5.7 on the Richter scale): the inner concrete containment vessel, the inner concrete structures and the outer metal containment vessel. Extensive civil engineering works were carried out, with the reinforcement of the reactor building itself and the strengthening or dismantling of adjacent buildings. In particular, 1500 tons of concrete structures were removed from the building itself in order to reduce the inertia of the inner structure (Fig. 11.6). The office building that hosts the reactor control room was significantly reinforced while the front parts of the two guide halls were dismantled to avoid damages to the reactor building, if they were to collapse during an earthquake.

The Refit dealt also with mechanical engineering studies and non-destructive tests on the primary heavy water cooling circuit and the storage of fuel elements to secure a safe shutdown in case of serious earthquakes. The whole

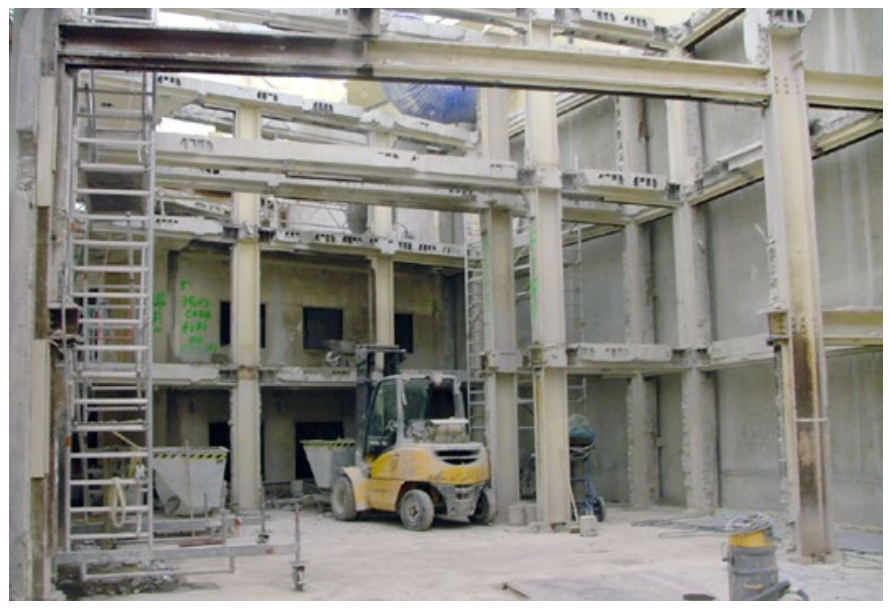

Fig. 11.6: Demolition and removal of internal structures at the top level of the ILL building to reduce inertia in case of a seismic event. 
Refit was closely monitored by the French safety authorities and was eventually signed off in 2007 with a total expenditure of $€ 30 \mathrm{M}$. It is noteworthy that the renewal of the neutron source during the Refit and Millennium programmes (involving a continuous upgrade programme of every key reactor component) proved essential in the light of the Fukushima events.

\subsubsection{Fukushima}

When the enormous tsunami hit the Fukushima Daiichi nuclear power plant in Japan on 11 March 2011, resulting in a nuclear accident of a severity unparalleled since the Chernobyl disaster of 1986 (both classified as level 7 of the International Nuclear Event Scale), the French safety authorities (ASN, L'Autorité de Sûreté Nucléaire) reacted immediately by requesting a re-evaluation of safety measures at all French nuclear installations.

Subsequently, the ILL undertook an extremely serious in-depth consideration of all of its safety regulations, organisation and systems. The ASN imposed a set of extreme situations with respect to which the ILL had to demonstrate that its installations would remain safe without any significant release of radioactivity. Notable among these was that the ILL reactor and buildings should withstand an earthquake of level 7.3 (expected roughly once every 20,000 years). In addition, the installations should resist, at the same time, the effects of a dynamic flood of $6 \mathrm{~m}$ depth at the ILL site, resulting from the collapse of four hydroelectric dams upstream on the river Drac. The ILL's engineering staff responded to these demanding requirements with a detailed plan, the Stress Test Response (STR) programme (REX Fukushima), which was executed from 2013 and completed in 2018.

Among the very extensive engineering works undertaken during the Fukushima programme, new systems were installed to further ensure proper cooling of the reactor core in any potential emergency situation. In addition, a new emergency control room (PCS3), designed to withstand the extreme conditions described above, was built above a new heavy water handling building; see Fig. 11.7. The ILL's skyline was also altered by the new chimney, strengthened to prevent any potential damage to the ILL reactor containment building. 


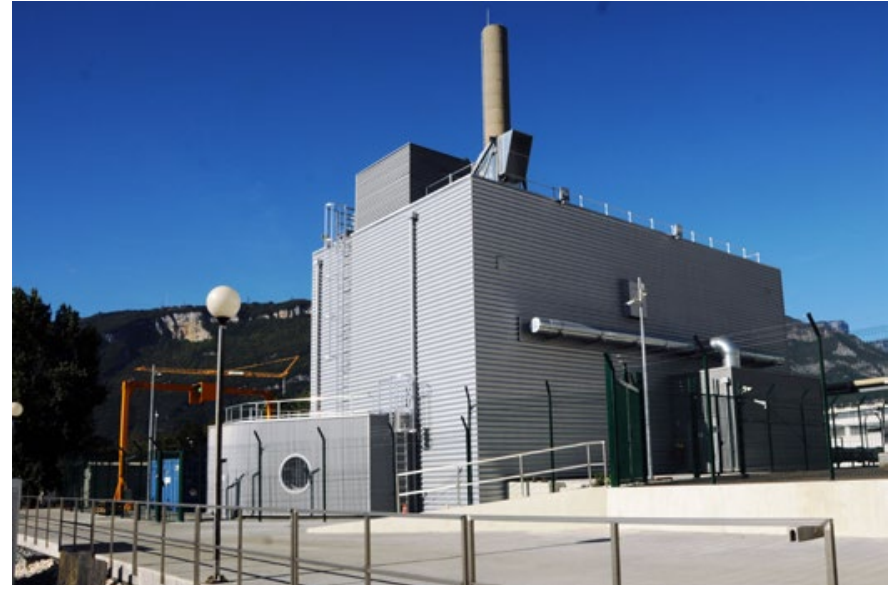

The STR programme required an exceptional effort on the part of the ILL's staff while the additional expense, totalling about $€ 30 \mathrm{M}$, resulted in severe financial difficulties. However, the strengthening and reconstruction work was financed with a significant contribution to the "extra" expenses by the ILL Associates and a restructuring of the ILL's budget over a 10-year period. It is worthy of note that the ILL was the first French nuclear operator to complete its STR programme.

\subsection{Funding the present and the future}

To further develop the quality of its instrument suite available to the scientific community the ILL has to fund both instruments and renewed infrastructures. Two important ways in which this has been achieved are described in this section.

\subsubsection{Hosting instruments from other institutions}

The concept of the Collaborating Research group (CRG) instrument was developed at the time of the "Deuxième Souffle" (Second Wind, 1979) when it became apparent that ILL did not have the resources, particularly where
Fig. 11.7: The new highly reinforced building hosting both the heavy water treatment facility and, on the roof, the emergency control room PCS3. 
Fig. 11.8: The Austrian CRG, S18, a perfect crystal neutron interferometer used for experiments on quantum and fundamental physics. scientific staff was concerned, to operate all existing instruments as new public instruments came on line. CRGs are composed of scientists from one or two research disciplines, and often multinational, carrying out a joint research programme centred on a specific instrument. These external groups finance and operate the instrument, receiving in return a major part of the available beamtime. Over the years the CRG concept further evolved to include new instruments conceived and constructed by the CRG partners, including three operated by scientists from the CEA (Grenoble) after the closure of the CEA's Siloé reactor in the mid-nineties.

By the time of the Endurance programme there were 29 public instruments and 10 CRG instruments, either already operating, in construction or to be upgraded. The CRG groups involved were based in Austria (Fig. 11.8), France, Germany, Italy, Spain, and Sweden. Thus, the CRG instruments provide a very significant part of ILL's total beam time and represent an important support for national scientific communities.

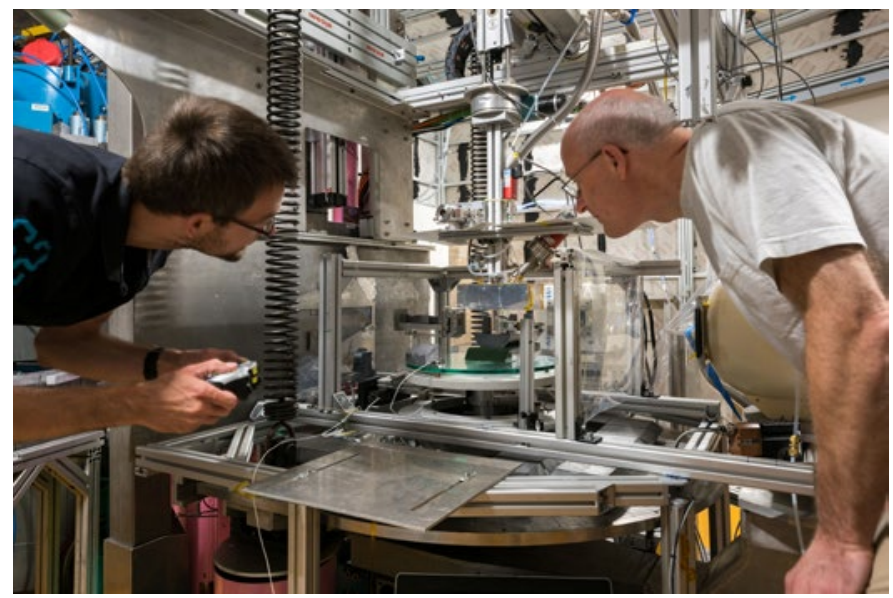

An important element of the CRG programme was the recognition that these instruments should be competitive at world-class level; they were in no way "second-class" instruments. To help maintain this high level of scientific quality, all CRG instruments were reviewed regularly, as were the public instruments. The investment required to maintain world-class operation was the responsibility of the CRG partners while the ILL looked after the neutron delivery system (beam and guide tubes, etc.). 


\subsubsection{Funding infrastructure}

While the improvement programmes described above were financed from the ILL's "normal" budget, with additional funding supplied by the Associates and Scientific Member countries, it was always difficult to find funds to cover necessary infrastructure projects; instrument and source developments were considered to have a higher priority.

A (partial) solution to this difficulty was identified when, in 2005, the ILL led a joint action (on behalf of the European institutes on the common site, ESRF, EMBL and ILL) to be recognised as a partner by the French local authorities when defining infrastructure policies. As a result, significant infrastructure projects (in particular, a new joint laboratory building and a new site entrance, but also new instrumentation), were made possible through special national French funding the CPER ("Contrat de Plan Etat-Régions"); this showed that indeed the activities at ILL and ESRF were important to the French authorities. In return, the main partner countries of ILL (and ESRF), whose scientists have benefitted also from these projects, were reassured by the financial commitments borne by local authorities. A second CPER finance plan for the years 2016 to 2020 is helping with the funding of the most recent upgrade and maintenance programme (Endurance) described above.

\subsubsection{Science - staying at the cutting-edge}

The ILL has always been the site of an active scientific life. The gains in sensitivity and accuracy induced by the recent upgrade programmes, Millennium and, most recently, Endurance, have expanded the breadth of the research performed at the ILL. Since around 2000, societal relevance and impact have become of increasing importance at ILL and in research in general. Neutrons provide a range of key methods in societally relevant research. The ILL's User communities and scientific staff adapted to this new environment, thanks to the newly created support facilities (D-Lab, C-Lab, PSB, PSCM, etc) ${ }^{135}$. In recent years there has been significant growth in a number of areas of applied

135 D-Lab: Deuteration Lab <www.ill.eu/D-Lab>, C-Lab: Computation Lab <www.ill.eu/C-Lab $>$, PSB: Partnershipfor Structural Biology <www.psb-grenoble.eu>, PSCM: Partnership for Soft Condensed Matter <www.epn-campus.eu/pscm> 
sciences, notably in materials science, cultural sciences, and engineering (strain-stress measurements, the principal area of industrial proprietary research), complementing the core subjects studied at ILL (physics, chemistry, biology...). Some examples are presented below.

\section{Neutrons and technological progress}

Until recent years mechanical components were designed on the basis of workpieces that had been milled or cast and optimising the manufacturing and the safety was obtained through extremely performing computer software aimed at optimising internal stresses under fatigue or extreme conditions. Industrial processes have recently included the new method of Additive Layer Manufacturing or 3-D printing, especially in the case of very complex or vital components. However, the existing software cannot determine internal stresses properly in the case of 3D-printing; they need recalibration that relies on the experimental determination of stresses through neutron methods. Indeed, neutron beams allow the accurate and non-intrusive measure of residual internal stresses in bulk and complex pieces (Fig. 11.9).

Fig. 11.9: A component of a meteorology satellite (Built by the Renishaw company

for Thales Alenia Space) being investigated at the SALSA instrument. Residual internal stresses are being determined in 3D-printed Aluminium pieces.

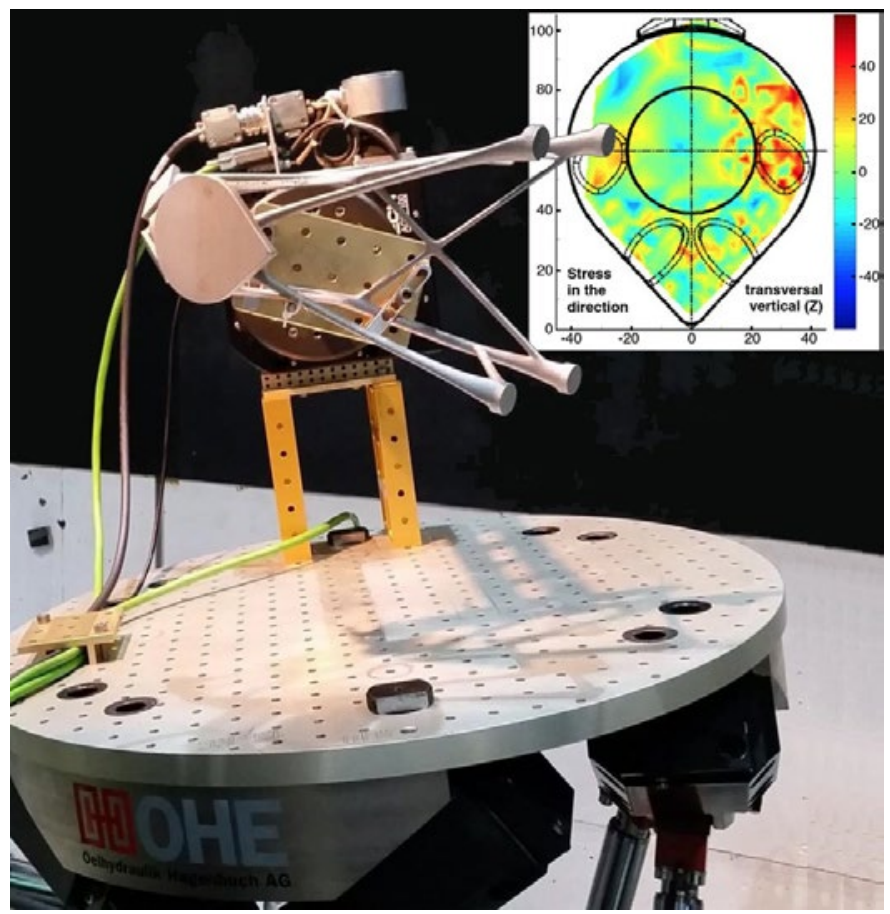




\section{Neutrons for society}

Studies at the ILL have provided invaluable information on the eminently practical subject of water purification. For hundreds of years the seeds of the Moringa oleifera tree have been used by African villagers to purify their water supply. A combination of small angle neutron scattering, neutron reflectivity and instrumentation at the PSB has been used $^{136}$ to understand the structure and properties of the Moringa protein, leading to a rational optimisation of the purification technique.

\section{Neutrons and the understanding of matter}

Even traditional fields of neutron science such as studies of vibrations in rather simple solids have evolved following the developments in neutron instrumentation at the ILL. The properties of complex materials of interest in our modern life are under investigation, in particular the transport of heat or electricity.

- Experiments at the ILL have demonstrated that models for heat conductivity in materials cannot reproduce observed properties; the dynamic properties which are crucial for thermal processes can be inferred from neutron experiments ${ }^{137}$.

- Exotic electronic phenomena are under investigation in a class of superconductors ${ }^{138}$. These are materials that could transport electricity with no resistance at almost practical temperatures and might have a strong impact on the world's economy.

\section{Neutrons and the Universe}

Even the properties of the neutron itself continue to be studied at ILL. After many years of investigation there is no firm conclusion as to the value of the lifetime of the neutron (of order 15 minutes); "disappearance"

136 M.S. Hellsing et al., Colloids Surf. A (2014), 460, 460-467, DOI 10.1016/j.colsurfa.2013.11.038; H.M. Kwaambwa et al., J. Colloid Interf. Sci. (2015), 448, 339-346, DOI 10.1016/j.jcis.2015.02.033

137 P.-F. Lory et al., Nat. Commun. (2017), 8, 491, DOI 10.1038/ s41467-017-00584-7

138 S. Limura et al., PNAS May 30, 114, E4354-E4359 (2017), DOI 10.1073/pnas.1703295114 ; L. Mangin-Thro et al., Nat. Commun. (2015), 6, 7705, DOI 10.1038/ncomms 8705 
Fig. 11.10: GraviTrap, a gravitational trap for ultra cold neutrons (UCNs) for the measurement of the neutron lifetime. The bathtub like trap coated with a special grease impervious to UCNs is here in the bottom of the enveloping copper cylinder. The UCNs accumulate in the trap as the atoms of a heavy gas would due to gravity. The trap can be horizontally rotated to empty it by pouring out the UCNs.

Serebrov A.P. et al., Phys. Rev. C97, 055503 (2018), DOI 10.1103/ PhysRevC.97.055503

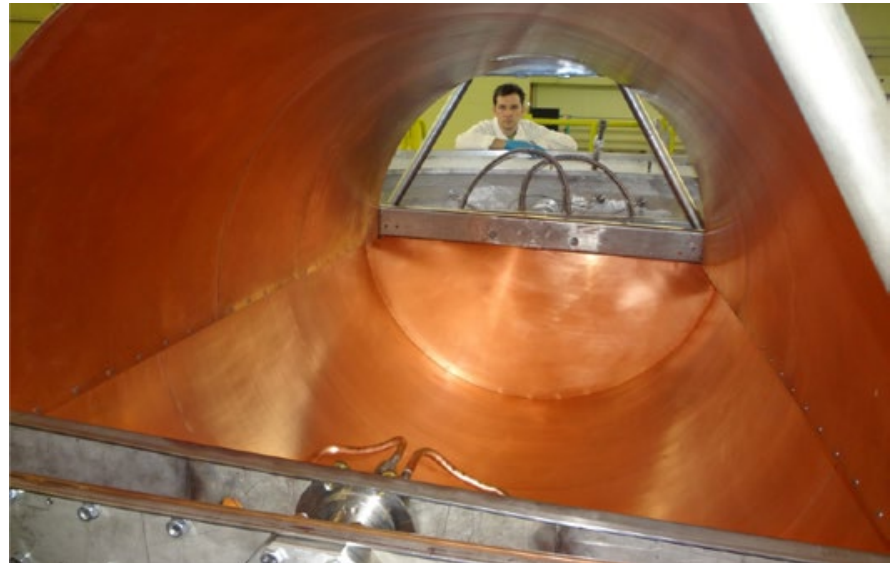

measurements using bottled ultra-cold neutrons (UCN) (Fig. 11.10) and decay rate measurements using neutron beams differ significantly, creating uncertainty in cosmological models. But to-date it is unclear whether this difference arises from experimental artefacts or profound physics $^{139}$.

A second striking example of fundamental research at the ILL is the quest to determine the value of the electrical dipole moment (EDM) of the neutron; how close to zero is this fundamental quantity? For decades, scientists at the ILL have been pushing the experimental detection limits in order to set upper values for the EDM, which are of importance when discussing the theory of the weak interaction (one of the four fundamental forces of nature) and models of the origin of the Universe, especially its matterantimatter asymmetry ${ }^{140}$.

\subsection{Conclusions and future}

We take this opportunity to look back at the more than 50 years of the ILL's existence. The ILL very rapidly attained a high level of productivity. By 1975, 7 years after

139 A.P. Serebrov, A.K. Fomin, Physics Procedia (2011), 17, 199-205, DOI 10.1016/j.phpro.2011.06.037; G.L. Greene and P. Geltenbort, Scientific American (2016), 314, 36-41, DOI 10.1038/scientificamerican0416-36

140 A.P. Serebrov et al., Crystallography Reports (2016), 61, 129138, DOI 10.1134/S1063774516010193 
the signature of the Intergovernmental Convention and only 4 years after the first criticality of the reactor (with many distinctive features - compact high neutron density core, large cold source, and many guide tubes), the ILL's reactor source was operating for about 250 days per year.

In parallel with the development of this remarkable neutron source, more than 25 instruments had been designed and constructed to be available within the public programme. At this time, there were also a large number ( 15) of "special" instruments, constructed principally by external groups for particular experiments.

One important indicator of scientific productivity is the rate of publication in the peer-reviewed scientific literature. The growth in scientific articles describing scientific work at the ILL by ILL's Users and staff is presented in Fig. 11.11. The rate of publication was rather constant at between 500 and 600 publications recorded annually, over the period from 1980. The "bump" around 1995 reflects the major shut-down of 1991-94 when ILL users and ILL scientists concentrated on the publication of previously acquired data. The cumulative total reached 20,000 some 40 years after the reactor start-up.

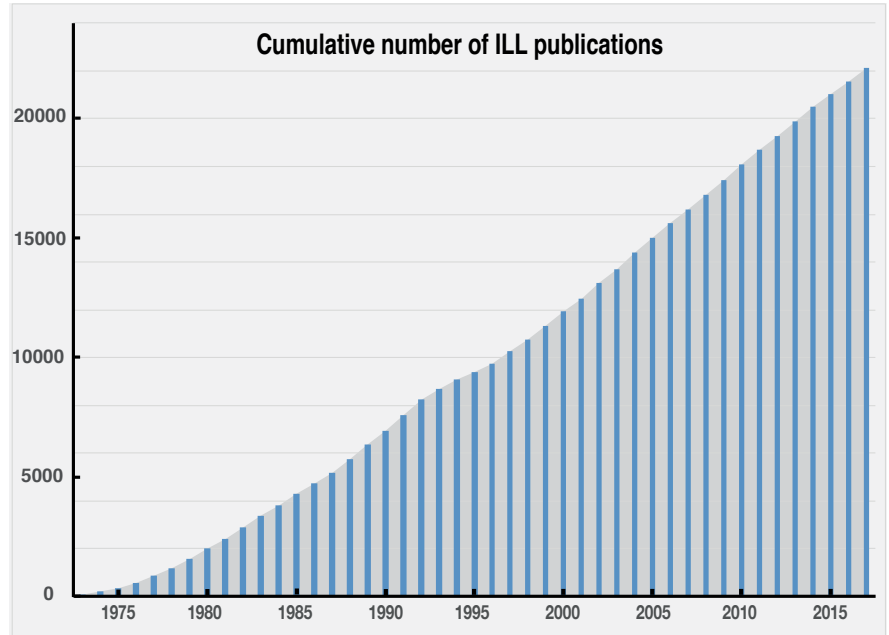

The ILL has maintained its position as the world leader in neutron science for more than 50 years. As well as the exceptional reactor, outstanding personnel, and the advantages (and difficulties) of being a service institute, there are three main reasons for this success.
Fig. 11.11: Cumulative of the number of ILL publications. 
First, the international nature of the ILL: scientists from more than 30 countries bring their different expertise and experience to bear on outstanding scientific problems. Second, the remarkable local scientific environment of the ILL (CEA, CNRS, ESRF, EMBL, UGA, ...) $)^{141}$ has led to a wide range of fertile scientific interactions. Third, and by no means least, the long-term financial "loyalty" of the three Associate countries - France, Germany and the UK - and the commitment of the Scientific Member countries, has allowed the ILL to make long-range scientific plans and to weather the major (and minor) difficulties that have arisen.

Changes in the planning and nuclear regulatory framework mean that it would not be possible today to design and build such a research facility as rapidly as was the case of the ILL. Nevertheless, the extensive reconstruction and additional security work carried out during the Refit and STR programmes, allied to the instrumentation and infrastructure improvements of the Millennium and Endurance programmes, ensure that the ILL remains at the forefront of scientific research. The Institut LaueLangevin is in excellent shape to confront future scientific challenges and, for many years, to act as an essential scientific partner, in harmony with the developing ESS.

${ }^{141}$ CEA: Commissariat à l'Énergie Atomique et aux Énergies Alternatives, CNRS: Centre National de la Recherche Scientifique, ESRF: European Synchrotron Radiation Facility, EMBL: European Molecular Biology Laboratory, UGA: Grenoble-Alpes University. 


\section{Chronology of ILL events}

\begin{tabular}{|c|c|c|}
\hline 1961 & & First idea of a European high flux reactor \\
\hline 1964 & August & Presentation of a French project at Geneva \\
\hline 1967 & 19 January & Creation of the ILL \\
\hline 1968 & December & Start of construction \\
\hline 1969 & 1 March & ILL1 building completed \\
\hline 1970 & 13 February & Accident on construction site of the reactor \\
\hline 1970 & 6,7 March & First visit of SRC \\
\hline 1970 & 5,6 November & Visit of the UK committee with John Kendrew \\
\hline 1970 & 2 December & Second visit of SRC \\
\hline 1970 & End & Main building handed over \\
\hline 1971 & 31 August & Reactor goes critical \\
\hline 1971 & 16-21 December & Reactor increased to full power \\
\hline 1972 & June & Normal operations with cold and hot sources \\
\hline 1973 & January & UK becomes partner of the ILL \\
\hline 1976 & & $\begin{array}{l}\text { The European Molecular Biology Laboratory outstation is established on } \\
\text { the ILL site }\end{array}$ \\
\hline 1979 & October & Start of modernisation programme \\
\hline 1981 & December & Extension of intergovernmental agreement to 31/12/92 \\
\hline 1984 & September & Major shutdown for maintenance \\
\hline 1985 & September & Restart with new vertical cold source \\
\hline 1987 & January & Spain becomes an associate scientific member \\
\hline 1987 & December & Installation of second cold source \\
\hline 1988 & January & Switzerland becomes an associate scientific member partner \\
\hline 1990 & January & Austria becomes an associate scientific member \\
\hline 1991 & April & $\begin{array}{l}\text { Cracks were observed in an anti-turbulence grid. The reactor is stopped and } \\
\text { its future is uncertain. }\end{array}$ \\
\hline 1991 & November & SERC reduces UK funding to $25 \%$ from 1994 \\
\hline $\begin{array}{l}1991 \\
\text { to } 1995\end{array}$ & & Reconstruction of reactor changing reactor vessel \\
\hline 1992 & & The synchrotron of the ESRF produces its first X-ray beams \\
\hline 1993 & January & Extension of international agreement until 31/12/2003 \\
\hline 1995 & January & Reactor restart with its new vessel \\
\hline 1996 & 1 January & Jülich Research Centre replaces Karlsruhe as German partner \\
\hline 1996 & November & Russia becomes an associate scientific member \\
\hline 1997 & January & Italy becomes an associate scientific member \\
\hline
\end{tabular}




\begin{tabular}{lll}
\hline 1998 & & $\begin{array}{l}\text { The MENI consortium of Austria and the Czech Republic becomes an } \\
\text { associate scientific member }\end{array}$ \\
2000 & January & Launch of Millennium Programme \\
2002 & December & $\begin{array}{l}\text { Extension of intergovernmental agreement to 31/12/2013 } \\
\text { SERC funding back to normal (27\% 2000, 29\% 2001, 32\% 2002, 33\% 2003) } \\
2003\end{array}$ \\
2003 & $\begin{array}{l}\text { Launch of the Refit programme (2003-2007), 1st reconstruction/strengthen- } \\
\text { ing project }\end{array}$ \\
\hline
\end{tabular}

\section{9 additions}

2006 Publication of the full scope of the Millennium Programme, "Future Perspectives and Opportunities for the Institute Laue-Langevin"

2010 Transfer from the CEA to the ILL of environmental monitoring responsibilities

2010 Launch of the EPN (European Photon and Neutron) science campus

2011 Post-Fukushima safety evaluations and start of reinforcement works

2011 New open access data policy. More secure data storage and retrieval, opening to a wider community, etc.

2012 Start of the Stress Test Response programme - REX Fukushima, (2012-2018)

2013 The Intergovernmental Agreement is extended to 2023

2013 The IBS (Institut de Biologie Structurale) relocated to the EPN Campus

2014 Science Building inauguration, a joint ESRF-ILL facility hosting the soft matter groups, the joint chemistry lab, the joint scientific library and the industrial units

2014 New EPN Campus entrance

2016 End of the Millennium modernisation programme. Replacement of several guide tubes and more than 20 spectrometers were upgraded with an average gain in efficiency of 24 !

2016

Launch of the Endurance modernisation programme (phase 1). Replacement of 4 guide tubes, 9 instrument projects, etc.

2017 The ILL turned 50. This important milestone was duly celebrated 


\section{Key people involved in the history of the ILL}

This list is incomplete (additional names have been added in this revision of Jacrot's book); it is not possible to mention all those who have contributed to this story. For scientists and engineers of the ILL the nationality is not specified.

[2018 addition: It is only right to mention at this point the engineers and physicists who designed the reactor and its experimental environment. This list is taken from the "Bulletin d'Informations Scientifiques et Techniques" of the CEA: BIST 165 (1971) and BIST 166 (1972). https://wwwarchive.ill.fr/about/what-is-the-ill/history/ ill-founding-papers/]

J. CHATOUX, "Description of the reactor and main options."

L. BREGEON, F. LAFAURIE and J.P. SCHWARTZ, "Neutron and thermal aspects. The fuel element."

D. COLZY, G. DUPUY and J.P. MARTIN, “The nuclear system of the high flux reactor."

M. CHAZALON and Y. LECUYER, "The cooling circuits and detritiation."

G. LHOR, "The fuel handling."

M. DEBRU, "The control and command system."

R. LEVET, "Civil engineering works and containment of the reactor building."

J. BUREAU DU COLOMBIER and H. REUTLER, "Safety aspects of the reactor."

P. AGERON, "Experimental possibilities."

P. AGERON, J.M. ASTRUC, H. GEIPEL and J. VERDIER, "The cold neutron source of the high flux reactor."

G. BOHME, W. DREXEL and F. WUNDERLICH, "The hot source of the high flux reactor."

J.C. FAUDOU, "In-pile systems for nuclear physics."

P. AGERON and P.A. BLUM, "The neutron beam tubes."

G. GOBERT, "The solid state physics spectrometers." 


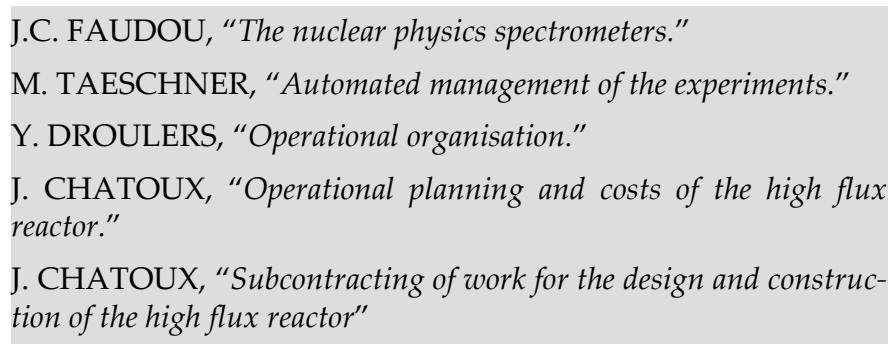

ABELE Hartmut: Physikalisches Institut, University of Heidelberg

ABRAGAM Anatole: French physicist, Director of Physics at the CEA (1965-1970) and professor at the Collège de France.

ALLEN Geoffrey: English chemical-physicist, professor at the University of Manchester (1965-1975), chairman of SRC in 1977

AGERON Paul (1931-1998): engineer and physicist who built the cold source and neutron guides

ALDEBERT Pierre: Thesis student from the French solar furnace at Montlouis

ARMBRUSTER Peter: nuclear physicist. Deputy Director (1989-1992)

ARNDT Ulrich (1924-2006): crystallographer of biological molecules, coming from Max Perutz's group, ILL: 1972-1973

ASTRUC Jean-Marie: reactor engineer

AVERBUCH Pierre: physicist university of Grenoble

AXMANN Anton: engineer and physicist responsible for electronics

BACON George: English physicist who has written much on neutrons

BALLIGAND Pierre (1917-1987): deputy director of the CENG

BAUER Ekkehardt: third head of reactor service (1989-2003), he was the ILL responsible for the reactor reconstruction

BECKURTS Heinz (1930-1986): physicist Karlsruhe, co-author of the reactor project with Robert Dautray, was murdered by the Red Army faction

BERTAUT Felix (1913-2003): head of crystallography at the CENG and CNRS in Grenoble

BLACKETT Patrick: English physicist, Nobel Prize 1948

BLOW David (1931-2004): English protein crystallographer, one time student of Max Perutz; Cambridge then London 
BOTHE Walter: German physicist, Nobel prize 1954

BREGEON Louis: project engineer group, in charge of reactor physics

BRENIG Wilhelm: Max Planck Institute for Solid State Research in Stuttgart, from 1970 to 1978

BROCHIER Dominique: engineer, cryogenics

BROCKHOUSE Bertram (1918-2003): canadian physicist Nobel prize in 1994 for his pioneering work on triple-axis spectrometers BROWN Jane: physicist crystallographer

BRÜGELMANN Silvia: Maier-Leibnitz's secretary

BURLET Paul: crystallographer of CENG

CHARVOLIN Jean: physicist deputy director and then director (1989-1994) during the reconstruction of the reactor

CHATOUX Jean: head of reactor project

CHIEUX Pierre: physicist

CURRAT Roland: physicist

CREYSSEL Pierre: executive director of the CNRS

CRIBIER Daniel: physicist at Saclay, director of the Léon Brillouin institute

CURIEN Hubert (1924-2005): director of the CNRS department of physics, then director CNRS

DAINTON Frederick: English chemist, chair of the University Grants Committee (UK)

DAUTRAY Robert: author of the reactor project, then he had very great responsibilities in the CEA of which he became high commissioner

DIANOUX José: physical chemist

DORNER Bruno: physicist ILL, specialist 3-axis spectrometers

DOUCHIN François: engineer, one of the founders of the trade union SA-ILL

DREYFUS Bernard (1928-2005): physicist, deputy Director (1973-1976)

DREXEL Winfried: physicist

DROULERS Yves: first head of reactor service

EGELSTAFF Peter: Harwell physicist, pioneer of inelastic scattering and cold sources, worked in Canada at the University of Guelph for over 20 years

von EGIDY Till: nuclear physicist

EISERMANN Werner: deputy head of the reactor project 
EMBLING John Francis (Jack): Deputy Under-Secretary, Department of Education and Science; Council for Scientific Policy from SRC

FAUDOU Jean-Claude: engineer, head of the DPT (Départment Projets et Techniques)

FEILDEN Geoffrey Bertram Robert (Bob): English engineer, Deputy Director General, British Standards Institution; Council for Scientific Policy from SRC

FENDER Brian: chemist, deputy director, then director (1980-85)

FIEBIGER Nikolaus: German physicist, professor in Frankfurt/ Main (1963)

FILHOL Alain: crystallographer, thesis student, then physicist

FLEISCHMANN Rudolf: German physicist, teaching assistant to Walter Bothe

FLOWERS Brian: head of the Science Research Council (SRC)

FRANZETTI Franco: second head of the reactor service

FREUND Andreas: physicist, head of the Monochomator group

FRIEDEL Jacques: physicist Orsay

FULDER Peter: theoretician, head of Munich group GARIOD Roger: engineer CENG

de GENNES Pierre Gilles: theoretician Saclay, then Collège de France, Nobel Prize (1991)

GENTNER Wolfgang: German nuclear physicist

GHOSH Ronen (Ron): physical chemist

GOBERT Guy: mechanical engineer

GÖPPERT-MAYER Maria: German-born American theoretical physicist, and Nobel prize in Physics in 1963

GREIFELD Rudolf: German member of the ILL steering committee, sacked in 1976

GUINIER André (1911-2000): physicist Orsay

HALDANE Duncan: post-doctoral researcher in the ILL's Theory group from 1977 to 1981; winner of the Nobel Prize in Physics in 2016

HASENCLEVER Wolfgang: first chief administrative officer

HAUSSER Karl Wilhelm: first director of the physics department of the Kaiser Wilhelm Institute for Medical Research (Max-Planck-Institute).

HEIDEMANN Anton: physicist, student of Maier-Leibnitz HEWAT Alan: physicist crystallographer from Harwell HIGGINS Julia: physical chemist, elected Fellow of the Royal Society (FRS) in 1995 
HOROWITZ Jules: (1921-1995) see section 2.1

IBEL Konrad: physicist

IPOUSTEGUY Jean Robert: French sculptor and painter (1920-2006)

JACQUEMAIN Michel: head of technical services

JACQUINOT Pierre: Professor in spectroscopy and DirectorGeneral of the CNRS (1962-1969)

JOLLIFFE Christopher: Science Division, SRC; led the first negotiations for the SRC

JUST Wilhelm: Austrian physicist; abandoned physics in 1989 to become a psychoanalyst

KENDREW John (1917-1997): physicist, protein crystallography, Nobel Prize 1962

KLAR Bertram: physicist

KLEY Walter: physicist Euratom (Ispra)

KOUTS Herbert: head of the Brookhaven reactor project

KOWARSKI Lew (1907-1979): physicist of Russian origin in Joliot's team, he was a pioneer of reactor physics, he directed the construction of the first reactor of the CEA, then left for CERN

LACAZE Albert: physicist engineer in cryogenics at the university of Grenoble

LAJZEROVITZ Janine: professor at the University of Grenoble, crystallographer

LEHMANN Mogens (Mons): physicist

\section{LE SOURNE Mathurin: computer engineer}

LOMER Mick: Atomic Energy Authority (AEA); member of the SRC-AEA Joint Research Programme; first British deputy director from 1973 to 1974.

LOOSCH Reinhart: German, Under-Secretary of the Federal Ministery for Education and Science, ILL Steering Committee in 1971

LOTH Wilhelm: German visual artist (1920 - 1993)

LOWDE Ray: physicist Harwell

MAIER Bernd: physicist, first scientific secretary

MAIER-LEIBNITZ Heinz (1911-2000): see section 2.2

MAMPE Walter: nuclear physicist

MARTIN Jean-Paul: project engineering group, delegated construction supervisor (1968-1971), reactor vessel replacement supervisor (1991-1994)

MATHO Konrad: theoretical physicist

MASON Saxon (Sax): physicist 
MERRISON Alexander Walter (Alec): British physicist born in 1924. Vice-chancellor of University of Bristal; Council for Scientific Policy from SRC

MEZEI Ferenc: physicist inventor of the neutron spin echo-technique and supermirroirs

MITCHELL William (1925-2002 ): responsible in the UK committee for the use of neutron beams (NBRC)

MOLL Eberhard: nuclear physicist, one of the founders of the trade union SA-ILL

MÖSSBAUER Rudolf (1929-2011): second director, Nobel Prize in physics 1961

MOUSSA André: Grenoble nuclear physicist

NEEL Louis (1904-2000): see section 2.3

NEWPORT Ron: responsible for SERC

NIEFNECKER Hervé: nuclear physicist CENG

NOZIERES Philippe: theoretical physicist, member of the Academy of Sciences

PALEWSKI Gaston: French politician, President of the Constitutional Council of France from 1965 to 1974

PERRIN Francis: High Commissioner CEA from 1951 to 1970

PEYREFITTE Alain: French Deputy Minister for Scientific Research and Atomic and Space Matters

PLATTENTEICH Adalbert: Head of Administration from 01/11/73 to $31 / 12 / 77$

PRETSCH Joachim (1909-1970): head of the German division of nuclear research

SCHELLING Erich: German architect in Karlsruhe who supervised the development of Karlsruhe's nuclear research centre

SCHLEMMER Oskar: German artist (painting, sculpture, theater) from the Bauhaus (1888-1943)

SCHNEIDER Jochen: physicist

SJÖLANDER Alf: Swedish physicist from Chalmers

STEINER Michael: German physicist from Tübingen University STOLTENBERG Gerhard: German Minister for Scientific Research

RAIEVSKY Victor: physicist, proponent of the Euratom pulsed reactor

RENOUPREZ Albert-Jean: French physicist from CNRS, specialist of catalysis

REUTLER Herbert: engineer project group responsible for safety issues

ROTH Michel: physicist 
SCHERM Reinhard: physicist early ILL, became director 20 years later

SCHOENBORN Benno: protein crystallographer, pioneer at Brookhaven in the use of neutron crystallography for proteins

SCH ḦRPF Otto: physicist

SCHWEIZER Jacques: physicist very active in the development of crystallography at CENG

SHULL Clifford (Cliff): pioneer in crystallography with neutrons, Nobel Prize in physics 1994

SIRET Yvon: responsible for computing

SPRINGER Tasso: physicist deputy director (1977-1980) and director (1980-1982)

STIRLING William (Bill): ILL physicist (1973-1987), became director general of the ESRF in 2001, then ILL director (2014-2016)

STUHRMANN Heinrich: physicist developed neutron applications in biology

TASSET Francis: physicist. With BROWN Jane and FORSYTH Bruce, he invented CRYOPAD, a technique allowing the spherical polarisation analysis of neutrons.

TAESCHNER Michael: computer engineer

THOMAS Michel: physicist

TIPPE Armin: German physicist from the Max-Planck Institute

TOCHETTI Defendente: physicist

VAN VLECK John: American physicist and mathematician (1899-1980), Nobel Prize in Physics in 1977

VALENTINE Jim: Neutron Beam Research Committee from SRC. VILLAIN Jacques: theoretical physicist

VETTIER Christian: thesis student, physicist, became deputy director 1999

VOLINO Ferdinand: physicist from CEA-CENG

WADE B. (Mrs.): Reactor Division of the AERE; Neutron Beam Research Committee from SRC

WEIL Louis (1914-1968): professor at the university of Grenoble, director of research low temperature laboratory (CRTBT) Grenoble

WHITE John: physical chemist Australian deputy director (1975-1977) and director (1977-1980)

WOOD W. (Mr.): Reactor Division of the AERE; Neutron Beam Research Committee from SRC

ZACCAI Giuseppe (Jo): physicist, later biologist 



\section{Appendixes}

\section{Some historical documents}

\section{A1 - Franco-German intergovernmental agreement}

\section{Agreement between the government of the French Republic and the government of the Federal Republic of Germany on the construction and operation of a very high flux reactor.}

et

Le Gouvernement de la République Française

Le Gouvernement de la République Fédérale d'Allemagne,

- soucieux de poursuivre la mise en application des dispositions du Traité franco-allemand du 22 janvier 1963, en particulier, de celles relatives au développement de la coopération scientifique entre les deux pays,

- considérant l'intérêt des recherches qui ont déjà été effectuées tant en France qu'en République Fédérale d'Allemagne dans le domaine de la physique nucléaire et de la physique du solide,

- constatant, qu'en Europe, des installations nouvelles sont nécessaires au développement de ces recherches,

- désireux que d'autres Etats européens puissent participer aux actions qu'ils se proposent d'entreprendre en commun, ont décidé de promouvoir la construction et l'exploitation à des fins pacifiques d'un réacteur à très haut flux de neutrons et sont en conséquence convenus des dispositions suivantes:

\section{ARTICLE I}

La construction et l'exploitation du réacteur qui fait l'objet de la présente convention sont confiées à une société civile dont les associés sont la Société à responsabilité limitée "Gesellschaft für Kernforschung $\mathrm{mbH}^{\prime}$ ", d'une part, le "Commissariat à l'Energie Atomique" et le "Centre National de la Recherche Scientifique", d'autre part.

La Société dont les statuts sont déposés auprès des deux gouvernements:

- n'entreprendra d'activités qu'à des fins pacifiques,

- est désignée sous le nom d'“Institut Max von Laue - Paul Langevin",

- aura son siège à Grenoble,

- sera dirigée par une haute personnalité scientifique allemande,

- utilisera pour ses travaux la langue française et la langue allemande, en outre:

- les membres français et allemands du Comité de direction de la Société ne peuvent être nommés et révoqués qu'avec l'accord de leur Gouvernement respectif; 
- les litiges survenus entre les associés sont soumis aux gouvernements lorsqu'ils n'ont pu être réglés à l'amiable;

- les associés demanderont l'approbation conjointe des gouvernements pour toute modification des statuts;

- de nouveaux associés pourront être admis une fois que la construction du réacteur, de ses installations annexes et de ses dispositifs d'expérimentation sera achevée.

\section{ARTICLE II}

1. Les deux Gouvernements s'engagent à mettre à la disposition des associés:

- d'une part, une somme de 163 millions de francs français (132 millions de DM) destinée à couvrir les dépenses de construction du réacteur.

- d'autre part, et à concurrence de 43 millions de francs français (35 millions de $\mathrm{DM}$ ) une subvention annuelle destinée à couvrir les dépenses d'exploitation.

2. Chaque Gouvernement participe pour moitié aux dépenses prévues à l'article II paragraphe 1 ci-dessus. Toutefois pendant la phase d'exploitation du réacteur dont le début est fixé par le Comité de direction de la Société, les dépenses de fonctionnement sont réparties à raison de $49 \%$ pour le Gouvernement de la République Fédérale d'Allemagne et de $51 \%$ pour le Gouvernement de la République Française. Le montant de cette participation de chacun des gouvernements devra tenir compte de certaines recettes fiscales perçues par chacun des deux Etats à l'occasion de la création et du fonctionnement de la Société.

3. Si le montant des dépenses est supérieur aux sommes fixées au paragraphe 1 ci-dessus, les deux Gouvernements après avoir pris l'avis des organes compétents de la Société, se consulteront pour déterminer les moyens de poursuivre en commun la construction et l'exploitation du réacteur. Les deux Gouvernements se consulteront également si les taux de change en vigueur lors de la conclusion de la présente convention viennent à varier.

4. Les deux Gouvernements s'assurent que les sommes mises la disposition de la Société pour la construction et l'exploitation du réacteur sont employées dans les conditions les meilleures et prennent les mesures nécessaires à cet effet.

\section{ARTICLE III}

Sous réserve des exigences de l'ordre public et de la sécurité publique, chaque Gouvernement s'engage à faciliter le déplacement et le séjour des nationaux de l'autre partie contractante employés par la Société ou qui seront appelés par elle à effectuer des travaux de recherches.

\section{ARTICLE IV}

1. La présente convention est ouverte à l'adhésion des Etats tiers. Toute adhésion doit recueillir l'agrément des Gouvernements signataires. Les conditions de l'adhésion font l'objet d'un accord entre les Gouvernements signataires et le Gouvernement de l'Etat adhérent.

2. Au cas où les autres Etats membres de la Communauté Européenne de l'Energie Atomique souhaiteraient adhérer à la Convention, les deux Gouvernements 
s'efforceraient de placer les activités de la Société dans le cadre du programme de recherches établi par cette Communauté.

\section{ARTICLE V}

1. Les différends relatifs à l'interprétation ou à l'application des dispositions de la présente convention seront réglés par voie de négociation entre les deux Gouvernements.

2. Si les deux Gouvernements ne parviennent pas à un accord sur la solution d'un différend, chacun d'eux peut soumettre celui-ci à la décision d'un Tribunal d'arbitrage composé de trois membres.

3. Chaque partie contractante désigne dans un délai d'un mois un arbitre; les deux arbitres ainsi désignés choisissent parmi les ressortissants d'un Etat tiers, dans un délai de deux mois à compter de leur nomination, un surarbitre qui assumera les fonctions de président du Tribunal d'arbitrage.

4. Si les délais prévus à l'alinéa 3 ne sont pas observés et à défaut d'un autre arrangement, chaque partie pourra prier le Président de la Cour de Justice des Communautés Européennes de procéder aux nominations nécessaires.

5. Le Tribunal d'arbitrage prend ses décisions à la majorité des voix.

6. Le Tribunal d'arbitrage prend ses décisions sur la base des dispositions de l'article 38 paragraphe $1 \mathrm{du}$ Règlement de la Cour Internationale de Justice. Ses décisions sont obligatoires.

7. Le Tribunal fixe ses règles de procédure selon les modalités prévues au chapitre 3 du Traité de La Haye du 18 Octobre 1907.

8. Chaque partie prend à sa charge ses propres frais et la moitié des frais du Tribunal d'arbitrage.

9. Les dispositions du présent article, à l'exception de celles du paragraphe 6 ci-dessus, sont applicables lorsque des différends surviennent entre les associés au sujet du fonctionnement de la Société et doivent être soumis à leurs Gouvernements en vertu de l'article 24 des Statuts. Le Tribunal délibère sur la base des règles de droit applicables au litige considéré.

\section{ARTICLE VI}

La Présente Convention s'appliquera également au Land de Berlin sauf déclaration contraire faite par le Gouvernement de la République Fédérale d'Allemagne au Gouvernement de la République Française dans les trois mois qui suivront l'entrée en vigueur de la présente convention.

\section{ARTICLE VII}

1. La présente Convention entrera en vigueur dès que les deux Gouvernements se seront mutuellement informés de l'accomplissement des procédures constitutionnelles nécessaires à cet effet.

2. La présente Convention est conclue pour une durée de 13 ans. A l'expiration de ce délai, elle sera prorogée d'année en année par tacite reconduction et ne pourra être dénoncée qu'avec un préavis d'un an. 
En foi de quoi, les représentants des deux gouvernements ont signé la présente convention et y ont apposé leur sceaux.

Fait à Grenoble, le 19 Janvier 1967, en double exemplaire en langue française et en langue allemande, les deux textes faisant également foi.

Pour le Gouvernement de la République Française

Alain PEYREFITTE

Ministre Délégué Chargé de la recherche Scientifique

et des questions atomiques et spatiales

Pour le Gouvernement de la République Fédérale d'Allemagne

G. STOLTENBERG

Ministre fédéral de la recherche scientifique

\section{A2 - Activity report by Maier-Leibnitz 1968}

Activity report presented by Maier-Leibnitz in 1968 in which he outlined his vision of what the Institut Laue-Langevin should be. The text is left unchanged (with minor errors in French). I think it was written directly in French.

Institut Max von Laue - Paul Langevin, Grenoble 13 Novembre 1968.

Le rôle du Réacteur à Haut Flux dans la recherche de la matière solide et liquide. Par le Prof. Maier-Leibnitz

\section{A2.1 Général}

L'utilisation des neutrons lents permet un nombre d'expériences spéciales et parfois uniques dans le domaine de la recherche fondamentale. Le Réacteur à Haut Flux étant la source la plus forte du monde de tels neutrons, a été choisi, après de longues discussions qui ont commencé dans le cadre de l'OECD, comme instrument qui est suffisamment grand pour être utilisé par les chercheurs de plus d'une nation et qui peut stimuler la recherche dans des champs intéressants, surtout sur l'état solide où, après les travaux fondamentaux d'il y a 40 ans, les contributions provenant de l'Europe n'ont pas connu un accroissement aussi important qu'on voit dans les grands pays et qui semble être justifié là et par le progrès dans notre connaissance de la matière et par la multitude d'applications.

\section{A2.2 Les autres Laboratoires du Réacteur}

Les grands réacteurs (surtout Brookhaven et Oak Ridge) donnent autant de neutrons que le réacteur proposé pour Grenoble et l'on pourrait penser que - avec un délai de cinq 
ans avec ces réacteurs - il ne restera plus beaucoup de travail intéressant. Nous avons dû regarder ce point avec attention, en utilisant notre expérience approfondie avec un réacteur et notre connaissance d'un grand nombre d'autres réacteurs. Certes, beaucoup de beau travail est fait sur les réacteurs existants. Pourtant, partout, ou presque partout, on pourrait faire mieux. A tout réacteur on peut trouver une des objections qui suivent:

1. Souvent, le réacteur sert en première ligne pour les irradiations, loops, production d'isotopes, mesures de réactivité, etc., et le travail sur faisceaux de neutrons n'a pas assez de priorité pour bien pouvoir utiliser l'équipement et le temps des chercheurs. Parfois, l'esprit d'ambiance n'est pas favorable à la recherche pure. Cela peut décourager les scientifiques, surtout ceux qui ne sont pas eux-mêmes "du métier".

2. La plupart des expériences utilisant les réacteurs, sauf peut-être sur la diffraction des neutrons, sont encore faites par les spécialistes de la physique des neutrons et non pas les physiciens des champs comme la physique du solide, d'où les bons problèmes prennent leur origine.

3. Dans beaucoup de laboratoires, la théorie est trop faible, ce qui conduit à un choix des expériences souvent sans bonne relation avec le "courant" du progrès en physique.

4. Presque partout, les réacteurs sont "sous-peuplés" de scientifiques. Le rendement des installations coûteuses pourrait être bien meilleur s'il y avait assez de physiciens pour faire ces mesures nuit et jour, pour vraiment évaluer les résultats, pour trouver des problèmes nouveaux et pour élaborer des méthodes perfectionnées.

5. Sauf quelques exceptions remarquables, il n'a pas été possible de créer une organisation d'accueil pour les scientifiques visiteurs appartenant aux universités et aux autres laboratoires.

6. Il nous semble que presque partout, les méthodes d'expérimentation ne sont pas à la hauteur du perfectionnement du réacteur même. C'est peut-être dû au nombre relativement faible des chercheurs utilisant un réacteur (en comparaison, par exemple, avec les accélérateurs), que la plus grande partie de l'équipement est relativement conservateur et non optimisé.

Dans beaucoup de cas, la recherche de meilleures méthodes montre qu'il faudrait faire des changements sur les réacteurs ou même sur les bâtiments ou sur le site qui ne sont plus possible après la construction.

\section{A2.3 Le Réacteur à haut flux de l'Institut Laue-Langevin}

1. Les considérations esquissées ci-dessus nous ont guidées dans tous nos plans pour le Réacteur. Surtout, nous avons prévu, ou espérons obtenir, les conditions suivantes, favorables, nous l'espérons, pour la réussite de notre entreprise.

a. Le Réacteur est, comme d'ailleurs à Brookhaven H.F.B.R., destiné à la recherche seulement. Il est un réacteur à faisceaux de neutrons;

b. Des irradiations seront possibles pour un nombre limité d'échantillons de petites masses pour ne pas interférer avec le fonctionnement des expériences sur canaux. 
2. Le bâtiment réacteur contient une surface pour expériences plus vaste que les autres réacteurs (diamètre de $60 \mathrm{~m}$ ). Cette surface est séparée de la surface d'exploitation. Le plan expérimentateur est au niveau d'un remblai à l'extérieur; cela permet de faire passer les neutrons hors du bâtiment jusqu'à plus de 500 mètres (expériences de temps de vol, etc.).

3. Le Réacteur, avec sa protection, les canaux, les conduits de neutrons, la source froide et la source chaude ont été projetés en coopération avec les expérimentateurs, futurs utilisateurs du réacteur. Nous pensons que le réacteur offrira un nombre d'avantages pour ces derniers. Nous espérons pouvoir installer un nombre optimum d'expériences (peut-être 40) autour du réacteur, et on pourra appliquer un nombre de techniques qui ne sont pas possibles sur les autres réacteurs.

Voici une liste non complète des avantages:

- Flux de neutrons constant (barre de contrôle à l'intérieur du cœur). Protection importante pour réduire le bruit de fonds dans le hall et au dehors.

- Niches près des canaux pour installations variables près du cœur, avec protection du sable fluidisé.

- Source froide (50 fois plus d'intensité pour les neutrons très lents).

- Source chaude (20 fois plus d'intensité autour de $500 \mathrm{meV}$ ).

- Canaux à ouverture $230 \mathrm{~mm}$ hors de la zone $\mathrm{D}_{2} \mathrm{O}$.

- Canal transversal avec suppression de toute radiation directe du cœur du réflecteur.

- Canal vertical semi-traversier à grande ouverture.

- 10 conduits de neutrons $3 \times 16 \mathrm{~cm}$ : suppression de tout bruit de fonds non causé par les neutrons lents, augmentation de la surface utile pour faisceaux sortant; long parcours sans perte d'intensité pour temps de vol. Séparation des expériences dans l'espace.

4. En même temps, avec le projet du réacteur, le travail a commencé sur les appareils pour expériences. Après discussion des méthodes nouvelles ou améliorées utilisant des conduits de neutrons, des systèmes de cristaux monochromateurs, des méthodes de temps de vol, des systèmes de détecteurs multiples, etc., par ces développements, coûteux, mais pas coûteux en comparaison avec le coût annuel du réacteur, nous espérons gagner autant en intensité ou en résolution pour nos expériences que par le réacteur même.

\section{A2.4 Organisation du travail scientifique}

Le nombre de chercheurs qui pourront travailler à Grenoble ne peut évidemment pas être fixé aujourd'hui, mais nous pensons qu'il sera autour de 200 dont 50 à 70 pour cent visiteurs. Nous espérons qu'un nombre important parmi eux pourra être des boursiers de thèses pour que notre Institut puisse contribuer à la formation des jeunes dans un domaine moderne et important.

Le budget (sans tout ce qui est exploitation du réacteur "Reaktorbetrieb", mais avec salaires, dépenses pour expériences nouvelles et existantes, nouveaux bâtiments après 
la première tranche) sera de 25 millions de francs environs par ans, ce qui devrait être en bonne relation avec le nombre de chercheurs.

Quand le réacteur sera prêt en 1969, on aura un bâtiment laboratoires de $3000 \mathrm{~m}^{2}$ environ et un hall d'essais pour grandes expériences, des ateliers, etc. On espère profiter de la coopération avec le CENG et avec les laboratoires de Grenoble du CNRS pour les grands ateliers, l'électronique, les basses températures, les ordinateurs, la préparation des cristaux, etc. Mais nous savons que cette coopération requiert que nous soyons partie prenante, et que les contributions venant de notre Institut doivent être attractives pour nos partenaires.

Structures d'accueil. Tout nouveau venu est frappé par la complexité des expériences autour d'un réacteur, par les précautions qu'il faut prendre et par les techniques qui sont peu connues à la plupart des chercheurs mais dont la tradition et le développement font le secret du succès d'un laboratoire de réacteur. C'est pourquoi il faut faire tout, pour donner aux chercheurs, et surtout à ceux qui viennent d'autres laboratoires, toute information et aide pour leur expérience. Les méthodes à suivre ne sont pas encore élaborées. Nous pensons aux stages suivants:

- Informations sur les recherches semblables à l'expérience proposée: discussion et optimalisation de la méthode.

- Dessins et peut-être construction à Grenoble de certaines parties de l'appareil, surtout la partie en pile et la protection. Peut-être coordination par un "project engineer" comme à Oak-Ridge.

- Aide pendant l'expérience par les techniciens, et si nécessaire par les chercheurs de l'Institut.

- Evaluation des données par les méthodes développées par l'institut pour toutes les expériences.

Relations avec les autres laboratoires. Le programme autour du réacteur est la plus grande responsabilité du Conseil Scientifique qui est composé de 16 membres, moitié français, moitié allemands. La plupart des membres ne sont pas membres de l'Institut Laue-Langevin. Ils sont réélus tous les deux ans, et nommés par le Comité de direction, organe suprême. Dans la première phase qui n'est pas encore déterminée, la grande partie du programme a été, outre le travail de définir quelques caractéristiques du réacteur, de décider sur le choix d'appareils et de méthodes pour les futures expériences. Après cette phase, et commençant maintenant, la tâche importante est l'élaboration du programme scientifique. Le Conseil scientifique reçoit et considère toute proposition d'expériences provenant d'autres pays sera possible dans le futur, et la coopération avec des individus chercheurs est toujours sans formalité).

Le Conseil scientifique a quatre sous-comités: diffusion élastique (diffraction et diffusion à petits angles), diffusion inélastique, évaluation des données, physique nucléaire. Pour le moment, l'activité de ces comités concerne en première ligne le choix et le développement d'appareils autour du réacteur.

Pour le moment, les "neutronistes" dominent dans ces comités parce qu'ils connaissent les possibilités et les problèmes d'un réacteur. Mais dans le futur, la situation sera différente. On espère que les deux tiers environ des expériences au réacteur seront proposées par les chercheurs qui ne sont pas membre de l'Institut Laue-Langevin et seront exécutés, soit par eux-mêmes avec l'aide technique dont on a parlé plus haut, soit 
par eux, en collaboration avec les chercheurs de Grenoble. Dans quelques cas, il sera possible de faire des mesures "sur commande" avec des substances qui sont envoyées par un laboratoire.

Quand le réacteur sera prêt, on aura un comité des utilisateurs présidé par un chercheur venant de l'extérieur pour assigner les positions et appareils au réacteur, le temps pour la préparation, les mesures et l'aide technique.

Le Conseil scientifique, quand à lui, pourra bientôt changer de composition pour mieux représenter les utilisateurs non spécialistes du réacteur.

Nous sommes très conscients du fait que, même si la valeur exceptionnelle du réacteur pour la recherche est connue, il n'est pas facile de convaincre les chercheurs qui sont contents de leur travail dans leurs propres laboratoires, qu'il vaille la peine d'élargir leur activité, de former un groupe pour Grenoble, de trouver des problèmes qui peuvent être résolus avec le réacteur, ou même d'inventer des expériences nouvelles.

Nous ferons un effort de bien informer tous ceux qui pourront s'intéresser au réacteur. L'année prochaine, on aura la première école d'été qui nous permettra d'initier une quarantaine d'étudiants aux applications du réacteur pour la physique des solides et liquides. Nous pouvons offrir d'inviter les intéressés de venir à Grenoble pour un séjour court ou plus long, ou de venir nous-mêmes aux autres laboratoires pour discuter de nos problèmes. On commence maintenant à Grenoble d'avoir des séminaires réguliers sur la physique du solide en vue de nos applications, avec une audience très limitée il est vrai pour le moment, et nous espérons étendre cela dans le futur.

Un effort relativement important a déjà commencé, c'est le travail d'un groupe de théorie qui, dans notre opinion, est indispensable pour développer un bon programme. En regard à la situation particulière de Grenoble, ce groupe a commencé à Munich. Il comprend maintenant des théoriciens. Cette année, on a eu un programme de visites de ces théoriciens à Grenoble, où quelques-uns seulement travaillent en permanence. On espère pouvoir obtenir une répartition entre Munich et Grenoble au cours de l'année prochaine; en même temps qu'une augmentation vers le nombre final qui sera vingt.

\section{A3 - Visit of SRC 6-7 March 1970 - Conclusions (Jolliffe)}

I would summarise my impression thus:

1. Despite difficulties of Franco-German collaboration, the project seems to be going forward fast and smoothly and they hope it will be in operation by mid-1971.

2. It appears to be costing about $£ 25 \mathrm{M}$ capital and running costs are estimated at $£ 4 \mathrm{M}$.

3. Collaboration with UK, which would chiefly benefit UK for the next 5-7 years, was freely offered and warmly welcomed.

4. Detailed information was freely given and anything more we want was promised.

5. The success of the scheme so far is, in substantial measure, due to the Director, Prof Maier-Leibnitz and his policy of appointing able senior staff at an early stage. 


\section{A4 - Letter from Flowers to Creyssel in January 1972}

This telex was sent in January 1972 from Brian Flowers to Pierre Creyssel, Head of the Steering Committee. I have reproduced with no comments the text as it was forwarded by Creyssel to the 24 other members of the Steering Committee on the 23 or 24 January 1972.

Editor's Note: Like any telex of the time, the original text was written in uppercase. However, to make the text more readable, we have reproduced a transcription using conventional typography.

May I start by congratulating your election as president of the ILL and wishing the institute every success in the new year.

At our meeting on 14 December we explored most of the possibilities for collaboration between the Franco-German ILL and the SRC on the provision of high flux neutron beams. My summary of the meeting was:

The French and German representatives rejected the exploratory proposal which the SRC had made in Grenoble for a collaborative high flux neutron beam programme based on partenership in the use proposed HFBR in the UK.

They did not think it necessary to decide on the building of a second high flux reactor for some years and in any case would not wish to combine irradiation facilities and neutron beam facilities in the same reactor. For the UK the AEA and SRC explained that the limited funds available made it important to provide both irradiation and neutron beam facilities in the proposed programme and that experience proved it perfectly satisfactory to provide both in one reactor.

You stressed the desirability of the SRC becoming a full partner in the ILL as soon as possible.

You proposed that the SRC should pay, in addition to its one-third share of the budget less taxes agreed each year, an initial capital contribution of $13 \mathrm{M}$ Francs a year at January 1972 prices for ten years. You assessed this as being to equivalent to about $72 \%$ of a full one-third share of the capital cost. If the SRC joined ILL, France and Germany would agree, for a number of years to be determined, to undertake high flux neutron beam research only in collaboration with the UK. If, during that period, it were decided to build a second reactor jointly, that reactor would be in UK.

The French and German representatives recognised that the decision of how best to provide high flux neutron beam facilities posed severe problems for the UK. They therefore indicated that if, having joined the ILL, the SRC still wished to carry out the design study of the HFBR, they might be willing to adjust the rate of payment of the annual contribution towards the capital costs of Grenoble reactor. This might enable the capital contribution in 1972 and 1973 at a lower rate than 13 M Francs a year.

The SRC appreciated the proposals described in (b) and (c) but, as became clear after the recess, the funds available for the UK programme were not sufficient to 
enable the SRC to become a partner in ILL and also to collaborate with the AEA in pursuing the HFBR proposal.

Professor Maier-Leibnitz suggested that the possibility of converting the ILL into a widely based European organisation like CERN should be examined. Such an arrangement could help to resolve the SRC financial problem but both French and German representatives considered that it would be impraticable to widen the collaboration to such an extent.

As at earlier meetings, neither the French nor German representatives were authorised to discuss the SRC request for information about possible financial arrangements under which British scientists could be permitted to carry out an approved programme on the Grenoble reactor. The SRC had in mind the possible use of up to about $10 \%$ of the capacity under such arrangements.

The meeting ended without our being able to see a way to achieve a joint European programme which would satisfy the different requirements of France and Germany on one hand and the UK on the other. We therefore provisionally arranged to meet again on 2 February in case there were any further ideas for satisfying the different requirements in a single acceptable programme to discuss and in case The French and German representatives were by then authorised to discuss possible arrangements for a limited use of the Grenoble reactor by British scientists.

Since then, despite earnest consideration with AEA and other bodies concerned in the UK, the SRC has so far been unable to develop any praticable scheme which likely to meet both French and German wishes and the British needs. On the other hand, our annual revision of the whole financial programme is not yet far enough advanced to enable us to say whether any possible adjustement of the rate of SRC capital contributions towards the ILL could offer a way of resolving the difficulties. We should, therefore, on 2 February be unable to add anything substancial to what we said in Paris last month.

We would still welcome the meeting if you were able to discuss possible financial arrangements on the lines of those originally suggested by the SRC for limited use of the Grenoble reactor by British scientists or if you had succeeded in developing any new ideas. However, if the Franco-German partners in the ILL are, like SRC, unable to add to the views expressed at the December meeting, I suggest it would be best to postpone the proposed meeting for a few weeks. I would however suggest that if we do postpone the meeting we should aim for another date in April or May. 


\section{A5 - Fender: recommendation to build the synchrotron on the ILL site}

In this report recommending construction of the European synchrotron radiation source on the ILL site, the part which describes the applications of synchrotron radiation, has been omitted.

21 February 1984

\section{The European Synchrotron Source at the ILL}

\section{Introduction}

This paper proposes the European synchrotron source should be sited the Institut Laue-Langevin at Grenoble.

There are three main arguments:

1. The synergic effect of coupling the world's leading neutron research centre with a "state of the art" X-ray synchrotron source.

2. The ILL infrastructure is an excellent base for the new source. Technical expertise associated with neutron research is readily transferable. The site itself is welladapted to the proposed ESRF and considerable saving in time and money is possible.

3. The style of operation of the ILL: the international collaboration; the co-operation between visitor and in-house research; the provision of research facilities for long and short-term visitors, which lie at the heart of the Institut's success, are entirely appropriate to a synchrotron research centre - they provide the best possible general guarantees that the ESRF can be built up to be an equally effective Institute in the minimum time.

The combined effect of the ILL and the ESRF (called the Maxwell Institute for convenience) would be to create a centre for condensed matter and materials research quite unequalled anywhere else. The ILL already draws scientists from all over the world in collaborations with European scientists. The focussing effect of the ILL-Maxwell would be even greater and the influence on European research profound.

\section{The case for the European Synchrotron Source}

The detailed arguments for a 'state of the art' X-ray synchrotron source are advanced in several papers and are not restated here. We underline the simple point that the scattering of X-rays provides most of our direct information about the structure of substances down to the atomic level. Much of our understanding therefore in physics,

\section{Co-existence of the Maxwell Institute and the ILL}

It is important to emphasise that this proposal is not a take-over bid by the ILL for the ESRF. At first sight this view, taken with the arguments we have previously advanced, might seem to imply two distinct and apparently contradictory philosophies. One is to preserve a separate identity and independence for the new synchrotron source and the 
existing ILL; the second is to achieve the maximum scientific interaction and technical co-operation coupled with considerable financial and manpower savings. In fact the two aims can be achieved easily by adaptation of the existing ILL structure.

Independence is achieved for the new Maxwell Synchrotron Institute by the following major recommendations:

a) There should be a separate Directorate plus the Services of the Direction.

b) There should be a separate Scientific Council and sub-committee system.

c) The scientists, immediate technical support and Accelerator Department should be the separate responsibility of the Maxwell Institute.

d) A matching organisation is retained by the ILL with the Reactor Department instead of the Accelerator Department.

e) For these separate departments, and for ILL or Maxwell investments, individual budget lines would be provided, with transfers between Institutes only possible with the approval of the Steering Committee.

Several departments would be run jointly by the two institutes: Instruments and Methods, Site and Buildings, Computing and Administration. The management of these departments is ensured by the combined directorates meeting regularly with all Heads of Department and Senior Scientists.

\section{A6 - Intervention of Dr. Newport at the Steering Committee of 28 November 1991}

Dr. Newport's statement was as follows:

As the Associates will be aware, the Science and Engineering Research Council (SERC) has conducted a review of relative scientific priorities for future council support, having regard to known future resource availability. The Council has now concluded that financial expenditure on the neutron sources at ILL and ISIS should be reduced by $£ 5$ million per annum beyond previously planned levels with effect from 1994/1995. The resources so released would make possible the support of other high priority science.

In the light of its recent review of UK neutron science, the Council has further decided that financial support for the ISIS facility should remain broadly in line with currently planned levels. Accordingly, the SERC has advised the UK Government that it will need to seek a reduction in the level of the UK's contribution to the ILL, post 1993.

At present the ILL is out of commission for repairs, and is likely to remain closed for a considerable time. Subject to a satisfactory outcome to the present assessment of refurbishment costs for the reactor; agreement on how these costs should be met; and on future terms for membership, the UK would hope to see the refurbishment proceed and to remain a partner following re-commissioning.

It has to be emphasised, however, that the UK, with other Associates, will need to be finally satisfied about the level of refurbishment costs and the extent to which these can be met from within existing available resources. 


\section{A7 - Ipoustéguy's interpretation of the work he made for the ILL}

\section{The fulfilment of Man walking towards Unity}

1. The original fire

2. The creation of first member of mankind.

3. Prometheus (the liver eaten by a vulture).

4. The atomic bomb destroys man

- physically - legs torn off,

- genetically deformed limbs.

5. The young pregnant woman; strong hope of the new man looking towards the future. The onset of labour, legs apart for the birth of the child.

6. In labour belly extended. The frame represents the work needed for delivery.

7. The birth; the child with head down sent to his destiny, but attached to a framework, the lifetime of work which awaits.

8. The child becomes man:

- is going to enter the Institut (science, research),

- is protected from head to toe against the atom,

- is pushed by the right leg,

- is held back by the left leg,

- arms are stretched towards the future (where he's going),

- hands are raised in a gesture of fear; he fears what awaits while feeling obliged to go; that will be his future.

9. The Institut: his destiny of work is represented by a frame through which he must pass. 



\section{Acknowledgements}

\section{Past and present}

\section{A few words from the author}

Throughout writing this account I have benefited from unlimited help from past and present members of the ILL, or those involved in the construction. Robert Dautray provided me with invaluable information and took me back to a period of considerable nostalgia. I think too of Reinhard Scherm, who always responded as soon as possible to my emails, of Sylvia Brügelmann and Andreas Freund for much information on Maier-Leibnitz. Tasso Springer unearthed old letters from pre-history. Jean Charvolin made me understand a little better what I have called the dark years. Philippe Leconte explained the problems of the supply of uranium-235. Alain Filhol arrived at the ILL in 1971, and has always returned my calls either to clarify a historical point, or help me troubleshoot my computer remotely. He also read my text and suggested corrections and additions; my special thanks for this. The French members of the project group (Jean Chatoux, Jean Paul Martin and Louis Brégeon) allowed me to refresh my memories on the construction of the reactor. Francis Tasset gave me a lot of help describing polarised neutrons; Pierre Flores an old union activist was very cooperative; Robert Gariod, (retired from the CENG) was very involved in the beginnings of the ILL provided valuable information on Louis Néel.

Serge Claisse and Brigitte Aubert obtained the photographs used in this book. The current management (Colin Carlile, Werner Press and Christian Vettier) offered me all material and moral help I needed, respecting an author's freedom. I also thank them for a critical reading of my text. G. Zaccaï gave me useful suggestions. Françoise Vauquois corrected many errors of French. I am also grateful to Claire Gubian, secretary of Christian Vettier who has always found time to procure documents, and organise my stays in Grenoble. This list is by no means complete. I beg all those not mentioned to forgive me.

Bernard Jacrot (2006)

\section{A few words about the current version of the book}

Producing this updated version of the English translation of Bernard Jacrot's book was not an easy task. Many thanks to Bernard and Bernard's family, who gave us the permission to do so, and to Ron Ghosh, who immediately agreed to do the translation work. The project was supported and funded by both ILL Management and the ILL Communication group. Among those who contributed, special thanks go to Bill Stirling, Christian Vettier, Joe Zaccaï, Peter Timmins and also to Susan Tinniswood (translation), Sylvie Crozel and Clément Steinhausser (Indesign). 



\section{Postscript}

\section{Translator's note}

When I arrived at the ILL in 1974, with the exception of Bernard Jacrot and Paul Ageron, the original reactor design and construction team had left the site and returned to the establishments whence they had been detached. This book therefore offers unique insight into the creation of the ILL by one of its originators. By 1975 there were over a dozen scientists from Britain at the ILL, who had known each other either at university, or, had met at Harwell working on their theses with help from their neutron scatterers to use the British instruments. They were also involved there in the design of ancillary equipment, and the control systems. While the design of the ILL reactor was exceptional, the instruments reflected some inexperience in design, sample environments were inflexible, and the control systems were inefficient. With their prior experience there was pressure from the new arrivals to bring about improvements rapidly.

In 1976 a mixed group of about 30 scientists set off for a neutron scattering meeting in Gatlinburg, USA. This was the first occasion to display the range of results (albeit with our grey Polaroid slides and all too brief measurements due to scheduling pressures) which could be obtained in Grenoble. The Americans were amazed by results from the new high resolution instruments, long wavelength and small angle scattering facilities, unavailable in their laboratories. The ILL scientists were equally surprised that the British identified themselves more closely with the Europeans, rather than the Americans. The results had been obtained through a lot of effort from informal mixed nationality teams compensating for the limitations of the new instruments, and crude sample facilities. The challenge today is to apply all the technological improvements to solve problems in new fields.

The ILL continues to advance as evidenced by the addition of new scientific member countries (now 12). While the overall budget has only increased a little the CRG instruments though dependant on the ILL engineering and support for infrastructure and safety, are not directly reflected in the overall budget. The fundamental physics experiments now use advanced UCN techniques to increase fluxes and obtain exceptional sensitivities. New detectors are under development to avoid use of expensive ${ }^{3} \mathrm{He}$. In solid state physics very low temperature devices are available routinely, and polarisation techniques are more generally installed. New techniques use modern contra-rotating disc choppers in white beam blind-chopper configurations which allow time of flight techniques to benefit from optimal repetition rates maximising use of the continuous flux, with applications in SANS (D33) and reflectometry (D17 and Figaro). Biologists have extended their use of contrast variation to include reflectometry on membranes, with samples created by the Deuteration Facility. Although in the 1980s during some years more than 216 user days were scheduled (with 6.5 cycles of 44 days in 1980), safety upgrades costly in time and money restrict current operations. 
There appears to be much material for the sequel to this book. In July 2013 the governments of France, Germany and the U.K. extended the original 1971 intergovernmental Convention supporting the ILL for a further ten years at least.

Having read and digested every word in Bernard Jacrot's narrative, where much is written in the first person, I decided it was best to offer a minimalist translation. I hope those who know B.J. will still recognise his style and personal viewpoint. The alternative would be to paraphrase everything. In naming his peers Bernard Jacrot uses only surnames, more generally for co-workers he uses full names, and for those in high office he adds a title, though this is usually simplified. (Professor Mossbauer was always referred to as Monsieur Mössbauer at the ILL).

The missing element in the whole book is a better knowledge of the author who has exerted such influence on all phases of the Institut Laue-Langevin, but apparently has been too modest to accept his own importance. Providing a version in English will open up the story of the early times of the ILL to a wide audience, and perhaps prompt another author to update the tale.

I am grateful for the assiduous comments and corrections noted by friends who have read this text, notably Professor Adrian Rennie who was also so helpful in checking many of the references and George Stirling for his incisive criticism of fuzzy parts of the translation. Special thanks are due to Alain Filhol for instigating and managing the translation project.

Ron Ghosh, (ILL, 1974-2008), Epsom, 2014 


\section{Credits for the illustrations}

Fig. 1.1 (c) and courtesy of the Department of Physics, Cavendish Laboratory, Cambridge. Photo P24

Fig. 1.2 (c) and courtesy of the Department of Physics, Cavendish Laboratory, Cambridge. Photo P442

Fig. 1.3 C and courtesy of the Oak Ridge National Laboratory, USA.

Fig. 1.4 (C) and courtesy of the CERN, <cdsweb.cern.ch> a crop from photo 6410039

Fig. 1.5 (c) hewat.net/science

Fig. 1.6 (C) 1973 German TV ZDF, "Die stiellen Stars"

Fig. 1.7 (C) "New trends in atomic research and their international significance", Kowarski, L., 1961, Organisation for European Economic Co-operation. European Nuclear Energy Agency, Ed. OEEC-ENEA Paris

Fig. 1.8 (C) 1994 ILL and Jean-Luc Baudet, Grenoble

Fig. 1.9 (C) 2000 ILL and Serge Claisse, Grenoble

Fig. 1.10 (C) and courtesy of the Museum of History of Science and Technology of JINR, $<$ museum.jinr.ru>

Fig. 2.1 (C) 1995, ILL and Serge Claisse, Grenoble.

Fig. 2.2 C ILL, Grenoble

Fig. 2.3 (C) 1980 Photo library < alamy.com>, Photo CR7CWP

Fig. 2.4 (C) and courtesy of the CNRS Grenoble.

Fig. 3.1 C ILL, Layout of spectrometer IN20 from https://www.ill.eu/in20

Fig. 3.2 C ILL, Grenoble

Fig. 3.3 C ILL, Layout of spectrometer IN5 from https://www.ill.eu/in5

Fig. 3.4 (C) ILL, Layout of spectrometer IN15 from https://www.ill.eu/in15

Fig. 4.1 (C) Siemens AG, Munich/Berlin - Siemens Historical Institute beckurts-stiftung.de

Fig. 4.2 Unknown original document.

Fig. 4.3 Left: @ Henri Manuel. Wellcome Collection $<$ wellcomecollection.org $>$. Attribution 4.0 International (CC BY 4.0); right: (C) The Nobel Foundation, unknown photographer. From <en.wikipedia.org>

Fig. 4.4 Unknown original document

Fig. 4.5 Unknown original document

Fig. $5.1 \quad$ (C) 1971 ILL, Grenoble

Fig. $5.2 \quad$ (C) 1971 ILL, Grenoble

Fig. 5.3 (C) 1971 ILL, Grenoble

Fig. 5.4 (C) 1970 ILL, Grenoble

Fig. 5.5 (C) 1998 ILL, Grenoble and C. Designolles

Fig. 5.6 (C) 1970 Le Dauphiné Libéré, Grenoble, 14 Feb. 1970

Fig. 5.7 (C) 2004 ILL, Jean-Luc Baudet

Fig. 5.8 (C) 1979 ILL, Grenoble

Fig. 5.9 "La source de neutrons froids pour le réacteur à haut flux franco-allemand de Grenoble », Ageron P., Ewald R., Harig H.-D. and Verdier J, (1971) Energie Nucléaire, 13, 1-7 
Fig. 5.10 Adapted from the booklet "L'Institut Max von Laue - Paul Langevin", undated but presumably 1971, Presses de Lescuyer at Lyon, France, page 27. See also BIST (Bulletin d'Information Scientifique et Technique du CEA), P. Ageron, 166, Jan. 1972), 17-22

Fig. 5.11 Adapted from the booklet "L'Institut Max von Laue - Paul Langevin", undated but presumably 1971, Presses de Lescuyer at Lyon, France, page 26. See also BIST (Bulletin d'Information Scientifique et Technique du CEA), P. Ageron, 166, Jan. 1972, 17-22

Fig. 5.12 Adapted from the booklet "L'Institut Max von Laue - Paul Langevin", undated but presumably 1971, Presses de Lescuyer at Lyon, France, page 9. See also BIST (Bulletin d'Information Scientifique et Technique du CEA), P. Ageron, 166, Jan. 1972, 17-22

Fig. 5.13 (C) 1984 ILL, Grenoble

Fig. 5.14 Photo from Bernard Jacrot's archives.

Fig. 5.15 From Ipoustéguy

Fig. 5.16 (C) 1989 "Ipoustéguy", Pierre Gaudibert, Ed. Cercle d'Art, Paris (1989) p 139

page 97 Alan Daramsy and Thomas Hansen, (C2014 ILL and Max Alexander

page 97 Oscar Ramon Fabelo Rosa, (C2016 ILL and Ecliptique <ecliptique.com>, Laurent Thion

page 97 Matthew Blakeley, (2015 ILL and Robert Cubitt

page 97 Thilo Pirling and Sofiane Terzi, (02016 ILL and Ecliptique

page 99 C2009 ILL and Artechnique

page 99 Daniela Russo, (C2012 ILL and Ecliptique

page 99 Sacha Ivanov and Eric Bourgeat Lami, (C2016 ILL and Ecliptique

page 99 Peter Falus and Ingo Hoffmann, (C2017 ILL and Ecliptique

page 101 Richard Campbell, C2016 ILL and Ecliptique

page 101 Valery Nesvizhevsky, @2009 ILL and A. Chézière

page 101 Tobias Jenke and Erwin Jericha (02016 ILL and Ecliptique

page 101 Thomas Materna, C2015 ILL and Ulli Köster

Fig. 6.1 C ILL, Grenoble

Fig. 6.2 (C) ILL, Grenoble

Fig. 7.1 1968 ILL and Studio Givet, Grenoble

Fig. 7.2 (C) 2013 ESRF and Jean Moulin

Fig. 7.3 (C) 2001 ILL, Millennium Symposium 2001

Fig. 7.4 C 2003 ILL, Rapport de sureté, Dec 2003, Fig. 23.24.1

Fig. 8.1 (C) 1994 ILL and Jean-Louis Baudet

Fig. 9.1 (C) ILL, Grenoble

Fig. 11.1 (C) 2006 ILL and P.-Y. Meynent

Fig. 11.2 (C) 2018 ILL and A. Filhol

Fig. 11.3 (C) 2008 ILL and Serge Claisse

Fig. 11.4 (C) 2018 ILL, Grenoble

Fig. 11.5 (C) 2019 ILL and Ecliptique

Fig. 11.6 (C) 2003 ILL, Grenoble

Fig. 11.7 (C) 2011 ILL, Grenoble

Fig. 11.8 (C) 2016 ILL and Ecliptique

Fig. 11.9 (C) 2018 ILL and renishaw.com

Fig. 11.10 (C) 2014 Serebrov A., Petersburg Nuclear Physics Institute

Fig. 11.11 @ 2018 ILL and G. Cicognani 
